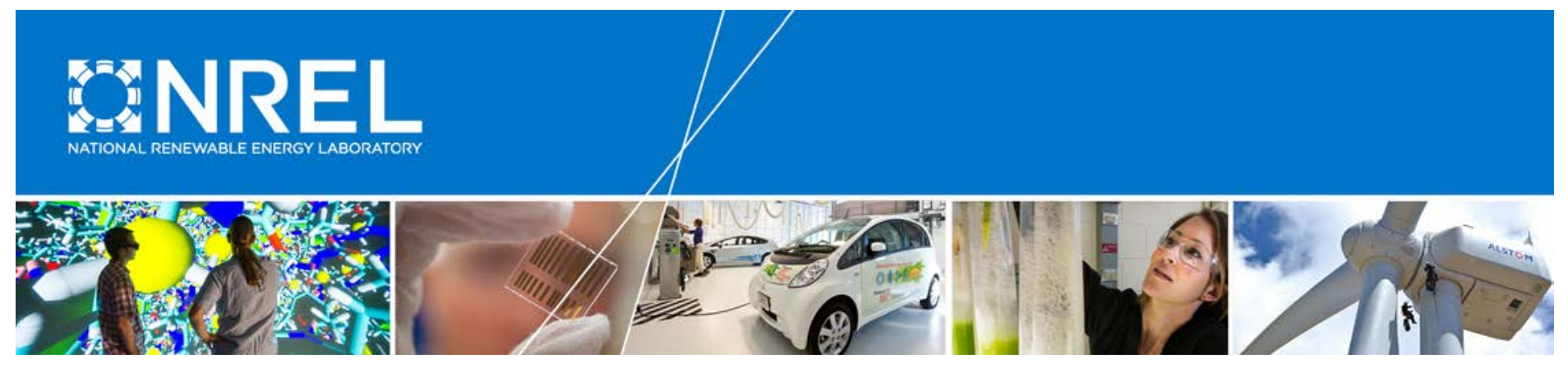

\title{
Impact of Flexibility Options on Grid Economic Carrying Capacity of Solar and Wind: Three Case Studies
}

Paul Denholm, Joshua Novacheck, Jennie Jorgenson, and Matthew O'Connell National Renewable Energy Laboratory

NREL is a national laboratory of the U.S. Department of Energy Office of Energy Efficiency \& Renewable Energy Operated by the Alliance for Sustainable Energy, LLC

This report is available at no cost from the National Renewable Energy Laboratory (NREL) at www.nrel.gov/publications.

Technical Report

NREL/TP-6A20-66854

December 2016 


\section{Impact of Flexibility Options on Grid Economic Carrying Capacity of Solar and Wind: Three Case Studies}

Paul Denholm, Joshua Novacheck, Jennie Jorgenson, and Matthew O'Connell National Renewable Energy Laboratory

Prepared under Task No. SA151017
National Renewable Energy Laboratory 15013 Denver West Parkway Golden, CO 80401

303-275-3000 • www.nrel.gov
NREL is a national laboratory of the U.S. Department of Energy Office of Energy Efficiency \& Renewable Energy Operated by the Alliance for Sustainable Energy, LLC

This report is available at no cost from the National Renewable Energy Laboratory (NREL) at www.nrel.gov/publications.

\section{Technical Report}

NREL/TP-6A20-66854

December 2016

Contract No. DE-AC36-08G028308 


\section{NOTICE}

This report was prepared as an account of work sponsored by an agency of the United States government. Neither the United States government nor any agency thereof, nor any of their employees, makes any warranty, express or implied, or assumes any legal liability or responsibility for the accuracy, completeness, or usefulness of any information, apparatus, product, or process disclosed, or represents that its use would not infringe privately owned rights. Reference herein to any specific commercial product, process, or service by trade name, trademark, manufacturer, or otherwise does not necessarily constitute or imply its endorsement, recommendation, or favoring by the United States government or any agency thereof. The views and opinions of authors expressed herein do not necessarily state or reflect those of the United States government or any agency thereof.

This report is available at no cost from the National Renewable Energy Laboratory (NREL) at www.nrel.gov/publications.

Available electronically at SciTech Connect http:/www.osti.gov/scitech

Available for a processing fee to U.S. Department of Energy and its contractors, in paper, from:

U.S. Department of Energy

Office of Scientific and Technical Information

P.O. Box 62

Oak Ridge, TN 37831-0062

OSTI http://www.osti.gov

Phone: 865.576.8401

Fax: 865.576.5728

Email: reports@osti.gov

Available for sale to the public, in paper, from:

U.S. Department of Commerce

National Technical Information Service

5301 Shawnee Road

Alexandria, VA 22312

NTIS http://www.ntis.gov

Phone: 800.553 .6847 or 703.605 .6000

Fax: 703.605.6900

Email: orders@ntis.gov 


\section{Acknowledgments}

This work was funded by the U.S Department of Energy under Contract No. DE-AC3608GO28308 with the National Renewable Energy Laboratory. The authors would like to thank the following for review and comment-Paul Beagon, Nate Blair, Aaron Bloom, Aruna Chandrasekar, Tom Edmunds, Udi Helman, Ookie Ma and Andrew Arana — as well as editing by Scott Gossett and Don Gwinner. 


\section{Nomenclature or List of Acronyms}

\begin{tabular}{|c|c|}
\hline BA & Balancing Area \\
\hline BAU & business as usual \\
\hline BTU & British thermal unit \\
\hline CAISO & California Independent System Operator \\
\hline $\mathrm{CC}$ & combined-cycle \\
\hline CHP & combined heat and power \\
\hline CPUC & California Public Utilities Commission \\
\hline CSP & concentrating solar power \\
\hline $\mathrm{CT}$ & combustion turbine \\
\hline DR & demand response \\
\hline ECC & economic carrying capacity \\
\hline EI & Eastern Interconnection \\
\hline EIM & Energy Imbalance Market \\
\hline ERCOT & Electric Reliability Council of Texas \\
\hline ERGIS & Eastern Renewable Generation Integration Study \\
\hline FMPP & Florida Municipal Power Pool \\
\hline FPL & Florida Power \& Light \\
\hline FRCC & Florida Reliability Coordinating Council \\
\hline HVDC & high-voltage direct-current \\
\hline IOU & investor-owned utility \\
\hline JEA & Jacksonville Electric Authority \\
\hline LBNL & Lawrence Berkeley National Laboratory \\
\hline $\mathrm{LCOE}$ & levelized cost of electricity \\
\hline LTPP & Long-Term Procurement Plan \\
\hline MISO & Midcontinent Independent System Operator \\
\hline MMBTU & million BTU \\
\hline NREL & National Renewable Energy Laboratory \\
\hline ORNL & Oak Ridge National Laboratory \\
\hline PV & photovoltaics \\
\hline $\mathrm{RE}$ & renewable energy \\
\hline ReEDS & Regional Energy Deployment System \\
\hline RPS & Renewable Portfolio Standard \\
\hline SEC & Seminole Electric Cooperative \\
\hline SERC & Southeastern Electric Reliability Council \\
\hline SPP & Southwest Power Pool \\
\hline TECO & Tampa Electric Company \\
\hline TEPPC & Transmission Expansion Planning Policy \\
\hline & Committee \\
\hline TES & thermal energy storage \\
\hline TWh & terawatt-hour \\
\hline UC\&D & unit commitment and dispatch \\
\hline VG & variable generation \\
\hline VOM & variable operations and maintenance \\
\hline WECC & Western Electricity Coordinating Council \\
\hline
\end{tabular}




\section{Executive Summary}

Background. Flexibility - the ability of a system to respond to the variability of load - has always been part of operating a power system because the normal demand for electricity varies significantly on a daily and seasonal basis. Traditional approaches to system planning have supported flexibility that is sufficient to meet load reliably.

However, the growing share of variable generation (VG) technologies such as photovoltaic (PV) systems and wind turbines may make traditional planning approaches inadequate to ensure sufficient flexibility in the future. In practice, higher penetration of VG renewable energy (RE) has increased the scrutiny on the economically efficient operation of the grid and places greater need for planning to meet increased variability and uncertainty of load over multiple time scales.

The flexibility of a power system is directly related to its ability to accommodate VG, as well as to maintain a reliable balance of supply and demand at a reasonable cost. Limited flexibility can result in increased operations costs, reduced operational value of VG (including RE curtailment), or the need for additional conventional capacity to meet reserves or peak demand.

Focus of Our Study. In this study, we attempt to quantify the benefits of various options for improving grid flexibility by measuring their impact on two measures: economic carrying capacity and system costs.

The first measure - economic carrying capacity (ECC) — determines the level of penetration of variable-generation $\mathrm{RE}$ at which the costs outweigh the benefits and where additional VG is no longer economically desirable. In all cases, we define penetration as the fraction of annual electricity demand met by RE. Fundamentally, an ECC results from the decline in value of renewables as they are added to the grid. Increased flexibility can increase the value of RE, and therefore, can also increase the ECC.

The concept of ECC, particularly when applied to VG, has evolved over time. Historically, physical or technical issues have been perceived to fundamentally limit the penetration of VG. However, a more nuanced understanding has been gained through grid integration studies and operational experience. Specifically, there is growing recognition that although technical challenges to integrating VG are real, they can generally be addressed by a variety of solutions already available - each one having an associated implementation cost. As a result, the limit of RE penetration is primarily economic, driven by factors that include transmission availability and operational flexibility.

The second measure looks at the reduction of system costs. Quantifying this measure includes determining the reduction in operating costs resulting from increased operational efficiency, as well as reduction in capital costs if the flexibility measure reduces the need for conventional capacity. (The operational value of VG represents its ability to offset the variable costs of operating a power system, including fuel costs, variable operations and maintenance costs, and emissions costs. The capacity value of VG represents its ability to offset the need for conventional capacity, driven by the coincidence of electricity demand with VG output.) A costbenefit analysis can then be made by comparing this reduction in costs to the implementation costs. 
Specific goals of our study are to examine the following:

- The operational and capacity value of VG as a function of penetration using a grid simulation tool, comparing this value to its cost. In our analysis, we use PLEXOS, a production cost model.

- Drivers behind limited ECC, including increasing levels of curtailment and decreasing capacity value of VG.

- The impact of grid flexibility options on ECC.

- The net cost savings from different flexibility options.

From the analysis, results, and conclusions of this report, system operators and planners can better understand how best to use flexibility options to accommodate greater amounts of RE on the grid across different regions and conditions.

Our Approach. We consider case studies in three regions of the country-California, Florida, and the central U.S.- - which allows us to study different aspects of VG integration, including conventional generation mix and wind/solar mix. This analysis can help to further understand the flexibility supply curve and provide system planners with greater insights into the value of various grid flexibility options.

To illustrate the concept of VG ECC and the relationship between ECC and grid flexibility, we use an example that demonstrates the decline in total value of PV as a function of penetration. Figure ES-1 illustrates the framework used to evaluate a set of options to increase the ECC of $\mathrm{PV}$. The total value is the sum of capacity value and operational value, which totals about $\$ 80 / \mathrm{MWh}$ in the base case, but declines rapidly. This value can be compared to the levelized cost of energy from $\mathrm{PV}$, which is initially assumed to be $\$ 58 / \mathrm{MWh}$, corresponding to an ECC of $\sim 17 \%$ (indicated by the red dashed line). Increasing ECC requires some combination of decreasing costs or increasing value of PV. The following figure shows that decreasing the levelized cost of electricity (LCOE) of PV to $\$ 40 / \mathrm{MWh}$ would increase the ECC to more than $19 \%$. Alternatively, a more flexible grid could increase value, primarily by avoiding curtailment. The figure also shows a hypothetical "increased flexibility curve" that indicates a higher value of PV created by grid flexibility. Here, the increased flexibility case increases ECC to $21 \%$, whereas decreasing costs as well as increasing value produces an ECC of almost $28 \%$. The value curves and associated ECC provide one metric of improved flexibility, but it does not consider the cost of flexibility options, which are also discussed in this work. 


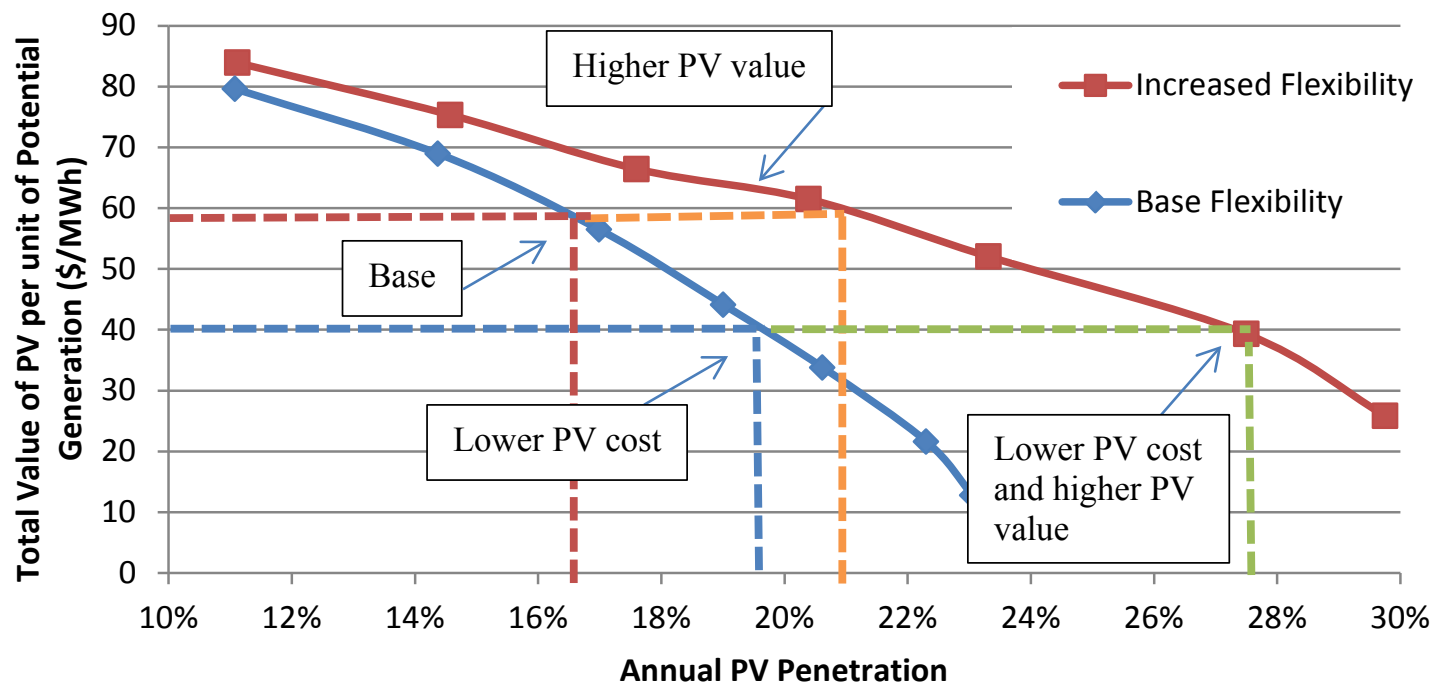

Figure ES-1 Possibility of increased economic carrying capacity-either by decreased PV costs or increased value of PV.

Using PLEXOS, we performed grid simulations with assumptions for a variety of PV and wind penetration scenarios to calculate the curtailed energy and value at each incremental RE penetration level.

Many grid flexibility options - such as improved forecasting and power system schedulinghave already been implemented or are being implemented in the U.S. and in countries with significant PV and wind penetration. In our analyses, we considered the options described below (although not every option was used in each region):

- Add demand response. Demand response (DR) and load shifting — which requires that a load can be used earlier or later than would normally occur-can improve system flexibility by changing the load to better match the supply of PV and wind generation. DR provides operational benefits by increasing demand during periods of high VG output, including the ability to reduce curtailment. It can also reduce peak demand, reducing the operation of the highest-cost peaking plants.

- Add energy storage. Battery storage provides a mechanism to shift energy in time and provide operating reserves; therefore, it can add grid-significant flexibility. We can consider various scenarios, such as low- and high-storage options. We also make assumptions of the number of hours of storage capacity and roundtrip efficiency.

- Allow PV or wind to provide reserves. A major reason for a system-wide minimum thermal generation level is due to the amount of thermal generation required to be online to provide spinning reserves. The number of units that must be online depends on what types of generators are available, their size, and how fast they can ramp to meet the requirement. Reducing the required amount of thermal generation on the system can allow higher levels of $\mathrm{VG}$, thus reducing curtailment.

- Reduce minimum generation level of combined-cycle and coal units. Reducing the minimum generation level adds flexibility to the system because it increases the overall operating range of the thermal fleet. This can benefit the integration of PV because it can 
reduce the minimum conventional generator operating level, allowing more of the peak PV generation to be used rather than curtailed due to net load (normal load minus the contribution from renewable generation) falling below the minimum generation level.

- Enhance cooperation between balancing areas (BAs). This flexibility option removes market friction between BAs (represented by a hurdle rate, which is the minimum price difference for two regions to exchange power) and assumes that generation is scheduled by a central system operator instead of by each BA; the result is greater sharing of operating reserves.

- Allow exports. Creating market opportunities increases the ability for a region to export energy that would otherwise be curtailed. It can allow a region to export energy to a neighboring region, although constrained by existing transmission limits.

- Increase transmission capacity. This option expands transmission capacity between the study region and surrounding regions, allowing increased exports and improved system efficiency by sharing the diversity of both the loads and the VG resources. One challenge to properly valuing this option is the assumed amount of $\mathrm{VG}$ added in regions outside of the focus region. For consistency between scenarios, we fix VG penetration outside the region of focus, even as the penetration changes within the focus region. This assumption may overvalue increased transmission capacity. Neighboring regions may install a similar amount of wind or solar as the focus region. However, due to differences in resource quality, a neighbor may invest in VG within a focus region if there is sufficient transmission capacity to export it.

General Results. Overall, adding flexibility produces two impacts - decreased operational and capacity costs, and increased ECC.

Comparison between the case studies is difficult because the ECC of a power system is highly specific to region and can change over time - as when inflexible generators retire, or the forecasting of demand and renewable supply improves, or market designs evolve, or enabling technologies such as storage become more affordable. Nevertheless, we highlight some key takeaways from our three analyses.

- California case study. This study examined the value of PV. Figure ES-2 shows the results for the flexibility options considered. This graph shows the decline in value for the various cases, and also shows the resulting carrying capacity assuming a PV LCOE of about $\$ 50 / \mathrm{MWh}$. The PV value was based on natural gas prices of \$5.2/MMBTU and a $\$ 50 /$ ton carbon cost. The "Increased Operational Flexibility" case considers flexibility options expected to be deployed in California by 2020. These include allowing VG to provide more than $60 \%$ of instantaneous demand, and development of about 1,300 MW of new storage. This case will substantially increase ECC and reduce operating costs in California. The other cases, such as further deployment of DR, exports and storage are added to this increased operational flexibility case, as well as near-term flexibility options now being deployed. As explained in the full report, the DR assumptions used in the study produce only a modest increase in ECC, although they can provide significant reduction in operating costs. This outcome is due to the limited availability of shiftable load in the spring and fall, which are periods of greatest PV curtailment. This result 
points to the need for additional understanding of the potential to shift load during periods characterized by the so-called "duck curve."

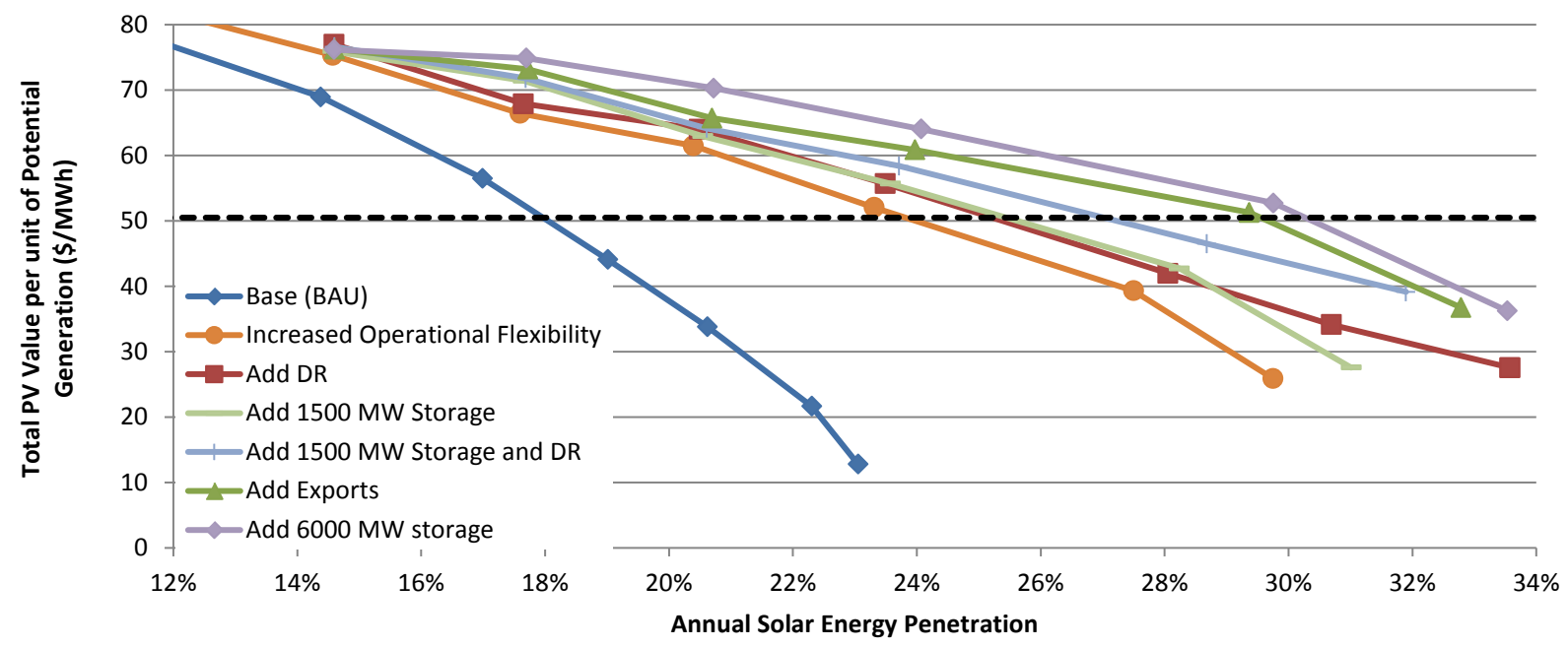

Figure ES-2 Possibility of increased economic carrying capacity in California-either by decreased PV costs or increased value of PV.

- Florida case study. This study also evaluated PV. Figure ES-3 shows the impact of flexibility on PV value at various PV penetrations. The figure also shows the change in ECC of PV when flexibility is added compared to a PV LCOE of about $\$ 55 / \mathrm{MWh}$. The $\mathrm{PV}$ value is based on an average price of natural gas of $\$ 6.8 / \mathrm{MMBTU}$ and a social cost of carbon of $\$ 50 /$ ton. The case study demonstrates significant operational value and increased ECC from both increased transmission and energy storage. Limited benefits were demonstrated from providing reserves from PV. This result is due, in part, to the limited ability to evaluate the very short-term benefits of PV providing frequency response and frequency regulation. Limited benefits were also found from increasing combined-cycle flexibility. This counter-intuitive result is largely due to the inherent flexibility of the combined-cycle fleet to frequently cycle on/off, even on a daily basis. Even with the ability to turn down to lower outputs, most combined-cycle units simply turn off during peak PV output, limiting this flexibility option to reduce PV curtailment. 


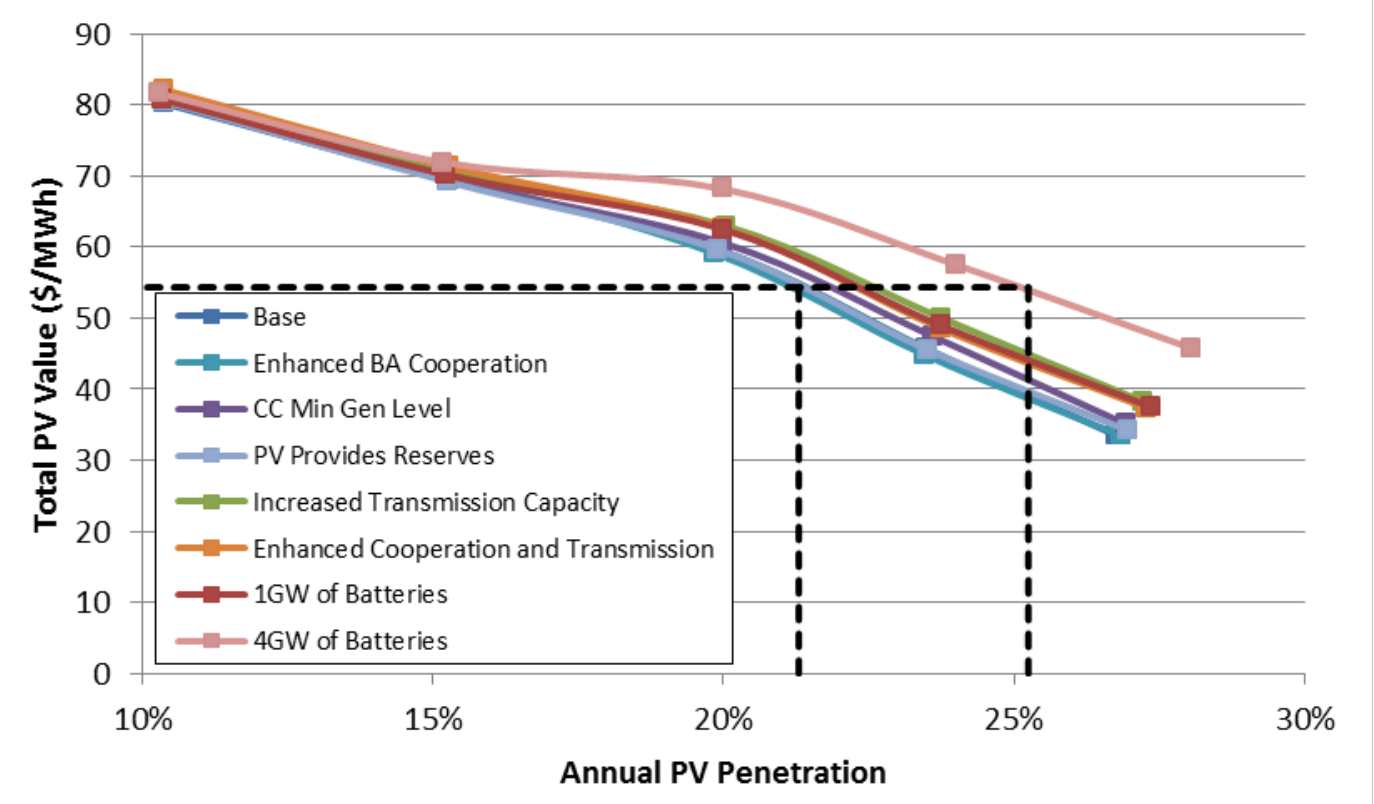

Figure ES-3 Possibility of increased economic carrying capacity in the Florida Reliability Coordinating Council-either by decreased PV costs or increased value of PV.

- Southwest Power Pool case study. The results of this study, which evaluated wind, are substantially different from the other regions. Figure ES-4 shows the impact of flexibility on wind value at various wind penetrations. The value of wind is based on an average coal price of $\$ 2.3 / \mathrm{MMBTU}$ and an average natural gas price of $\$ 5.6 / \mathrm{MMBTU}$ and a social cost of carbon of $\$ 50 /$ ton. The value of wind as a function of deployment is fairly flat relative to PV, with an ECC of at least $50 \%$ due to the low cost of wind, and when including the assumed cost of carbon. As a result, wind did not need flexibility options to increase the ECC under the scenarios evaluated. Although the impact on ECC is limited, this case shows significant value of new transmission. Net cost savings, rather than increasing ECC, is the more important value of flexibility in this region. 


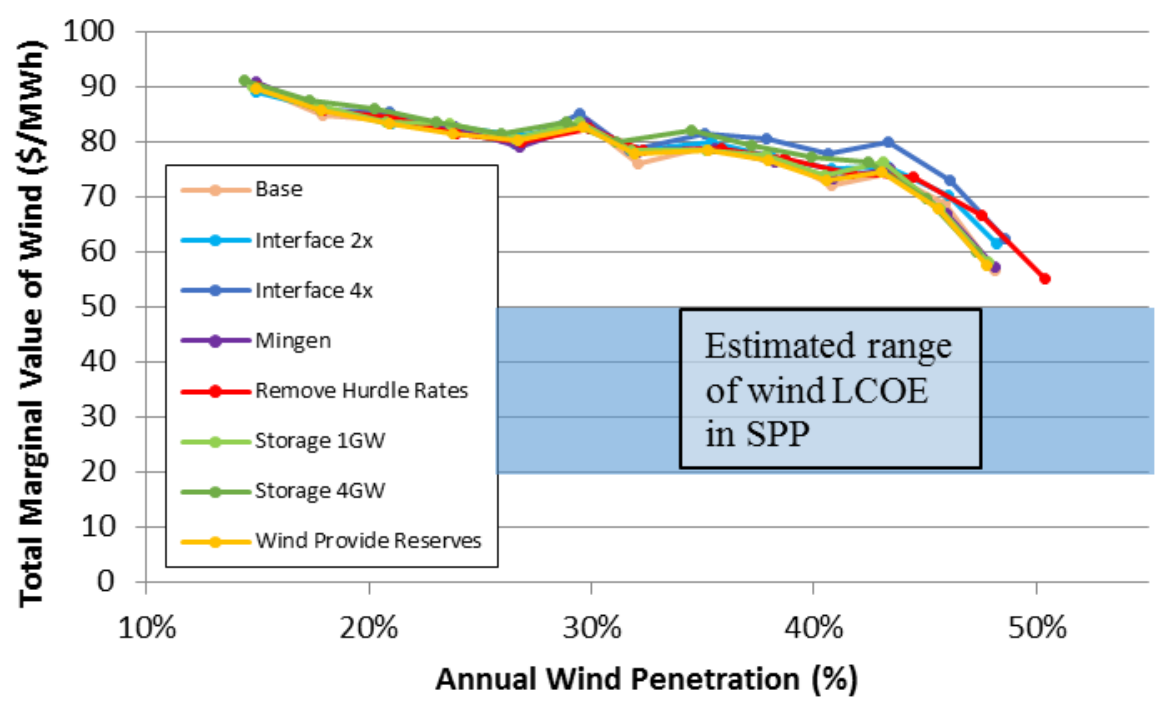

Figure ES-4 Economic carrying capacity in the Southwest Power Pool was never reached due to low LCOE of wind and high value.

Conclusions. In addition to the region-specific conclusions, there are several general conclusions from our study:

- Flexibility can increase ECC and reduce overall system costs. In some cases, options that provide a limited increase in ECC can provide significant operational savings, thus demonstrating the need to evaluate flexibility options using multiple metrics. The value of flexibility options varies regionally due to different generation mixes and types of renewables. The more rapid decline in PV value compared to wind makes PV more dependent on adding flexibility options, including transmission and energy storage.

- Even though certain flexibility options may provide similar services, their benefits may not be additive. Therefore, to understand the net additive benefits, multiple combinations of flexibility options must be evaluated.

- New analysis methods and data sources will be needed to evaluate some flexibility options, including the ability of VG to provide reserves and the role of demand response in integrating VG. In addition, more work is needed to assess the reliability and resiliency values of implementing flexibility options. 


\section{Table of Contents}

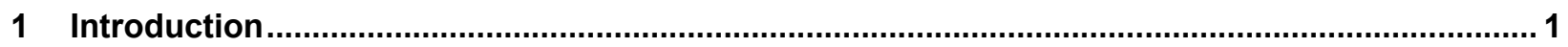

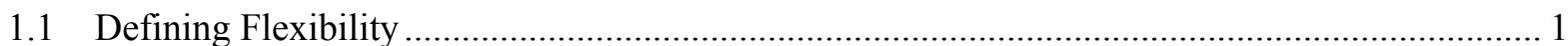

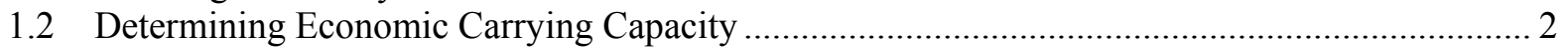

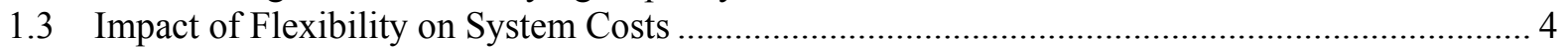

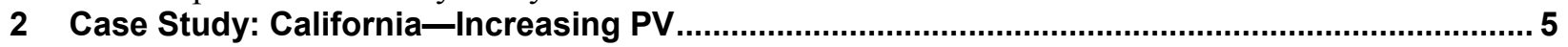

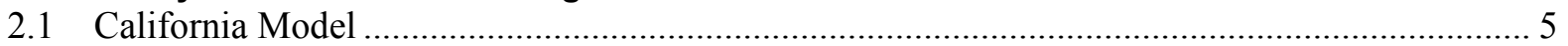

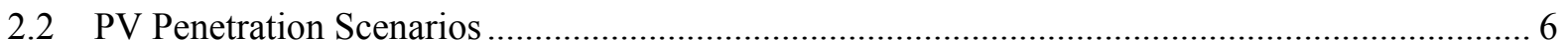

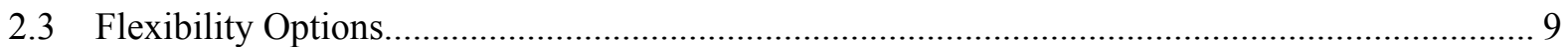

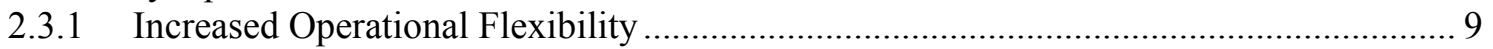

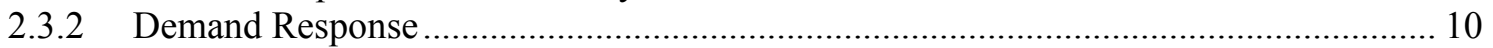

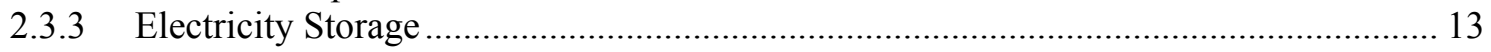

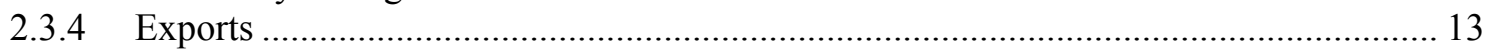

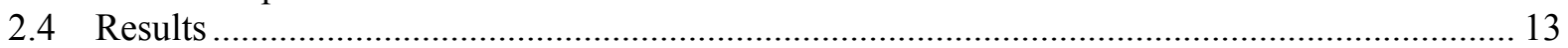

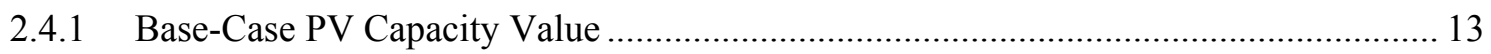

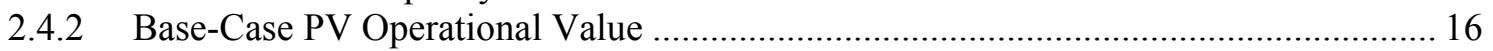

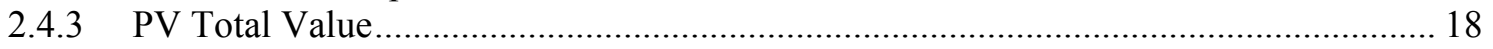

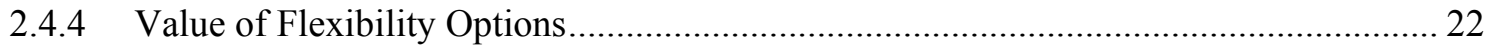

2.5 Discussion of Results for Individual Flexibility Options ........................................................ 22

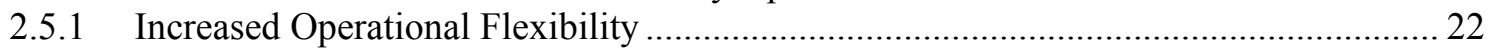

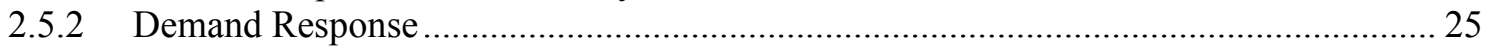

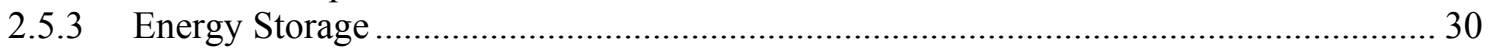

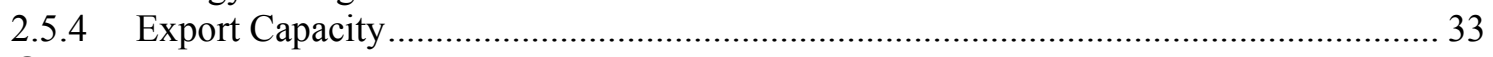

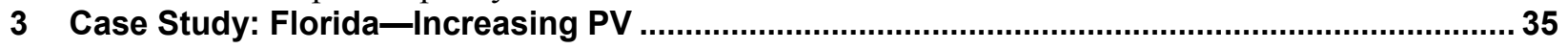

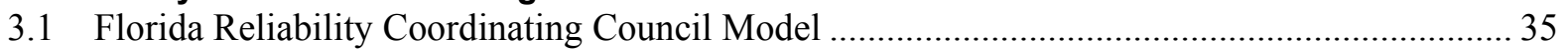

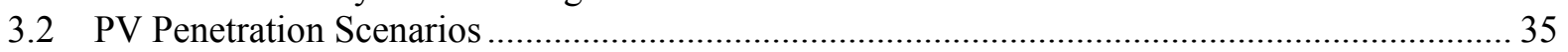

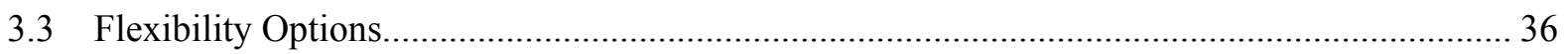

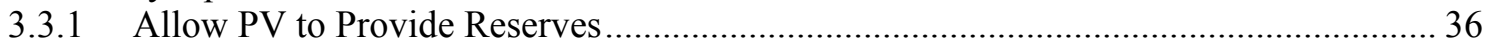

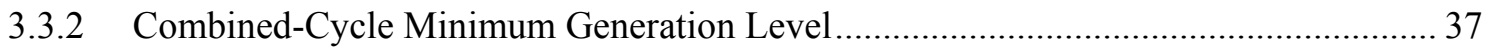

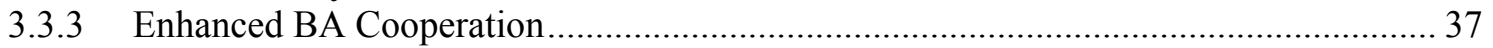

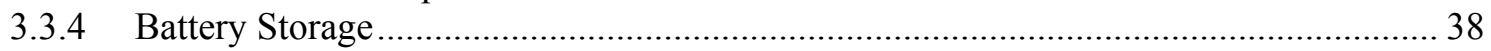

3.3.5 Increased Transmission Capacity between SERC and FRCC.................................... 38

3.3.6 Enhanced BA Cooperation and Increased Transmission between SERC and FRCC .... 38

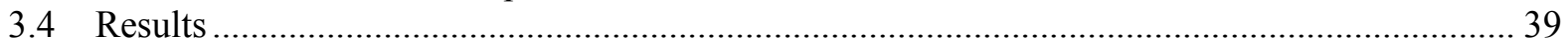

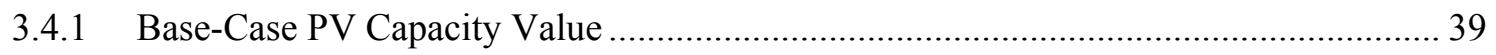

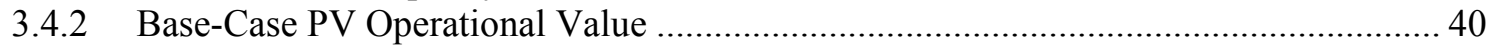

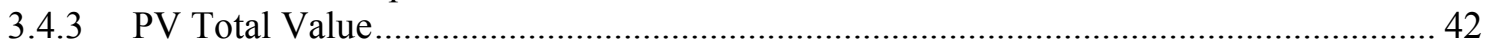

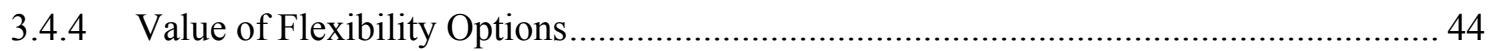

3.5 Discussion of Results for Individual Flexibility Options ........................................................ 45

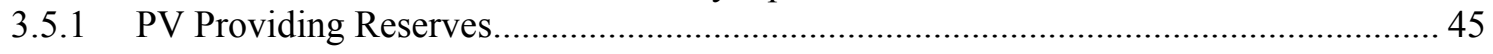

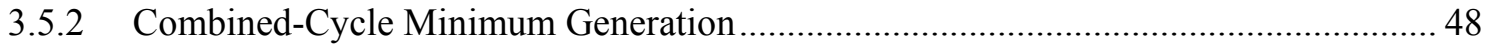

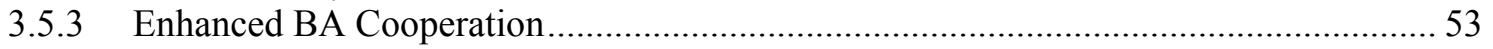

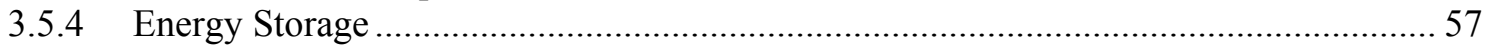

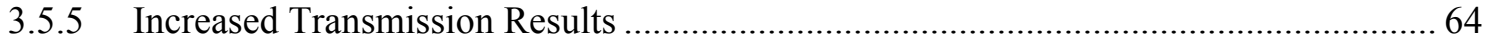

3.5.6 Combined BA Cooperation and Increased Transmission Results...................................6 68

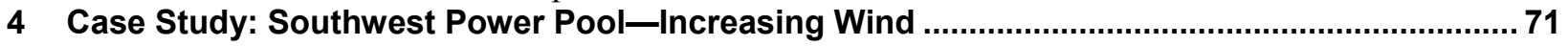

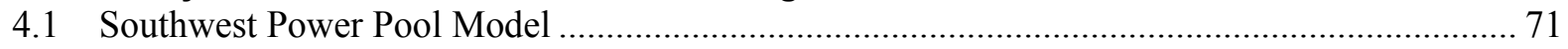

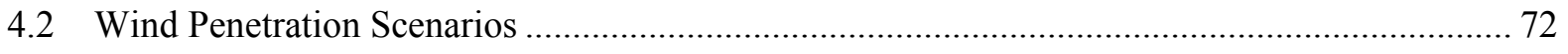

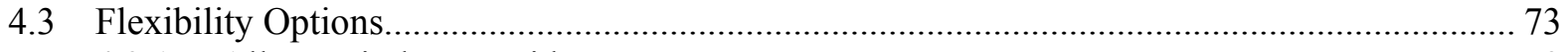

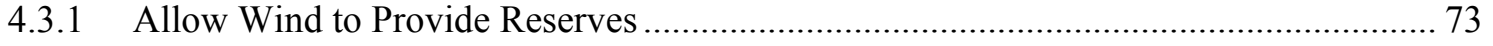


4.3.2 Gas Combined-Cycle and Coal Minimum Generation Level .................................... 73

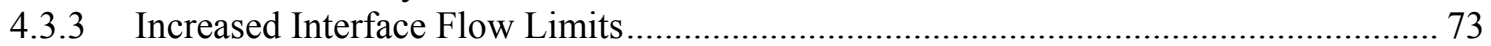

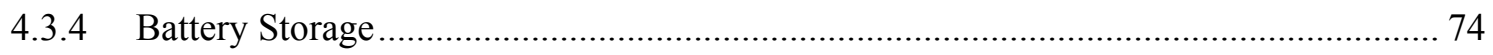

4.3.5 Increased Cooperation between SPP, MISO, and Canadian Regions ............................ 74

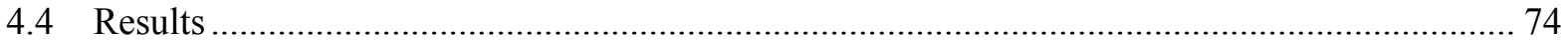

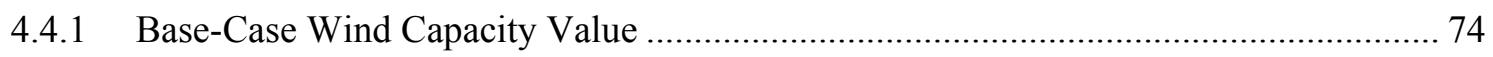

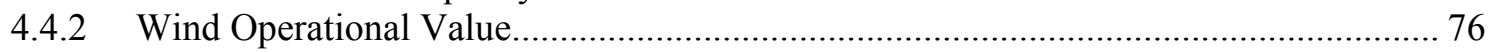

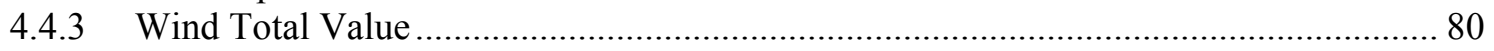

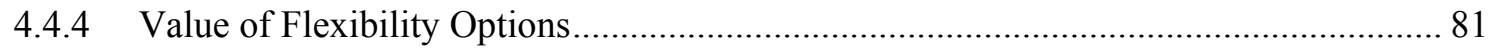

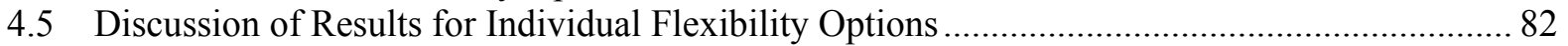

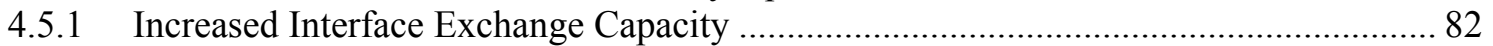

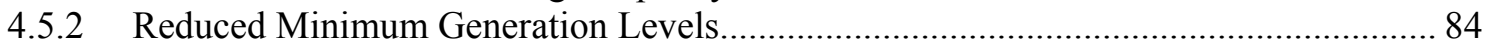

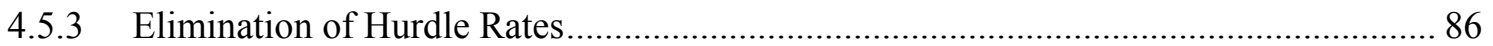

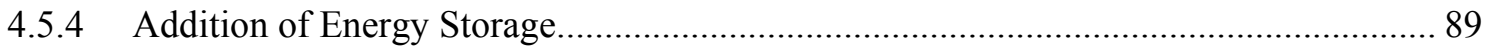

4.5.5 Allowing Wind to Provide Reserves ............................................................................ 93

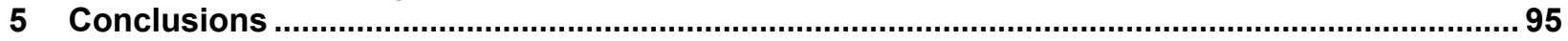

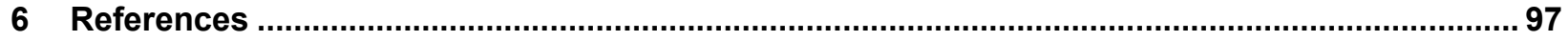

Appendix A

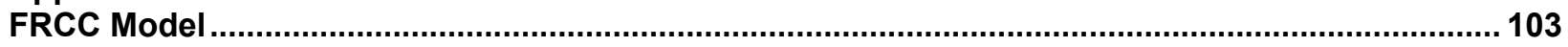

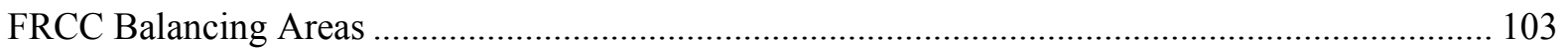

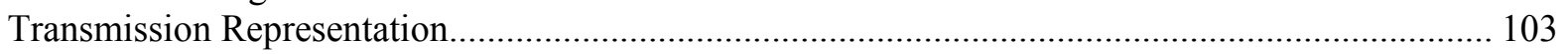

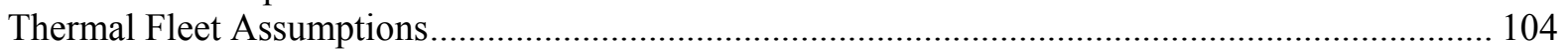

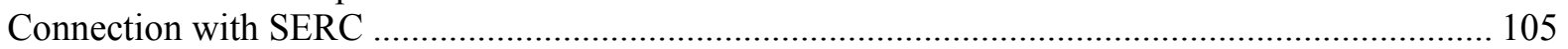

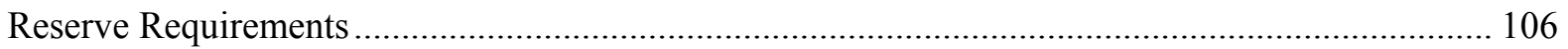

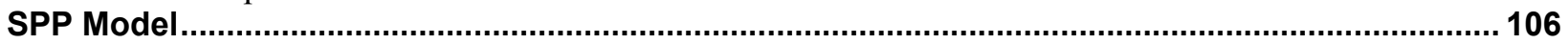

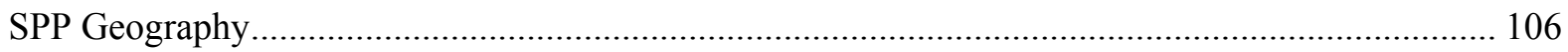

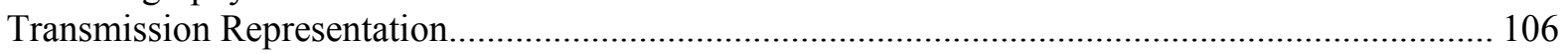

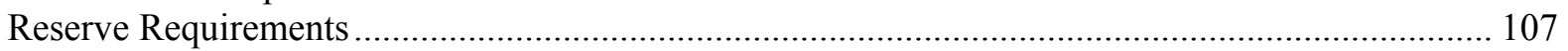




\section{List of Figures}

Figure ES-1 Possibility of increased economic carrying capacity—either by decreased PV costs or increased value of PV . ............................................................................................ vii

Figure ES-2 Possibility of increased economic carrying capacity in California-either by decreased PV costs or increased value of PV. ................................................................. ix

Figure ES-3 Possibility of increased economic carrying capacity in the Florida Reliability Coordinating Council - either by decreased PV costs or increased value of PV ....................

Figure ES-4 Economic carrying capacity in the Southwest Power Pool was never reached due to low LCOE of wind and high value. ..................................................................................... $\mathrm{xi}$

Figure 1. Possibility of increased carrying capacity — either by decreased PV costs or increased

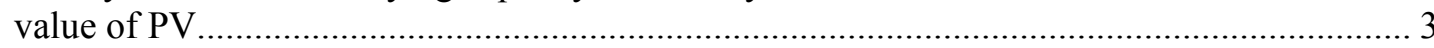

Figure 2. Flexibility options for improving system operational and VG integration................................ 4

Figure 3. California-wide system dispatch for six days in the spring and summer at a solar

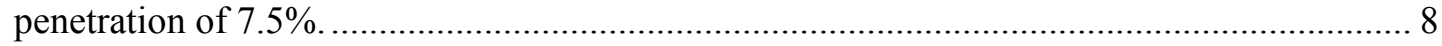

Figure 4. Shiftable load in the LBNL technical potential resource dataset.............................................. 12

Figure 5. Fraction of total hourly load that can be shifted using both LBNL and

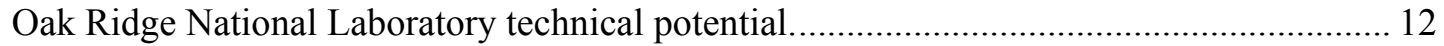

Figure 6. Load and net load profiles for California July 27-29 ...................................................... 14

Figure 7. Decline in PV capacity credit using the capacity-factor approximation. ................................ 15

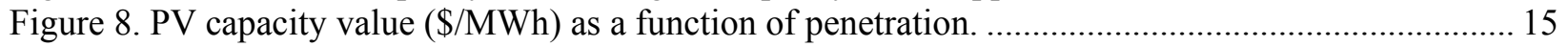

Figure 9. Annual marginal and total solar curtailment due to over-generation under increasing penetration of PV in California in a system with limited grid flexibility............................. 17

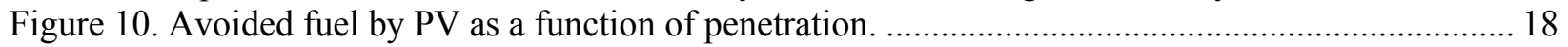

Figure 11. Avoided production cost from PV as a function of penetration. .......................................... 18

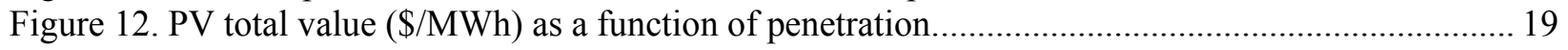

Figure 13. Impact of individual flexibility options on marginal curtailment........................................... 20

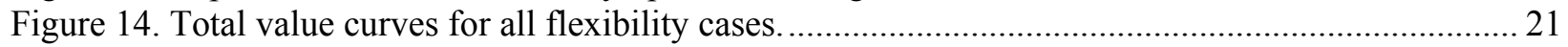

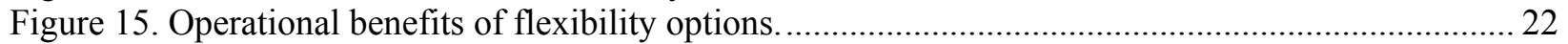

Figure 16. Impact of adding 1,285 MW of storage on March 29 in a scenario with $15 \%$ annual solar. .... 23

Figure 17. VG curtailment on March 29 in a scenario with $15 \%$ annual solar after removing the

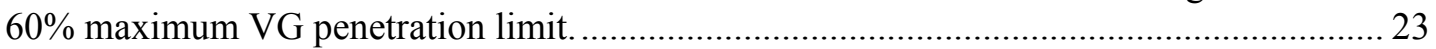

Figure 18. Increase in economic carrying capactiy resulting from increased operation flexibility........... 24

Figure 19. Operational savings and curtailment reduction associated with added flexibility....................25

Figure 20. Increase in economic carrying capactiy resulting from added DR ....................................... 25

Figure 21. Demand response availability during a spring day and seasonally..................................... 26

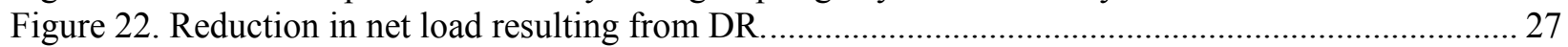

Figure 23. Total annualized benefit of demand response including capacity benefits..............................28

Figure 24. Load with and without PV demonstrating possibility of increasing availability of DR........... 30

Figure 25. Increase in economic carrying capactiy resulting from added storage................................... 31

Figure 26. Total annualized benefit of energy storage including capacity benefits................................. 32

Figure 27. Hours of storage needed to reduce peak demand by 1,500 MW and 6,000 MW as a

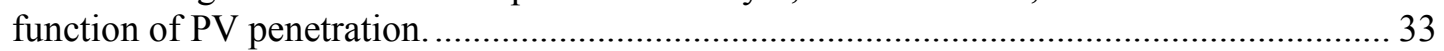

Figure 28. Increase in economic carrying capactiy resulting from added export capacity...................... 33

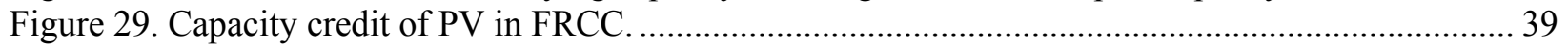

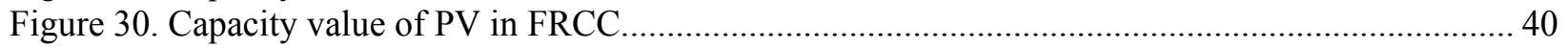

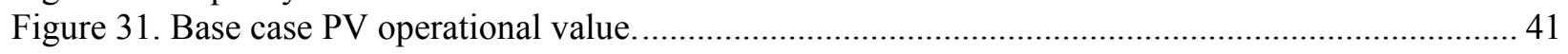

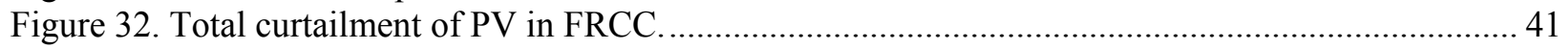

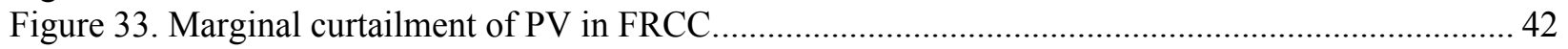

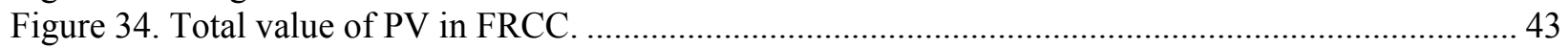

Figure 35. Operational benefits of flexibility options in FRCC........................................................... 45 
Figure 36. Total reserves provided by generator type for the base case (blue) and when PV is allowed to provide reserves (red), for each PV penetration.

Figure 37. Operational value of PV when allowing PV to provide reserves.

Figure 38. Online capacity during the day between the base case and when PV is allowed to provide reserves for each PV penetration.

Figure 39. Change in operational value of PV with reduced combined-cycle minimum generation levels.

Figure 40. Median curtailment for both scenarios (Base Case and Reduced CC Minimum Generation Level).....

Figure 41. Median total combined-cycle capacity online.

Figure 42. Median extra capacity used by combined cycles. Additional extra capacity is defined as the amount below $50 \%$ of installed capacity that a particular unit is operating.....

Figure 43. Annual operational savings and reduced curtailment with reduced minimum generation levels of combined cycles.

Figure 44. Change in the total reserve requirement when reducing BA friction for each PV penetration. 54

Figure 45. Change in PV operational value when enhancing BA cooperation in FRCC......................... 55

Figure 46. Change in CC and CT capacity online and flow on the SERC-FRCC interface when enhancing BA cooperation in FRCC, for each PV penetration.

Figure 47. Annual operational savings and reduced curtailment with enhanced BA cooperation. ............ 57

Figure 48. Change in PV operational value with energy storage ......................................................... 58

Figure 49. Change in SERC net imports, CC online capacity, and CT online capacity when adding energy storage, for each PV penetration.

Figure 50. Median storage operations over the day. Positive values are the storage discharging, whereas negative values are the storage charging, for each PV penetration.

Figure 51. Annual operational savings and reduced curtailment with enhanced BA cooperation. ............ 61

Figure 52. Real-time PV curtailment when including (dotted lines) and not including (solid lines) curtailment due to storage losses.

Figure 53. a) Total storage loss curtailment by penetration and b) proportion of storage loss curtailment relative to all curtailment.

Figure 54. Total value (operational and capacity) of energy storage in FRCC.

Figure 55. Change in PV operational value when increasing the capacity of the SERC-FRCC interface.

Figure 56. Change in CC and CT capacity online and flow on the SERC-FRCC interface when the capacity of the interface is increased, for each PV penetration.

Figure 57. Annual operational savings and reduced curtailment with increased transmission capacity between FRCC and SERC.

Figure 58. Change in PV operational value when increasing the capacity of the SERC-FRCC interface and removing BA friction.

Figure 59. Change in CC and CT capacity online and flow on the SERC-FRCC interface when the capacity of the interface is increased and BA friction is removed, for each PV penetration.

Figure 60. Annual operational savings and reduced curtailment with enhanced BA cooperation combined with increased transmission capacity between FRCC and SERC.

Figure 61. Map of SPP territory.

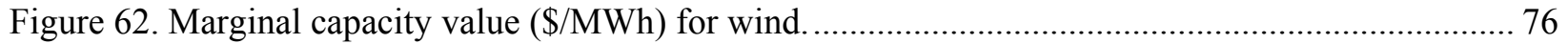

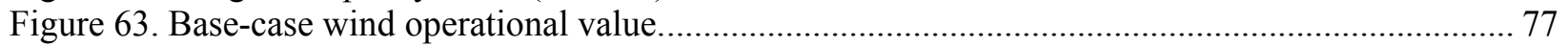

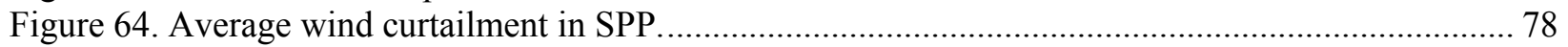

Figure 65. Impact of flexibility options on marginal curtailment in SPP. ............................................ 79

Figure 66. Marginal operational value of wind for all flexibility cases in SPP ..................................... 80 
Figure 67. Marginal total value of wind for all flexibility cases in SPP

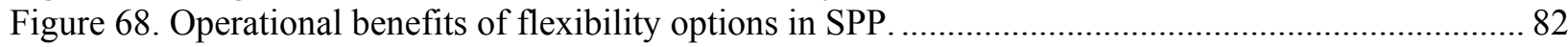

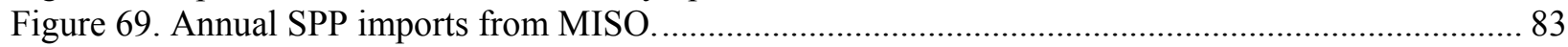

Figure 70. Annual operational savings and reduced curtailment with increased interface

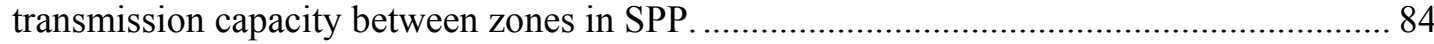

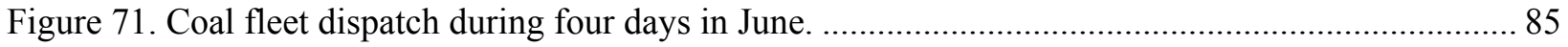

Figure 72. Annual operational savings and reduced curtailment with reduced minimum

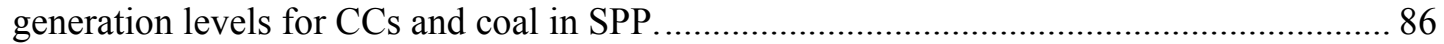

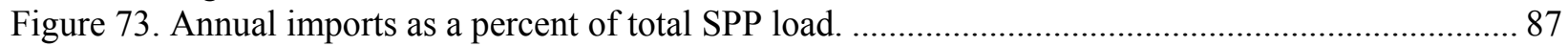

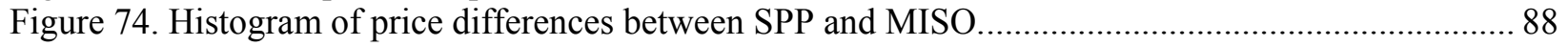

Figure 75. Annual operational savings and reduced curtailment with the elimination of hurdle

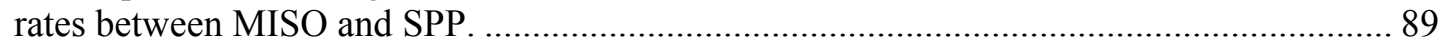

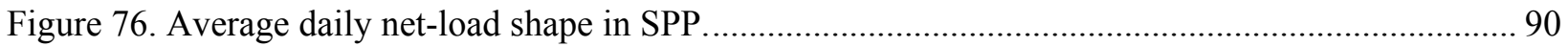

Figure 77. Average daily operation of storage in SPP for various wind penetrations. ............................. 91

Figure 78. Annual operational savings and reduced curtailment with different capacities of

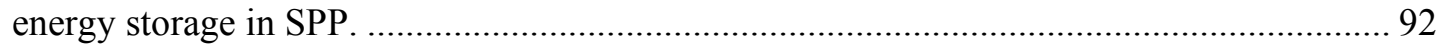

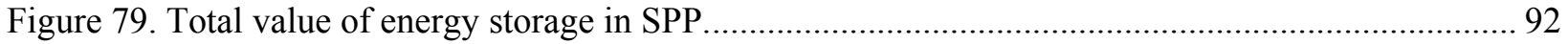

Figure 80 . Breakdown of reserve provision by generator type............................................................ 93 


\section{List of Tables}

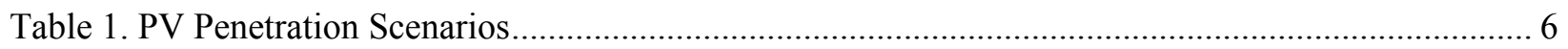

Table 2. Classification of Demand Response by End Use in the Enhanced Demand

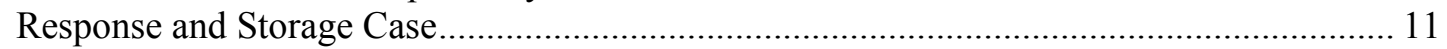

Table 3. Change in Economic Carrying Capacity due to Flexibility Options.......................................... 21

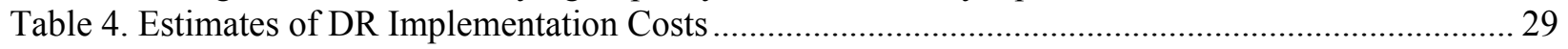

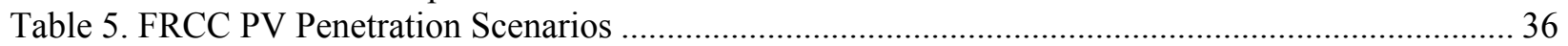

Table 6. Change in Economic Carrying Capacity due to Flexibility Options........................................ 44

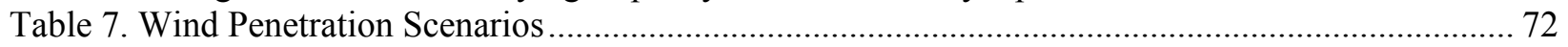

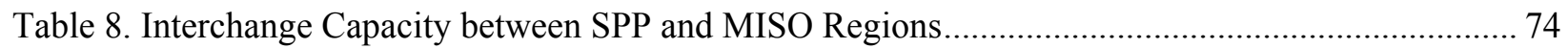

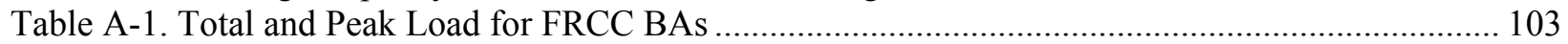

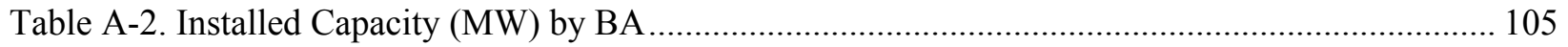




\section{Introduction}

In this report, we attempt to quantify the benefits of various options for improved grid flexibility by measuring their impact on two measures: economic carrying capacity and system costs. Our four goals are specifically to examine:

1. The operational and capacity value of variable generation $(\mathrm{VG})$ as a function of penetration using a grid simulation tool, comparing this value to its cost.

2. Drivers behind economic carrying capacity, including increasing levels of curtailment and decreasing capacity value of VG.

3. The impact of grid flexibility options on economic carrying capacity.

4. The net cost savings from different flexibility options.

We consider three regions of the country-California, Florida, and the Southwest Power Pool region in the central U.S. - which allows us to study different aspects of VG integration, including conventional generation mix and wind/solar mix. The benefits of increased carrying capacity in each region are compared to costs, which help to further understand the flexibility supply curve and provide system planners with greater insights into the value of various grid flexibility options.

\subsection{Defining Flexibility}

Flexibility is an important aspect of power system planning and operation, particularly with increased penetration of VG renewable energy resources such as wind and solar photovoltaics (PV) (Holttinen et al. 2013). Although it does not have a uniformly accepted definition, power system flexibility generally reflects the ability of a system to respond to the variability of net load, which is the load minus the contribution of VG (Lannoye et al. 2012, Ela et al. 2014). ${ }^{1}$

Flexibility has always been part of power system operation because the normal demand for electricity varies significantly on a daily and seasonal basis. Traditional approaches to planning have supported flexibility that is sufficient to meet load reliably. However, increasing VG may make traditional approaches inadequate to ensure sufficient flexibility. In practice, higher penetration of VG renewable energy (RE) has increased the scrutiny on the economically efficient operation of the grid and places greater need for planning to meet increased variability and uncertainty of load over multiple time scales.

A system that is totally flexible can meet any demand or reserve requirements. But in the context of renewable integration, a system will have limited flexibility, which means that it can only accommodate part of the output and value of VG resources. Limited flexibility can result in increased operations costs, reduced operational value of VG (including renewable curtailment), or the need for additional flexible conventional capacity to meet reserves or peak demand (Cochran et al. 2014).

\footnotetext{
${ }^{1}$ Additional discussion of flexibility metrics is provided by Zhao et al. (2016), Bertsch et al. (2016), Lannoye et al. (2015), and Nosair and Bouffard (2015)
} 
We evaluate two metrics of grid flexibility in this report. The first is the economic carrying capacity of VG (Section 1.2), and the second is reduction in system costs (Section 1.3).

\subsection{Determining Economic Carrying Capacity}

The concept of carrying capacity, particularly when applied to VG, has evolved over time. Historically, physical or technical issues have been perceived to fundamentally limit the penetration of variable RE. However, a more nuanced understanding has been gained through grid integration studies and operational experience. Specifically, there is growing recognition that although technical challenges to VG integration are real, they can generally be addressed by a variety of solutions - each one having an associated implementation cost. As a result, the limit of RE penetration is primarily economic, driven by factors that include transmission availability and operational flexibility.

One approach to estimating this limit is to determine the penetration of VG (i.e., the fraction of a system's energy met by VG) at which the costs outweigh the benefits and where additional VG is no longer economically desirable. This can be measured as economic carrying capacity (ECC) (Cochran et al. 2015). Fundamentally, an ECC results from the decline in value of renewables as they are added to the grid (Mills and Wiser 2012a). Many studies have identified a decrease in the value of VG as it begins to represent a larger percentage of an electric grid, particularly in systems that are unable to increase system flexibility. The ECC could be evaluated for the current grid (including transmission configuration and operational practices), as well as under a variety of potential future conditions, to determine the incremental costs and benefits associated with increasing carrying capacity. The ECC of any power system is highly specific to region and can change over time- - with examples including when inflexible generators retire, or demand and renewable supply forecasting improves, or market designs evolve, or enabling technologies such as storage become more affordable.

As an emergent concept, ECC has not been analyzed in detail for any specific grid. Challenges to calculating ECC include lack of consensus on the components of a cost-benefit ratio, and the complexity of valuing many of these cost and benefit components. Valuation of some benefitssuch as avoided fuel, emissions, and capacity_require detailed grid modeling of both the generation and transmission system. Additional benefits - such as the value of fuel diversity, reduced fuel price volatility, local economic benefits, and air quality-require different tools and may be difficult to estimate.

Decreases in the ECC value result from both reduced operational value and reduced capacity value. The operational value of VG represents its ability to offset the variable costs of operating a power system, including fuel costs, variable operations and maintenance (O\&M) costs, and emissions. The capacity value of VG represents its ability to offset the need for conventional capacity, driven by the coincidence of electricity demand with VG output. All energy resources decline in value as a function of penetration, but VG is particularly impacted by its limited dispatchability, which is the ability to provide energy on demand.

In our three case studies, we examine the relationship between system flexibility and economic carrying capacity. To illustrate the concept of variable-generation ECC and the relationship between carrying capacity and grid flexibility, we use an example that demonstrates the decline in total value of PV as a function of penetration. Figure 1 illustrates the framework used to 
evaluate a set of options to increase the economic carrying capacity of a VG resource - in this case, PV. The total value is the sum of capacity value and operational value, which totals about $\$ 80 / \mathrm{MWh}$ in the base case, but declines rapidly. This value can be compared to costs, which are initially assumed to be $\$ 58 / \mathrm{MWh}$, corresponding to an economic carrying capacity of almost $17 \%$. Increasing economic carrying capacity requires some combination of decreasing costs or increasing value of PV. Figure 1 shows that decreasing the levelized cost of electricity (LCOE) of PV to $\$ 40 / \mathrm{MWh}$ would increase the carrying capacity to more than $19 \%$. Alternatively, a more flexible grid could increase value, primarily by avoiding curtailment, as discussed in the individual case studies. Figure 1 also shows a hypothetical "increased flexibility curve" that indicates a higher value of PV created by grid flexibility. In this example, the increased flexibility case increases ECC to $21 \%$, whereas decreasing costs as well as increasing value produces an ECC of almost $28 \%$.

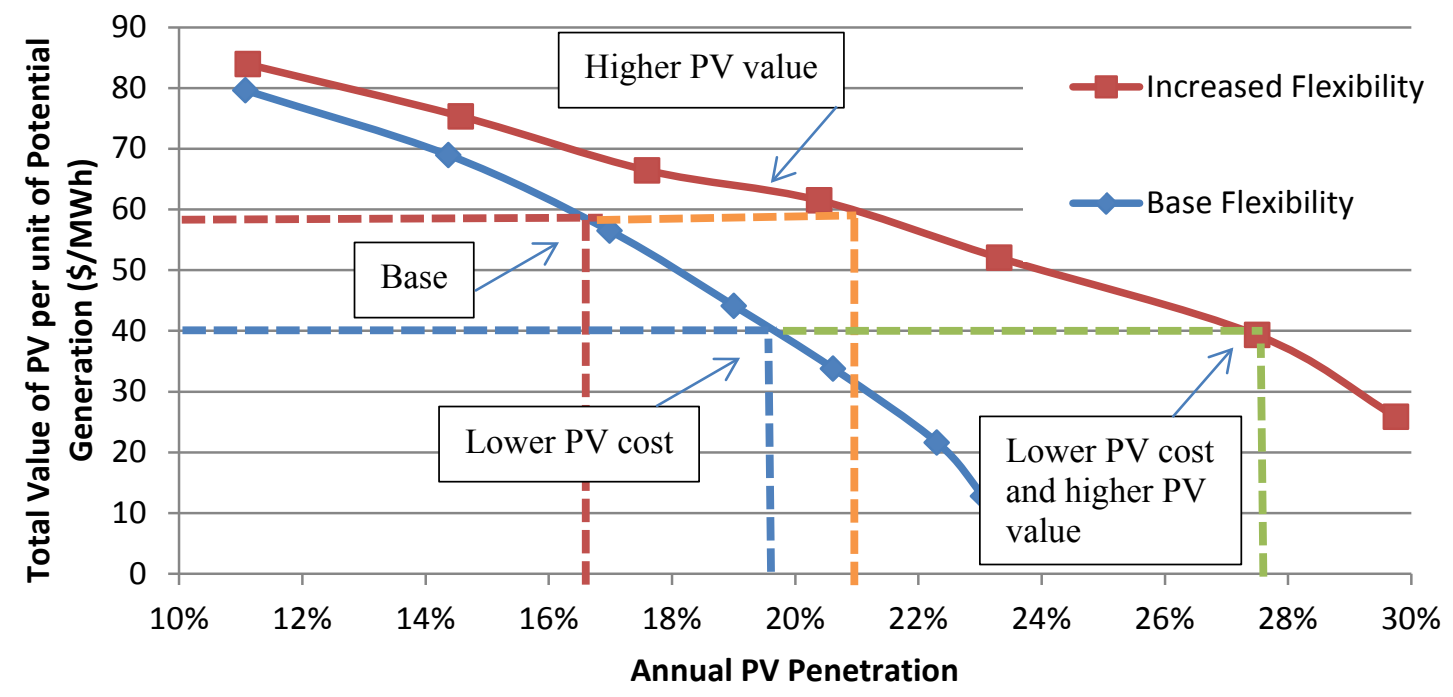

Figure 1. Possibility of increased carrying capacity-either by decreased PV costs or increased value of PV.

A variety of flexibility options are available to system operators and planners, as shown in Figure 2. Many of these options - such as improved forecasting and power system scheduling - have already been implemented or are being implemented in the U.S. and in countries with significant wind and PV penetration (Cochran et al. 2014, IEA 2014). We examine a subset of these options, which are discussed in more detail in the case studies in Sections 2, 3, and 4. 


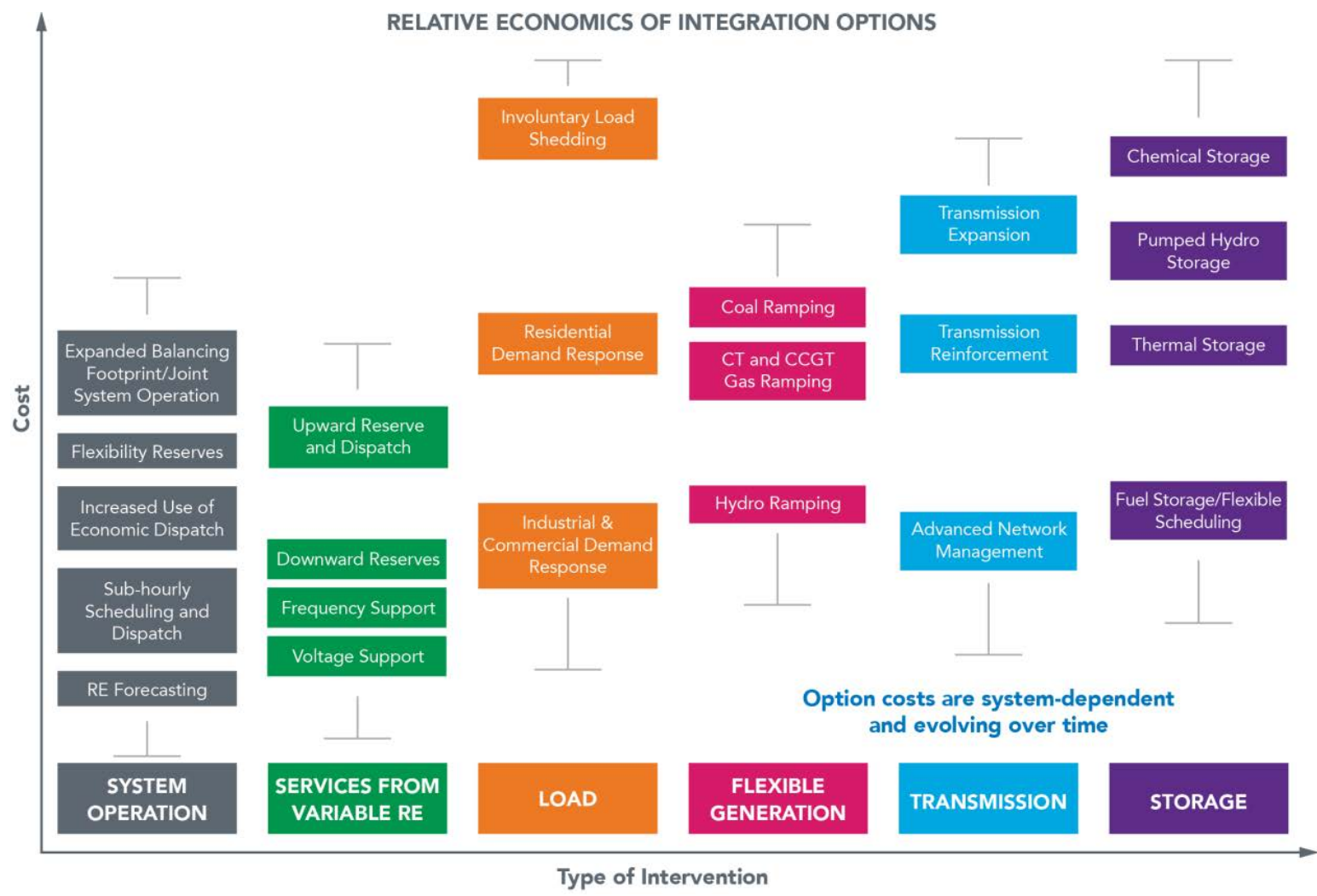

Figure 2. Flexibility options for improving system operational and VG integration. Note that costs cannot be compared across the $x$-axis.

\subsection{Impact of Flexibility on System Costs}

The impact of grid flexibility can also be measured by system costs. Quantifying this measure includes determining the reduction in operating costs resulting from increased efficiency of operation, as well as reduction in capital costs if the flexibility measure reduces the need for conventional capacity. A cost-benefit analysis can then be made by comparing this reduction in costs to the implementation costs. 


\section{Case Study: California-Increasing PV}

\subsection{California Model}

The California case study examines the economic carrying capacity of PV in the entire state of California including the service territories of all investor-owned and publicly owned utilities.

This study uses the PLEXOS production-cost model, which simulates the operation of all power plants throughout the Western Interconnection. The data and assumptions are derived from NREL's 2030 Low Carbon Grid Study (LCGS) (Brinkman et al. 2016) with additional modifications derived from Denholm et al. (2016). As discussed in LCGS, the underlying data sets are largely derived from the Western Electricity Coordinating Council (WECC) Transmission Expansion Planning Policy Committee (TEPPC) 2024 Common Case (WECC 2014) and the California Independent System Operator (CAISO) 2014 Long-Term Procurement Plan (LTPP) data $\operatorname{set}^{2}$ (CPUC 2013).

In this study, we examine the impact of several flexibility options compared to a base case. The base case is a "limited flexibility" case that includes a set of restrictive assumptions about grid operations in California, and it could be considered a "business-as-usual" scenario.

Key assumptions in this limited flexibility case include the following:

- There are no net exports of electricity from California. ${ }^{3}$

- No new demand response (DR) or storage is installed beyond what is in service in 2015 . $^{4}$ Existing pumped storage (about 2,500 MW) is allowed to respond to net load, but this simulation does not consider the 1,325 MW of additional storage that will be deployed as part of the California storage mandates; this is evaluated in later sections.

- Twenty-five percent of all generation within certain zones must be met with local fossil fuel or hydro generation. ${ }^{5}$

- Instantaneous penetration of VG in the state - including PV, wind, and concentrating solar power (CSP) without thermal energy storage (TES) - is limited to 60\% of the normal load. ${ }^{6}$

\footnotetext{
${ }^{2}$ Additional discussion of the California LTPP model can be found in Eichman et al. (2015).

${ }^{3}$ This is based on the fact that California has historically been a net importer, and there are limited market mechanisms to allow California to sell excess renewable energy out of state. Further discussion is provided in Liu (2014a).

${ }^{4} \mathrm{Up}$ to about $1.3 \%$ of peak demand (as much as about $900 \mathrm{MW}$ during periods of peak demand) can be shifted via economic DR programs. This value is about equal to the existing "price response" DR available from the three investor-owned utilities in the CAISO territory (CPUC 2015b).

${ }^{5}$ In the database from which this study is derived (the Low Carbon Grid Study from Brinkman et al. 2015), the zones that require the $25 \%$ local generation limit account for $77 \%$ of all California load. The Diablo Canyon nuclear power plant does not contribute to the local generation requirement, which is a conservative assumption based on the fact that nuclear power plants typically do not vary load to provide operating reserves. For additional analysis of the impact of the local generation requirement, see Nelson (2014) and Brinkman et al. (2015).
} 
- VG cannot be used to provide reserves.

The costs of fuel are assumed to vary by region and seasonally. However, the price of natural gas delivered to power plants in California is assumed to average \$5.1/MMBTU. We also assume a value of $\$ 50 /$ ton of $\mathrm{CO}_{2}$, based on the EPA's value for the social cost of carbon assuming a $3 \%$ discount rate. ${ }^{7}$ The total annual load (based on growth to 2030) is 320 terawatt-hours (TWh), with a peak demand of $64.7 \mathrm{GW}$, which is about 6\% higher than 2014 (CEC 2015)

Although we focus on analyzing California, the simulations actually consider the operation of the entire Western Interconnection. This is because of the extensive interaction between California and the rest of the West, including extensive imports and dedicated purchases of renewable energy generation from outside the state. We simulate this scenario to determine the total cost of operating the system for one year, accounting for fuel, variable O\&M, and emissions costs.

\subsection{PV Penetration Scenarios}

We performed grid simulations with these assumptions for a one year timeframe and for a variety of solar penetrations to calculate the curtailed energy and value at each incremental penetration level of PV. Table 1 summarizes the scenarios, with the first column representing the annual potential PV penetration, before curtailment, so the actual penetration is typically less, especially for the higher potential scenarios. The second column translates the annual \% penetration into annual energy potential, while the third adds the total potential from other renewable resources.

Table 1. PV Penetration Scenarios

\begin{tabular}{|c|c|c|}
\hline $\begin{array}{c}\text { Solar Pre-Curtailment } \\
\text { Potential Scenario (\%) }\end{array}$ & $\begin{array}{c}\text { Total Solar (PV + CSP) } \\
\text { Potential (GWh) }\end{array}$ & $\begin{array}{c}\text { Total Pre-Curtailment } \\
\text { Renewable Portfolio Standard } \\
\text { (RPS) Potential (\%) }\end{array}$ \\
\hline 7.5 & 23,973 & 24.5 \\
\hline 11 & 35,331 & 36.0 \\
\hline 15 & 46,473 & 39.6 \\
\hline 18 & 56,438 & 42.7 \\
\hline 21 & 66,155 & 45.8 \\
\hline 24 & 77,329 & 49.4 \\
\hline 31 & 98,964 & 56.3 \\
\hline 37 & 119,682 & 62.9 \\
\hline
\end{tabular}

\footnotetext{
${ }^{6}$ This is based on the provision that renewables cannot provide reserves and the concern that at $60 \%$ VG penetration without VG providing reserves, "the grid may not be able to prevent frequency decline following the loss of a large conventional generator or transmission asset" (CAISO 2013).

${ }^{7}$ http://www3.epa.gov/climatechange/Downloads/EPAactivities/social-cost-carbon.pdf
} 
Figure 3 shows the dispatch of generators in California for six days in two different time periods, spring and summer, in the $7.5 \%$ case. The scenarios assume that wind provides $11 \%$ of California's annual demand. This case is close to the actual contributions of VG in $2015 .^{8}$ In the figure, each generator type is aggregated and "stacked" in the order of operational cost. Low-cost nuclear and renewable generators are at the bottom, whereas higher-cost gas plants are at the top. PV is placed at the top of the dispatch stack to more clearly show its impact. Note that the announcement of the Diablo Canyon nuclear plant was made after the completion of the analysis, and the impact of this retirement on system flexibility was not considered in this study. California supplies a significant amount of its load from imports, which explains the difference between the stacked generation supply and the total load. The difference between the load and generation is met by imports. If total generation is larger than load and no power can be exported, VG must be curtailed to maintain the balance of electricity supply and demand.

\footnotetext{
${ }^{8}$ In 2014, California generated 12.7 terawatt-hours (TWh) from wind in-state and imported another 12.7 TWh of wind for a total of $25.4 \mathrm{TWh}$, which provides about $8.6 \%$ of the total demand (296.6 TWh). Penetration of utilityscale solar in 2014 was about $4.2 \%$, or about $6 \%$ including rooftop solar. Based on recent projections, $11 \%$ solar penetration could be achieved as early as the end of 2017. Sources: http://energyalmanac.ca.gov/electricity/total system power.html, http://energyalmanac.ca.gov/electricity/electricity_generation.html, GTM 2015.
} 


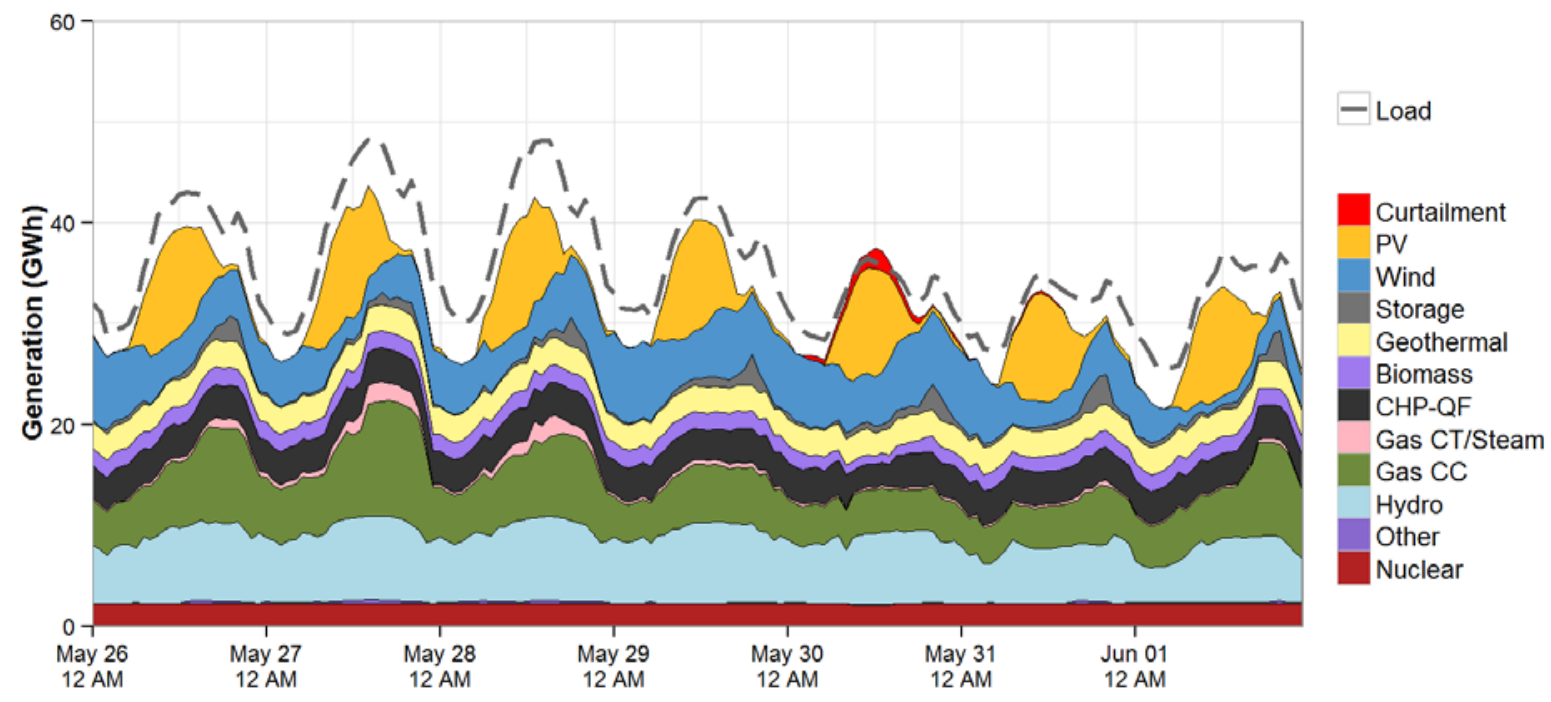

(a) Spring

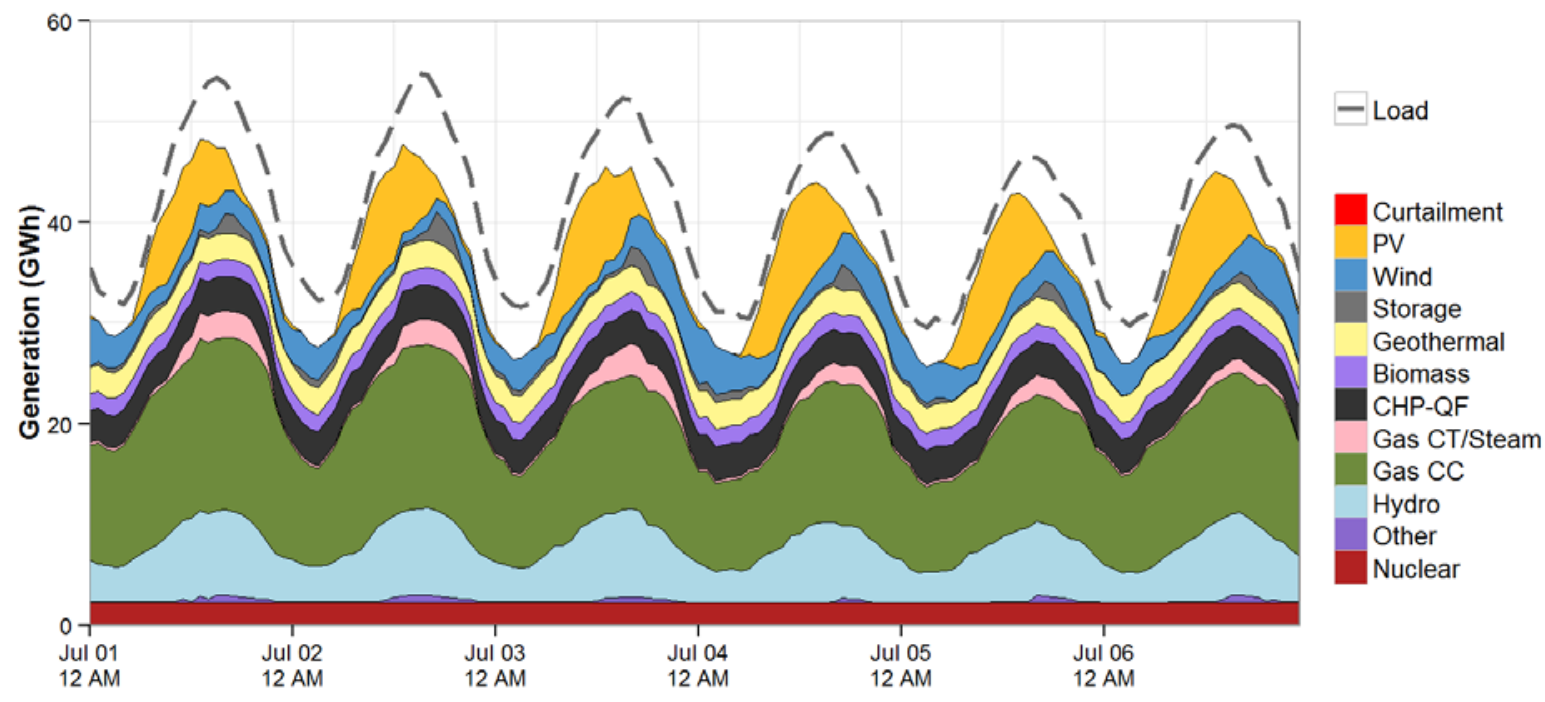

(b) Summer

Figure 3. California-wide system dispatch for six days in the spring and summer at a solar penetration of $7.5 \%$. 


\subsection{Flexibility Options}

\subsubsection{Increased Operational Flexibility}

Many of the assumptions in the base case represent business-as-usual (BAU) assumptions that are in the process of being modified in many parts of the country. Many regions are changing how the system is operated in response to increased capabilities of VG and distributed resources. The California Public Utilities Commission (CPUC) (2015a) discusses many flexibility options in a California-specific context, and how the grid in California is evolving. The specific set of changes we made is in response to projected changes in how California will operate the grid between now and 2020.

First, we added 1,290 MW of new storage, roughly following the California storage mandate (Eichman et al. 2015) and consisting of $550 \mathrm{MW}$ with 2-hour discharge duration, $520 \mathrm{MW}$ with 4-hour discharge duration, and $220 \mathrm{MW}$ with 6-hour discharge duration. ${ }^{9}$ The devices are assumed to have $80 \%$ roundtrip efficiency and are distributed among the three California investor-owned utility (IOU) zones in accordance with the storage mandate. We assume all of the storage added is optimized by the system operator to minimize the overall cost of system operation and can provide multiple services including provision of reserves. ${ }^{10}$ This is a critical assumption and would require optimization either 1) directly by a system operator in the case of utility-scale storage, or 2) indirectly through real-time pricing or other mechanisms that would optimize behind-the-meter storage.

Second, we removed the $60 \%$ instantaneous VG penetration limit and $25 \%$ local-generation requirements, representing the availability of frequency-responsive reserves from new storage, existing DR, and curtailed wind and solar. We also allow curtailed VG to provide upward regulation, contingency, and flexibility reserves. However, considering the possible stability impacts of extremely high instantaneous VG penetration, we restrict VG (including PV, wind, and CSP without TES) from providing more than $80 \%$ of load within California at any time. The ability of VG and distributed resources to provide reserves and stability services is an important change for accommodating increased penetration of VG. ${ }^{11}$ Use of distributed resources and load to provide frequency response will require loads to sense system frequency and automatically reduce load during low-frequency events. ${ }^{12}$ This incurs both an implementation cost and any costs associated with paying customers when load is curtailed.

\footnotetext{
${ }^{9}$ The 40-MW Lake Hodges plant is eligible for the storage mandate, and it existed in the base case, so the additional storage is less than the $1,325-\mathrm{MW}$ requirement.

${ }^{10}$ This is a deviation from the current assumptions in the LTPP model, which assumes a mix of transmission-, distribution-, and customer-sited storage, of which only a fraction can provide reserves (Liu 2014a).

${ }^{11}$ A summary of stability issues is provided by Kundur et al. (2004). They provide the following definitions: "Voltage stability refers to the ability of a power system to maintain steady voltages at all buses in the system after being subjected to a disturbance from a given initial operating condition" and "Frequency stability refers to the ability of a power system to maintain steady frequency following a severe system upset resulting in a significant imbalance between generation and load."

${ }^{12}$ An example of an existing program that uses frequency-responsive loads is the ERCOT Responsive Reserve Service, which pays loads to reduce demand automatically when the frequency drops below a certain threshold (ERCOT 2014).
} 
It is important to emphasize that this assumption requires greater visibility and control of multiple distributed resources, including both PV and storage. These distributed resources will likely be needed to perform many functions currently met by conventional generation resources, with appropriate controls and market mechanisms put in place to compensate owners for providing these services.

The increased flexibility case is in the process of being deployed in California, so all subsequent flexibility options are added to this case.

\subsubsection{Demand Response}

The base-case analysis assumes a small amount of responsive demand that approximates the amount available in 2015. Additional demand response could improve system flexibility by shifting the load to better match the supply of wind and solar generation. DR provides operational benefits by increasing demand during periods of high VG output, including the ability to reduce or avoid curtailment. It can also reduce demand during periods of net load peak, reducing the operation of the highest-cost peaking plants. Directly controllable responsive demand can provide the system operator with increased flexibility to provide operating reserves, respond to VG resource uncertainty, and address emergency events. Demand shifting can be implemented through market-based incentives such as time-varying prices. But using DR to allow for increased VG penetration will likely require DR to provide grid-stability services such as primary frequency response. Use of DR in this manner will require provision of services not typically provided by loads.

To evaluate the role of DR in increasing PV value, we used an assessment of demand-shifting potential in the Western U.S. performed by Lawrence Berkeley National Laboratory (LBNL) (Olsen et al. 2013). The study estimates shifting of 13 classes of loads primarily in residential and commercial buildings, but also certain industrial "non-manufacturing" loads including municipal and agricultural water-pumping loads. The study provides estimates for the "projected" availability of DR using a number of filters that estimate acceptability and controllability of various loads. The amount of load estimated as shiftable over multiple hours in this case is very small. In the base-case assessments, using estimated "current" levels of consumer acceptability for demand response, the LBNL study identified an average of $248 \mathrm{MW}$ of shiftable load in California, with a peak of 964 MW. Overall, these studies indicate that using BAU-type assumptions, only a few hundred MW of load at best can be shifted during periods of high curtailment, which would have a negligible impact on curtailment reduction and on increase in PV value.

Very high PV penetration would likely change electricity pricing structures and create new incentives for load management. The LBNL reports provide a higher estimate for energy-shifting values referred to as "technical potential," where the potential for shifting is increased to an average of about 2,100 MW, with a peak of about 8,500 MW. ${ }^{13}$ Table 2 shows the breakdown of the DR availability by end use.

\footnotetext{
${ }^{13}$ This and other changes to system operation will likely require new market mechanisms. Several of these are discussed in Hogan and Paulos (2014).
} 
Table 2. Classification of Demand Response by End Use in the Enhanced Demand Response and Storage Case

\begin{tabular}{|c|c|c|c|c|c|}
\hline End Use & $\begin{array}{c}\text { Annual } \\
\text { Shiftable } \\
\text { Demand } \\
\text { (GWh) }\end{array}$ & $\begin{array}{c}\text { \% of } \\
\text { Annual } \\
\text { CA Load } \\
\text { (\%) }\end{array}$ & $\begin{array}{c}\text { Maximum } \\
\text { Load } \\
\text { Reduction } \\
\text { (MW) }\end{array}$ & $\begin{array}{c}\text { Load Reduction } \\
\text { during Top 20 } \\
\text { Load Hours } \\
\text { (MW) }\end{array}$ & $\begin{array}{c}\text { Maximum } \\
\text { Load } \\
\text { Increase } \\
\text { (MW) }\end{array}$ \\
\hline $\begin{array}{c}\text { Agricultural } \\
\text { Pumping }\end{array}$ & 2,400 & 0.75 & 614 & 623 & 921 \\
\hline Data Centers & 1,150 & 0.36 & 131 & 157 & 156 \\
\hline $\begin{array}{c}\text { Refrigerated } \\
\text { Warehouses }\end{array}$ & 620 & 0.2 & 117 & 124 & 164 \\
\hline $\begin{array}{c}\text { Residential Water } \\
\text { Heaters }\end{array}$ & 1,610 & 0.50 & 139 & 122 & 400 \\
\hline $\begin{array}{c}\text { Wastewater } \\
\text { Pumping }\end{array}$ & 161 & 0.05 & 18 & 21 & 21 \\
\hline $\begin{array}{c}\text { Commercial } \\
\text { Cooling }\end{array}$ & 1,020 & 0.31 & 1,790 & 1,450 & 1,790 \\
\hline $\begin{array}{c}\text { Commercial } \\
\text { Heating }\end{array}$ & 42 & 0.01 & 82 & 0 & 85 \\
\hline $\begin{array}{c}\text { Municipal } \\
\text { Pumping }\end{array}$ & 120 & 0.04 & 52 & 28 & 52 \\
\hline $\begin{array}{c}\text { Residential } \\
\text { Cooling }\end{array}$ & 3,900 & 1.2 & 5,750 & 3,670 & 5,750 \\
\hline $\begin{array}{c}\text { Total } \\
\text { (non-coincident) }\end{array}$ & 11,023 & 3.4 & 8,693 & 6,195 & 9,339 \\
\hline
\end{tabular}

DR availability has strong daily and seasonal patterns driven by the cooling demand. Figure 4 shows the estimated hourly shiftable load from the LBNL DR assessment for two days in the spring and summer. Each figure shows the total load, as well as the load evaluated by the LBNL study. The large amount of load that was not evaluated includes residential lighting, manufacturing, and all "plug" loads including items such as appliances and computers. 


\section{Total Load Evaluated Load Shiftable Load}

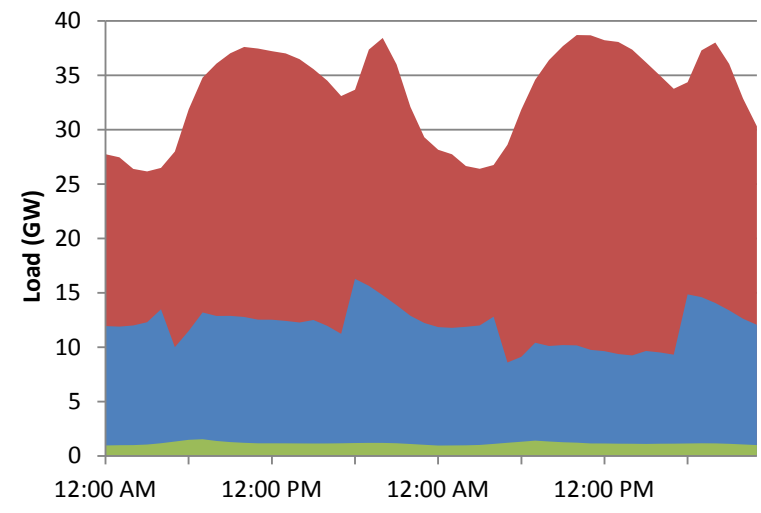

a) Spring (April 1-2)

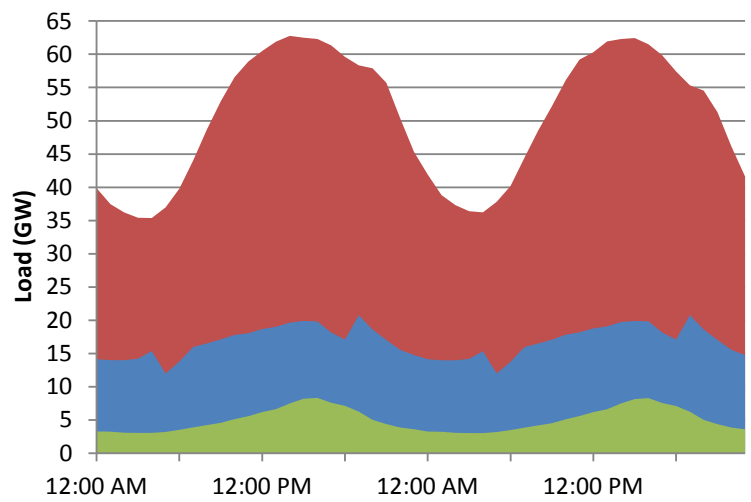

b) Summer (July 27-28)

Figure 4. Shiftable load in the LBNL technical potential resource dataset.

Figure 5 translates this into the fraction of the load that can be shifted in each hour over the entire year.

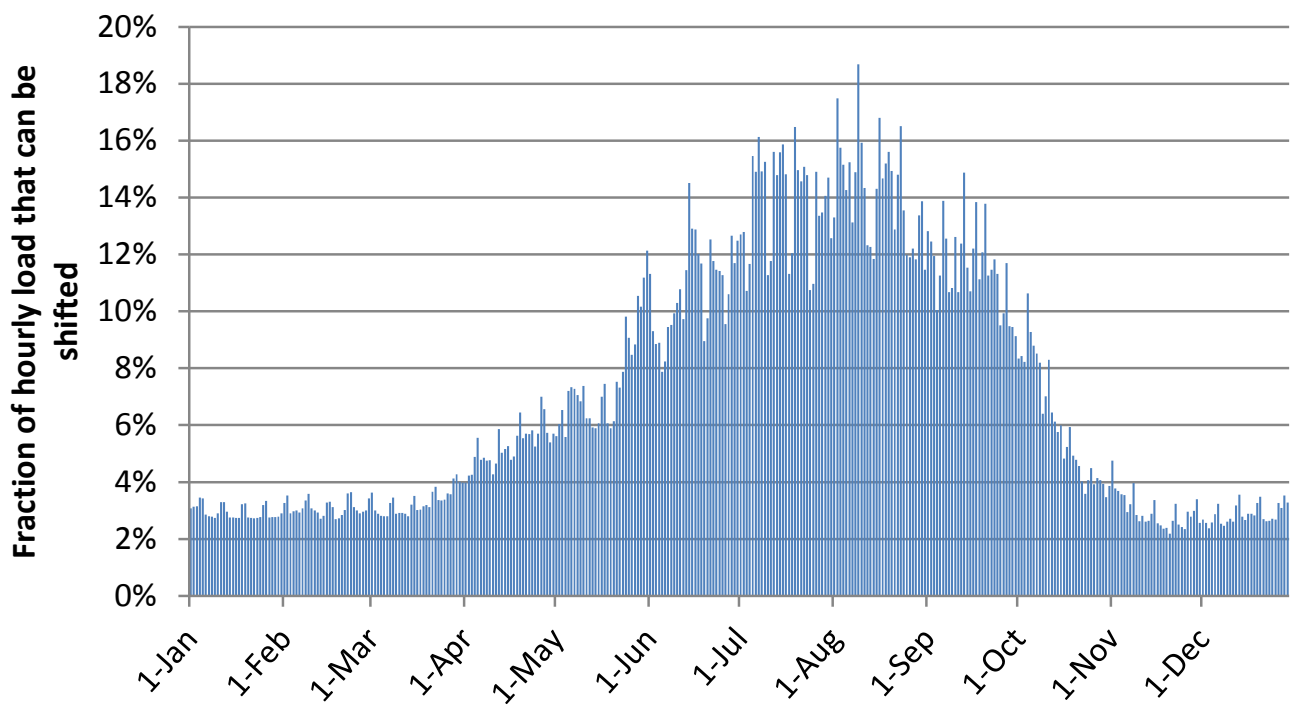

Figure 5. Fraction of total hourly load that can be shifted using both LBNL and Oak Ridge National Laboratory technical potential.

We implemented the DR resource availability and profiles in the PLEXOS model following methods documented in Olsen et al. (2013), Hummon et al. (2013a), and Brinkman et al. (2016). We assume that there is no cost associated with a load-shifting event, and costs are recovered through fixed annual payments, as discussed in Section 2.5.2. 


\subsubsection{Electricity Storage}

The base-case system includes 2,518 MW of existing pumped storage ${ }^{14}$ plus 1,290 MW of storage to be installed in response to the California storage mandate. We consider the addition of either 1,500 MW or 6,000 MW of new storage. This addition results in as much as $8,300 \mathrm{MW}$ of total storage, or about 2.2 times the amount of storage expected in 2020 , including existing pumped hydro and new mandated storage. The storage is assumed to have 6 hours of capacity and a roundtrip efficiency of $80 \%$. We assume this addition of storage is effectively optimized to minimize the overall cost of system operation. This is a critical assumption and would require either direct optimization by a system operator (in the case of utility-scale storage) or indirectly through real-time pricing or other mechanisms to optimize behind-the-meter storage. We also considered a case with both 1,500 MW of new storage as well as the full DR technical potential.

\subsubsection{Exports}

The base-case system does not allow net energy exports from California. This is because California has historically been a net importer, and limited market mechanisms have existed to allow California to sell excess renewable energy out of state (Liu 2014a). However, the creation of the Energy Imbalance Market (EIM), along with prospects of further market opportunities, increases the ability for California to export energy that would otherwise be curtailed. In this flexibility case, we allow California to export energy to its neighbors, constrained by existing transmission limits.

\subsection{Results}

\subsubsection{Base-Case PV Capacity Value}

The capacity value of solar depends on the extent to which solar generation aligns with demand patterns. Solar energy provides capacity value by reducing the demand that must be met by conventional generators during periods of high demand. Figure 6 shows normal load and net load for increasing levels of solar. The data are from the same studies discussed previously, but with solar profiles scaled to provide different potential annual penetrations from $0 \%$ to $14 \%$. These three days include the day with the highest demand of the year.

\footnotetext{
${ }^{14}$ These values are for the four existing California pumped-storage plants in the Transmission Expansion Planning Policy Commission (TEPPC) common case (Castaic, Eastwood, Helms, and Lake Hodges). The CAISO Long-Term Procurement Plan (LTPP) model has a combined capacity of 2,728 MW for these four plants.
} 


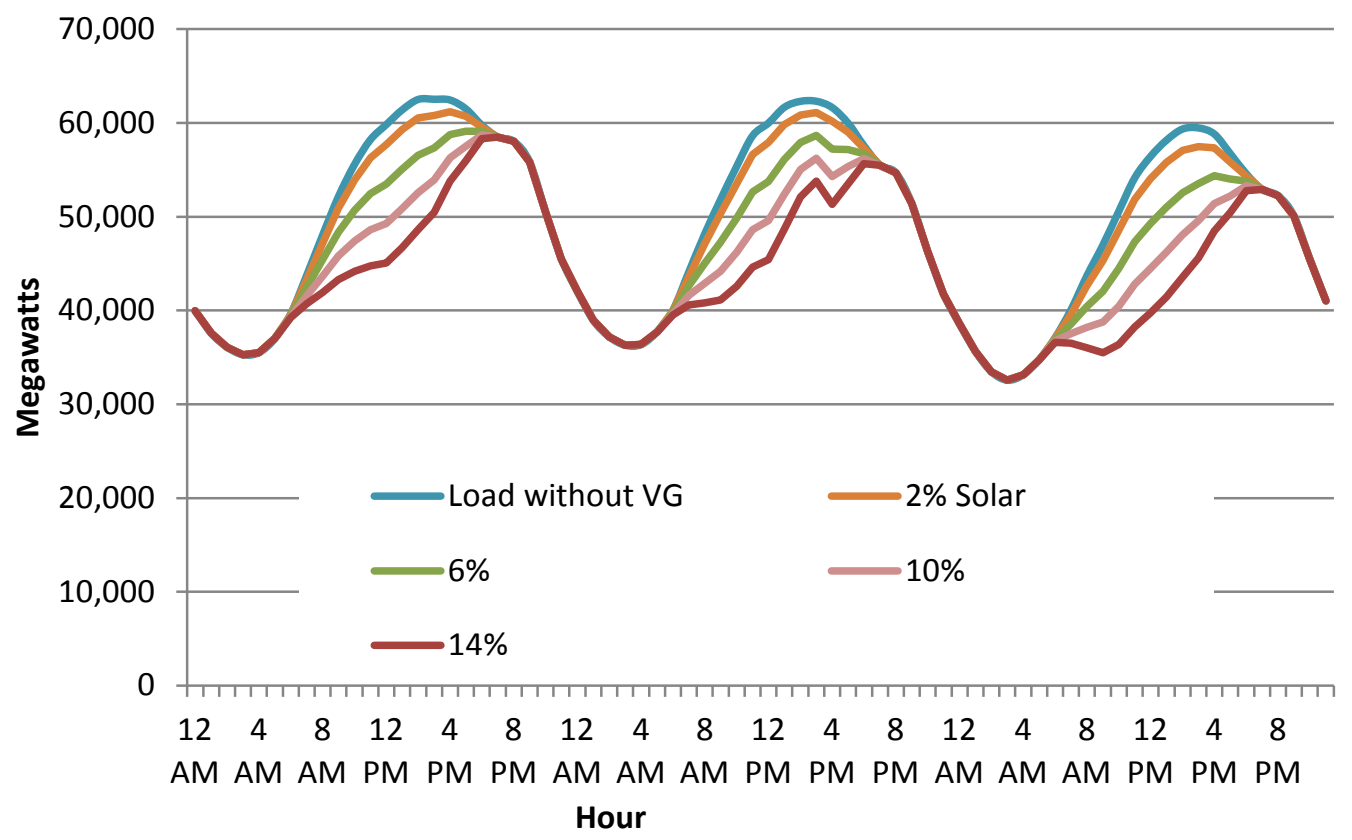

Figure 6. Load and net load profiles for California July 27-29.

Figure 6 illustrates how PV can reduce the net load by generating electricity during the hours of peak demand (typically 4 to $6 \mathrm{pm}$ ). This results in a capacity value - that is, the ability of PV to replace conventional generation.

Capacity credit can be expressed either as a value (kW, MW) or as the annual fraction of the renewable generator's nameplate capacity that adds to system reliability by offsetting conventional capacity. To distinguish between physical capacity and the monetary value of capacity, we follow Mills and Wiser (2012b), who use "capacity credit" to refer to physical capacity and "capacity value" to refer to the monetary value of the physical capacity.

As more PV is added, the net-demand peak is shifted later into the evening, to periods of lower PV output. Figure 7 shows the decline in capacity credit for the additional PV cases. This figure estimates capacity credit by using the capacity-factor approximation technique, which measures the average PV capacity factor during the top 100 load hours. This approach is an approximation of the more detailed reliability-based metrics used to assess the capacity contribution of different resources. These methods use statistical approaches to determine the ability of a generation resource (such as PV) to maintain a reliable system and meet demand (Madaeni et al. 2013). 


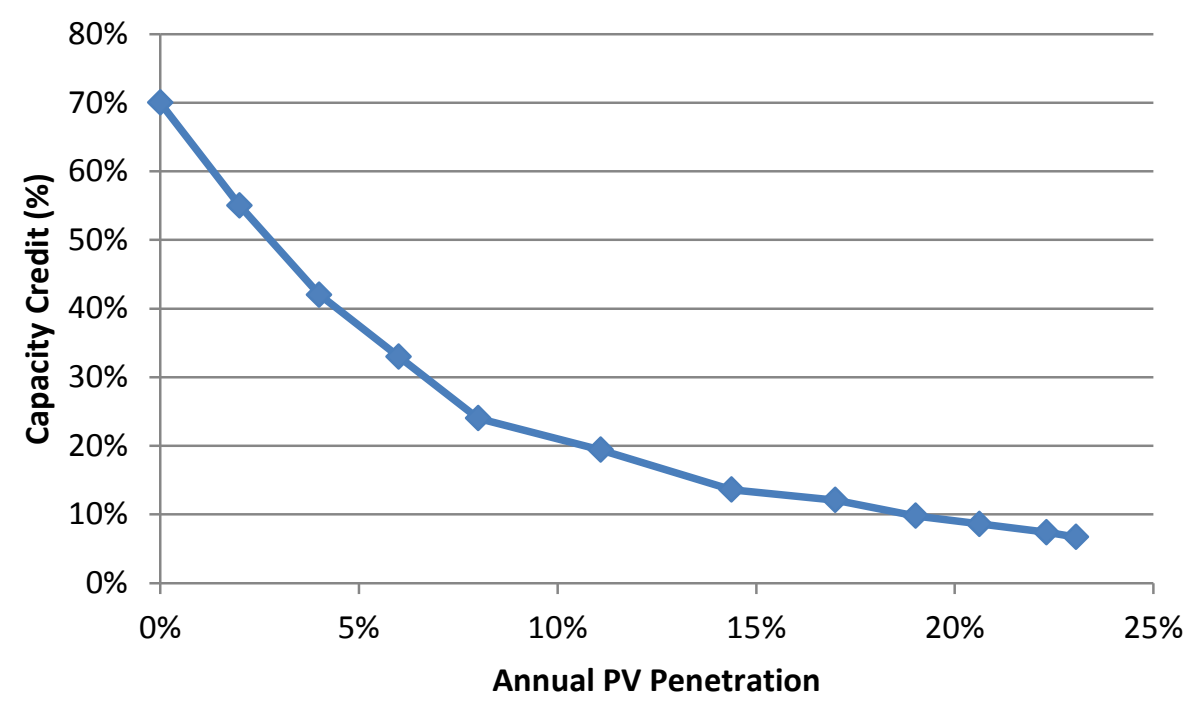

Figure 7. Decline in PV capacity credit using the capacity-factor approximation.

The estimate in Figure 7 follows previous analysis, summarized by Mills and Wiser (2012b), that follows two general trends described above. The first is that at low penetration, PV can have considerable capacity credit, typically within $50 \%-75 \%$ for locations in the Western U.S. The second common result is the significant drop in PV capacity credit as a function of penetration.

The capacity credit values in Figure 7 can be used to estimate a monetary capacity value by applying an assumed cost of capacity. Because the energy value of PV is expressed in value per unit of potential generation $(\$ / \mathrm{MWh})$, some conversions must be made to translate PV generation into capacity value. In this case, we first derive an estimate of the annualized cost of new capacity ( $\$ / \mathrm{kW}$-year) and multiply this value by the capacity credit. This number, divided by the PV potential generation, provides the capacity value per unit of PV generation. Figure 8 provides the results, using $\$ 190 / \mathrm{kW}$ for the annualized cost of new capacity (CAISO 2012).

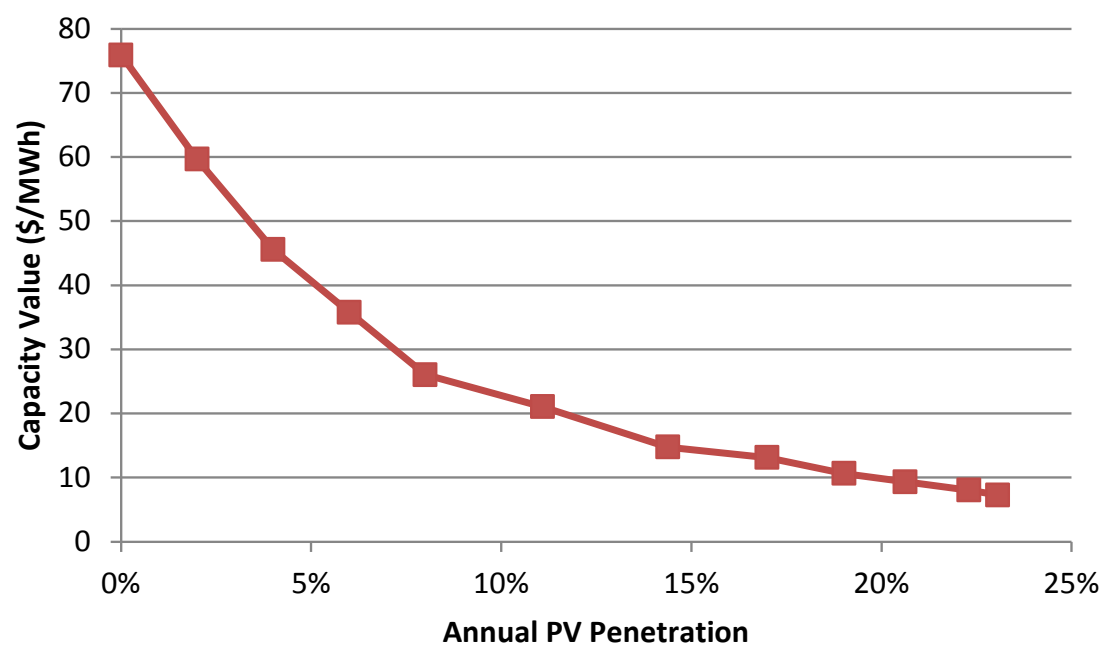

Figure 8. PV capacity value (\$/MWh) as a function of penetration. 


\subsubsection{Base-Case PV Operational Value}

Determining the operational value of PV requires measuring the avoided cost of electricity generation when PV is added. This is done by calculating the reduction in production costs that result from PV displacing fossil fuel consumption and emissions in each scenario.

In the periods of high load (such as summer), at lower penetration, PV tends to displace lowerefficiency (higher-cost) units such as gas combustion turbines (CTs). However, as more PV is added, it begins to displace lower-cost, higher-efficiency combined-cycle (CC) units either in California or from out-of-state generators. During periods with relatively low load (such as the spring), PV or wind can provide more energy than can actually be accommodated by the system. This challenge has been popularized by the publication of the "duck chart" by the CAISO (CAISO 2013). This figure shows the potential for "over-generation" and the need to curtail solar energy. The over-generation risk occurs when conventional dispatchable resources cannot be backed down further to accommodate the supply of VG. Part of this challenge is the need to have sufficient capacity online to meet the increased ramp rate of net load that occurs when solar output drops in the evenings (Bouillon 2014).

Over-generation has a relatively simple technical solution, often referred to as curtailment, which occurs when a system operator decreases the output from a wind or solar PV plant below what it would normally produce. For wind, this is performed by changing the energy actually captured from the wind (changing blade pitch angle) (Aho et al. 2012). For solar, generation is curtailed by either reducing output from the inverter or completely disconnecting the plant. This, of course, requires that a plant or system operator has physical control of the generation resourcewhich is typically available for large renewable power plants, but uncommon for smaller systems, particularly distributed or rooftop systems. This situation is seen in Figure $3 \mathrm{a}$, where on May 30, the supply of energy exceeded the load in California, resulting in curtailed solar energy. Although curtailment is technically easy, it has the obvious undesirable trait of reducing the economic and environmental benefits of VG. That is, each unit of VG curtailed represents a unit of energy not sold onto the grid and a unit of fossil fuel not avoided.

Curtailment is inherently related to the flexibility of the power system to vary output and accommodate VG. All generation resources have limits on their ability to vary output for a host of technical, economic, and institutional reasons. Most thermal plants have a minimum stable operating point below which the plant cannot run. Because certain plant types cannot be started and stopped quickly, they are forced to remain online and operate at this minimum generation level. Additional factors include contractual and institutional restrictions on plant operation, including long-term "must-take" contracts, self-scheduling, and combined heat and power (CHP) plants. Solar generation may also compete with other renewable resources such as wind or geothermal.

These constraints result in curtailed energy, and as more PV is added, there will also be more days with PV curtailment. On an annual basis, increasing the annual solar potential from $11 \%$ to $15 \%$ increases the total curtailment from $0.4 \%$ to $1.6 \%$ of potential solar generation. However, marginal curtailment — that is, the curtailment of additional PV required to increase solar 
potential from one level to the next - increases at a greater rate. ${ }^{15}$ Increasing annual solar potential from $7.5 \%$ to $11 \%$ requires that only $1.2 \%$ of the added PV generation be curtailed. However, increasing annual solar potential from $11 \%$ to $15 \%$ requires that about $5.5 \%$ of the added PV generation be curtailed.

Figure 9 illustrates the total and marginal curtailment results from the addition of PV. The annual solar penetration is the fraction of total demand in California met by PV (plus the fixed amount of CSP), after removing curtailed solar energy. ${ }^{16}$ The points on the curve are the actual modeled scenarios.

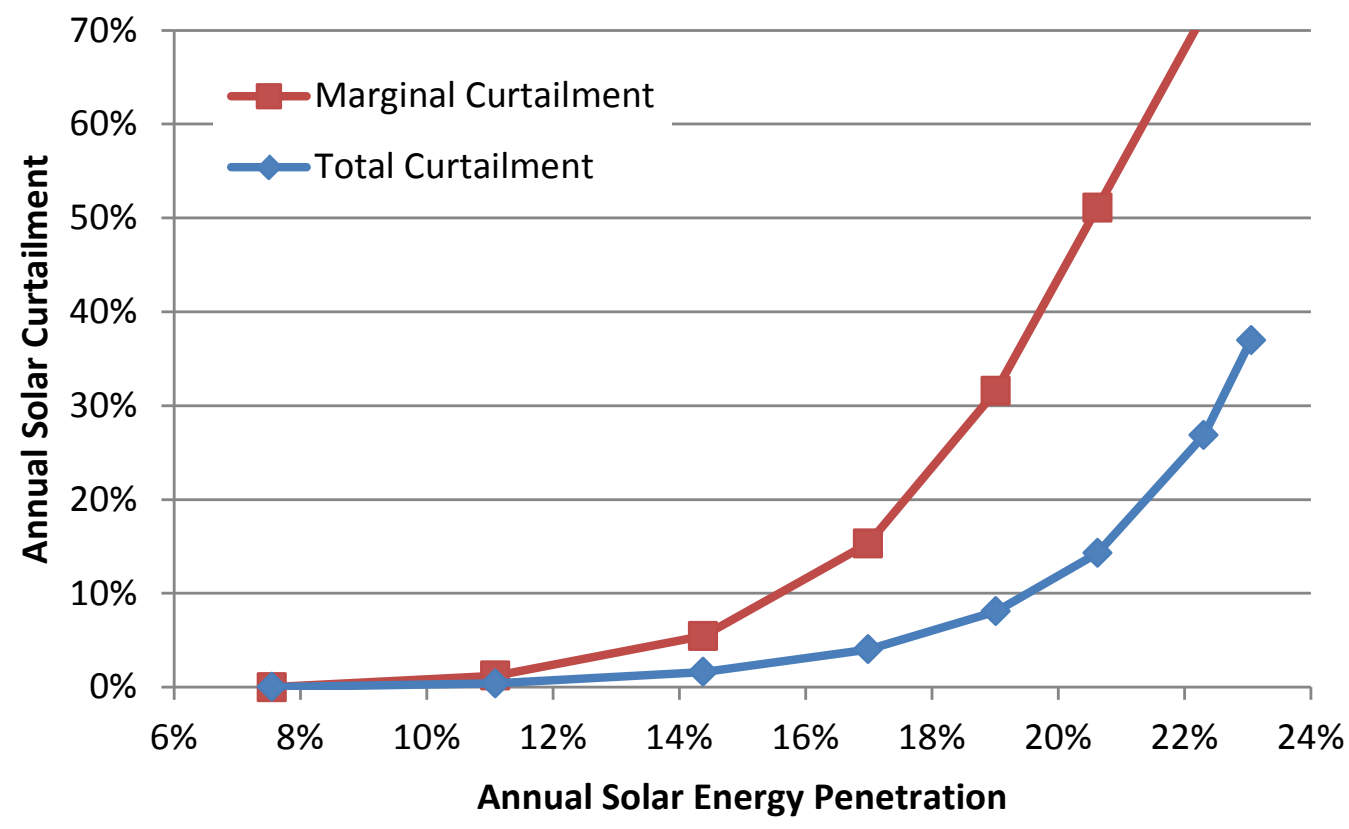

Figure 9. Annual marginal and total solar curtailment due to over-generation under increasing penetration of PV in California in a system with limited grid flexibility.

The combination of displacing lower-cost generators and increasing curtailment results in a lower value of displaced fuel per unit of PV potential. The actual avoided fuel (British thermal units, BTUs) per unit of potential PV generation is illustrated in Figure 10. At low penetration, $\mathrm{PV}$ avoids about 7,000 BTU/kWh, which is approximately the heat rate of a $\mathrm{CC}$ gas generator. This value drops rapidly at about $15 \%$, where curtailment begins to increase substantially.

\footnotetext{
${ }^{15}$ This is actually the average marginal curtailment because it is not the true marginal curtailment of an extremely small addition of PV. It is the average curtailment for all incremental PV added from one scenario to the next.

${ }^{16}$ Where the total demand is equal to the consumer demand plus storage losses associated with pumped hydro.
} 


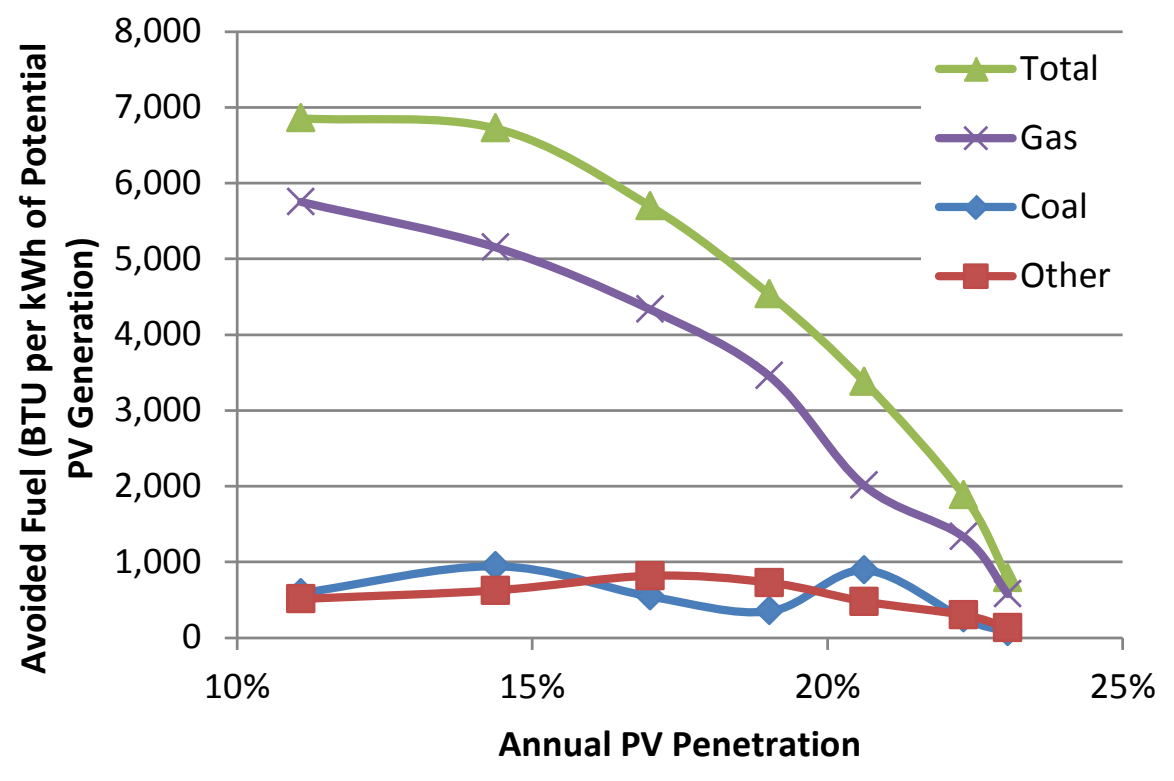

Figure 10. Avoided fuel by PV as a function of penetration.

The overall value per unit of PV potential generation is provided in Figure 11, which includes fuel, variable O\&M, start costs, and emissions. In addition to a reduction in value associated with fuel use, increased PV penetration also results in a greater number of power plant starts, which produces a small negative value.

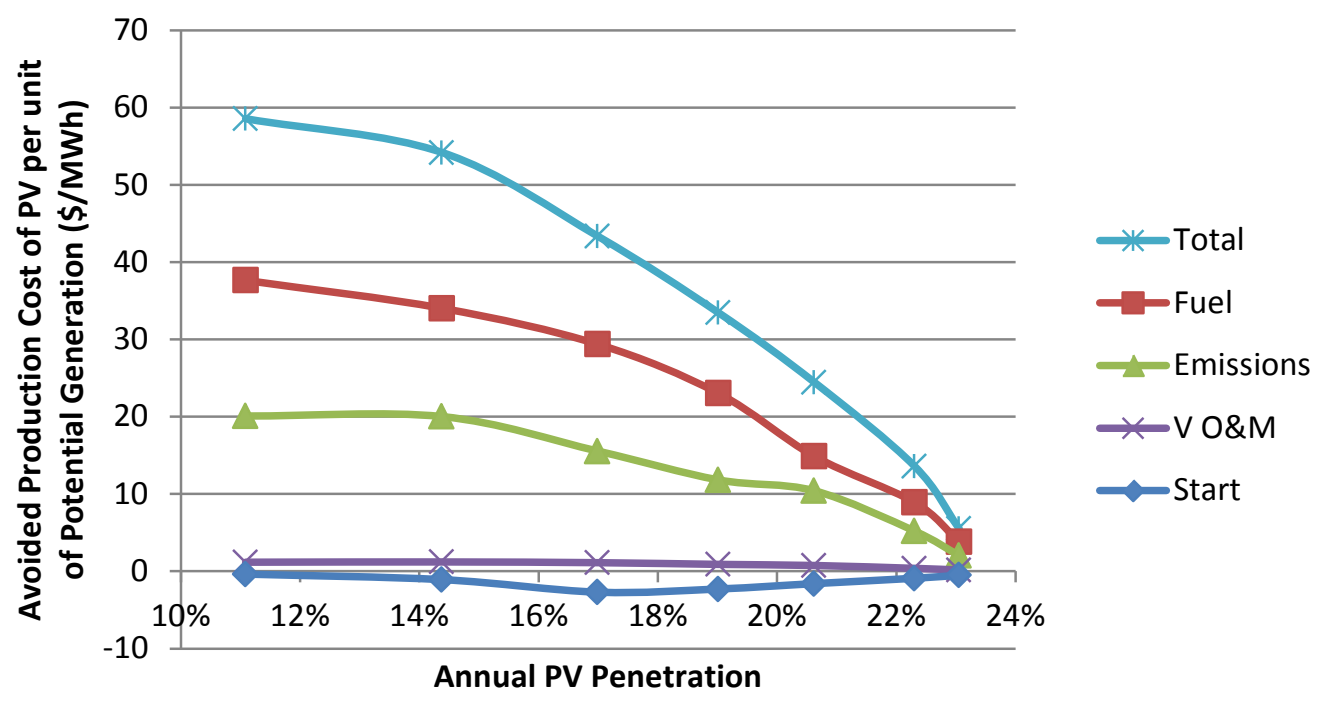

Figure 11. Avoided production cost from PV as a function of penetration.

\subsubsection{PV Total Value}

Adding the operational value and capacity value provides a total value that can be compared to costs. This forms a potential basis for calculating economic carrying capacity. Figure 12 provides the total value for the base system as a function of penetration. The figure also includes horizontal lines that represent an estimate for a range of utility-scale PV LCOE values (from 
about $\$ 54 / \mathrm{MWh}$ to about $\$ 64 / \mathrm{MWh}$ ) using 2015 estimated PV costs across various regions in California. These values include the federal investment tax credit. ${ }^{17}$ The value of PV falls below the estimated cost at the point where PV provides about $15 \%-17 \%$ of the system's annual energy. This implies that at current prices and under a limited grid-flexibility regime, the economic carrying capacity of PV in the California grid is restricted to about $15 \%$ to $17 \%$ of annual energy.

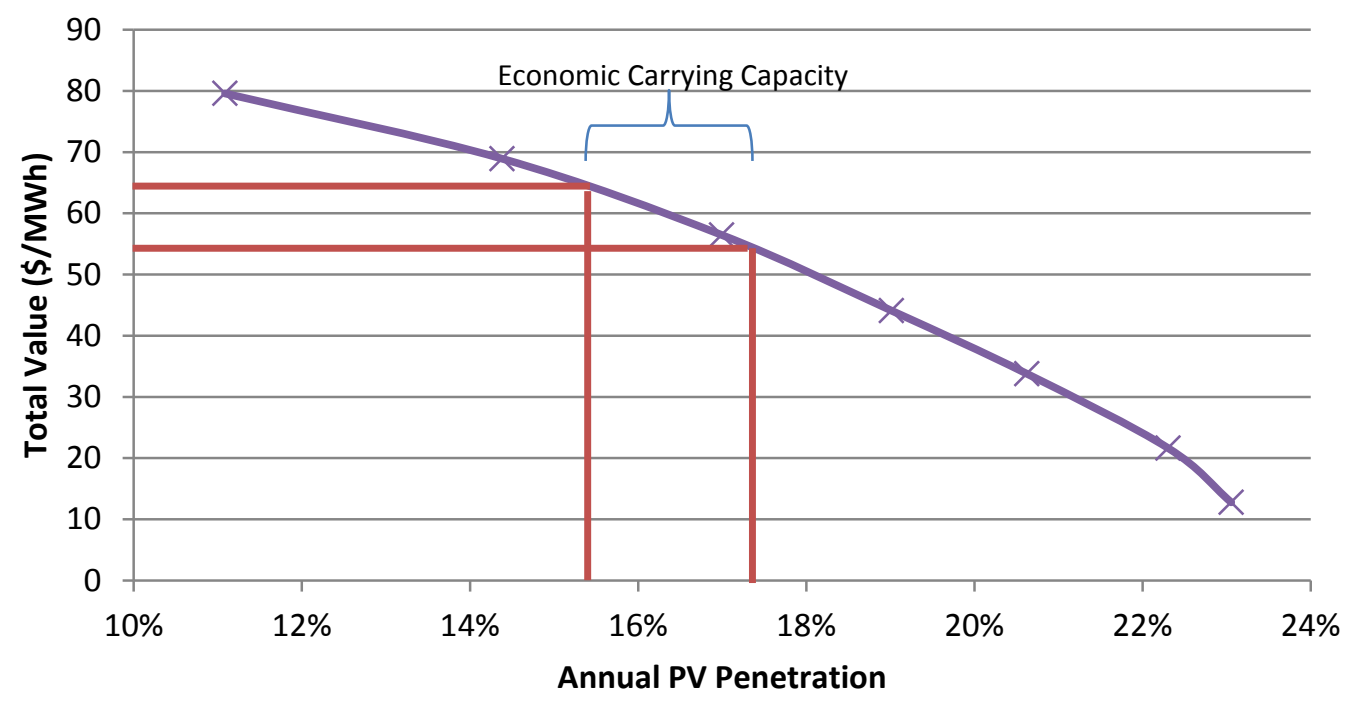

Figure 12. $\mathrm{PV}$ total value $(\$ / \mathrm{MWh})$ as a function of penetration.

It is important to recognize both the limitations of this approach and the sensitivity of economic carrying capacity to a variety of factors. The value of PV generated by this method includes a carbon price but does not account for other factors, such as the value of PV in reducing criteria pollutants, the associated health benefits of reduced pollutants, or the value of avoided water use. If included, these external benefits would raise the value of PV and increase the economic carrying capacity. Alternatively, a decrease in natural gas prices or the removal of the federal investment tax credit would decrease the economic carrying capacity.

These non-technical factors emphasize that economic carrying capacity is not a technical metric related solely to issues such as grid stability or transmission capacity. Rather, it is largely tied to a set of assumptions regarding future fuel prices and societal benefits.

Even within the limited framework considered above, our approach demonstrates the potential value of PV and provides an opportunity to explore the benefits of enhanced flexibility. The value of other generation sources also falls as a function of increases in their penetration, but the drop is typically less pronounced. ${ }^{18}$

\footnotetext{
${ }^{17}$ Calculations were performed using the NREL System Advisor Model using assumptions described in Woodhouse et al. (2016).

${ }^{18}$ For example, the capacity value of PV falls significantly as a function of penetration because the normal U.S. peak load, which typically occurs in the late afternoon, is met by PV; the new net load is effectively shifted later, to the early evening, when PV output has dropped substantially. Because the output of a conventional thermal plant is
} 
We discuss results for individual flexibility options in Section 2.5. As a result of more flexible operation, curtailment of PV is substantially reduced. Figure 13 provides the marginal curtailment curves for each of the flexibility cases. It is important to note that the five "Add" cases assume that each flexibility option is added to the "increased operational flexibility" case. Many of the changes associated with the increased operational flexibility case are in the process of being implemented, so this case represents a starting point for further grid-flexibility enhancements.

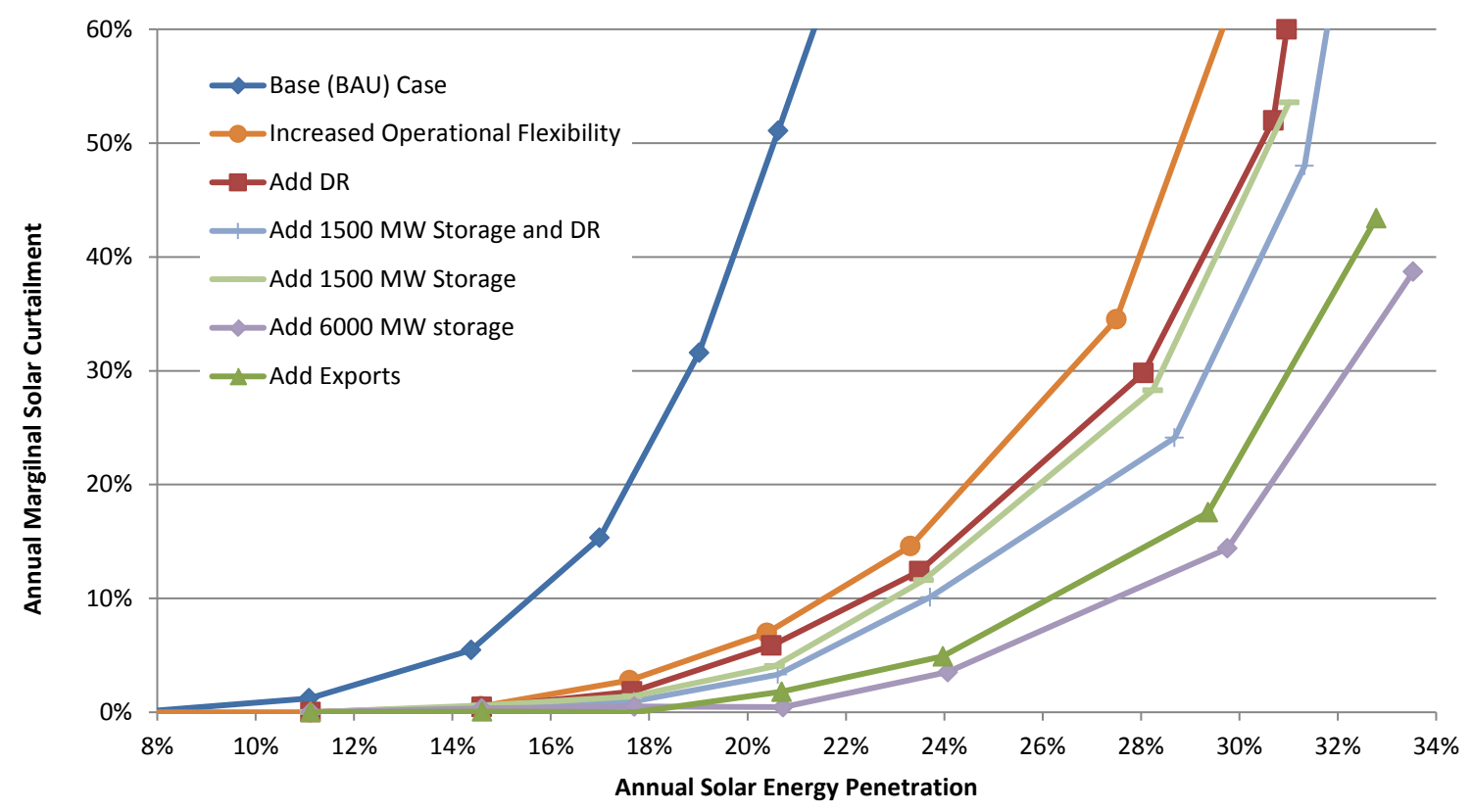

Figure 13. Impact of individual flexibility options on marginal curtailment.

Figure 14 shows the curves for total value. There is a large shift in value between the base (BAU) case and the case with changes that would be expected in the 2020 time frame (increased operational flexibility). Additional flexibility options added to the increased operational flexibility case have a less dramatic impact, but still increase the ECC. We discuss flexibility options in greater detail in Section 2.5, highlighting their benefits and comparing their value to implementation cost. 


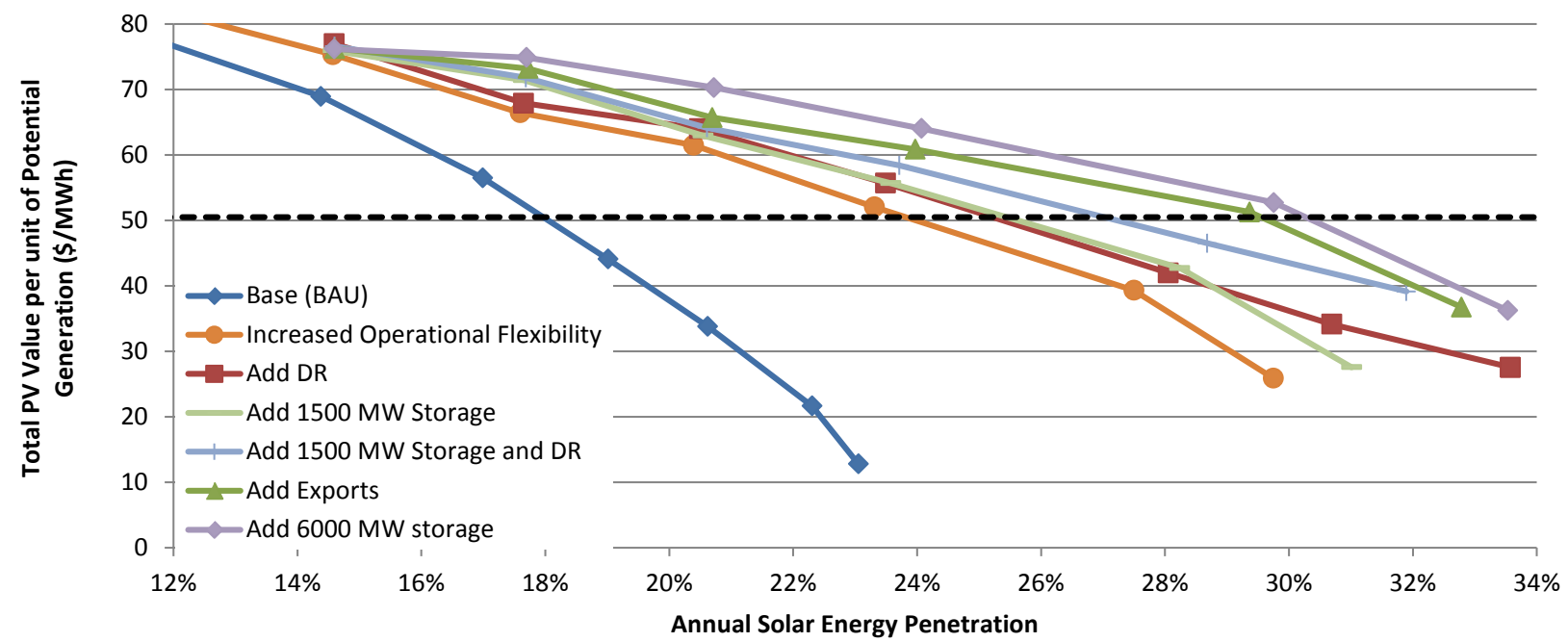

Figure 14. Total value curves for all flexibility cases.

The value of flexibility options can be measured using the economic carrying capacity presented in Section 1. Figure 14 also includes a horizontal line that represents an estimate for the average LCOE for utility-scale PV in California (about \$50.5/MWh) using 2020 estimated PV costs. ${ }^{19}$ This puts the economic carrying capacity of PV in the base case at $18.1 \%$. Table 3 shows how adding flexibility options impacts the economic carrying capacity of PV at particular LCOE values of PV.

Table 3. Change in Economic Carrying Capacity due to Flexibility Options

\begin{tabular}{|c|c|c|c|}
\hline \multirow[b]{2}{*}{ Flexibility Option } & \multicolumn{3}{|c|}{$\begin{array}{c}\text { Change in Carrying Capacity Relative to } \\
\text { Base Case (percentage point difference } \\
\text { from base) }\end{array}$} \\
\hline & $\begin{array}{c}\text { Highest- } \\
\text { Cost PV } \\
\text { System } \\
\text { (\$54.6/MWh) } \\
(\%)\end{array}$ & $\begin{array}{c}\text { Average- } \\
\text { Cost PV } \\
\text { System } \\
(\$ 50.5 / M W h) \\
(\%)\end{array}$ & $\begin{array}{c}\text { Min-Cost PV } \\
\text { System } \\
\text { (\$44.8/MWh) } \\
(\%)\end{array}$ \\
\hline $\begin{array}{l}\text { Increased Operational } \\
\text { Flexibility }\end{array}$ & 5.2 & 5.7 & 6.7 \\
\hline \multicolumn{4}{|c|}{ The following scenarios are in addition to the Increased Operational Flexiblity case } \\
\hline Add DR & 1.2 & 1.5 & 1.5 \\
\hline Add 1,500 MW Storage & 1.2 & 1.5 & 1.8 \\
\hline $\begin{array}{l}\text { Add 1,500 MW Storage } \\
\text { and DR }\end{array}$ & 2.7 & 3.3 & 3.8 \\
\hline Add Exports & 5.1 & 5.9 & 5.3 \\
\hline Add 6,000 MW Storage & 6.1 & 6.5 & 6.0 \\
\hline
\end{tabular}

${ }^{19}$ Calculations were performed using the NREL System Advisor Model using assumptions described in Woodhouse et al. (2016). 


\subsubsection{Value of Flexibility Options}

The second performance metric evaluated is the reduction in costs associated with each flexibility option. Figure 15 summarizes the annual operational savings from each flexibility option. It is important to note that as in previous cases, all the DR, storage, and export cases are added to the operational flexibility case. Further discussion of each option, including implementation costs, is discussed in the next section.

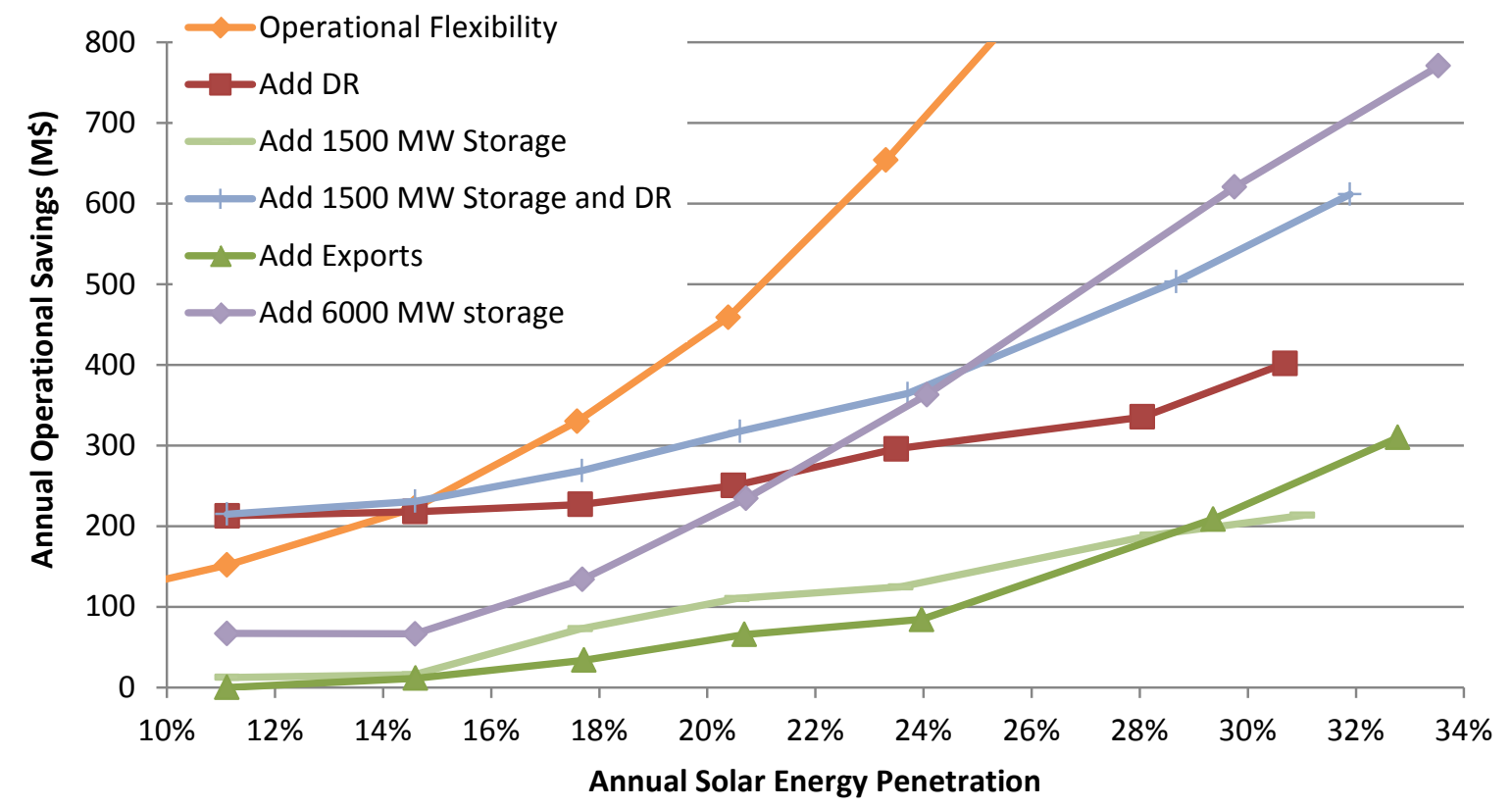

Figure 15. Operational benefits of flexibility options.

\subsection{Discussion of Results for Individual Flexibility Options}

\subsubsection{Increased Operational Flexibility}

The increased operational flexibility case introduces two distinct measures, as discussed previously. The first is adding 1,290 of new storage, and the second is removing instantaneous penetration limits. From the standpoint of curtailment reduction, instantaneous penetration limits appear to be far more important. Figure 16 illustrates how additional storage shifts load to change the net load shape and reduce curtailment on March 29, a day with low load and high solar generation. This figure shows the normal load from the $15 \% \mathrm{PV}$ case and load with the additional storage. The resulting curtailment is also shown and is compared to the case without the added storage. 


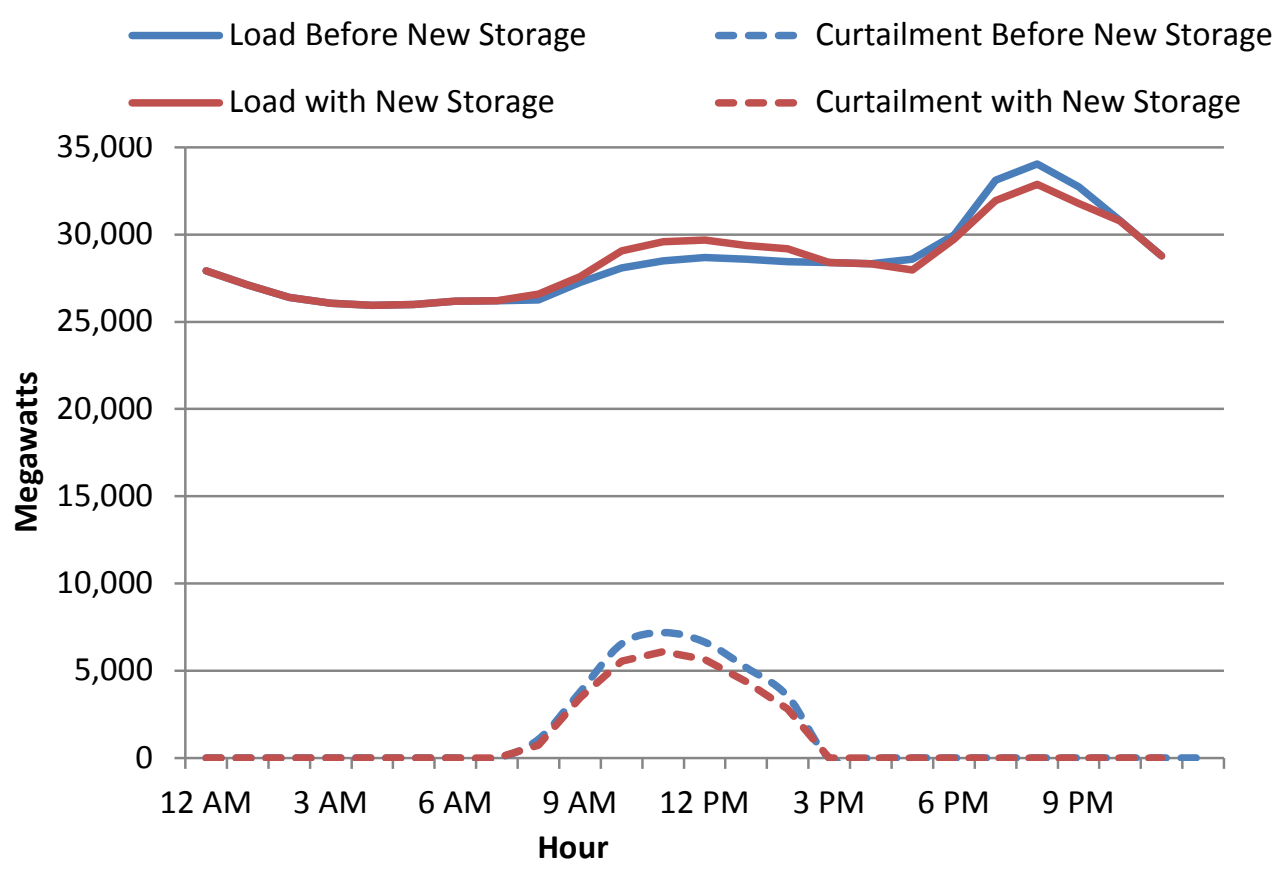

Figure 16. Impact of adding 1,285 MW of storage on March 29 in a scenario with $15 \%$ annual solar.

Alternatively, Figure 17 shows the curtailment reduction that results from reducing the maximum penetration limits. In this case, the curtailment of PV has been substantially reduced from about $13 \%$ on this day to about $7 \%$.

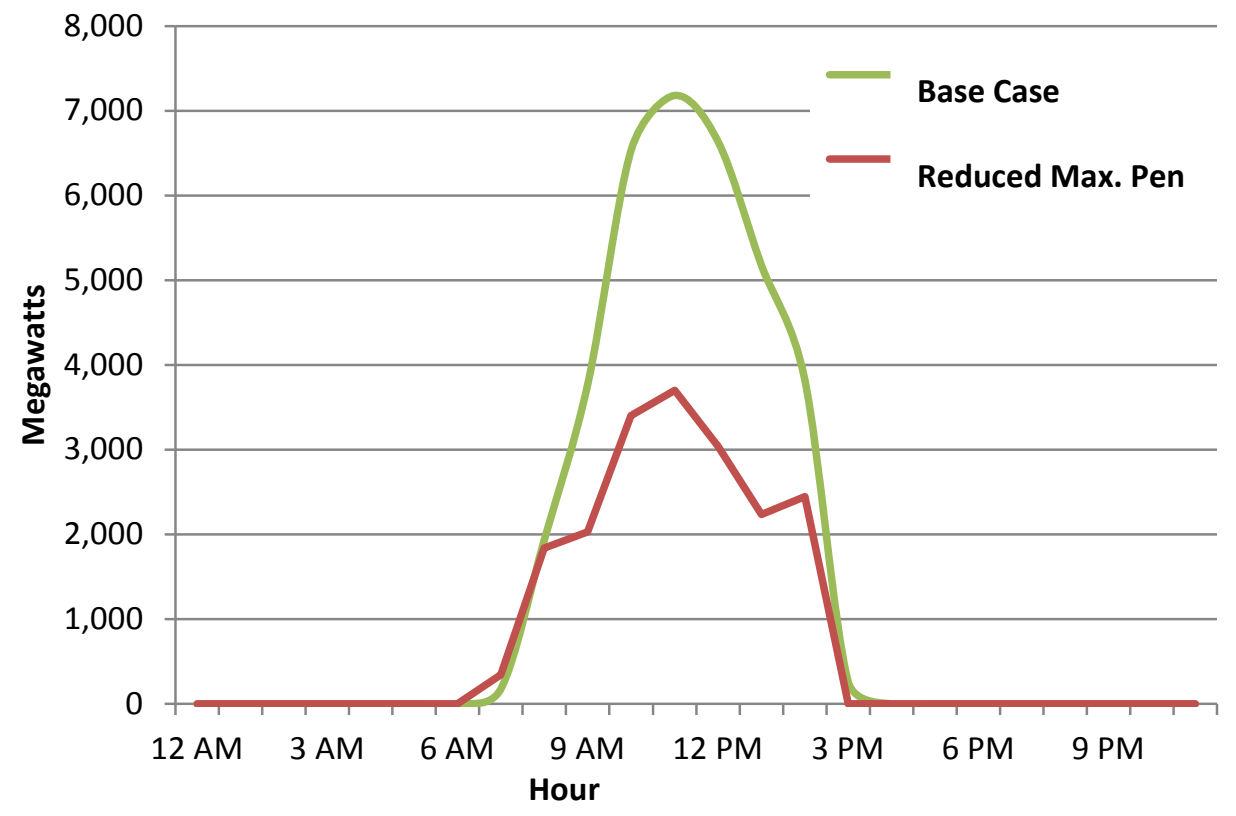

Figure 17. VG curtailment on March 29 in a scenario with $15 \%$ annual solar after removing the $60 \%$ maximum VG penetration limit. 
Operational flexibility increases the operational value (reduction in production costs), but it does not affect the supply/demand coincidence of PV with load. As a result, the capacity credit and capacity value curves do not change, and they still show a substantial reduction in value at relatively low penetration. ${ }^{20}$

Figure 18 shows the operational value for just the base and increased operational flexibility cases, magnified to show the change. The figure shows an increase in economic carrying capacity from about $16 \%$ of annual load to about $21 \%$ of annual load derived from PV (a spread of about 5 percentage points), assuming a \$60/MWh LCOE. However, at a lower-cost PV $(\$ 40 / \mathrm{MWh})$, the increase in ECC is greater, or about 8 percentage points from about $20 \%$ to about $28 \%$.

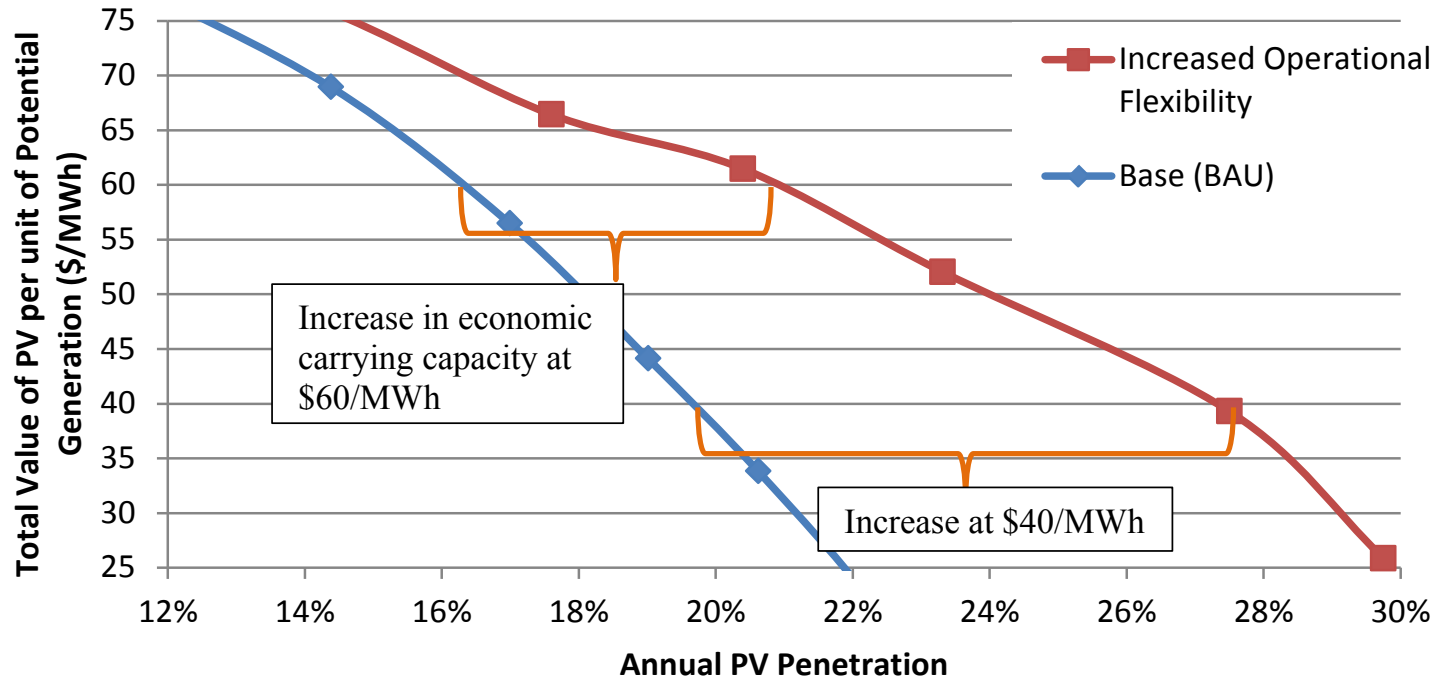

Figure 18. Increase in economic carrying capactiy resulting from increased operation flexibility.

Figure 18 demonstrates the increase in ECC, whereas Figure 19 shows the operational savings as a function of PV penetration for the increased operational flexibility case, as well as avoided curtailment. Even at low solar penetration (with almost no curtailment), significant benefit is still gained by adding the operational flexibility assumptions in this case (1,290 MW of new storage and eliminating the local generation and $60 \%$ instantaneous penetration limits). At the lowest PV penetration, this additional flexibility increases dispatch efficiency and saves about $\$ 100$ million per year.

\footnotetext{
${ }^{20}$ Reducing curtailment does not increase capacity credit, because there is typically no curtailment during periods of high net demand.
} 


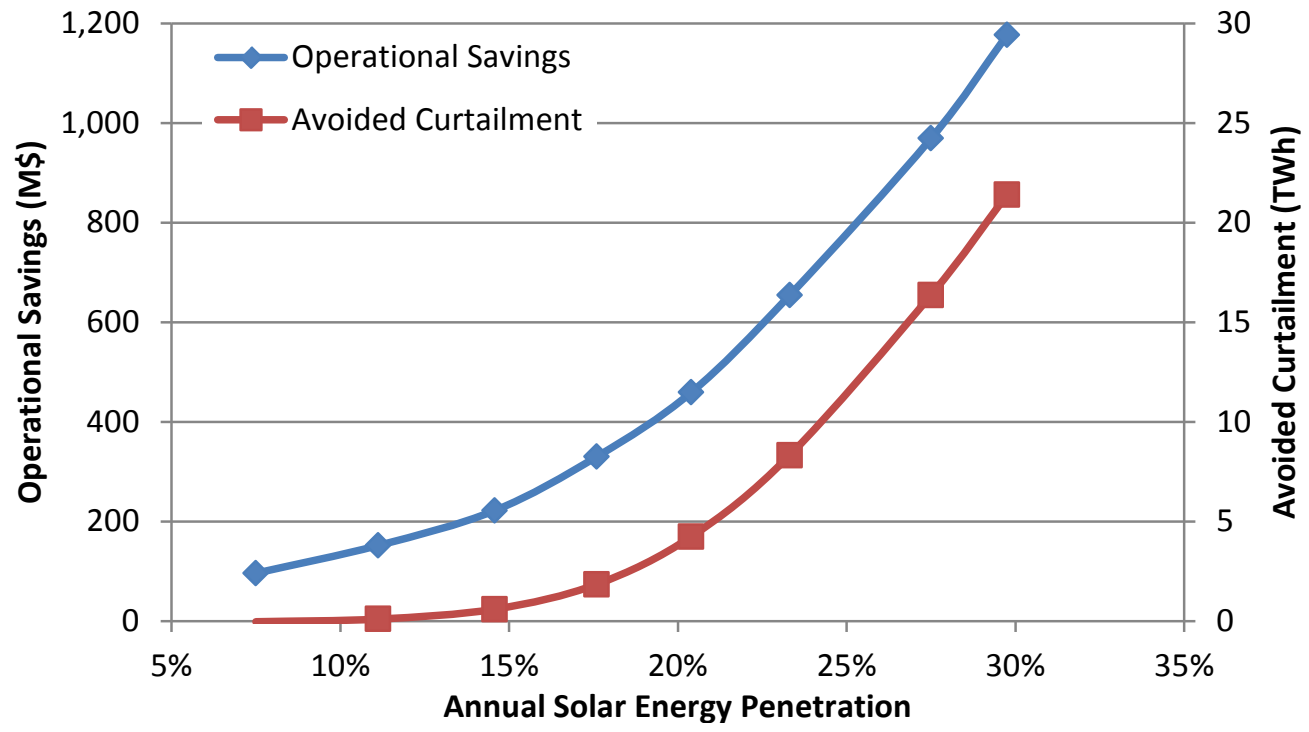

Figure 19. Operational savings and curtailment reduction associated with added flexibility.

It is difficult to generate a cost/benefit comparison for the increased operational case. This is because a variety of changes have been or are being implemented in the California grid to increase operational flexibility, and it is difficult to isolate the benefits to any individual flexibility measure. The following sections evaluate both the costs and benefits of further flexibility measures in the added flexibility case.

\subsubsection{Demand Response}

Adding demand response in these simulations has a modest impact on carrying capacity. Figure 20 shows the results for just the increased flexibility case and the added DR case (where DR is added to the increased flexibility case). Overall, the economic carrying capacity is increased by about 1 percentage point.

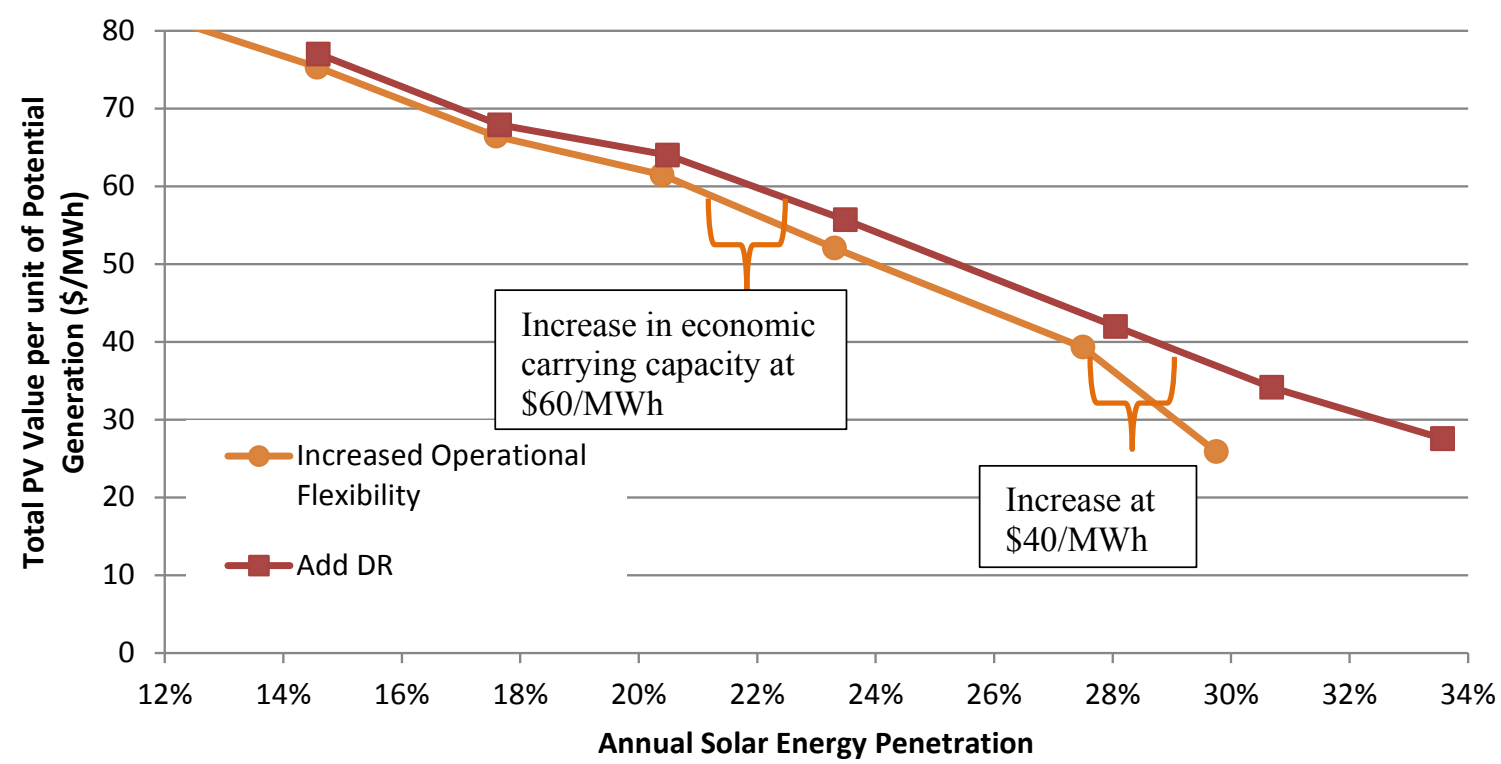

Figure 20. Increase in economic carrying capactiy resulting from added DR. 
The limited increase in PV value and associated increase in ECC are due to two factors. The first is the limited availability of DR during periods of very low PV value (including periods of curtailed PV), as shown in Figure 21. Figure 21a shows how the net load changes on March 29, which is a day with significant curtailment. The actual shifted load is extremely small because there is little need for either cooling or heating in the middle of the day; thus, there is low potential for demand shifting on this day based on the model assumptions. Figure $21 \mathrm{~b}$ shows the seasonal coincidence of DR availablity and curtailment in the $18 \%$ case. The figure shows the curtailment before the addition of DR, as well as hourly DR availability.

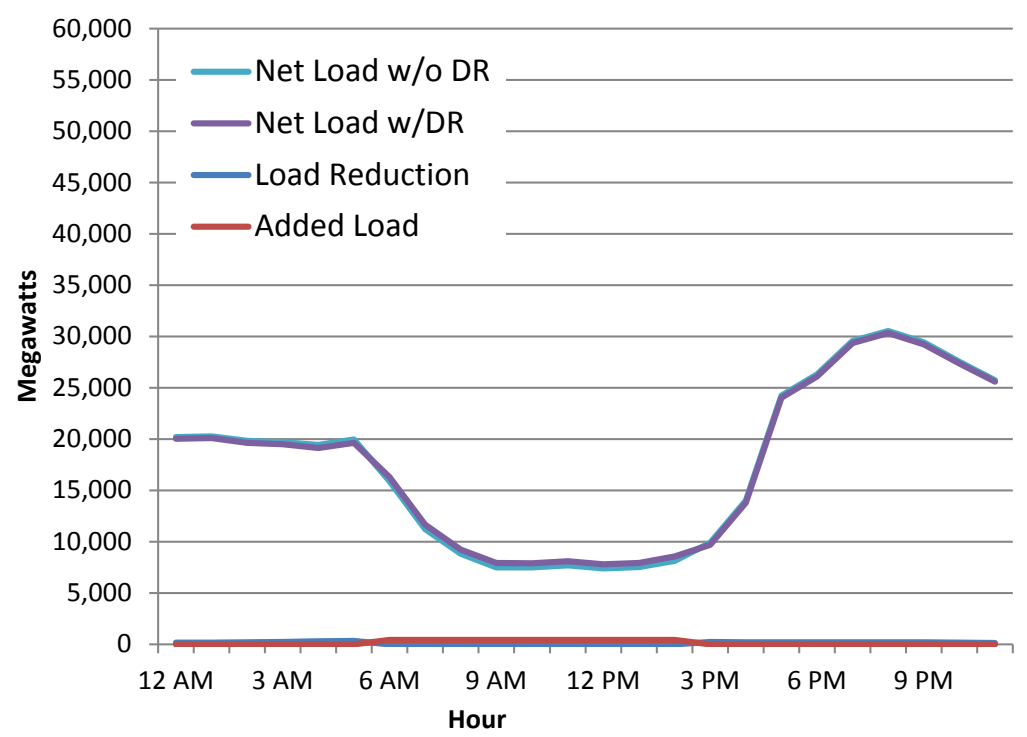

a) Impact of DR on March 29

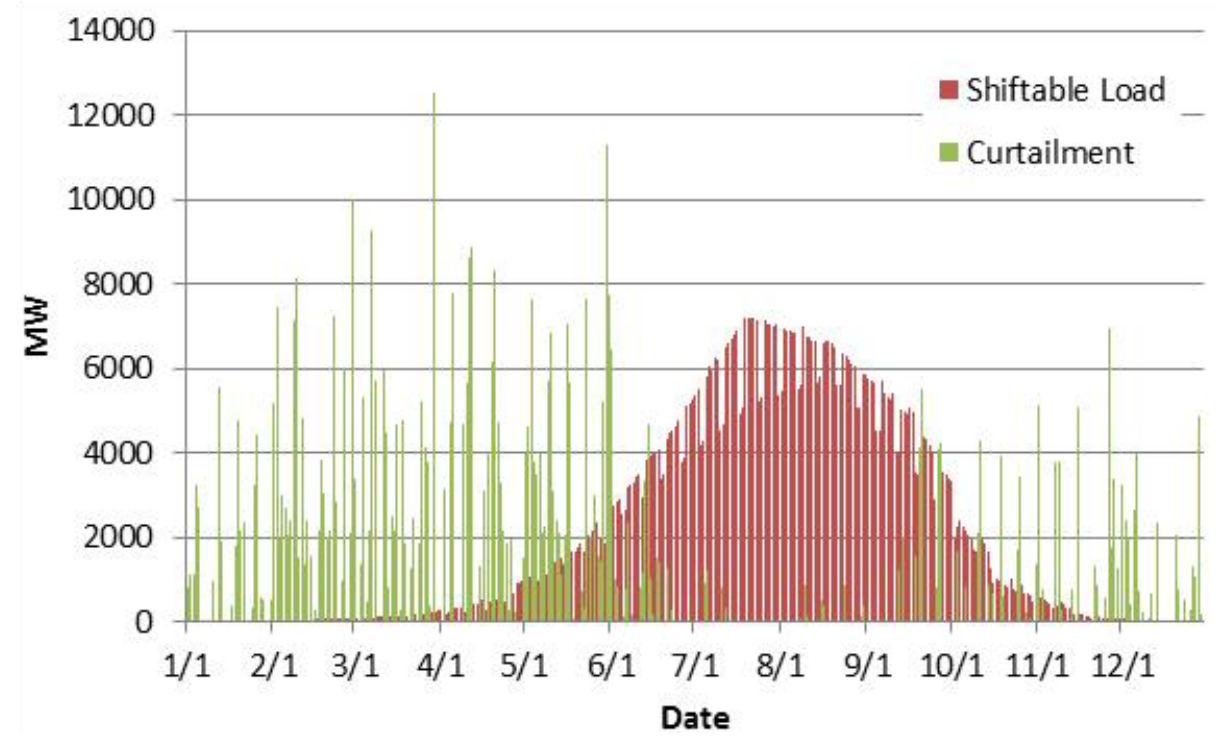

b) Seasonal availability of DR compared to curtailment in the $18 \%$ solar case

Figure 21. Demand response availability during a spring day and seasonally.

The second limitation in the value of DR applied to PV is how we account for potential changes in the capacity credit. A significant benefit of DR is its ability to reduce conventional capacity 
needs. Figure 22 shows the net load on July 27 with and without the addition of DR, indicating how the net load is reduced by more than 5,000 MW. This produces significant economic benefits of DR, but does not translate into a significantly higher ECC. The benefits of DR exist with or without the addition of PV, and the capacity value of DR would likely be accrued by the DR provider. Therefore, we did not attribute any capacity value of DR to PV.

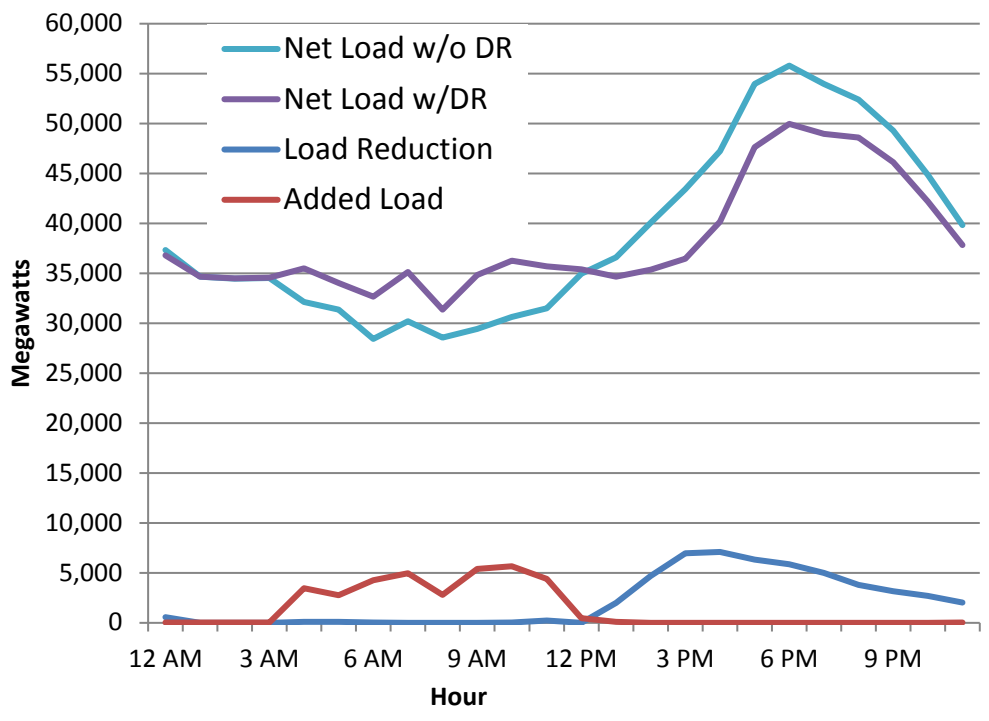

Figure 22. Reduction in net load resulting from DR.

The importance of examining multiple performance metrics is demonstrated by examining the operational and capacity cost savings associated with demand response, with the total savings shown in Figure 23. Even at low penetration, DR produces significant overall operational savings - in excess of \$200 million per year. This is in contrast to the ECC results, where DR showed relatively little benefit. This difference is largely due to the assumed profiles, where DR can provide significant shifting benefits in the summer, when demand peaks and there is relatively little curtailment. As noted previously, the DR scenario also provides significant reduction in peak demand of about $6,000 \mathrm{MW}$. The potential capacity benefits - avoiding the need for new generation capacity_-is significantly larger than its operational benefits, as demonstrated previously by Hummon et al. (2013a). Using a range of $\$ 100 / \mathrm{kW}$ to $\$ 200 / \mathrm{kW}$ for the annualized cost of new conventional capacity produces an overall potential benefit that is at least three times the operational savings. 


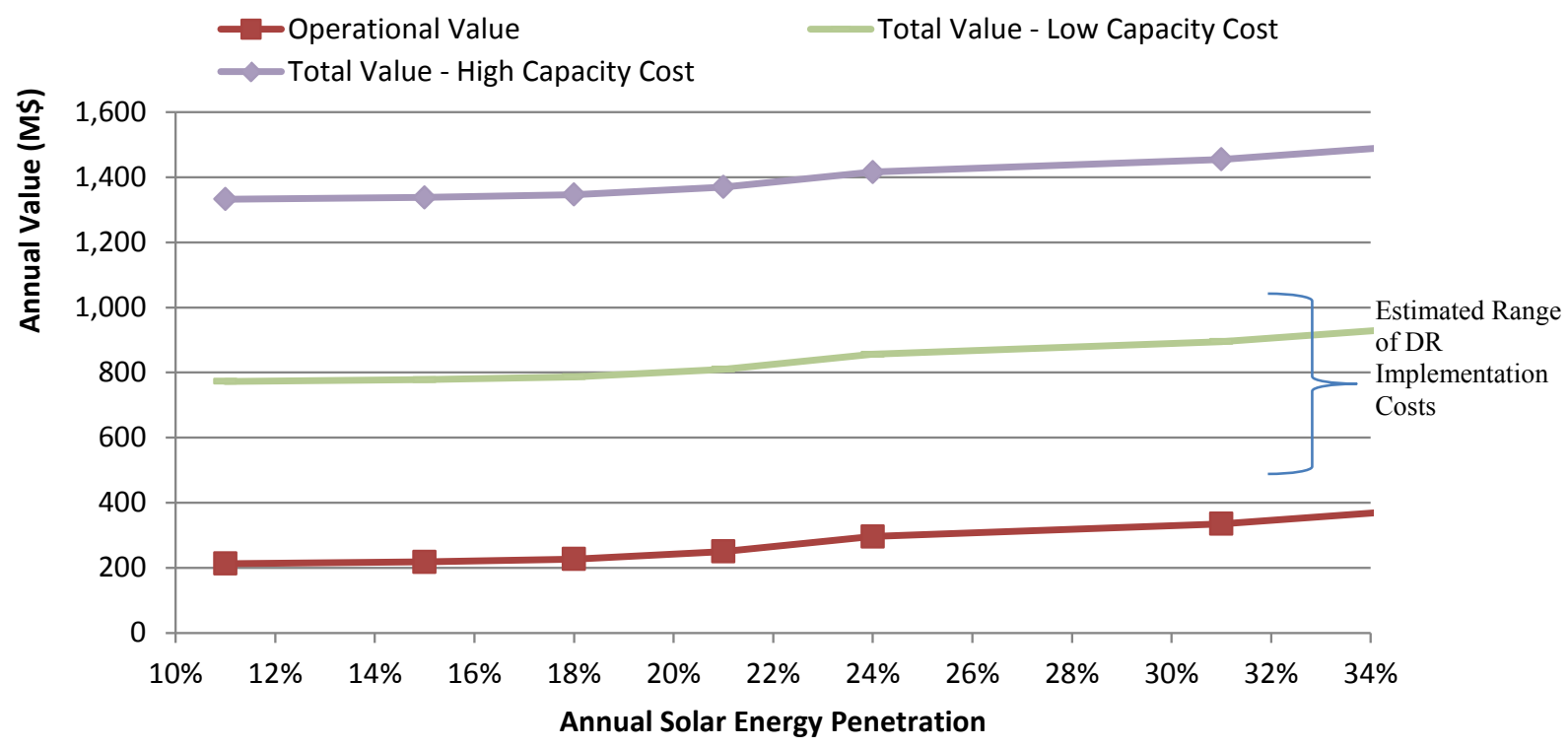

Figure 23. Total annualized benefit of demand response including capacity benefits.

These total benefits can be compared to estimates for implementation costs. Table 4 provides estimates of DR annualized implementation costs, and the total annual cost using these estimates ranges from $\$ 580$ million to $\$ 1.1$ billion. These numbers are substantially higher than the operational value of DR, which implies that implementing DR solely for its operational benefits appears to be uneconomic for most applications. However, using DR for capacity benefits can significantly exceed implementation costs (Ma et al. 2016). 
Table 4. Estimates of DR Implementation Costs

\begin{tabular}{|l|c|c|c|c|c|}
\hline \multirow{2}{*}{ End Use } & \multirow{2}{*}{$\begin{array}{c}\text { Enabled } \\
\text { Capacity } \\
\text { (MW) }\end{array}$} & \multicolumn{2}{c|}{$\begin{array}{c}\text { Total Annual Cost } \\
\text { (\$/kW-yr) }\end{array}$} & \multicolumn{2}{c|}{$\begin{array}{c}\text { Total Annual Cost } \\
\text { (\$M) }\end{array}$} \\
\cline { 3 - 6 } & Minimum & Maximum & Minimum & Maximum \\
\hline $\begin{array}{l}\text { Agricultural } \\
\text { Pumping }\end{array}$ & 623 & 50 & 75 & 31.2 & 46.7 \\
\hline Commercial Cooling & 1,790 & 50 & 100 & 89.5 & 179.0 \\
\hline Commercial Heating & 82 & 50 & 100 & 4.1 & 8.2 \\
\hline Data Centers & 131 & 50 & 100 & 6.6 & 13.1 \\
\hline Municipal Pumping & 52 & 50 & 75 & 2.6 & 3.9 \\
\hline $\begin{array}{l}\text { Refrigerated } \\
\text { Warehouses }\end{array}$ & 117 & 50 & 100 & 5.9 & 11.7 \\
\hline Residential Cooling & 5,750 & 75 & 150 & 431.3 & 862.5 \\
\hline $\begin{array}{l}\text { Residential Water } \\
\text { Heating }\end{array}$ & 139 & 50 & 125 & 7.0 & 17.4 \\
\hline $\begin{array}{l}\text { Wastewater } \\
\text { Pumping }\end{array}$ & 21 & 50 & 75 & 1.1 & 1.6 \\
\hline Total & $\mathbf{8 , 7 0 5}$ & $\mathbf{4 7 5}$ & $\mathbf{9 0 0}$ & $\mathbf{5 7 9}$ & $\mathbf{1 . 1 4 4}$ \\
\hline
\end{tabular}

Additional analysis and consideration is needed to understand potential synergies between PV and DR. PV may enable the system to derive more firm capacity from DR because of the reduced amount of time between on-peak and off-peak periods, as well as the overall narrowing of the on-peak period. These issues are illustrated in Figure 24, which shows the impact of PV on net load shape for a summer and winter period. The reduced amount of time between on-peak and off-peak periods is especially useful for DR. Demand response - and, in particular, load shifting - requires a load that can be used earlier or later than would normally occur. A large fraction of demand during peak periods in the summer and winter is associated with cooling and heating. One method of shifting cooling demand is pre-cooling. Pre-cooling —or cooling a building at or below a desired setpoint before the cooling is needed - depends on the ability of a building to store thermal energy. It is easier to pre-cool a building with a shorter delay between the pre-cooling period and when the building must stay at the desired temperature.

Figure 24a shows the load for two days in July. Without PV, the lowest net load occurs in the early morning (1-4 am), and the highest load occurs in the late afternoon (4-6 pm). This means that there is a roughly 12-hour time difference between the "ideal" period to pre-cool (increase load) and when this "stored" cooling load is used. With added PV, there is reduced demand in the late morning and early afternoon, which provides spare capacity that could provide energy from load shifting. Thus, the time needed for pre-cooling or other load-shifting applications is substantially reduced. Similarly, the winter load pattern creates another low net-demand period shortly before the peak demand in the early evening. This may create additional opportunities for demand shifting. The second impact of solar on net load shape is the narrowing of the peak 
period (Jorgenson et al. 2014). Figure 24 demonstrates how the number of peak-demand hours is shorter in the summer (the period of highest absolute demand).

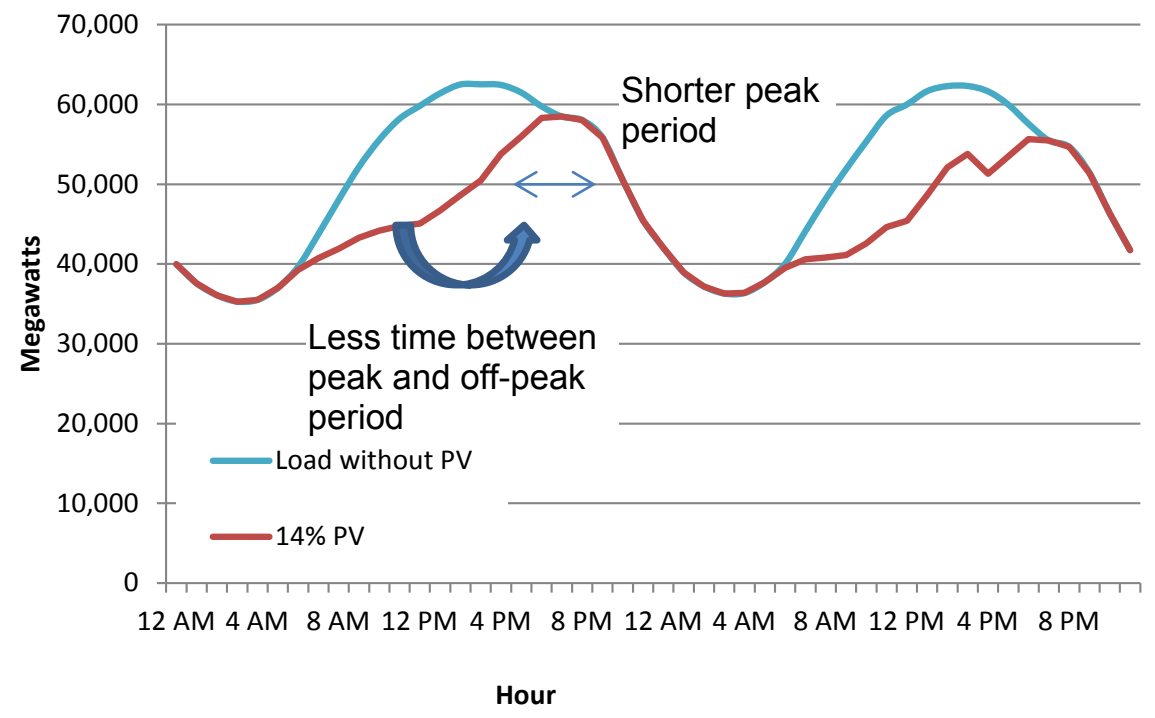

(a) July $29-30$

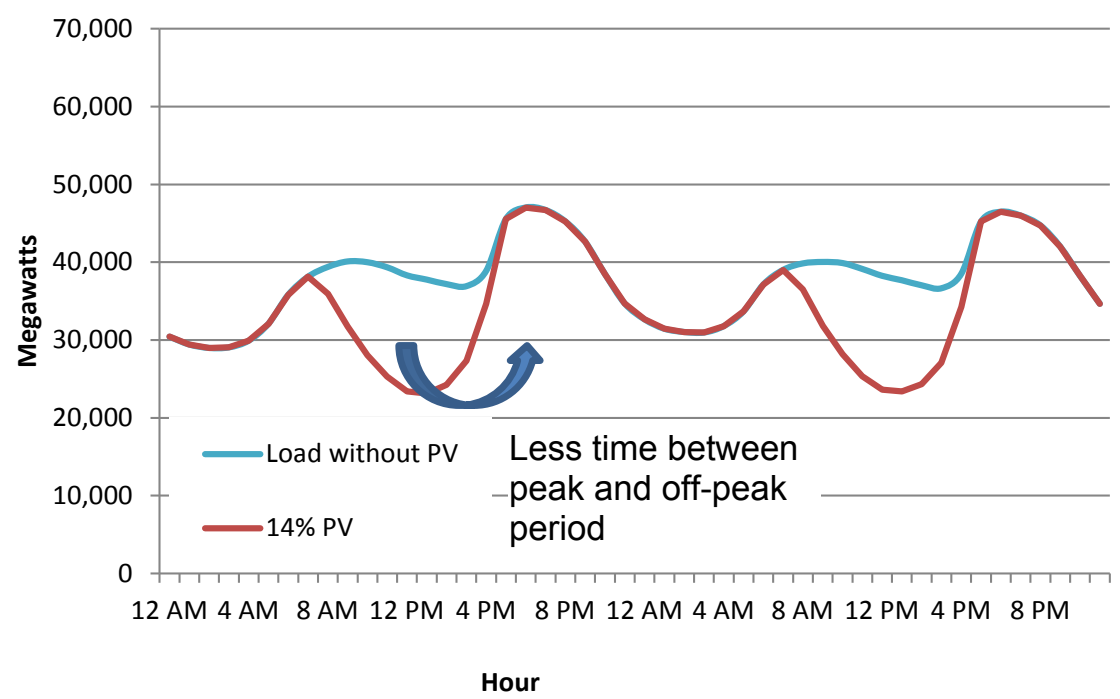

(b) December 21-22

Figure 24. Load with and without PV demonstrating possibility of increasing availability of DR.

The combined impact of midday off-peak energy availability and shortened peak periods should increase the availability of DR while decreasing the costs of storage used for meeting peak demand. Further analysis is needed to estimate the actual potential for demand shifting and associated costs under increased PV penetration.

\subsubsection{Energy Storage}

Figure 25 provides the total value curves for the two storage cases, as well as a case with both 1,500 MW of storage and the added demand reponse. 


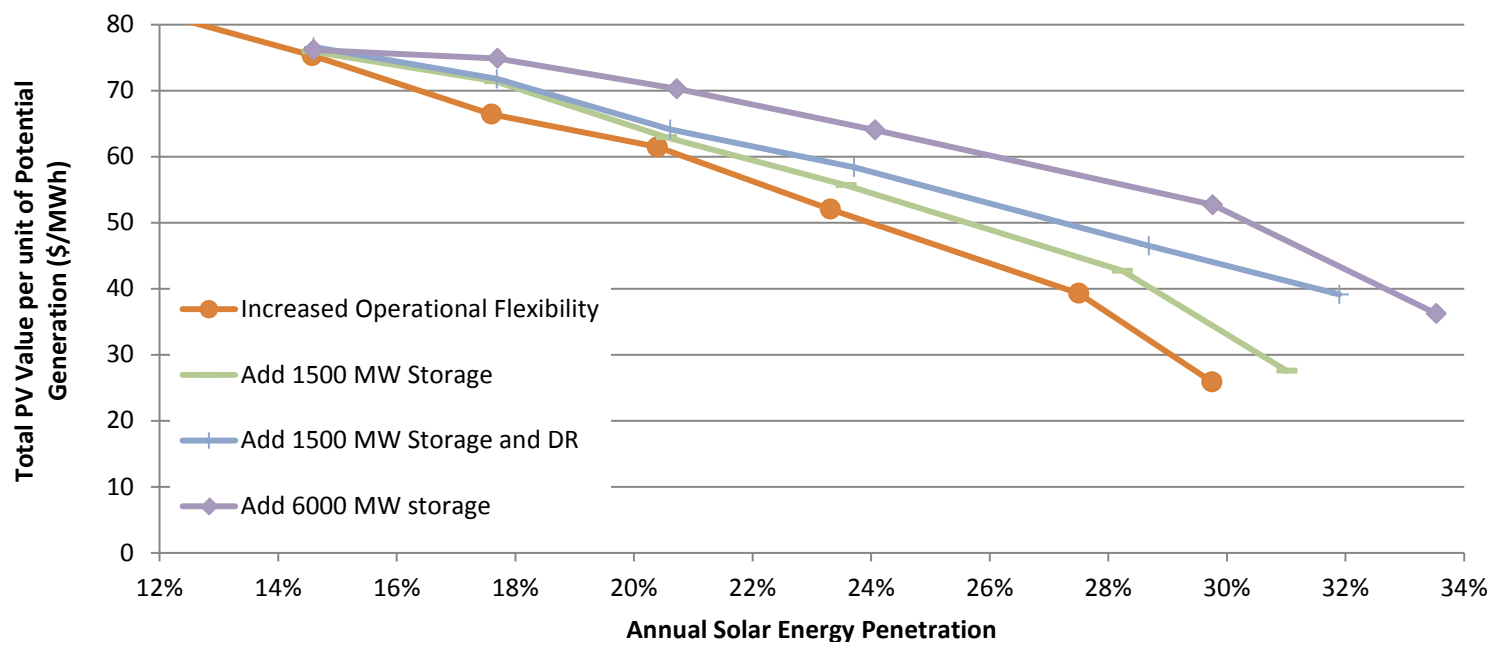

Figure 25. Increase in economic carrying capactiy resulting from added storage.

Energy storage increased the ECC by reducing curtailment and shifting the supply of PV. Limits to the benefits of storage include storage losses, which can be considered a kind of curtailment, because $20 \%$ of all PV energy cycled through storage will be lost. Other limits include the very high instantaneous curtailment rates that occur during the spring, as seen previously in Figure 21. The addition of 6,000 MW of storage increases ECC from about $20 \%$ to about $26 \%$. This is significantly higher than the DR case even though the peak load-shifting capacity in the DR case is about the same. This implies a higher value for storage despite the higher loss rate. This outcome is due entirely to storage being available during all hours of the year, whereas DR is tied to specific applications and is dominated in these simulations by cooling demand.

Similar to DR, the value of energy storage is heavily influenced by its ability to provide capacity value. This value is significantly greater than its operational value, particularly at low solar penetration. Figure 26 summarizes the total annualized benefits for the two storage cases. Each case has two value lines similar to the DR case, assuming an avoided capacity cost of either $\$ 100 / \mathrm{kW}$-yr or $\$ 200 / \mathrm{kW}$-yr. We assume the storage plants (with 6 hours of capacity) receive full capacity credit, based on Sioshansi et al. (2014) and Denholm et al. (2016). ${ }^{21}$ These values can be compared to the annual estimates for the cost of storage. Figure 26 also shows the "breakeven" point for new storage, assuming installed cost of $\$ 250 / \mathrm{kWh}$ to $\$ 350 / \mathrm{kWh}$ and a fixed charge rate of $12 \%$. Points where the value of storage exceeds the cost results in economic storage.

${ }^{21}$ This also assumes that storage is replaced or maintained to account for degradation in capacity due to cycling. 


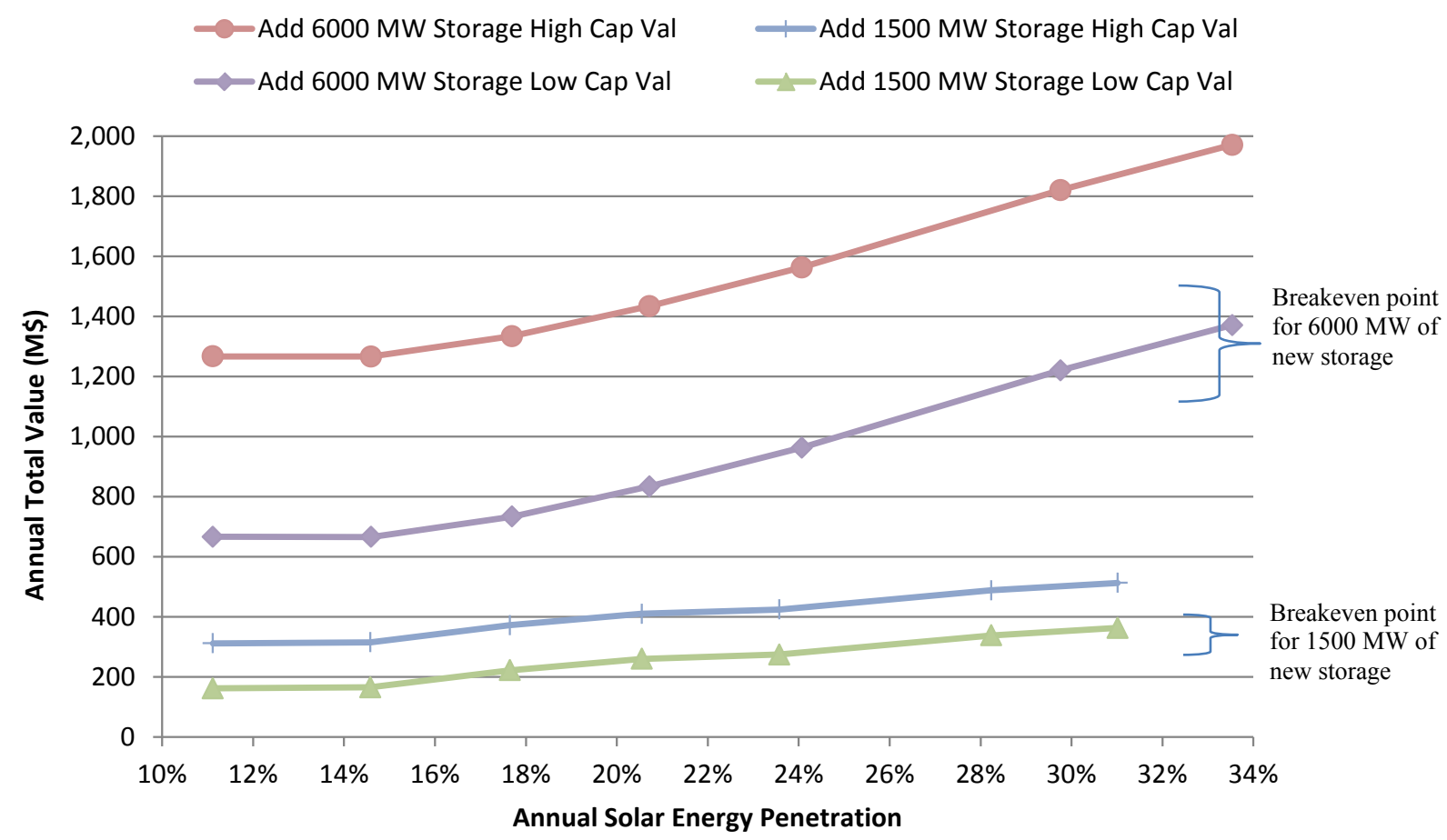

Figure 26. Total annualized benefit of energy storage including capacity benefits.

As with DR, there may be important synergies between PV and storage. As PV narrows the peak (as shown in Figure 24a), fewer hours of storage may be needed to provide the same level of capacity service. This general concept has also been referred to as the "minimum buffer energy storage capacity" (Perez et al. 2008).

Figure 27 shows the trend in storage energy capacity needed to provide firm capacity for the two amounts of storage power capacity added to the system (1,500 MW and 6,000 MW). This figure estimates the storage capacity needed (in hours) to reduce the net demand by the full capacity of the storage device for the top 50 demand days of the year. These curves consider the existing storage capacity. At low penetration of PV, 8 hours or more of battery capacity are needed to reduce load reliably by the rated capacity of the storage device, assuming an optimally scheduled battery (requiring perfect foresight of demand during the peak period). Note that this does not mean that the battery operates at full output during the entire period of discharge; rather, the battery output is assumed to follow the shape of the demand curve, often discharging at partial output. As PV penetration increases, the battery capacity requirement decreases, to the point where about 4 hours of storage capacity are needed at penetrations beyond $10 \%{ }^{22}$

\footnotetext{
${ }^{22}$ Beyond 20\% PV penetration, the net demand peak does not narrow any further, which is why the hours of storage needed do not decrease.
} 


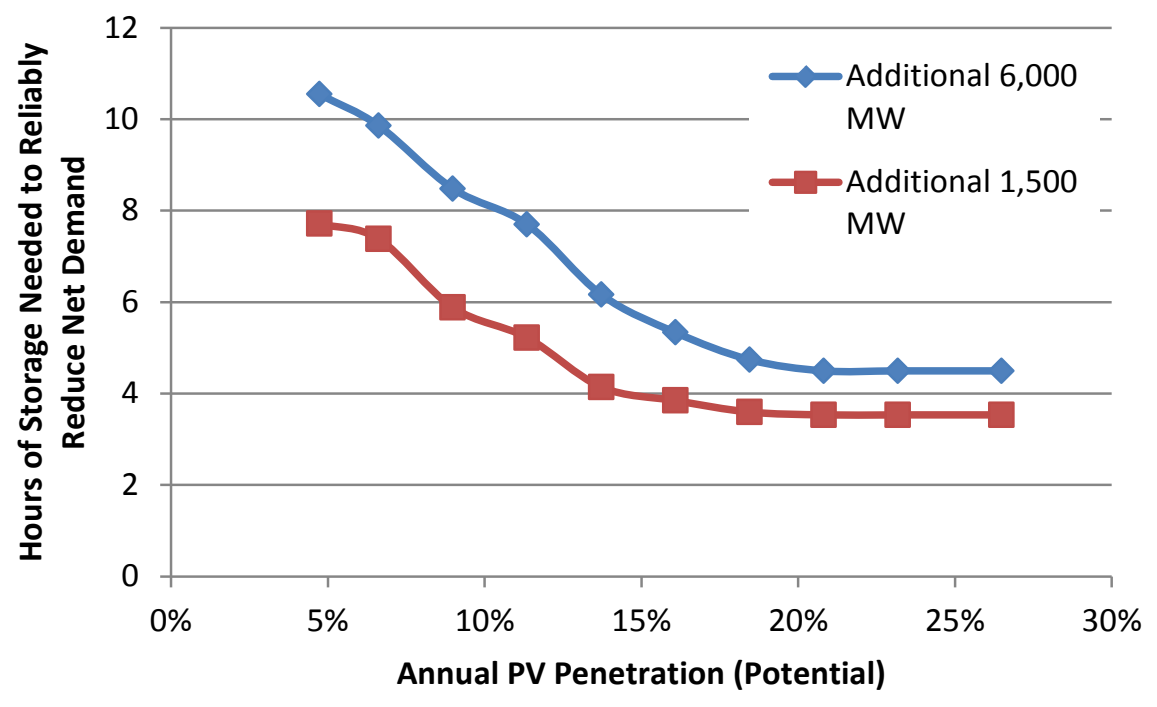

Figure 27. Hours of storage needed to reduce peak demand by 1,500 MW and 6,000 MW as a function of PV penetration.

Additional analysis would be required to determine the actual benefits of reduced storage capacity requirements as a function of PV. In theory, it may be possible to compensate PV generators for the reduced demand period and corresponding amount of storage. There would be some small tradeoff, because reduced storage energy capacity would reduce operational benefits; however, this should be much less than the reduction in cost, and thus, it provides a net benefit. If the PV and storage were not owned by the same entity, then new market mechanisms would likely be needed to facilitate the shared benefits.

\subsubsection{Export Capacity}

Figure 28 shows the impact of allowing exports on the total PV value. This option has the highest increase in value of all of the options except the 6,000 MW storage case.

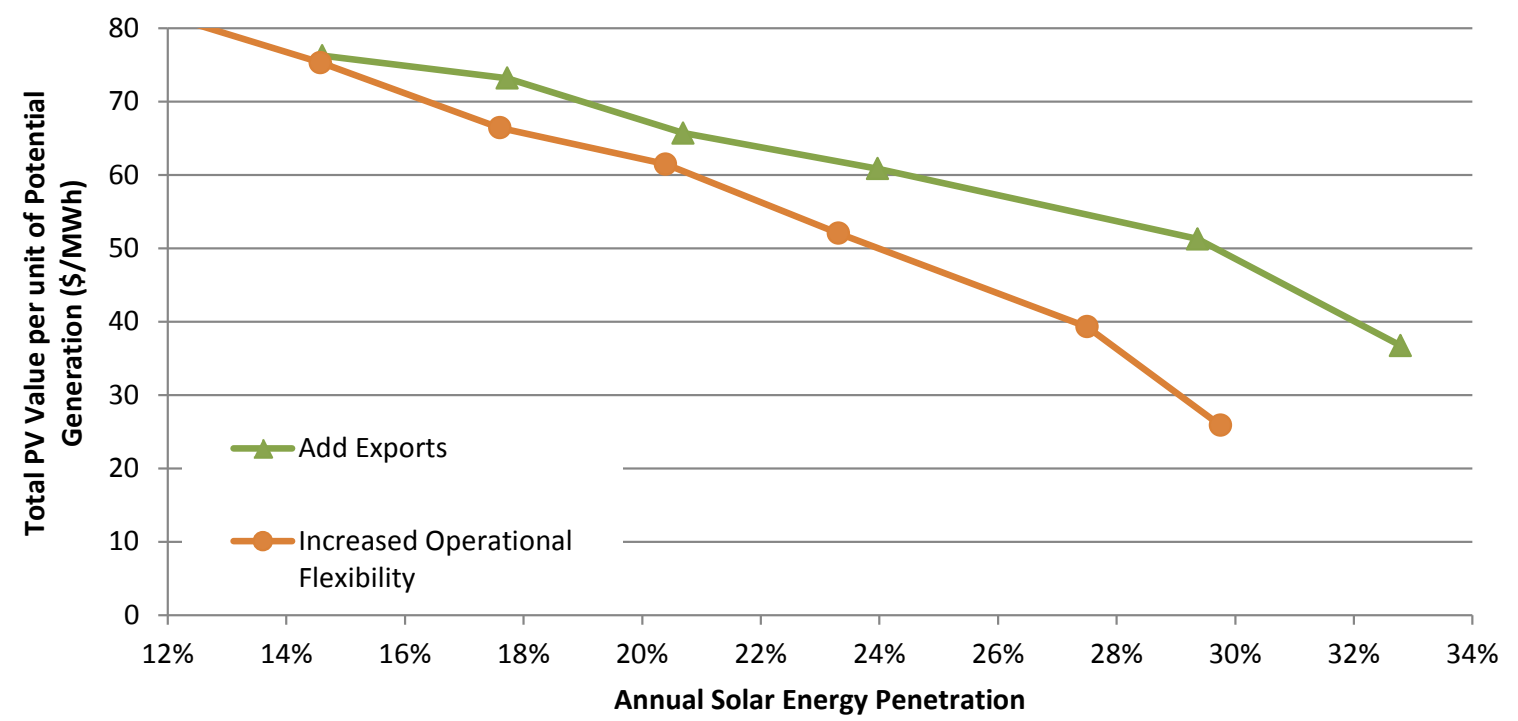

Figure 28. Increase in economic carrying capactiy resulting from added export capacity. 
The ability of California to export PV may require broader implementation of various market mechanisms that allow for exchange of energy across regions. ${ }^{23} \mathrm{~A}$ long-term challenge may occur when surrounding states also adopt increasing amounts of wind and solar PV, leading to regional surpluses of renewable energy. It is not clear that the "carrying capacity" is an entirely appropriate metric in this case, because the penetration of PV over the entire region in this scenario is much lower than in California alone. Additional analysis could examine the ECC of a larger region, and the regional ECC could increase when maximizing cooperation and coordination.

In contrast to its large impact on ECC, the exports case had the lowest operational benefits. Furthermore, exports do not provide additional capacity benefits of DR or energy storage. However, this case would likely have very low implementations costs. This case does not expand transmission, and it only creates mechanisms to increase the use of existing transmission to export surplus solar energy to surrounding states. This would likely occur through more efficient day-ahead and real-time energy exchange. The creation of the Energy Imbalance Market has already facilitated some of these transactions, but the export benefits calculated here would require greater day-ahead transactions, as well as transactions throughout the Western Interconnection. Costs of implementing these transactions are expected to be relatively low. For example, an estimate for implementing the EIM across all of the WECC was expected to be largely associated with a one-time cost of about \$19.6 million (CAISO 2015). Furthermore, the benefits calculated here only consider those to exports, and does not consider the full benefits of more-efficient system scheduling, which could provide much greater net benefits (CAISO 2016).

\footnotetext{
${ }^{23}$ An example is the Western Energy Imbalance Market. https://www.caiso.com/informed/Pages/EIMOverview/Default.aspx
} 


\section{Case Study: Florida-Increasing PV}

\subsection{Florida Reliability Coordinating Council Model}

In our study, we extracted the Florida Reliability Coordinating Council (FRCC) model from the 2026 Eastern Interconnection (EI) model developed for the Eastern Renewable Generation Integration Study (ERGIS). To create the EI model for ERGIS, NREL used two models. We used the PLEXOS unit-commitment/economic dispatch model to simulate an entire year of power system operations down to a 5-minute resolution. The second model was NREL's Regional Energy Deployment System (ReEDS) (NREL 2012), which is a capacity expansion model that was developed to accurately model the spatial and temporal availability of renewable generation technologies. We used ReEDS to determine the quantity and location of all generation additions and retirements in the study. The coordinated use of these models results in a detailed simulation of power system operations (Bloom et al. 2016).

In addition to extracting FRCC from the full EI, we made other changes to the model to enhance some of the assumptions and model configuration to better capture unique characteristics of FRCC. Those changes included the following:

- Breaking FRCC into six distinct Balancing Areas (BAs).

- Increasing the number of enforced transmission thermal limits to include all lines rated at $230 \mathrm{kV}$ or above.

- Reducing the installed thermal capacity to limit the planning reserve margin in FRCC to $20 \%$.

- Representing FRCC's connection with the Southeastern Electric Reliability Council (SERC) using a supply curve connected to the main lines that tie FRCC to SERC and the rest of the EI. The supply curve defines the price of electricity as a function of generation.

- Changing the amount of contingency reserves to be held to be consistent with the amount of contingency reserves held today in FRCC.

Further discussion of these changes and the FRCC model itself are included in the appendix.

\subsection{PV Penetration Scenarios}

Six penetrations of PV are tested in this study (Table 5), based on a percentage of annual FRCC load that would be met by PV if all of the available generation were used (not curtailed). The penetrations range from 5\%-29\% and increase in about 5\% increments, with installed capacity ranging from $7 \mathrm{GW}$ to $39 \mathrm{GW}$. For reference, peak load in FRCC in this model is $50 \mathrm{GW}$. Each flexibility option is modeled under all PV penetrations. 
Table 5. FRCC PV Penetration Scenarios

\begin{tabular}{|c|c|c|}
\hline $\begin{array}{c}\text { Solar Pre-Curtailment } \\
\text { Potential Scenario } \\
\text { (\%) }\end{array}$ & $\begin{array}{c}\text { Installed Capacity } \\
\text { (GW) }\end{array}$ & $\begin{array}{c}\text { Total Pre- } \\
\text { Curtailment Energy } \\
\text { (GWh) }\end{array}$ \\
\hline 5 & 7 & 12,854 \\
\hline 10 & 13 & 25,678 \\
\hline 15 & 20 & 38,552 \\
\hline 20 & 27 & 51,343 \\
\hline 24.3 & 33 & 62,369 \\
\hline 29.2 & 39 & 77,034 \\
\hline
\end{tabular}

The PV sites and output profiles from the ERGIS RTx30 scenario are used to achieve each penetration (Bloom et al. 2016). Discrete sites are added to the model until the desired penetrations are reached. Larger penetrations are supersets of the smaller penetrations. Sites are chosen so that the total capacity is spread out between the BAs proportionally to each BAs load.

The PV capacity is split roughly 60:40 between utility-scale projects and distributed-scale (commercial and residential) projects. Utility-scale includes sites with fixed-axis and single-axis tracking systems, whereas the distributed-scale sites are exclusively roof-mounted, south-facing systems.

\subsection{Flexibility Options}

In addition to a base case, a total of five flexibility options were considered in this analysis. The options include:

1) Allowing PV to provide reserves

2) Reducing minimum generation levels of combined-cycle generators

3) Enhancing cooperation between FRCC BAs

4) Adding energy storage

5) Increasing the transmission capacity between FRCC and SERC

6) Combining the two cases of increased transmission capacity with SERC and enhancing BA cooperation.

The following section details the assumptions used to model these flexibility options in the FRCC model.

\subsubsection{Allow PV to Provide Reserves}

One of the major reasons a system-wide minimum thermal generation level exists is due to the amount of thermal generation required to be online to provide spinning reserves. The number of units that must be online depends on what types of generators are available, their size, and how fast they can ramp to meet the requirement.

One method to reduce the minimum thermal generation level is to allow PV to provide reserves. PV has shown that it can respond to reserve signals (Gevorgian et al. 2016) and can provide upreserves during periods of curtailment, or down-reserves by curtailing when the reserves are 
called. This allows the minimum thermal generation level to be reduced because a conventional generator may be shut down rather than staying online simply to provide reserves.

To test this flexibility option, we allowed PV in FRCC to provide both contingency and regulation reserves. To simplify the model and reduce runtime, only up-reserves are modeled, even though PV can provide both up- and down-reserves.

\subsubsection{Combined-Cycle Minimum Generation Level}

The modeled FRCC system has about $39 \mathrm{GW}$ of combined-cycle gas generation, which is an increase of about $14 \mathrm{GW}$ compared to capacity in 2015. This increase is due to planned retirements of coal and oil capacity between now and 2026 (Bloom et al. 2016). Although more flexible than coal plants, gas plants still have limits on ramp rates and minimum generation levels (i.e., how much they can reduce their output relative to their nameplate capacity without needing to shut down).

Reducing the minimum generation level adds flexibility to the system because it increases the overall operating range of the thermal fleet. This can benefit the integration of PV because it can reduce the minimum conventional generator operating level, allowing more of the peak PV generation to be used rather than curtailed due to low net load.

In the base case, CCs in FRCC are assumed to have a minimum generation level of $50 \%$ of their installed capacity (Bloom et al. 2016). This flexibility option decreases the minimum generation level for all CCs in FRCC to 40\% of their installed capacity, which adds an additional $3.8 \mathrm{GW}$ of operational range to FRCC. However, the system only benefits from the increased operational range when these units are available and committed. Given outages and other reasons for a $\mathrm{CC}$ to be turned off, the actual benefit to the system at any given time will be less than $3.8 \mathrm{GW}$.

\subsubsection{Enhanced BA Cooperation}

Cooperation among the various investor-owned, municipal, and rural co-operative utilities in FRCC primarily amounts to the splitting of reserve requirements to maintain reliability on the Florida Peninsula. The scheduling of bulk generation is up to each individual utility. Individual utilities can buy generation from other utilities, but there is no central operator ensuring leastcost unit commitment and dispatch for all of FRCC.

In the base model, FRCC is assumed to have six BAs that commit and dispatch generation to meet load in their respective areas. In addition, each BA is required to provide a certain amount of FRCC's reserve requirement. Buying and selling generation is allowed, but is assumed to be more expensive given the market friction that exists in a bilateral market. We model market friction by adding a $\$ 10 / \mathrm{MWh}$ hurdle rate between BAs.

The flexibility option of increased cooperation between BAs removes this market friction between BAs and assumes that FRCC generation is scheduled by a central system operator instead of by each BA. In addition, each BA is no longer required to carry a certain amount of reserves. Instead, reserves can be met by using any eligible generator within FRCC, thus ensuring that reserves are met at least-cost to all of FRCC. 
Increased BA cooperation increases system flexibility primarily by ensuring that the mostefficient and least-expensive generators are committed first. In terms of flexibility used for integrating PV, increasing BA cooperation allows the system to better capture the benefits of the geographic diversity of PV sites. It allows sites within FRCC to partially cancel out each other's variability. For example, one part of the Florida Peninsula may have cloud cover moving over it, while another part may have clouds leaving the area. In this case, the decreased generation at the first site can be cancelled out by the increasing generation from the second site. In the base case, individual BAs were forced to deal with these two PV ramps separately. In addition to reducing net variability using PV sites throughout FRCC, BAs will also have a large suite of generators at its disposal to deal with PV variability under this flexibility option.

Unlike the technical flexibility options described earlier, this option does not decrease the total system minimum generation level. It can reduce minimum generation levels within individual BAs, but the total system minimum generation level remains unchanged. Therefore, much of the reduction in curtailment of this flexibility option is due to reduced market friction, facilitating $\mathrm{PV}$ generation from one BA to displace conventional generation in another BA.

\subsubsection{Battery Storage}

In FRCC, we examine two different deployments of battery storage. One scenario adds 1,000 MW of battery capacity (about $2 \%$ of peak FRCC load). Another high-storage scenario adds 4,000 MW of capacity (about $8 \%$ of peak FRCC load). In both cases, we assume that each battery has 6 hours of storage capacity. The battery capacity is evenly distributed between 20 discrete batteries. Therefore, in the first scenario, each battery has a maximum capacity of 50 MW and $300 \mathrm{MWh}$ of storage capacity. In the high-storage case, each battery is $200 \mathrm{MW}$ with 1,200 MWh of storage. All batteries are assumed to have an $80 \%$ roundtrip efficiency.

The batteries are distributed among FRCC's BAs according to each BA's proportion of total PV capacity. However, the batteries are not necessarily co-located with PV installations. Instead, the batteries are placed on high-voltage nodes to reduce the potential of transmission congestion caused by the introduction of the batteries.

\subsubsection{Increased Transmission Capacity between SERC and FRCC}

FRCC's connection with the rest of the EI is extremely limited, but the connection to SERC could be increased. Similar to the internal flexibility option of increased BA cooperation, this flexibility option allows the system to take advantage of the geographic diversity of PV between FRCC and SERC and more ramping ability.

In the base case, the flow of power between SERC and FRCC is limited to 3,200 MW of import from SERC and 1,000 MW of export to SERC. The smaller limit when exporting to SERC is based on stability limits that exist in SERC. This flexibility option assumes that the lines and supporting infrastructure are upgraded to allow 5,000 MW of import from SERC and 2,000 MW of export.

\subsubsection{Enhanced BA Cooperation and Increased Transmission between SERC and FRCC}

The final flexibility option combines increased transmission between SERC and FRCC and enhanced BA cooperation between FRCC BAs. This option assumes that the transmission 
capacity between SERC and FRCC is increased (5,000 MW import / 2,000 MW export) and FRCC's BAs enhance their cooperation to reduce market friction and share reserve requirements. This flexibility option measures how additive the internal and external flexibility options are when considered together.

\subsection{Results}

\subsubsection{Base-Case PV Capacity Value}

Similar to California, one component of PV's value in FRCC is the reduced need for firm capacity from conventional generation sources. Capacity credit is the percent total installed PV capacity that can be relied on to meet the peak net load. Consistent with earlier studies and the California case study (Section 2.4.1), that value decreases as PV penetration increases. Figure 29 shows the declining marginal capacity credit of PV as a function of annual PV penetration. The marginal capacity credit is calculated in the same manner detailed in Section 2.4.1 by measuring the average PV capacity factor of the incremental PV during the top 100 net-load hours.

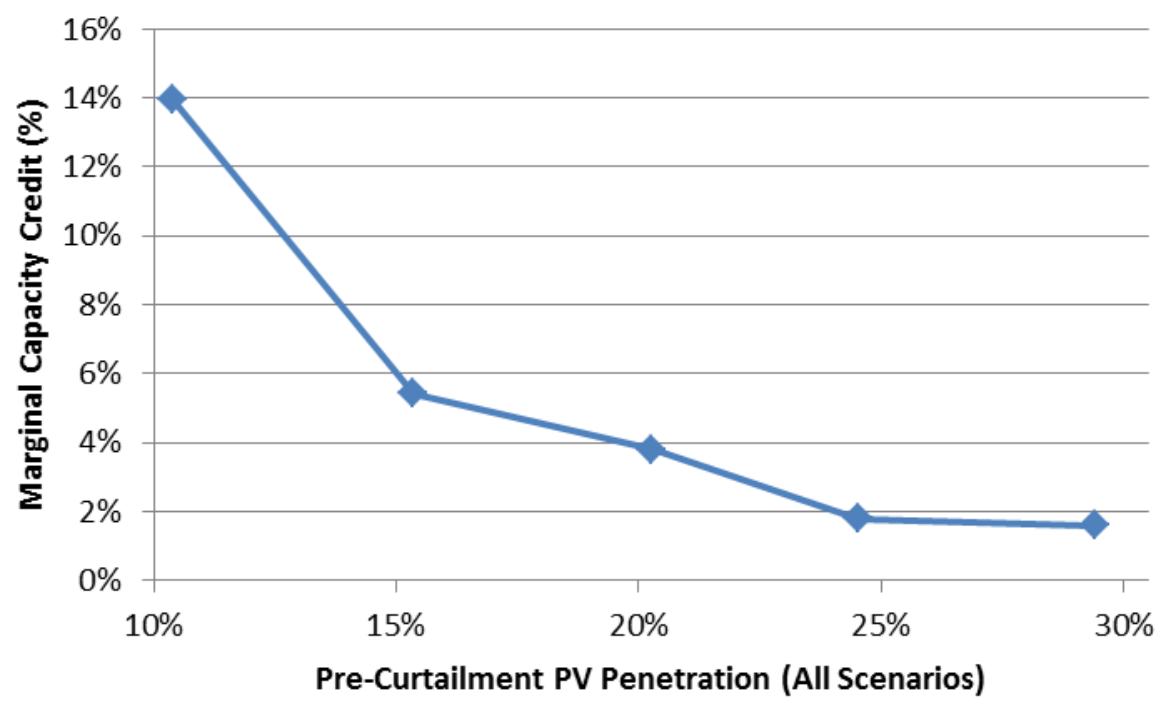

Figure 29. Capacity credit of PV in FRCC.

Assuming that new capacity costs $\$ 190 / \mathrm{kW}-\mathrm{yr}$, the capacity credit can be expressed as a monetary value, or the capacity value of PV in FRCC. Figure 30 shows the decline of PV capacity value as a function of penetration. The value of PV capacity drops rapidly, falling below $\$ 5 / \mathrm{MWh}$ before reaching a pre-curtailment penetration of $20 \%$. This drop is somewhat faster than other regions, including California. FRCC can have significant early morning winter peaks (due to significant electric-heater usage) when PV is not generating and cannot contribute capacity. 


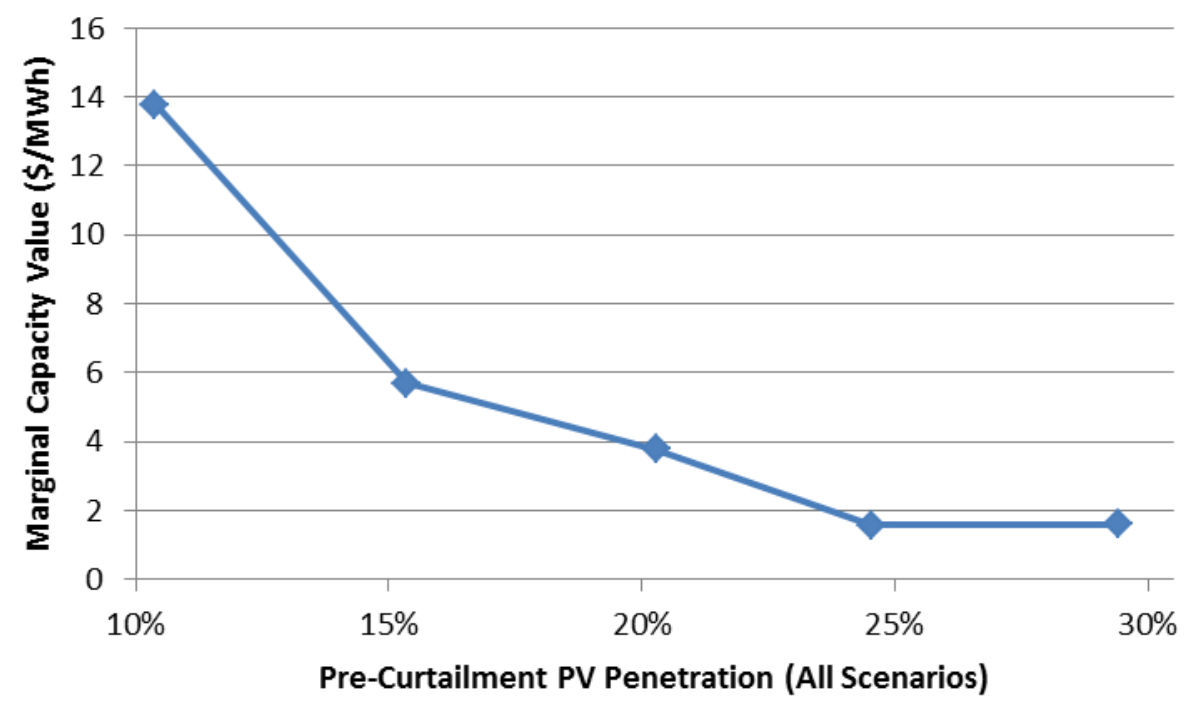

Figure 30. Capacity value of PV in FRCC.

Given that there is no shift in demand across the flexibility scenarios in FRCC (no DR was considered), the capacity value of PV is unchanged for all scenarios.

\subsubsection{Base-Case PV Operational Value}

The components of the operational value of PV for the base case are shown in Figure 31. The four components include: 1) displaced generator fuel and variable O\&M costs, 2) reduced $\mathrm{CO}_{2}$ emissions, 3) the change in generator start costs, and 4) the change in SERC-GA import/export costs. The modeling did not include the cost of $\mathrm{CO}_{2}$ emissions when considering how to commit and dispatch the system. Therefore, the $\mathrm{CO}_{2}$ emissions costs considered here reflect the cost borne by society due to generator $\mathrm{CO}_{2}$ emissions. In the following results, the social cost of $\mathrm{CO}_{2}$ emissions is assumed to be $\$ 50 /$ ton of $\mathrm{CO}_{2}$. 


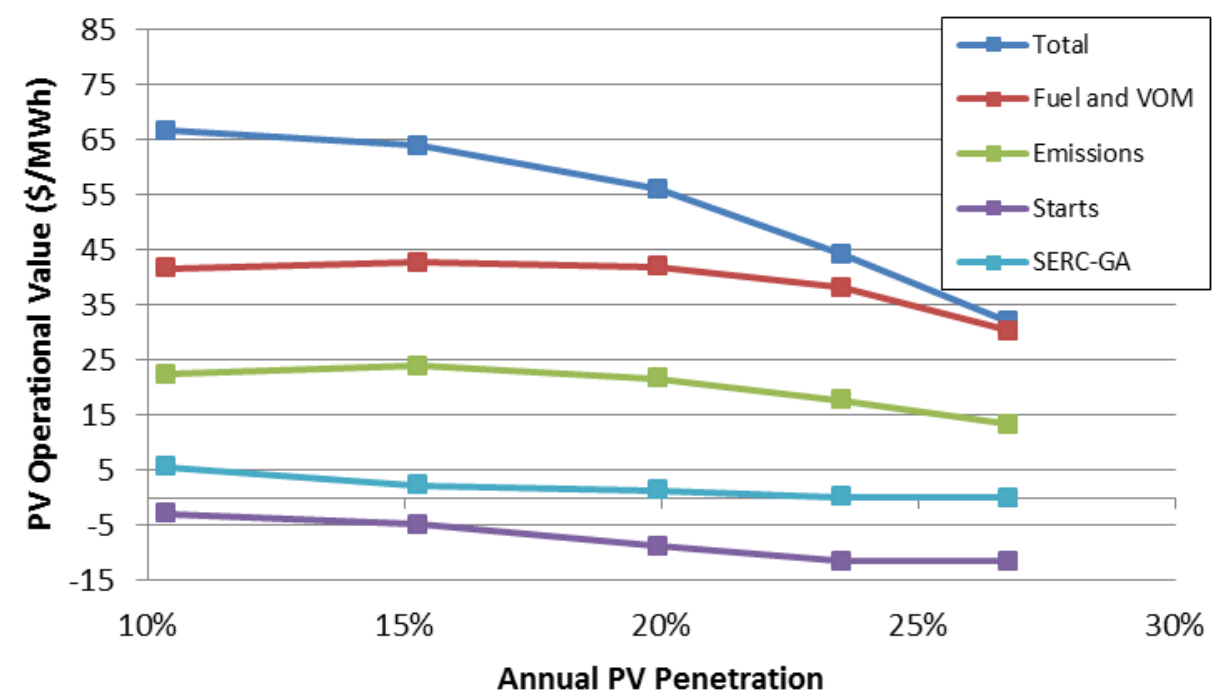

Figure 31. Base case PV operational value.

In the base case, the value of the displaced fuel, variable O\&M, and emissions remains constant for the smaller penetrations; this is due to the low PV curtailment in those scenarios. However, the total operational value drops across these penetrations as the cost of generator starts increases and the ability to export excess PV generation decreases. At the higher penetrations, curtailment reduces the amount of fuel, variable O\&M, and emissions that additional PV generation can displace. This leads to a more significant drop in total operational value of PV at the highest penetrations.

Much of the operational value of PV depends on the amount of PV that is curtailed. Figure 32 shows the total curtailment of PV in all flexibility scenarios.

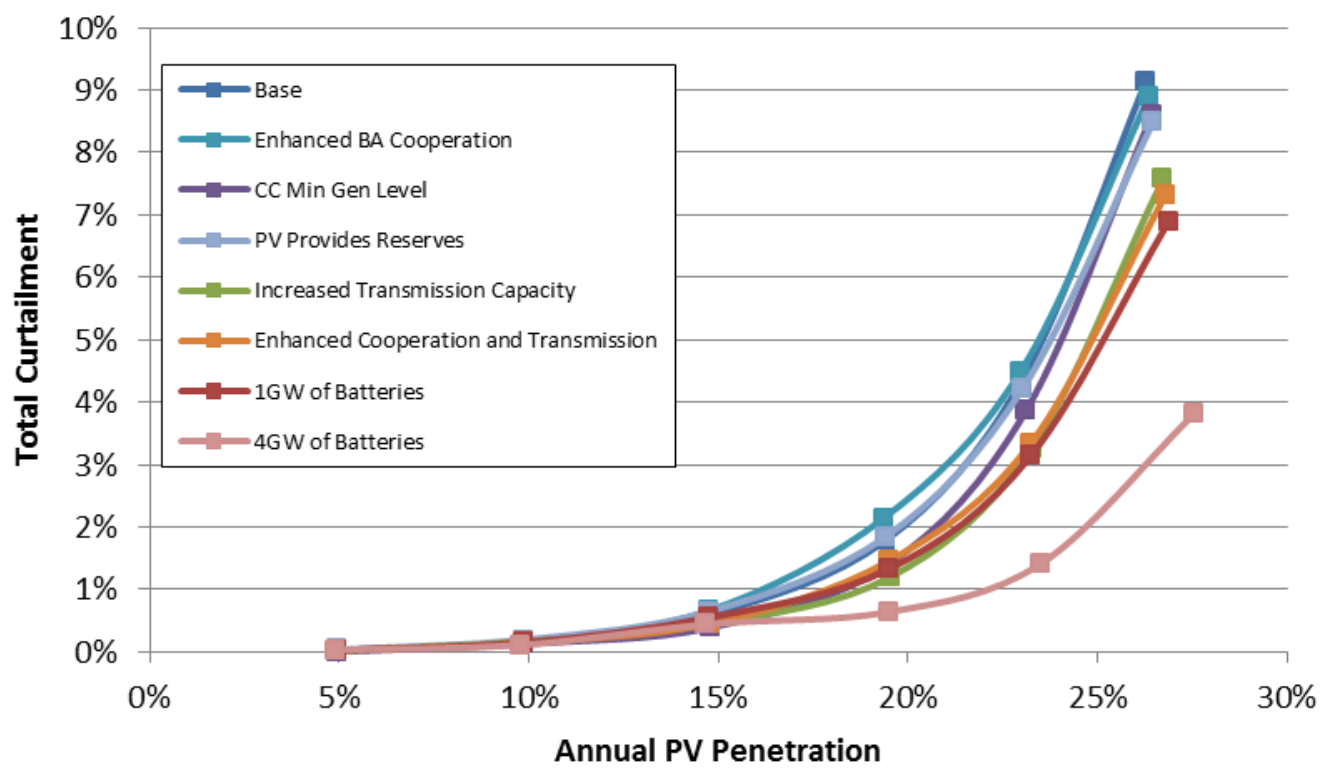

Figure 32. Total curtailment of PV in FRCC. 
At penetrations below $15 \%$, curtailment is below $1 \%$ in all scenarios. Beyond $15 \%$ penetration, curtailment becomes more significant, with a peak curtailment of greater than $9 \%$ in the base case. In the higher penetrations, all flexibility options decrease total PV curtailment. Adding battery storage and increasing export/import capacity with SERC provide the largest reductions in curtailment in these higher penetrations.

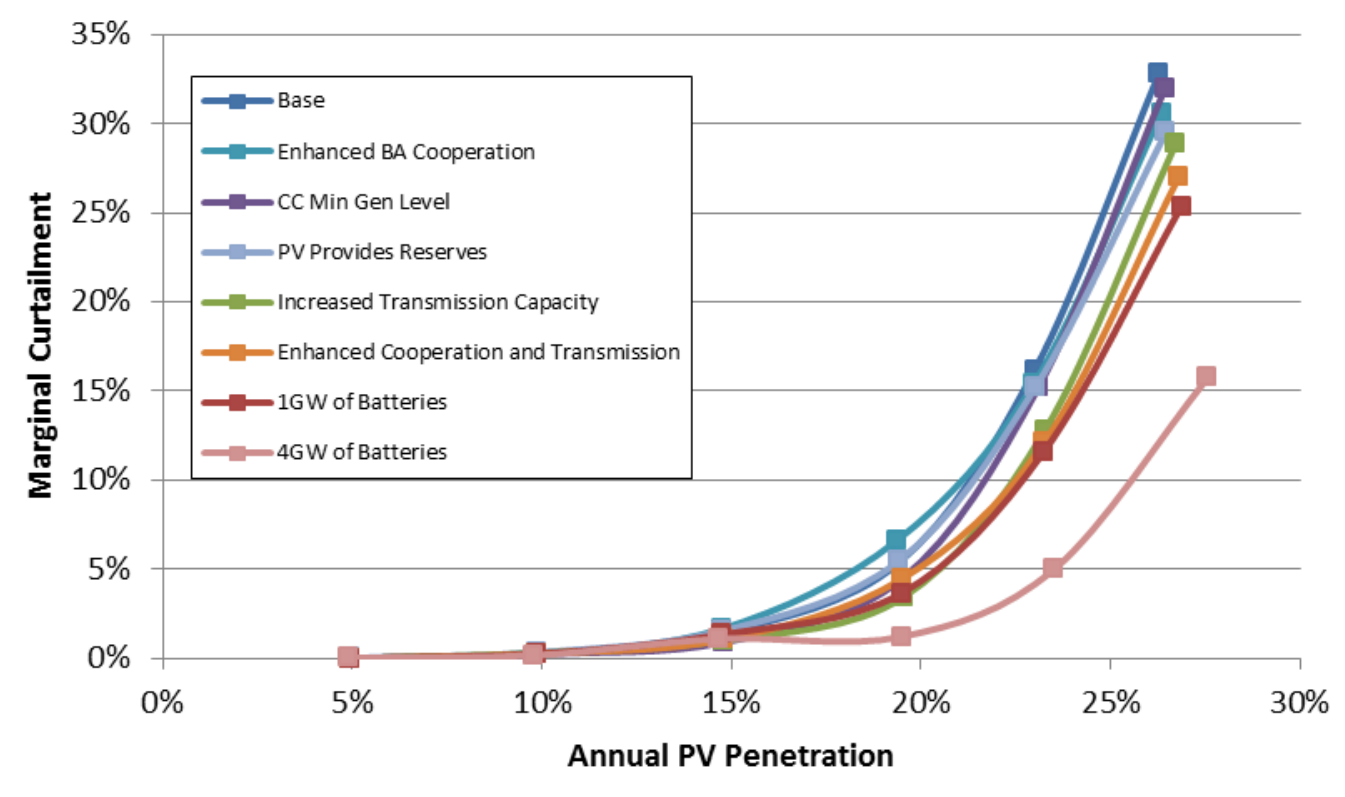

Figure 33. Marginal curtailment of PV in FRCC.

Figure 33 shows the marginal curtailment of all flexibility scenarios. ${ }^{24}$ This indicates how much of the new generation will be curtailed. The marginal curtailment of PV heavily influences the operational value of $\mathrm{PV}$, because the operational value is determined by the reduction in costs of the system from one PV penetration to the next. The largest reduction in marginal curtailment comes from adding $4 \mathrm{GW}$ of batteries to FRCC, which reduces marginal curtailment by more than $50 \%$ in the highest PV penetration. All other flexibility scenarios reduce marginal curtailment, but at a much smaller magnitude.

\subsubsection{PV Total Value}

Figure 34 shows the total value of PV in FRCC for all flexibility scenarios, where the total value of PV combines the capacity and operational values. Across all flexibility scenarios, the total value of PV decreases as the penetration increases. The value is impacted by both the decreasing capacity credit that PV receives at higher penetrations and the increase in curtailment.

\footnotetext{
${ }^{24}$ As noted previously, this is actually the average marginal curtailment, because it is not the true marginal curtailment of an extremely small addition of PV. It is the average curtailment for all incremental PV added from one scenario to the next.
} 


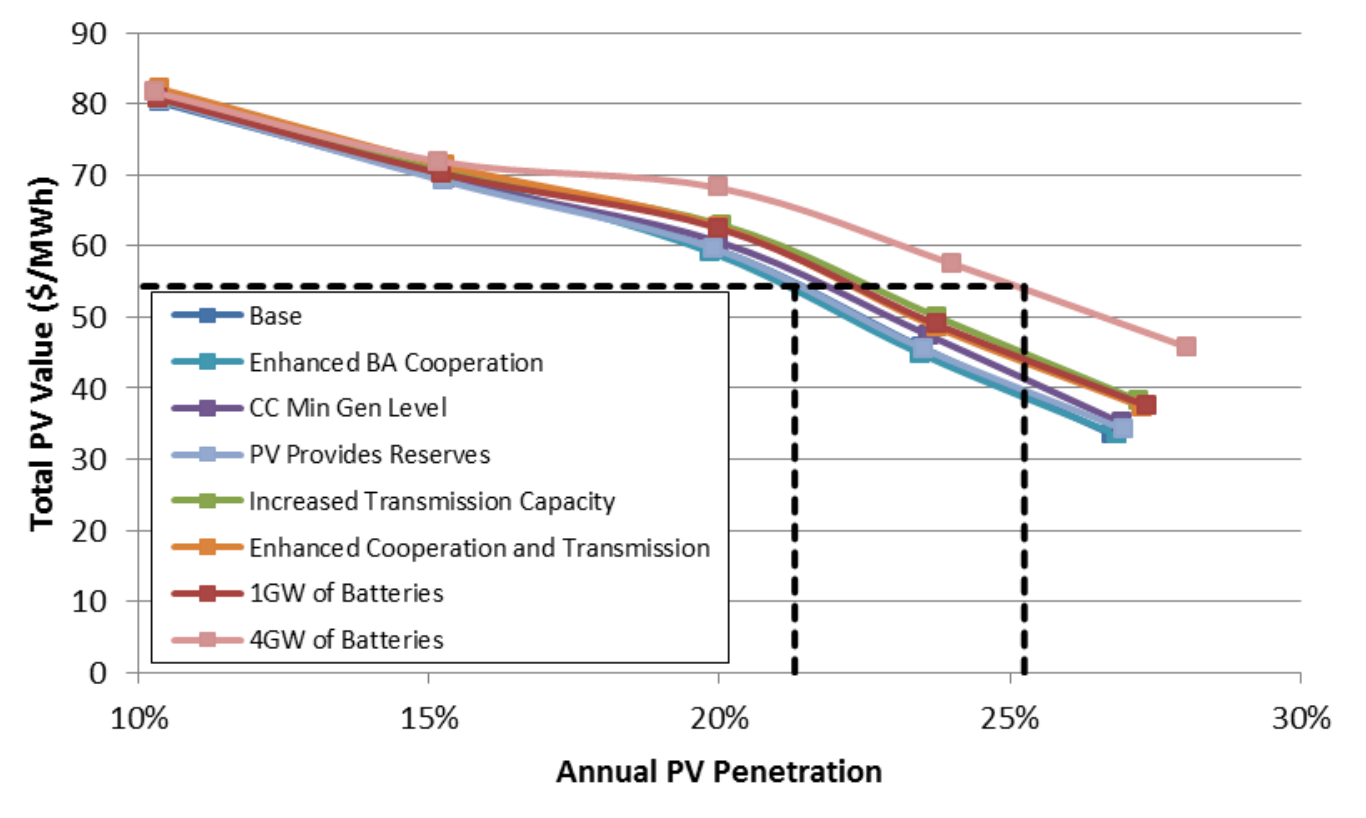

Figure 34. Total value of PV in FRCC.

The value of flexibility options can be measured using the economic carrying capacity presented in Section 1. Figure 34 also includes horizontal lines that represent an estimate for the average LCOE for utility-scale PV in Florida (about \$54.3/MWh) using 2020 estimated PV costs.25 This puts the ECC of PV in the base case at $20.9 \%$. Most of the flexibility options have a minimal impact on increased ECC, whereas the 4-GW battery case increases the ECC from $21 \%$ to $25 \%$. Table 6 shows how adding flexibility options impacts the ECC of PV at particular LCOEs of PV in FRCC. At the lower LCOE, the increase in ECC from all flexibility options increases slightly, but is still relatively small for all options except the 4-GW battery. The following section discusses these results in detail.

${ }^{25}$ Calculations were performed using the NREL System Advisor Model using assumptions described in Woodhouse et al. (2016). 
Table 6. Change in Economic Carrying Capacity due to Flexibility Options

\begin{tabular}{|c|c|c|c|}
\hline \multirow[b]{2}{*}{ Flexibility Option } & \multicolumn{3}{|c|}{$\begin{array}{c}\text { Change in FRCC Carrying Capacity } \\
\text { Relative to Base Case (percentage point } \\
\text { difference from base) }\end{array}$} \\
\hline & $\begin{array}{c}\text { Highest- } \\
\text { Cost PV } \\
\text { System } \\
\text { (\$59.3/MWh) } \\
(\%)\end{array}$ & $\begin{array}{c}\text { Average- } \\
\text { Cost PV } \\
\text { System } \\
\text { (\$54.3/MWh) } \\
(\%)\end{array}$ & $\begin{array}{l}\text { Min-Cost PV } \\
\text { System } \\
\text { (\$47.7/MWh) } \\
\text { (\%) }\end{array}$ \\
\hline Enhanced BA Cooperation & -0.3 & -0.2 & -0.3 \\
\hline CC Min Gen Level & 0.4 & 0.5 & 0.5 \\
\hline PV Provides Reserves & 0.0 & 0.0 & -0.1 \\
\hline $\begin{array}{l}\text { Increased Transmission } \\
\text { Capacity }\end{array}$ & 1.3 & 1.2 & 1.4 \\
\hline $\begin{array}{l}\text { Enhanced Cooperation and } \\
\text { Transmission }\end{array}$ & 1.0 & 0.9 & 1.0 \\
\hline 1-GW of Batteries & 1.0 & 1.0 & 1.1 \\
\hline 4-GW of Batteries & 3.4 & 3.8 & 4.4 \\
\hline
\end{tabular}

\subsubsection{Value of Flexibility Options}

In addition to increasing the economic carrying capacity of PV, flexibility options also provide additional value to the system. This is primarily measured via the reduction in production costs between systems with flexibility options and the base case with no flexibility options. Some flexibility options also provide capacity value, but this is only quantified for battery-storage flexibility options.

Figure 35 shows the annual operational savings for all flexibility options across all FRCC PV penetrations. The value of some flexibility options increases significantly as the PV penetration increases. These options tend to have the largest impact on PV curtailment. Other options change only slightly across the PV penetrations. These options provide a basic value to the system, but have little impact on curtailment. At the higher penetrations, the largest battery deployment provides the largest value. But transmission expansion and more coordination between BAs provide the most benefit at the lowest PV penetrations. The following sections provide additional discussion of the individual options. 


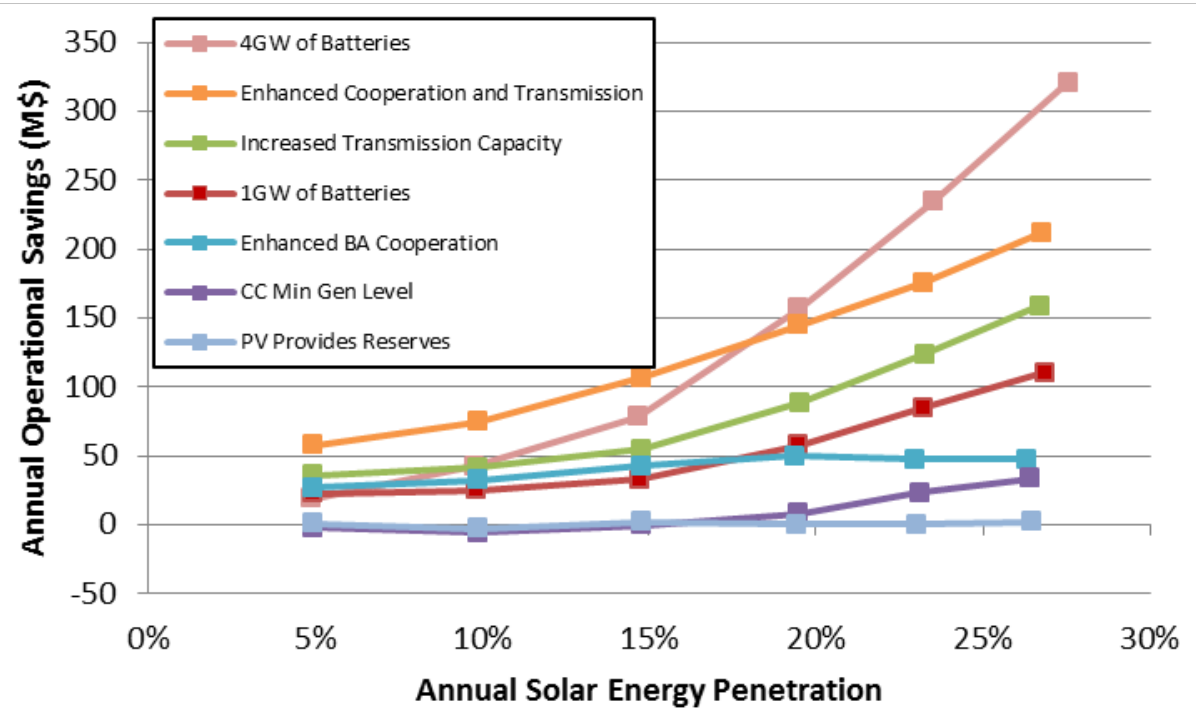

Figure 35. Operational benefits of flexibility options in FRCC.

\subsection{Discussion of Results for Individual Flexibility Options}

The following sections focus on individual flexibility options to demonstrate the degree of effectiveness of these options in increasing the value of PV and their value to the system overall. These sections focus on how the operational value of PV is impacted, because the capacity value portion of PV does not change with these flexibility options.

\subsubsection{PV Providing Reserves}

Allowing PV to provide reserves has the potential to increase the operational value of PV by reducing reserves provided by conventional generators - to the point of turning off more of those generators. This option will reduce the system's minimum generation level and therefore will reduce curtailment. Figure 36 shows how the share of reserves changes between different generator types when PV is allowed to provide reserves. 


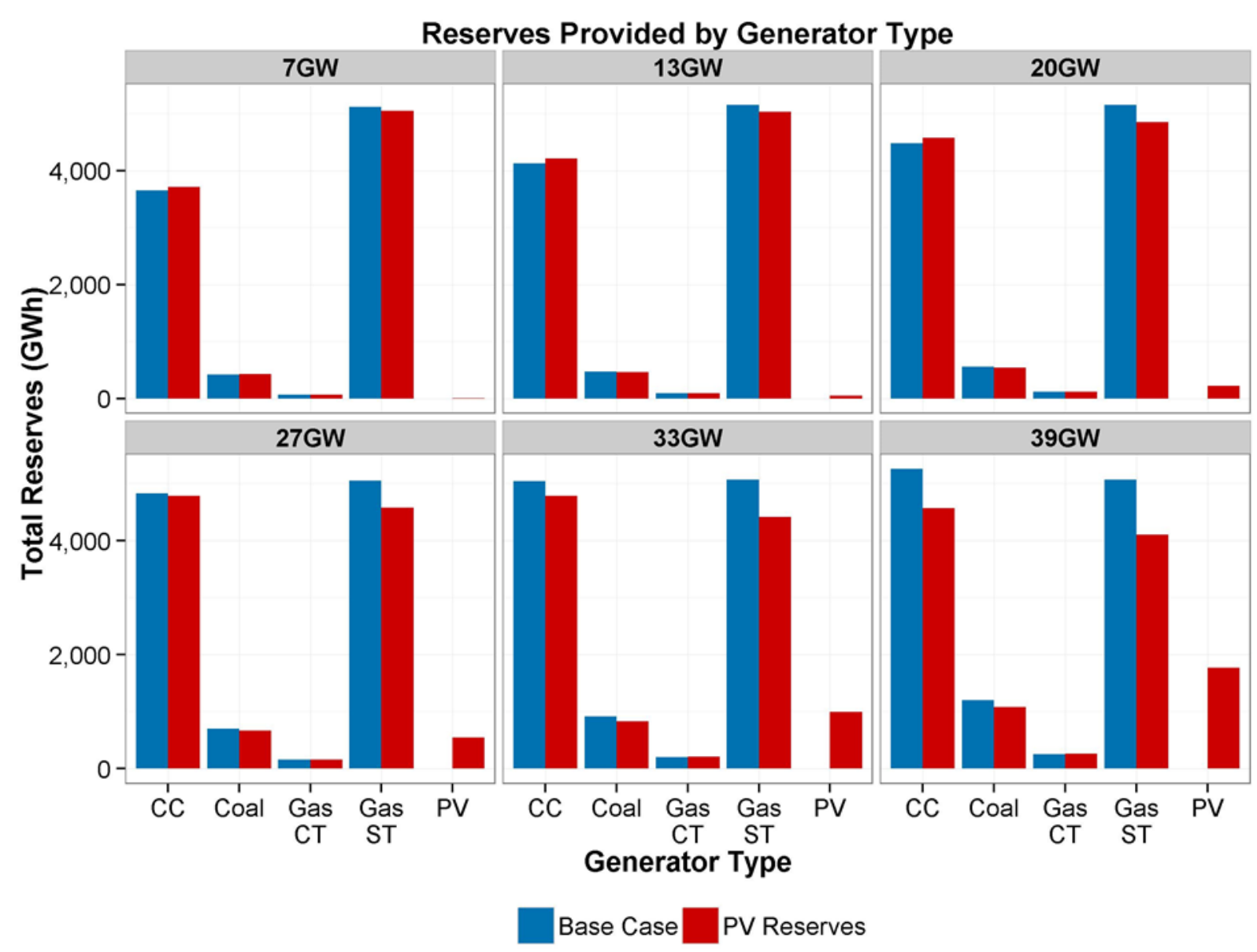

Figure 36. Total reserves provided by generator type for the base case (blue) and when PV is allowed to provide reserves (red), for each PV penetration.

As the penetration of PV increases, more PV is curtailed, thus allowing PV to provide a larger share of the overall reserve provision. However, this does not produce significant increased operational value of PV, as seen in Figure 37. 


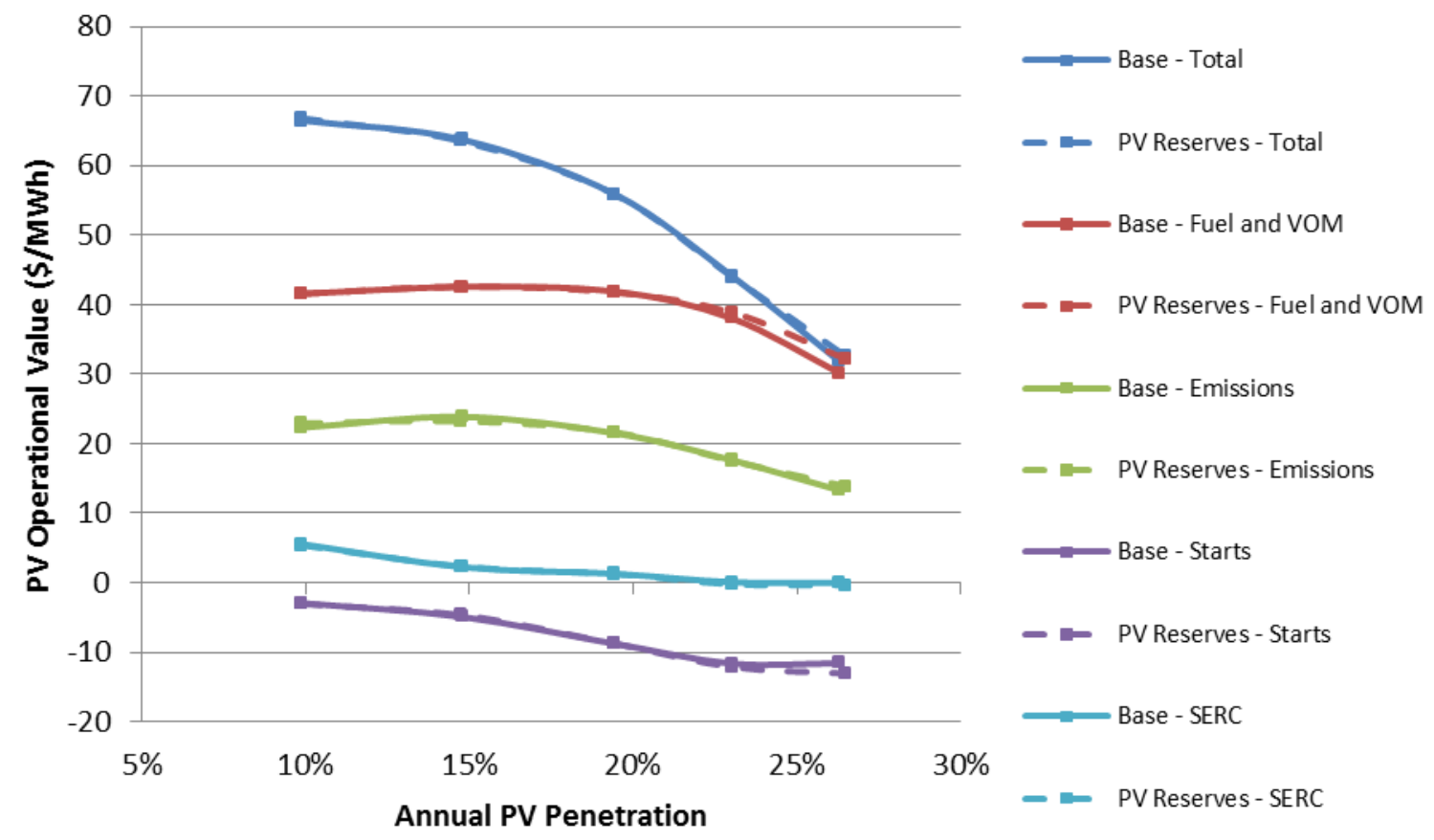

Figure 37. Operational value of PV when allowing PV to provide reserves.

A small benefit is found at the highest penetrations regarding reduced variable operations and maintenance (VOM) and fuel costs when PV is allowed to provide reserves. When PV is allowed to provide reserves, some units may be turned off if they were only on to provide reserves. This allows some reduction in PV curtailment, which displaces conventional generation. However, most of those benefits are eliminated by an increased burden from start costs. Once PV generation falls, the units that were able to turn off because PV was covering their reserves must turn back on to provide energy.

Figure 38 shows how little the online capacity of conventional generation changes between the base cases and when PV is allowed to provide reserves, which highlights why the operational value of PV barely changes. The online capacity lines are only distinguishable at the highest penetration, when some additional capacity shuts down during PV generation. 


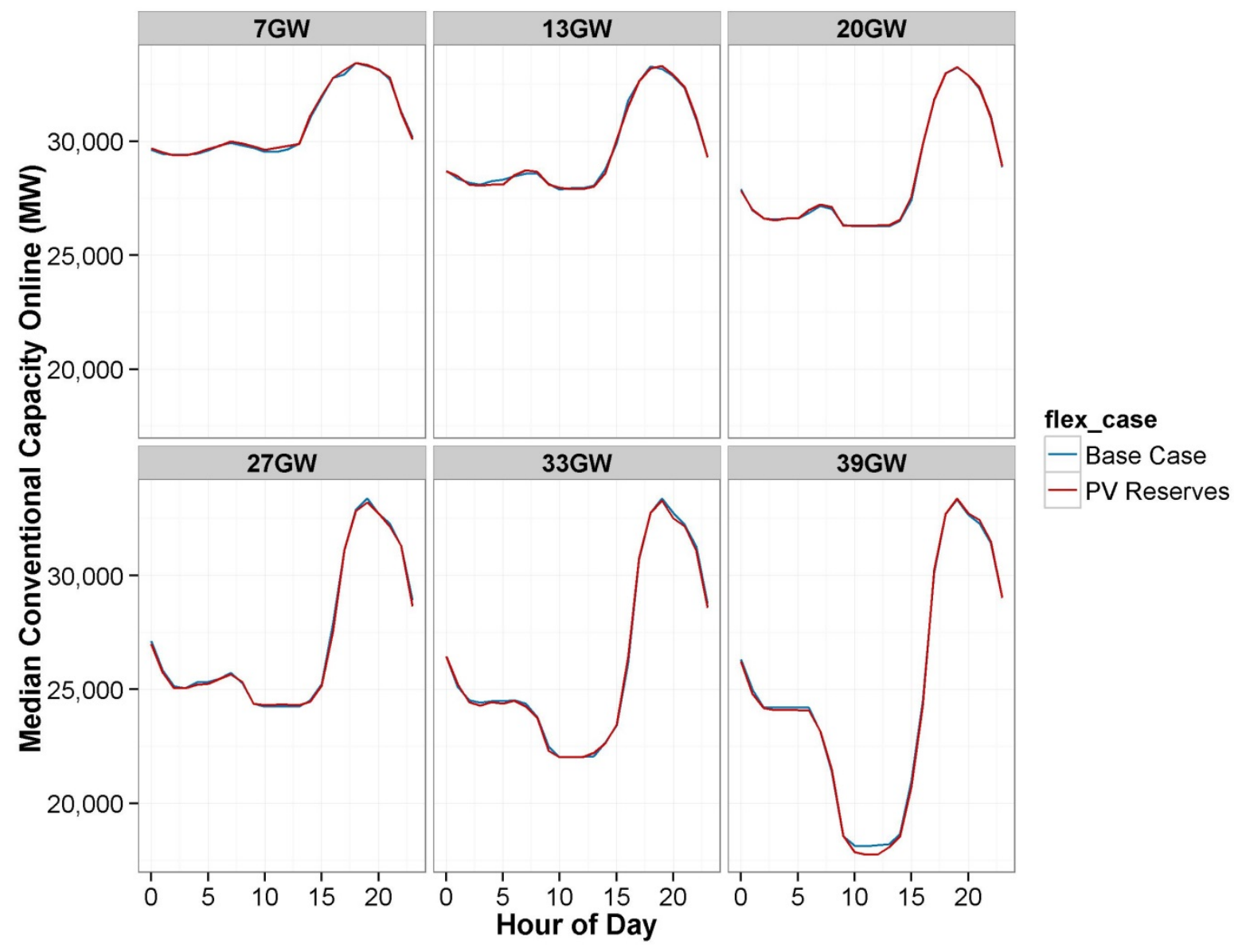

Figure 38. Online capacity during the day between the base case and when PV is allowed to provide reserves for each PV penetration.

As seen in Figure 35, allowing PV to provide reserves provides very little operational value at all $\mathrm{PV}$ penetrations. This outcome is despite the increase in the proportion of reserves served by PV at the higher PV penetrations (Figure 36). This result is somewhat surprising and may reflect some of the limitations in how reserves are modeled. For example, although the ERGIS model calculates the opportunity cost associated with holding reserves, it does not consider the additional cost of varying the output of plants to respond to a regulation signal (Hummon et al. 2013b). As a result, this analysis cannot provide the true value of PV in providing operating reserves. Furthermore, the expected cost of "smart" inverters is relatively small (Palmintier et al. 2016), so the added benefit of providing reserves could be small and still provide an overall savings.

\subsubsection{Combined-Cycle Minimum Generation}

Decreasing the minimum generation level of combined-cycle generators is often considered a means of reducing curtailment because it increases the operational range of thermal generators. However, the value of PV is minimally impacted by decreasing the CC's minimum generation level from $50 \%$ to $40 \%$ of installed capacity. Figure 39 shows the impact of the reduced CC minimum generation level on PV operational value. The largest impact comes from reducing the 
burden of start costs incurred by the system at higher PV penetrations; but overall, the PV operational value range increases only slightly. The primary reason that the value of PV does not change is that reducing the CC minimum generation has little impact on PV curtailment. This section investigates why reducing the CC minimum generation level did not yield larger reductions in curtailment.

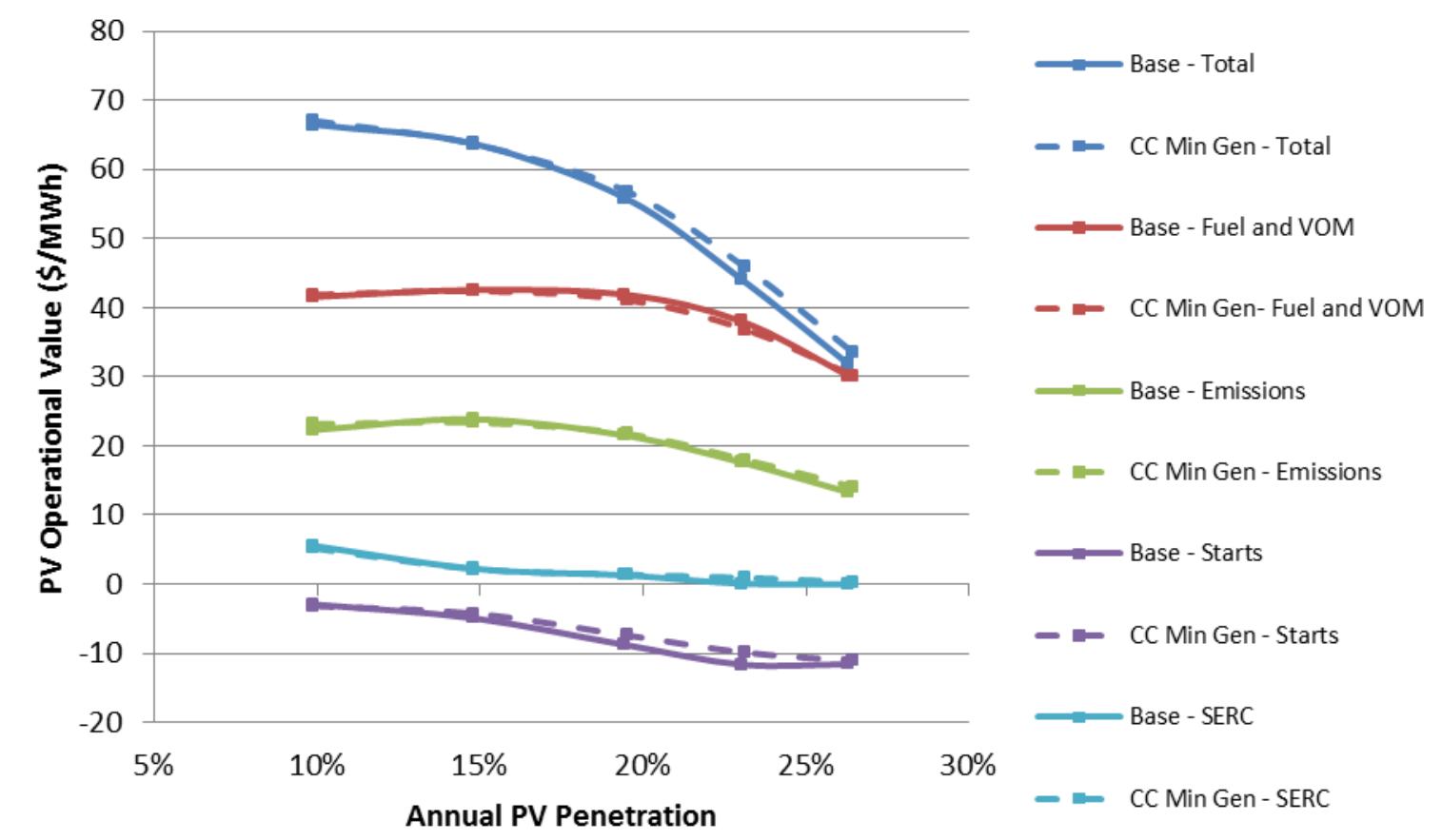

Figure 39. Change in operational value of PV with reduced combined-cycle minimum generation levels.

To help illustrate the impact of CC minimum generation changes, the figures in this section show curtailment and CC operation for a median day for each of the four PV penetrations. Four different days are shown. Days are grouped together based on the daily minimum pre-curtailment net load (total FRCC load less the total available solar energy before curtailment). The graphs show four quartiles - with the first quartile including days with the lowest $25 \%$ of precurtailment net load, and the fourth quartile including days with the highest $25 \%$ of precurtailment net load. This grouping shows how the extra operational range of the CCs is used during days of high curtailment-reduction potential $\left(1^{\text {st }}\right.$ quartile $)$ and on days with less potential ( $4^{\text {th }}$ quartile). The base case (no flexibility options) is compared next to the results from reducing the CC minimum generation level to $40 \%$ of maximum capacity.

Figure 40 shows the median curtailment over the day for all four groupings of days and both the base case and when CC minimum generation level is reduced. The first result to note in this figure is the large portion of curtailment that occurs on days in Quartile 1 and its even distribution around peak solar output. This emphasizes the importance of reducing the system's minimum generation level. For lower penetrations in Quartile 2 and all penetrations in Quartiles 3 and 4, the shape of the curtailment curves is skewed, with peak curtailment occurring in the late morning. The final result to note from Figure 40 is how nearly indistinguishable the curtailment curves are for both the base case and the reduced $\mathrm{CC}$ minimum generation case, 
particularly for Quartile 1. For the periods with the most curtailment-reduction potential, reducing CC minimum generation levels appears to offer little benefit.

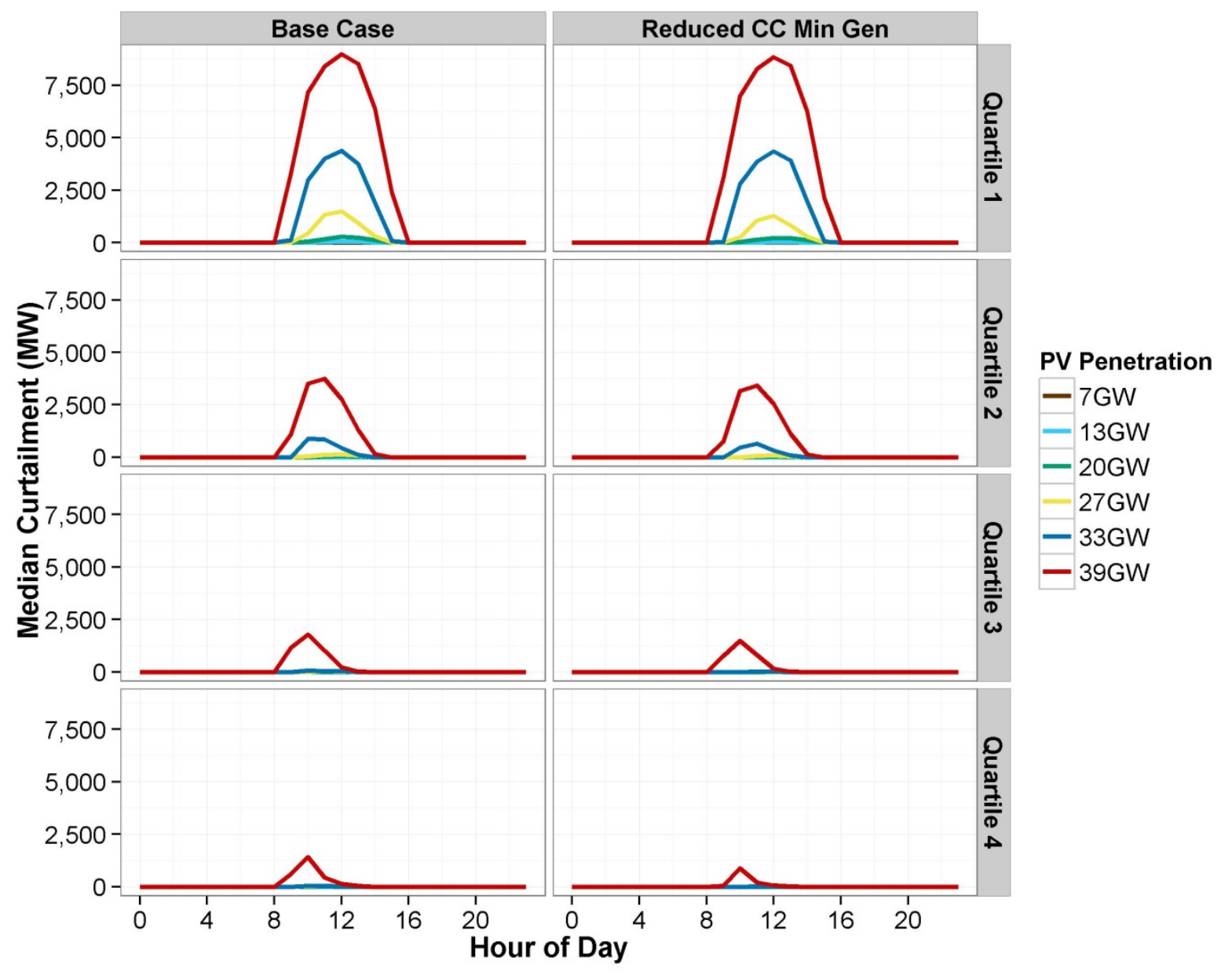

Figure 40. Median curtailment for both scenarios (Base Case and Reduced CC Minimum Generation Level).

Figure 41 illustrates the total CC capacity online throughout the day. As expected, the plots show large amounts of capacity shut-down during the middle of the day for the high penetrations on days with the lowest minimum net load. What is perhaps surprising is how little the total online capacity changes when $\mathrm{CC}$ minimum generation levels are reduced. Across all penetrations for each type of day (Quartile), reducing the $\mathrm{CC}$ minimum generation level either keeps total online $\mathrm{CC}$ capacity the same or increases it slightly during hours of solar generation. This suggests that reducing the minimum generation level of CC encourages some generators to remain online during the day, likely operating at their new minimum generation level of $40 \%$. They remain online to avoid having to incur start-up costs in the evening when solar generation decreases. However, the vast majority of CCs still shut down during the middle of the day at the higher penetrations of PV and start up again in the evening. 


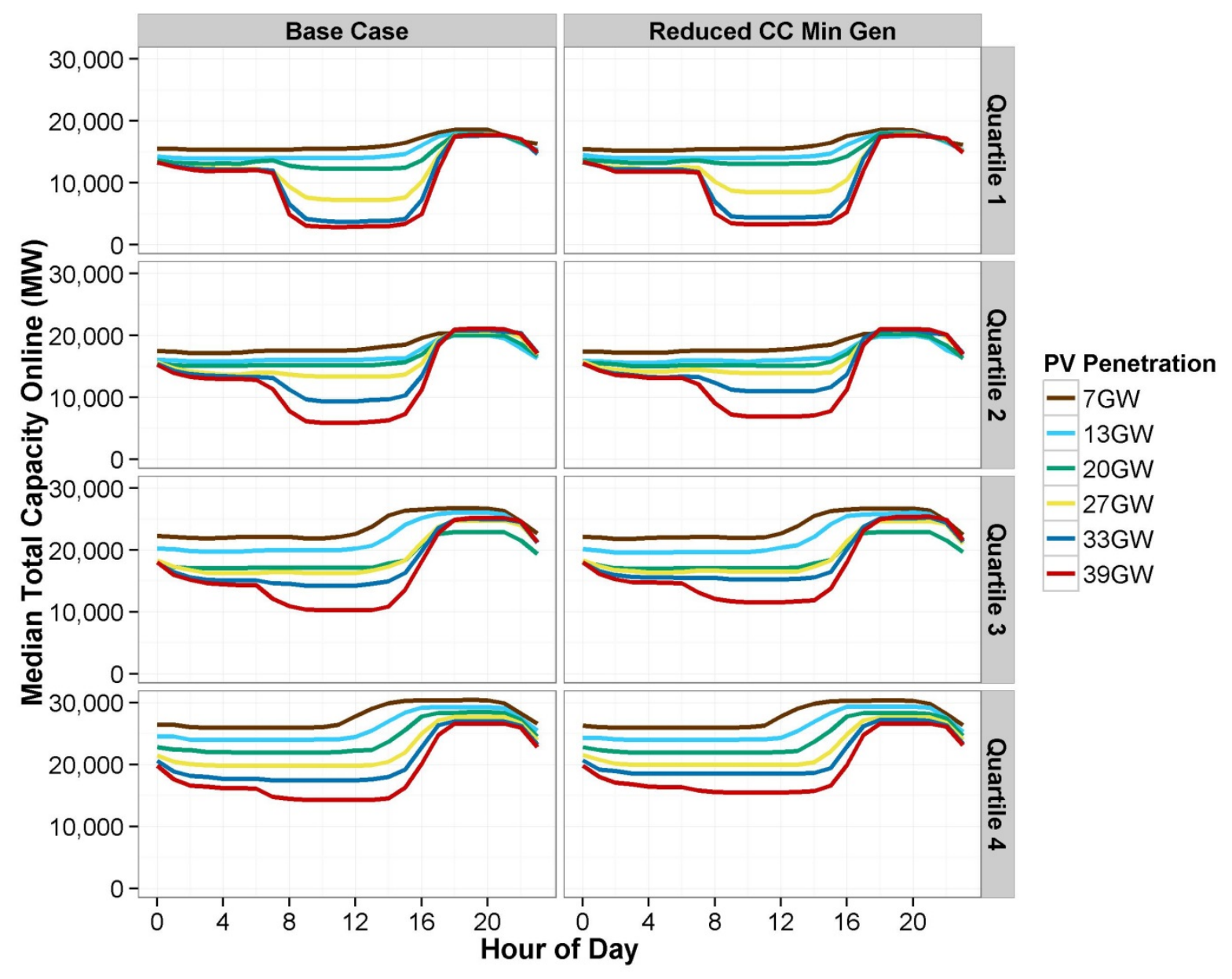

Figure 41. Median total combined-cycle capacity online.

Figure 42 presents exactly how much below the original 50\% minimum generation level the FRCC CCs are actually operating. In Quartile 1, the highest PV penetration uses less of the additional operational range than the middle PV penetrations. This emphasizes the importance of how much capacity is actually online during peak solar generation (Figure 41). Even though the CCs are able to turn down to a lower generation level, the vast majority of CCs are turned off, which drastically limits the ability of this flexibility option to impact curtailment. On aggregate, FRCC gained nearly $4 \mathrm{GW}$ of additional operational range; however, on the days with the highest solar curtailment (Quartile 1), the additional operating range is only about $400 \mathrm{MW}$, which has a minimal impact on the system's minimum generation level considering curtailment approaches 9 GW (Figure 40).

On days with less curtailment (Quartiles 2-4), more of the extra capacity is used at the higher penetrations, because there is more capacity online to be able to operate in the increased range. However, the usage of the additional range is never greater than 1,500 MW. 


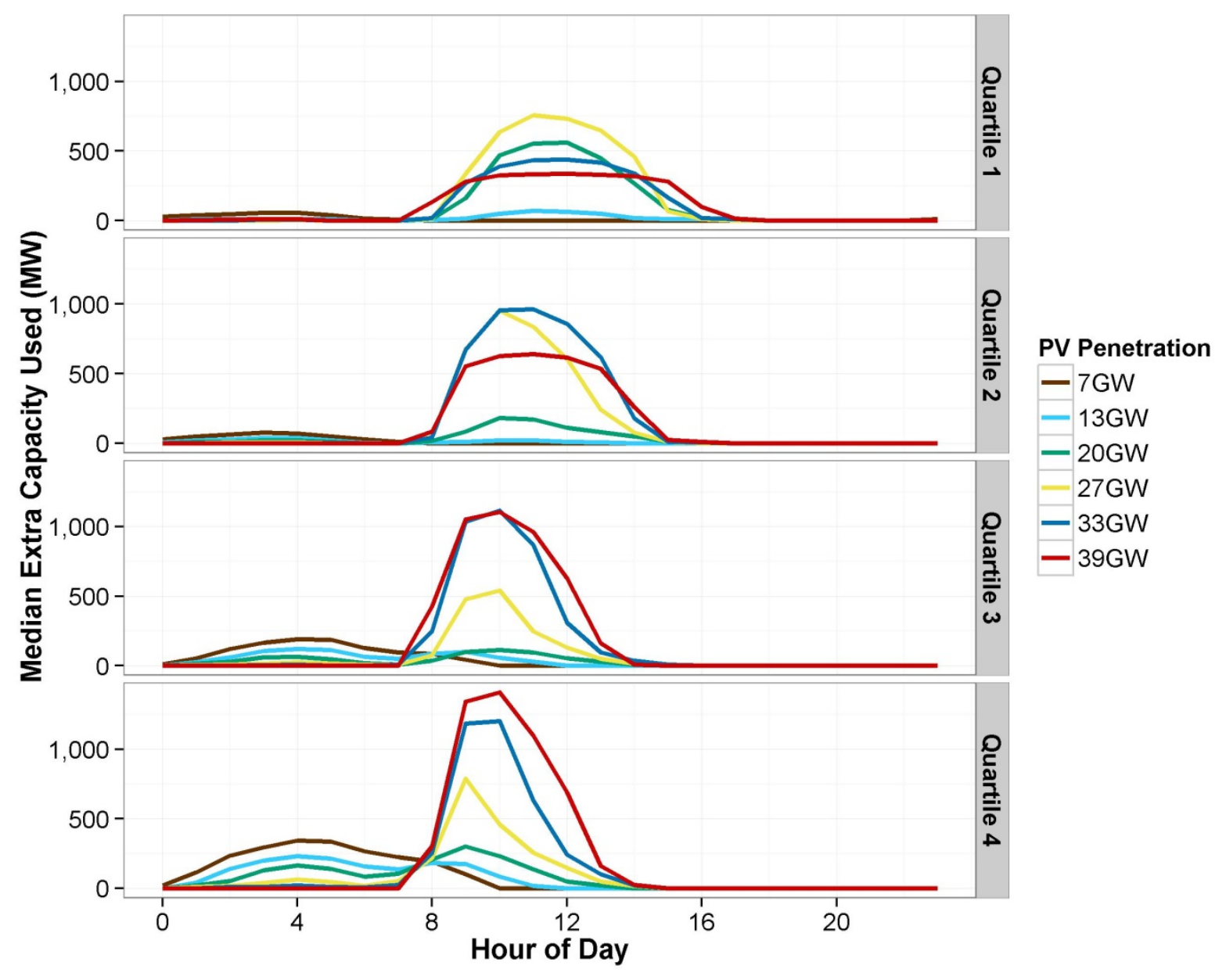

Figure 42. Median extra capacity used by combined cycles. Additional extra capacity is defined as the amount below $\mathbf{5 0 \%}$ of installed capacity that a particular unit is operating.

The results discussed in this section explain why reducing the minimum generation level of CCs did not result in a significant reduction in curtailment. Because most of the $\mathrm{CC}$ units are already shut down in the middle of the day, the gain in headroom does not substantially decrease curtailment.

Figure 43 shows that the operational savings is directly correlated to reduced PV curtailment. 


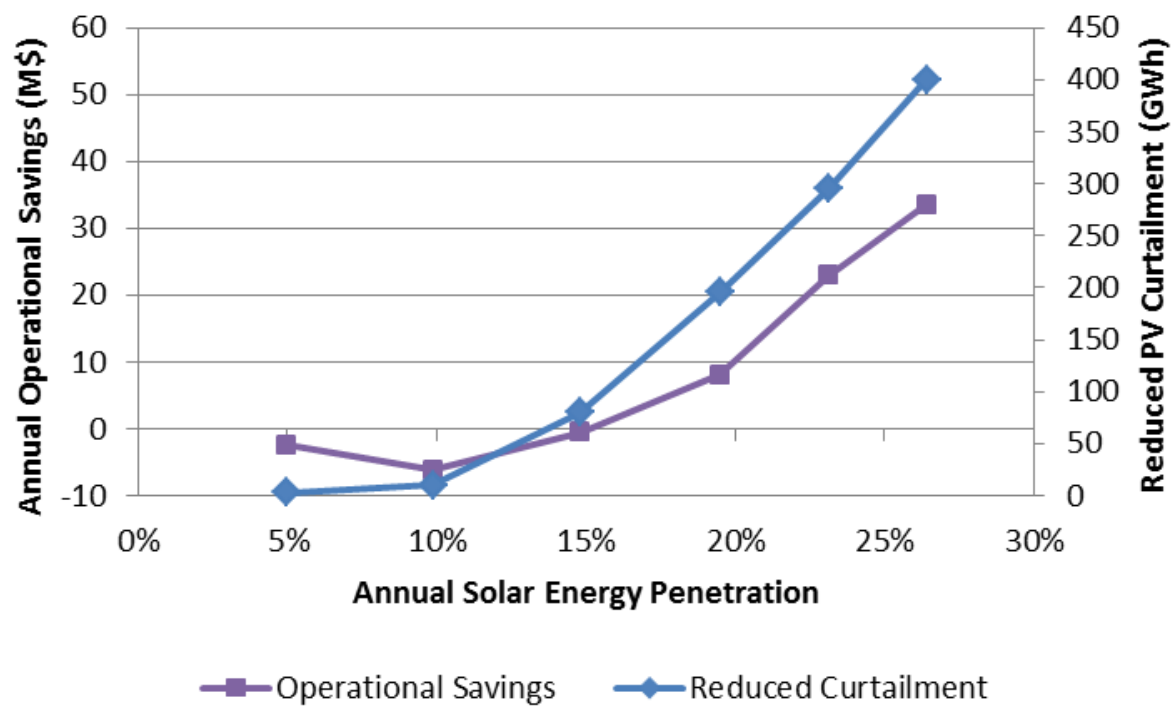

Figure 43. Annual operational savings and reduced curtailment with reduced minimum generation levels of combined cycles.

Many combined-cycle units operate with a minimum generation level at or below $40 \%$. Additional discussion of costs of increasing flexibility of existing plants is provided by Venkataraman et al. (2013).

\subsubsection{Enhanced BA Cooperation}

Increasing BA cooperation in FRCC includes two changes to the FRCC system. First, hurdle rates between regions are removed. This allows the most-efficient generators to meet load anywhere in FRCC (when transmission is not congested). This will reduce production costs of the system, but does not necessarily assist with the integration or increase the value of PV.

The second change removes the requirement for each BA to provide its own reserves, and it creates a single FRCC reserve product for both regulation and contingency. This allows reserves to be provided more efficiently, because there are fewer constraints on which generators can provide reserves. Also, on aggregate, the single FRCC product requires a smaller provision of reserves compared to all of the BA reserve products combined. This is because the reserve provision for a regulation reserve product is determined by the PV variability within the region. By combing the BAs into one region, the aggregate PV profile for FRCC is less variable due to geographic diversity of the PV capacity. Reducing the reserve requirement of the system sufficiently may reduce the total system's minimum generation level, allowing PV to hit a higher instantaneous penetration and therefore reducing curtailment. Figure 44 shows the reduction of the total reserve requirement between the base case and enhanced BA cooperation as the penetration of PV changes. 


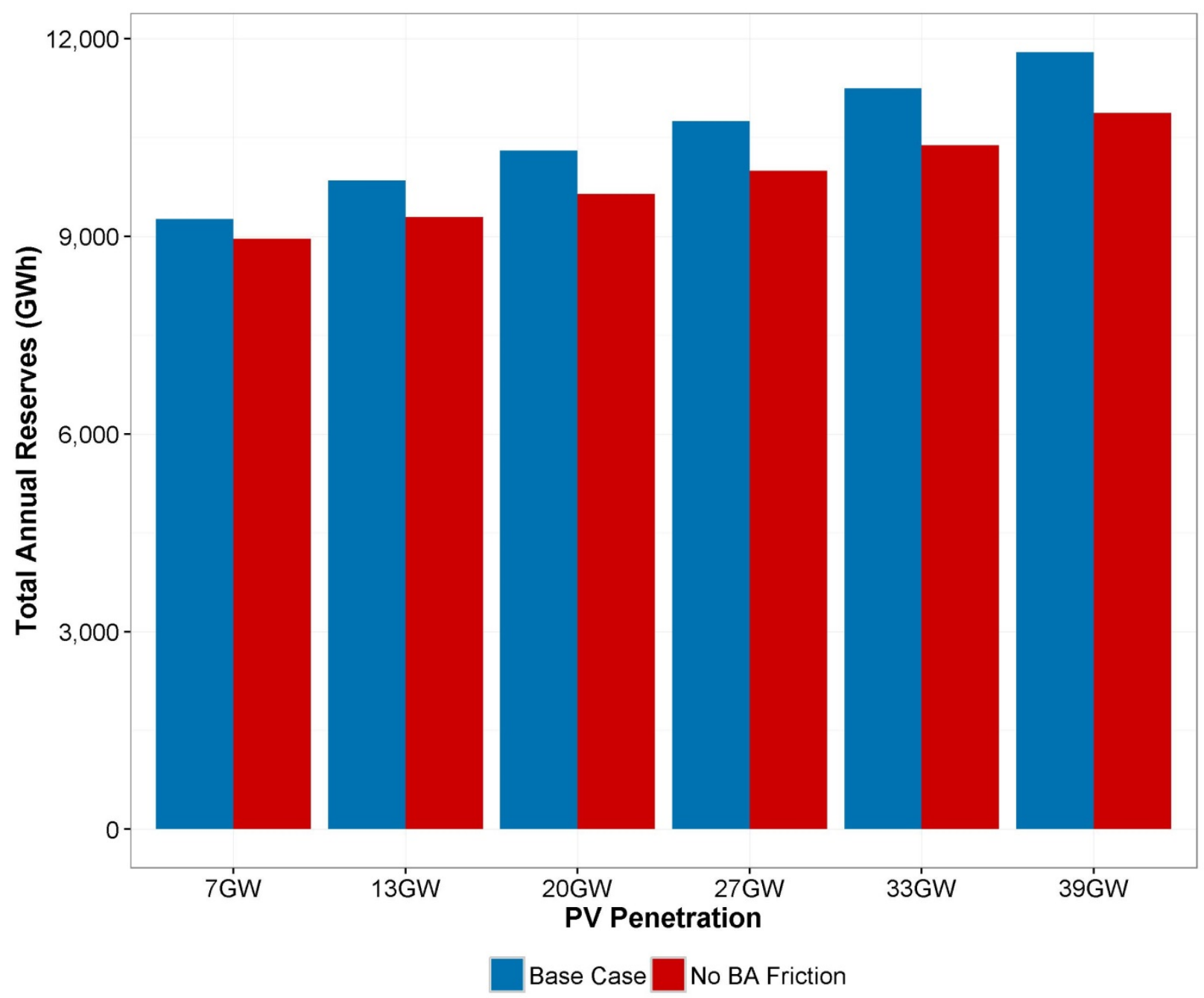

Figure 44. Change in the total reserve requirement when reducing BA friction for each PV penetration.

The total reserve requirement is reduced. However, this does not result in much of a change in the operational value of PV, as seen in Figure 45. It also did not lead to a significant change in curtailment (Figure 32). At $39 \mathrm{GW}$ of installed capacity of PV, total curtailment is only reduced by 0.25 percentage point, or $184 \mathrm{GWh}$. 


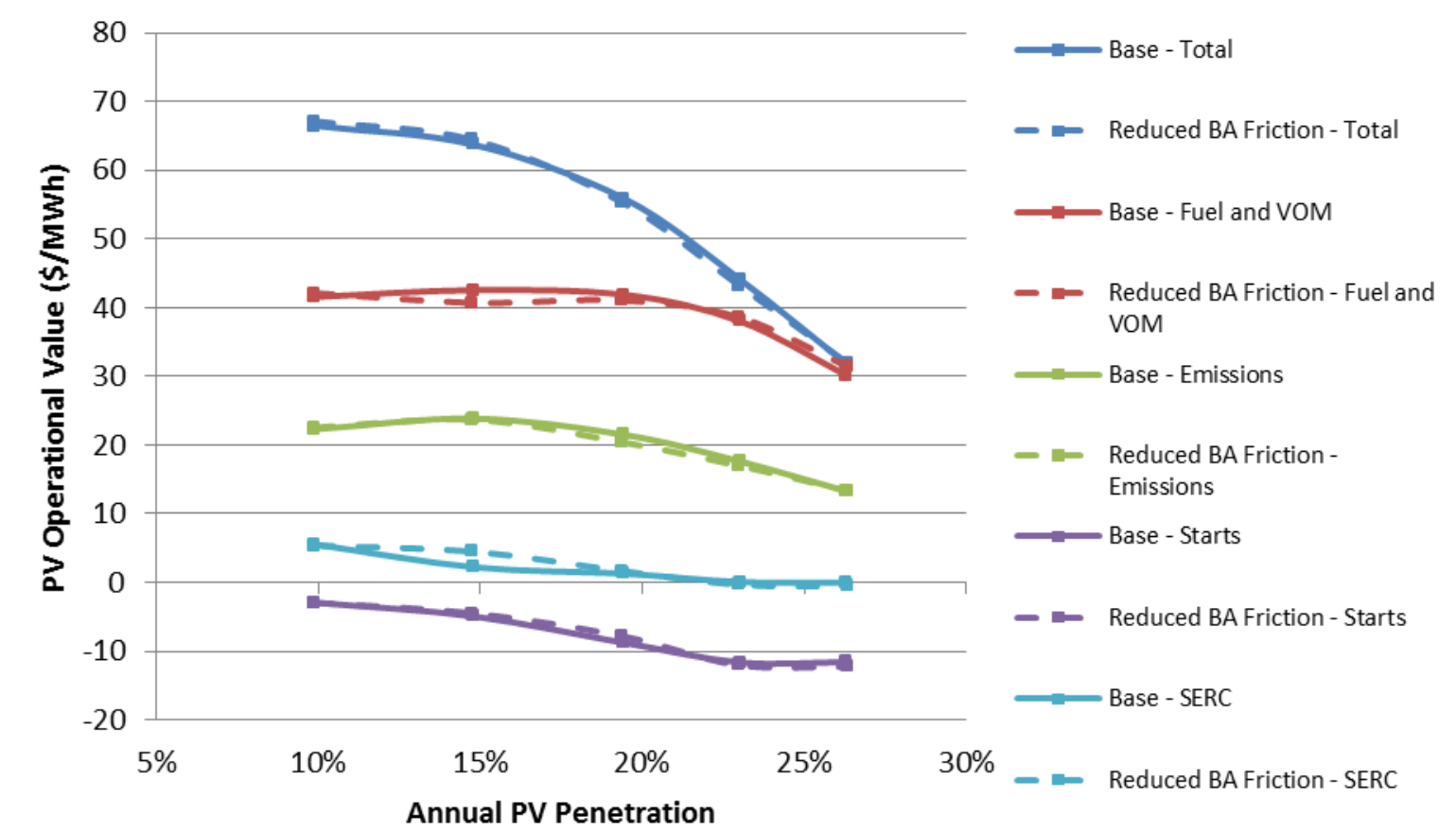

Figure 45. Change in PV operational value when enhancing BA cooperation in FRCC.

Figure 46 shows how the online capacity of CCs, CTs, and the flow on the SERC interface changes with enhanced BA cooperation. The main difference between the base case and this flexibility option is a reduced reliance on SERC and increased exports during PV generation at higher PV penetrations. FRCC is able to more fully take advantage of its most-efficient generators with enhanced BA cooperation. Therefore, the price difference between SERC and FRCC is less likely to be greater than the hurdle rate $(\$ 10 / \mathrm{MWh})$ between the two regions. 


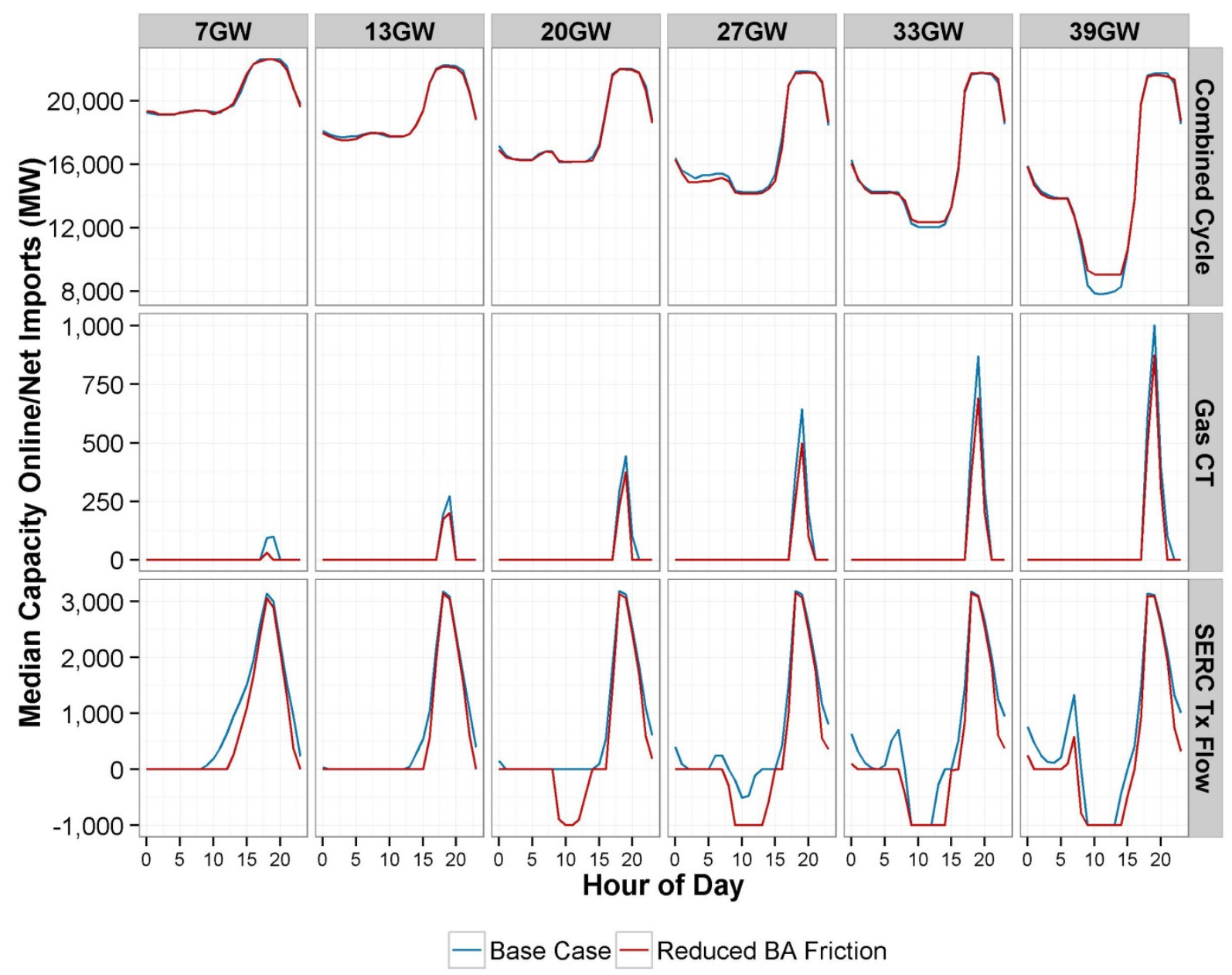

Figure 46. Change in CC and CT capacity online and flow on the SERC-FRCC interface when enhancing BA cooperation in FRCC, for each PV penetration.

$\mathrm{CC}$ and $\mathrm{CT}$ online capacity is largely unchanged between the base case and this flexibility option. This indicates that reducing the total reserve requirement over the year did little to reduce the system minimum generation level, and therefore, it did not reduce PV curtailment or increase the operational value of PV.

Unlike reducing the $\mathrm{CC}$ minimum generation level, the annual operational savings when enhancing BA cooperation has very little correlation with the change in PV curtailment, as shown in Figure 47. The savings are primarily due to the reduced reserve requirements when all reserves are shared across FRCC and the ability of the region to take greater advantage of the most-efficient generators. 


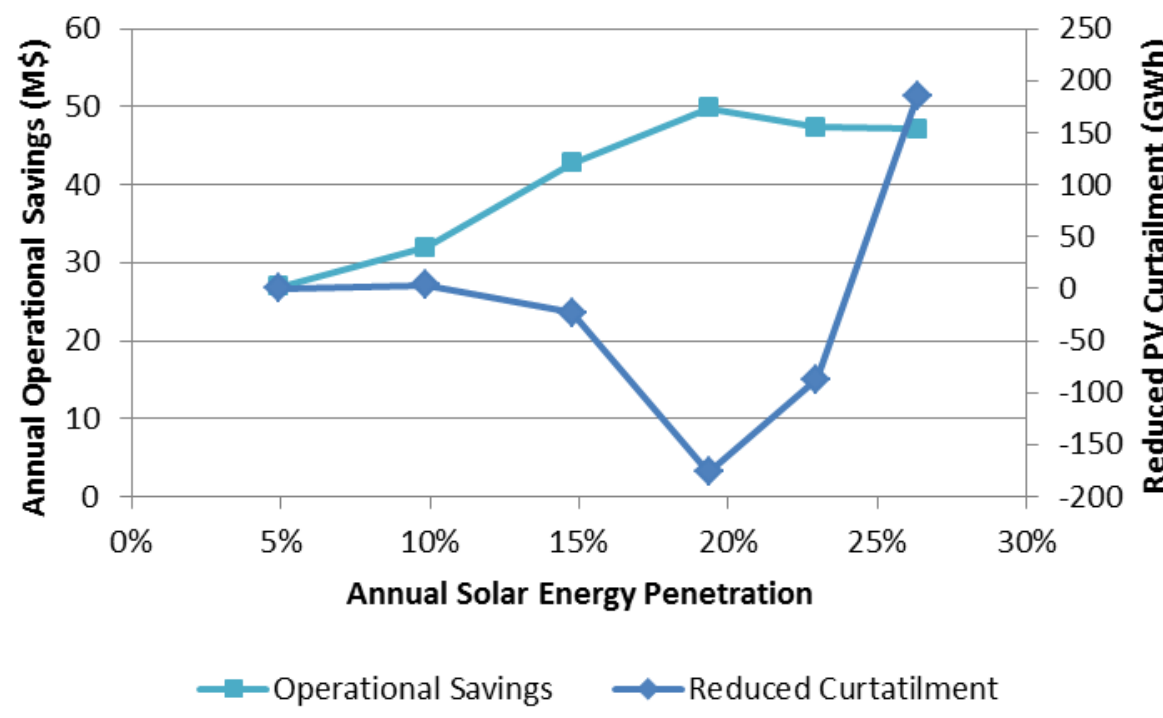

Figure 47. Annual operational savings and reduced curtailment with enhanced BA cooperation.

Enhancing cooperation in FRCC would primarily consist of removing market friction involved in generation commitment and dispatch. This would allow the most-efficient generators to be scheduled, regardless of in which BA they are located. Enhanced cooperation would also allow for more-efficient reserve scheduling. Ignoring the policy challenges associated with implementing this flexibility option, costs would include installing the needed communication infrastructure and software development and licensing. For comparison, the cost of implementing the expanded Energy Imbalance Market (EIM) across the WECC was estimated as a one-time cost of \$19.6 million (CAISO 2015). Peak load in WECC is about 3-4 times larger than that of FRCC. Therefore, it is reasonable to expect that enhanced cooperation between BAs in FRCC will likely cost less than $\$ 19.6$ million. Even at the 5\% PV penetration, the annual savings from enhanced BA cooperation of $\$ 25$ million is likely greater than the implementation cost of enhancing BA cooperation.

\subsubsection{Energy Storage}

Figure 48 shows the changes in the different components of the operational value of PV when adding the different-sized storage deployments. 


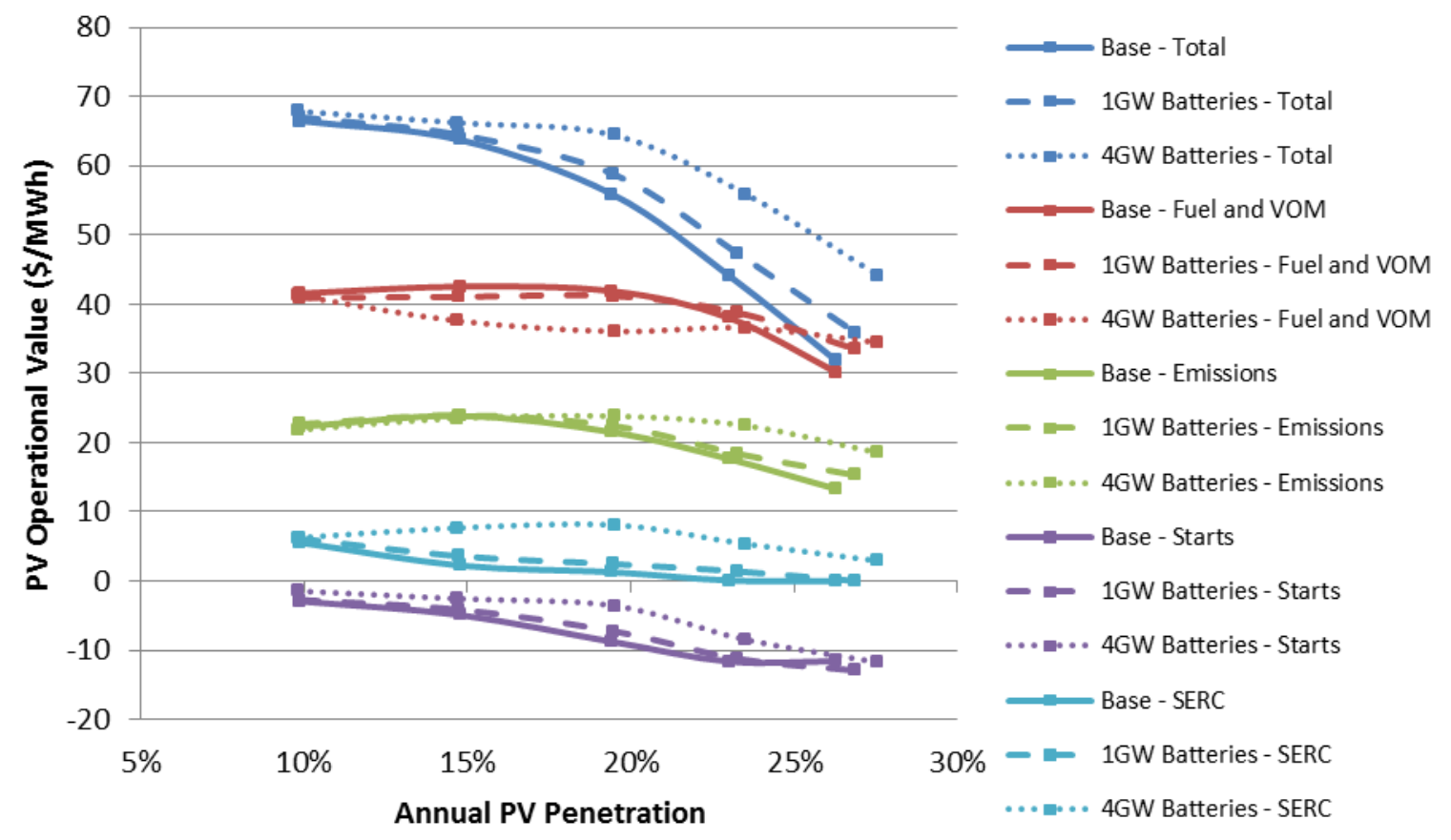

Figure 48. Change in PV operational value with energy storage.

As was seen in Figure 34, both storage deployments increase the value of PV. Most of the increased value comes from reducing net imports from SERC and reducing the cost of starts and stops. The fuel and VOM portion of the PV operational value does not increase by adding energy storage until the highest penetration that we studied. This suggests that the base case (no flexibility option) relies on imports from SERC and on starting generators to meet load as solar ramps down in the evening. The batteries remove some of the need to import and to start quickstart generators to deal with the increased net-load ramp by discharging during the early evening hours. The batteries can also reduce start costs by keeping CCs online during the solar peak that otherwise would have needed to shut down during the day, only to be turned back on in the evening. Figure 49 shows the change in net imports from SERC and the CC and CT online capacity. 


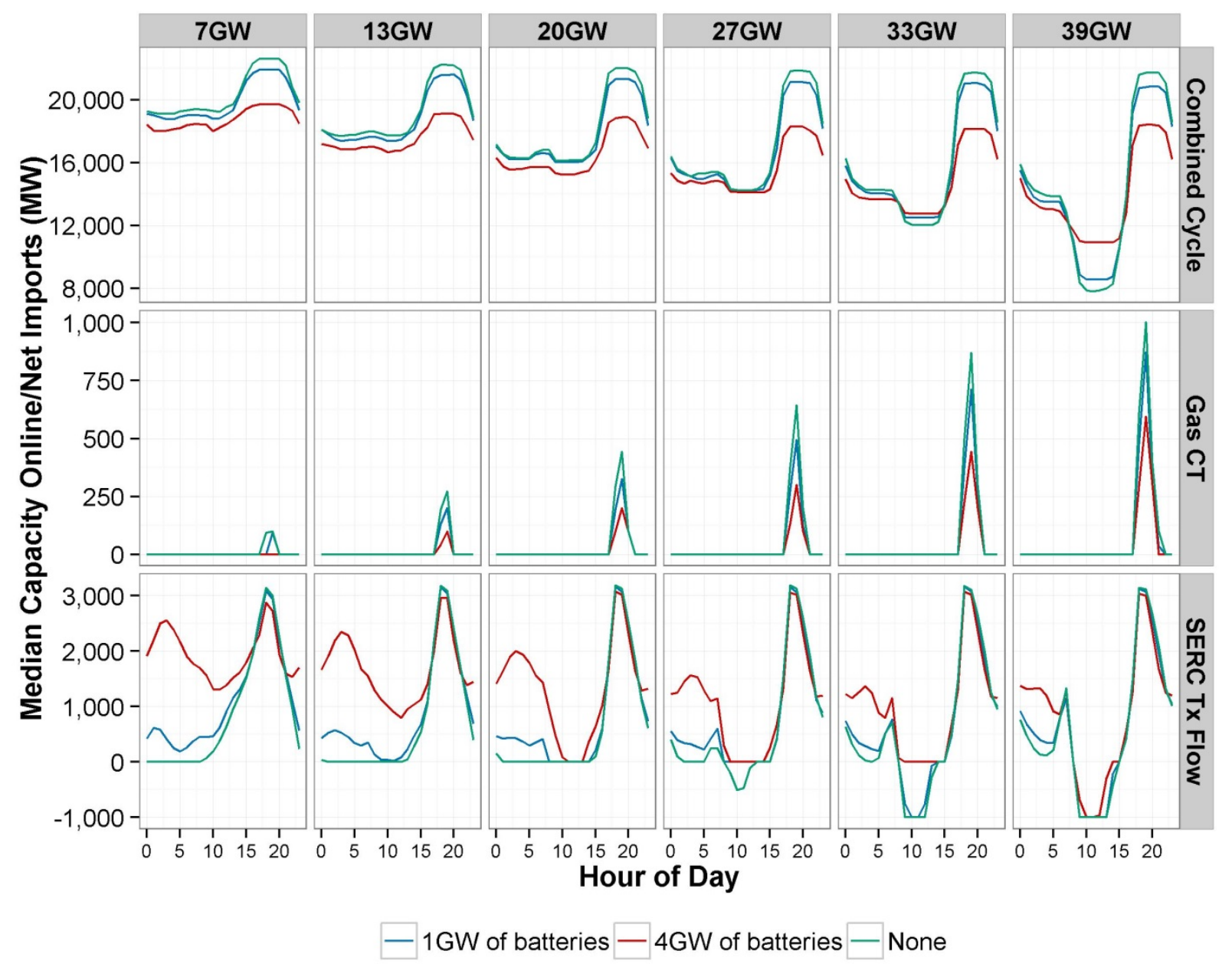

Figure 49. Change in SERC net imports, CC online capacity, and CT online capacity when adding energy storage, for each PV penetration.

At peak net-load times (between $4 \mathrm{pm}$ and $9 \mathrm{pm}$ ), the batteries reduce the online capacity of CCs and reduce the number of CTs started to help with peak. This is true across all PV penetrations, and the magnitude of the reduction in peak capacity online is essentially the same, as highlighted in Figure 50. The peak discharge (peak positive value) does not change significantly across the different PV penetrations. The shape of the discharge profile also does not change significantly, but simply becomes narrower at higher penetrations as some of the PV is able to help with afternoon load. What does change is the peak and shape of the charging profile (negative values). At the low PV penetrations, storage charging occurs overnight, when load is low and mostly baseload plants are on. However, charging shifts to daytime hours as more PV is added to the system. At the three lowest penetrations, this leads to less CC capacity online at all hours of the day (Figure 49). However, this changes with more PV. During high charging periods, there is actually more CC capacity online. This means that even during periods of high PV generation and possible curtailment, the batteries are used to keep CC units from shutting down. 
Batteries also change the interaction with SERC. In the lower PV penetrations, the storage scenarios increase imports from SERC in the early morning hours. The batteries in FRCC in these cases are charged using SERC generation (most likely coal). However, as the penetration of PV increases, imports from SERC in early morning hours drop significantly. This relative drop in the reliance on SERC imports is what decreases the burden of SERC imports on the value of PV in FRCC (Figure 48).

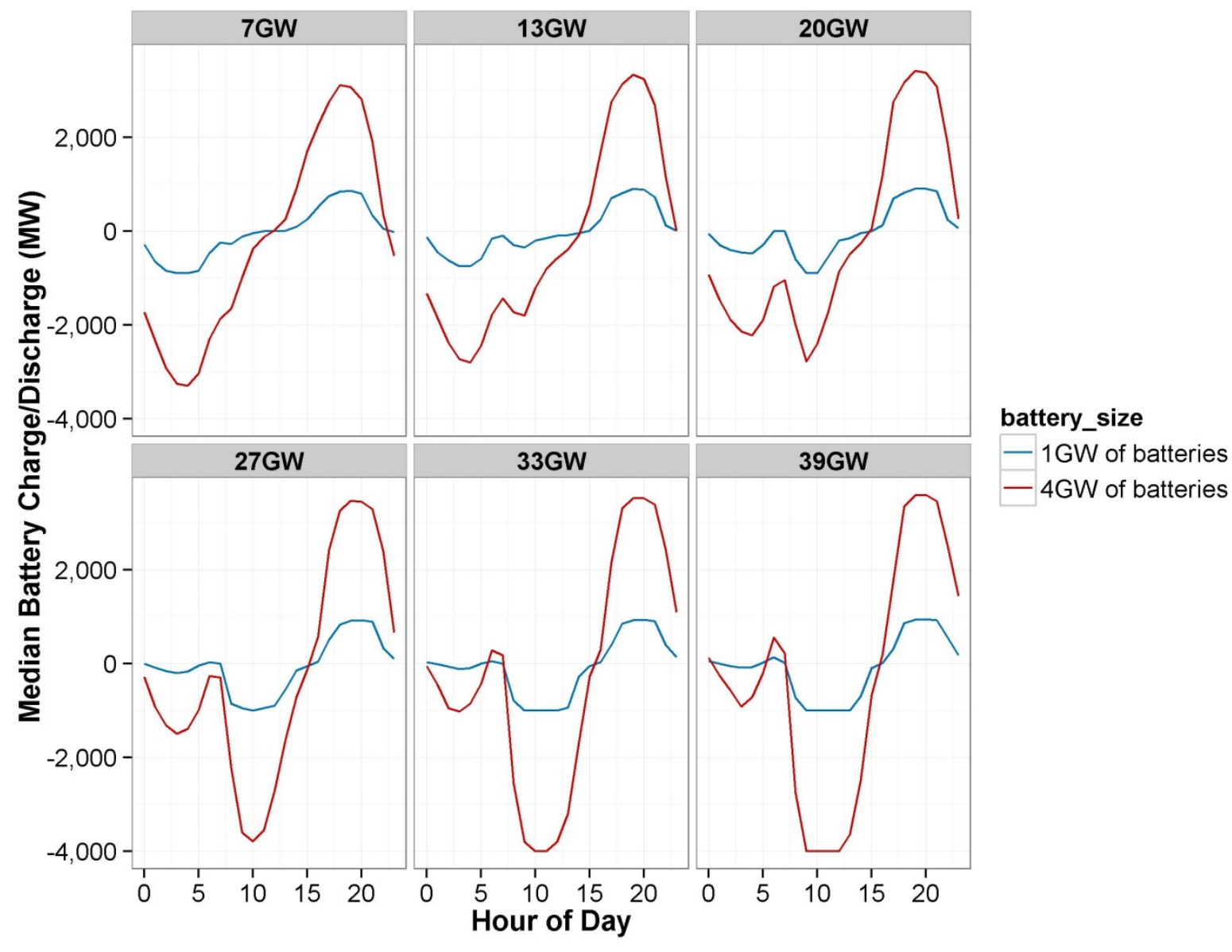

Figure 50. Median storage operations over the day. Positive values are the storage discharging, whereas negative values are the storage charging, for each PV penetration.

These plots demonstrate why adding energy storage primarily helps to reduce start/shutdown costs and economic imports of power from SERC during early-morning hours when storage is added with smaller PV penetrations. The storage displaces the need for evening startups of CTs and CCs at peak times and reduces the morning imports from SERC.

Figure 51 compares the reduction in PV curtailment and annual operational savings of the two battery flexibility scenarios ( $1 \mathrm{GW}$ of batteries and $4 \mathrm{GW}$ of batteries). For both battery sizes, savings increases substantially due to reductions in curtailment. 

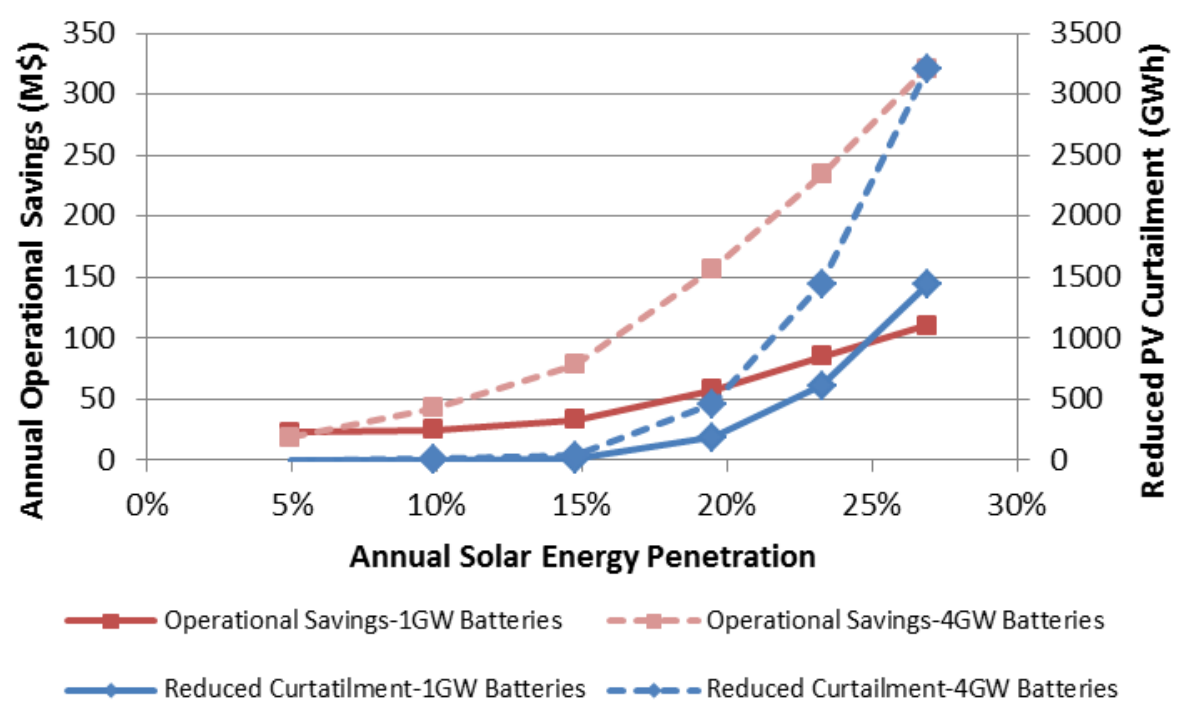

Figure 51. Annual operational savings and reduced curtailment with enhanced BA cooperation.

Figure 51 accounts the PV curtailment from storage losses when PV generation is used to charge batteries. These losses are an additional source of PV curtailment that suppresses the system operational savings. Calculating storage-loss curtailment requires knowledge of the amount of PV generation used to charge the batteries, but this is impossible to know exactly because we cannot determine which generation types are charging the batteries at any given time. Therefore, we must estimate storage-loss curtailment by using the 5-minute real-time operations results from the base case and storage case.

We know that only $80 \%$ of the energy used to charge the battery can be used later due to the assumed roundtrip efficiency of the batteries. For that reason, storage-loss curtailment is $20 \%$ of the PV generation used to charge the batteries. We estimate the amount of PV generation charging the batteries to be one of two values: either the reduction in PV curtailment between the storage case and the base case, or the total amount of battery charging. The estimated PV generation charging the batteries is the minimum of the two.

For example, at a given time, assume that batteries are storing $900 \mathrm{MW}$, and the storage case decreases curtailment by $300 \mathrm{MW}$ from the base case. This means that $300 \mathrm{MW}$ of the $900 \mathrm{MW}$ charging the batteries is PV generation that would otherwise be curtailed. The other $600 \mathrm{MW}$ originate from another source. For this situation, storage losses contribute $60 \mathrm{MW}$ of PV curtailment $(20 \%$ of $300 \mathrm{MW})$. This means that battery storage only decreased total curtailment by $240 \mathrm{MW}$ - not the $300 \mathrm{MW}$ as previously assumed.

If curtailment is instead reduced by 1,000 MW while the battery charging is at $900 \mathrm{MW}$, then PV generation is responsible for $100 \%$ of the charging that is occurring. The additional reduction of $100 \mathrm{MW}$ of PV curtailment is due to changes in the unit commitment and dispatch between the base case and the storage case. In this case, storage losses lead to $180 \mathrm{MW}(20 \%$ of $900 \mathrm{MW})$ of curtailment, and total curtailment is actually reduced by only $820 \mathrm{MW}$, rather than 1,000 MW. 


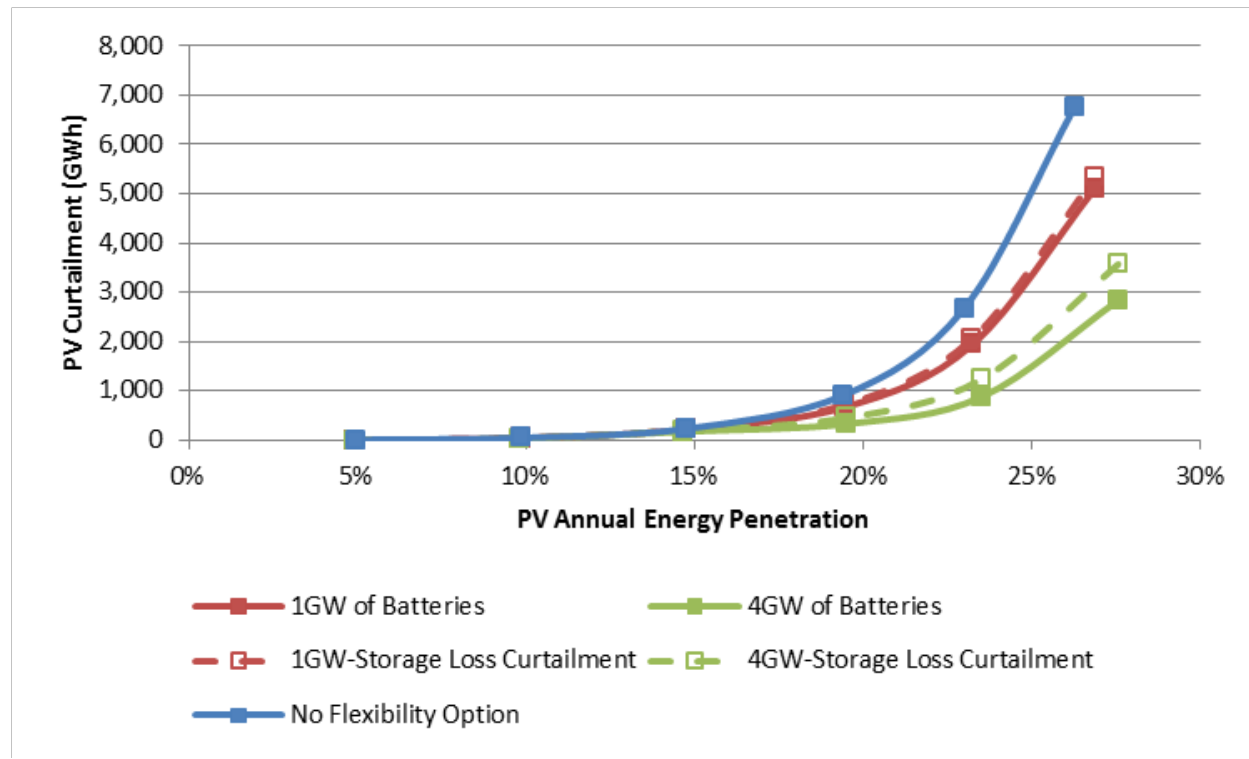

Figure 52. Real-time PV curtailment when including (dotted lines) and not including (solid lines) curtailment due to storage losses.

Figure 52 shows the impact of including the efficiency losses as curtailment. This additional curtailment is important because it accounts for a reduction in total PV value and the operational savings that may not be apparent when only considering traditional curtailment (i.e., reduction in output at the PV generator). Storage losses only add a modest amount of curtailment in the smaller-battery deployment, but have a larger impact in the larger-battery deployment. 


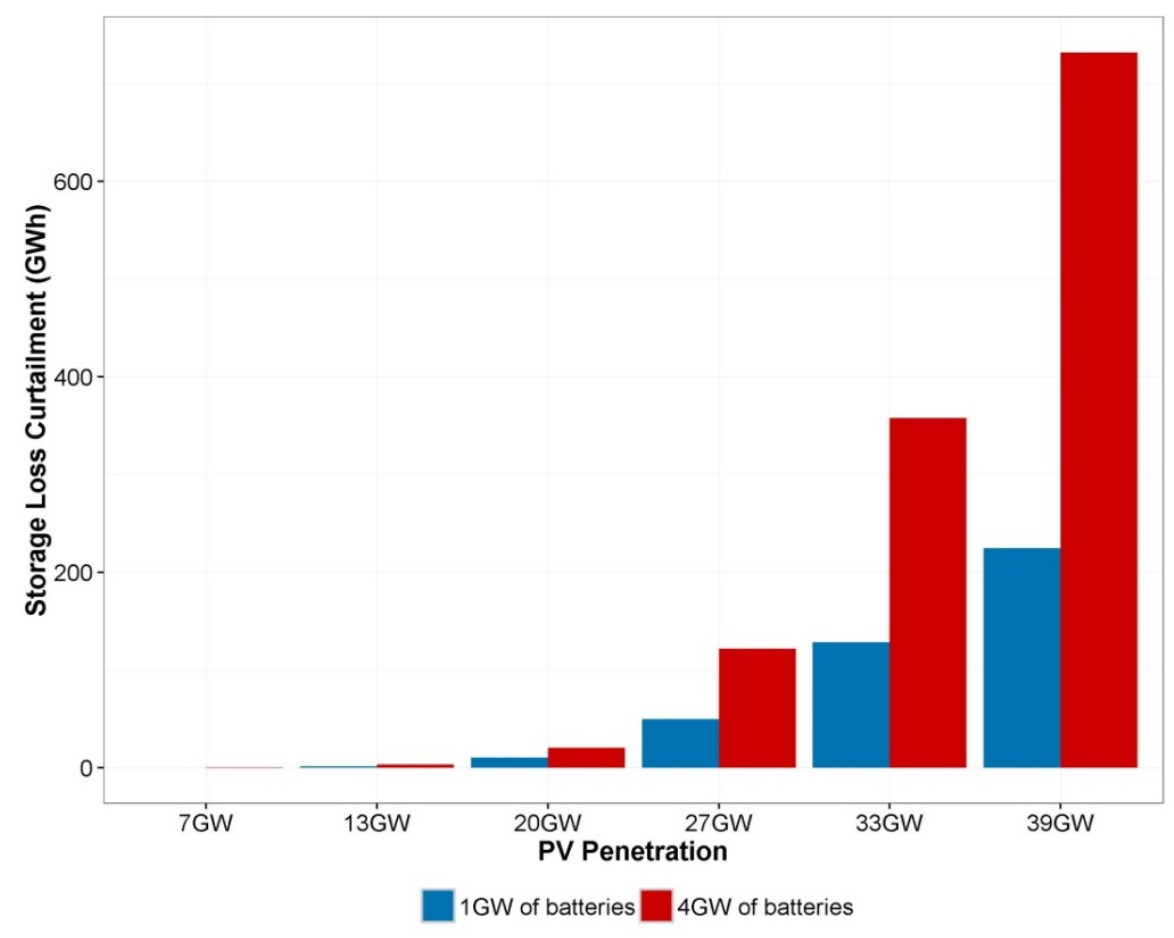

a)

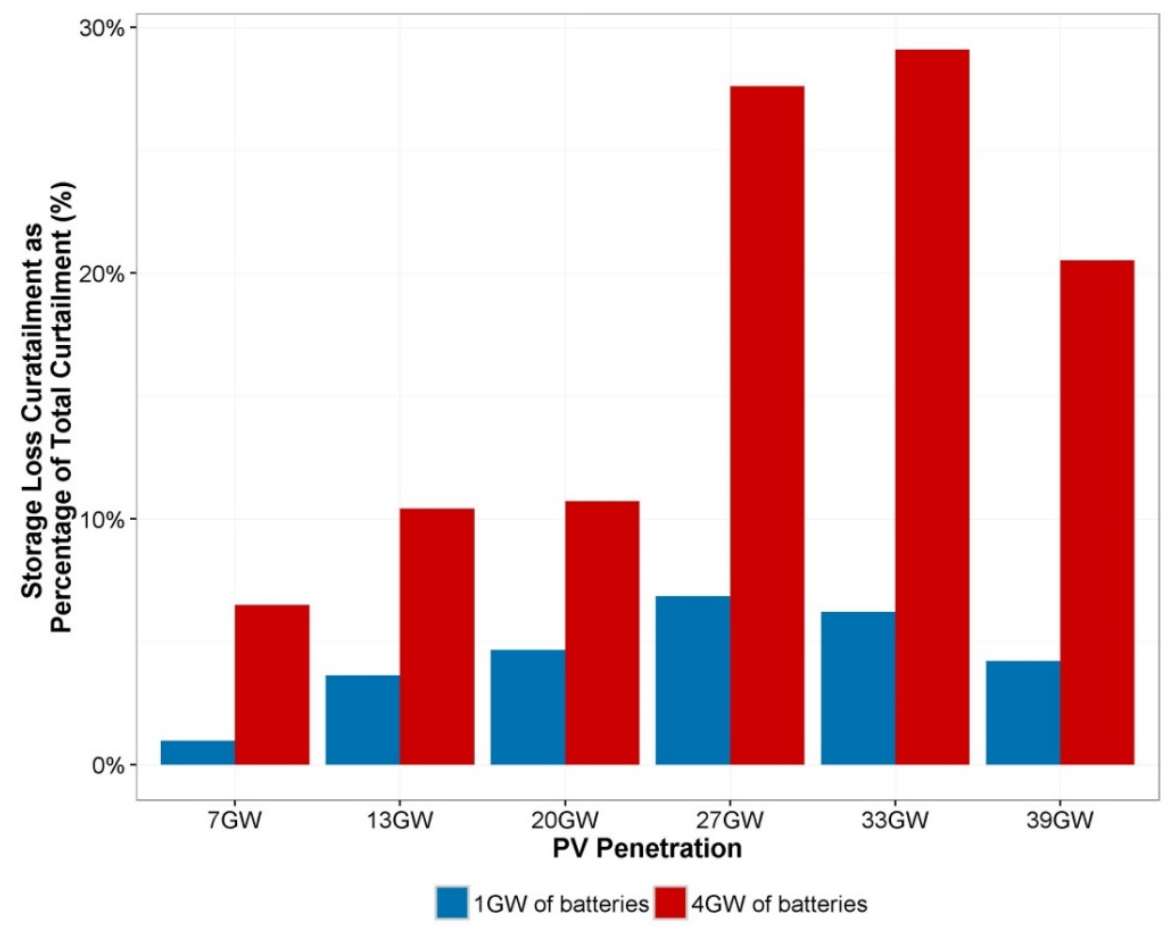

b)

Figure 53. a) Total storage loss curtailment by penetration and b) proportion of storage loss curtailment relative to all curtailment. 
Figure 53 shows the absolute and relative magnitudes of the storage-loss curtailment for the different PV penetrations and energy storage sizes. As expected, the total curtailment due to storage losses increases with more PV on the system, as seen in Figure 53a. At higher penetrations, more PV generation is stored and therefore leads to storage-loss curtailment. Figure $53 \mathrm{~b}$ shows the proportion of total curtailment that is due to storage losses. At the $27 \mathrm{GW}$ and 33 $\mathrm{GW}$ penetrations, that proportion is greatest. This suggests that between $27 \mathrm{GW}$ and $33 \mathrm{GW}$, the storage size becomes a limiting factor to further reductions in curtailment. Around $27 \mathrm{GW}$ and $33 \mathrm{GW}$, much of the curtailment seen in the base case can be avoided by charging batteries. However, at higher PV penetrations, the batteries are more frequently charging at their maximum capacity, forcing much of the PV generation to be curtailed in real time (at the PV generator), rather than stored for later use.

The operational impact of storage and how much curtailment is avoided adds value. But as discussed in Section 2.5.3 of the California case study, much of the value of energy storage comes from its capacity value. Figure 54 shows how high and low assumptions for the cost of provided capacity change the total value of the battery-storage options.

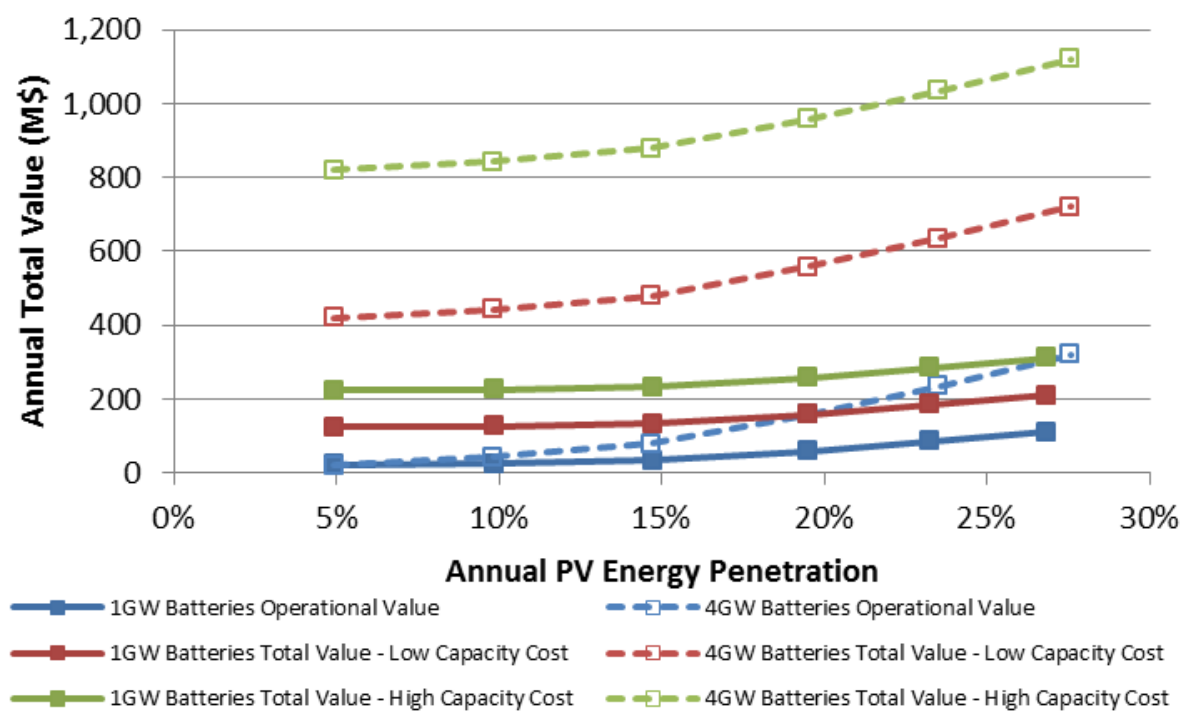

Figure 54. Total value (operational and capacity) of energy storage in FRCC.

Annualized costs of battery storage, using the same cost of storage $(\$ 200 / \mathrm{kWh}-\$ 350 / \mathrm{kWh})$ for the California case study, range from \$122-\$214 million for $1 \mathrm{GW}$ of battery deployment (solid lines in Figure 54) and \$489-\$856 million for $4 \mathrm{GW}$ (dashed lines in Figure 54). These costs fall within the range of the total annual value provided by the batteries. In the best-case scenario (high capacity value, low capital cost), battery storage easily is a net benefit to the system. In the worst case, battery storage does not break even in any PV penetration, but does come close at the highest penetration studied.

\subsubsection{Increased Transmission Results}

Increasing the transmission capacity of the SERC-FRCC interface increases the PV operation value slightly more than adding $1 \mathrm{GW}$ of energy storage. The interface is increased by $1 \mathrm{GW}$ - to $2 \mathrm{GW}$ - in the direction of FRCC to SERC, and is increased by $1.8 \mathrm{GW}$ - to $5 \mathrm{GW}$ - in the 
direction of SERC to FRCC. Ideally, the stability limits that cap the export capacity, as discussed in Section 3.3.5, could be addressed to increase the export limit to the same as the import limit. The export limit is particularly important to the value of PV because PV that would have been curtailed could be exported out of FRCC if the export limit were increased. Additional analysis is needed to fully assess the value of removing the stability limits.

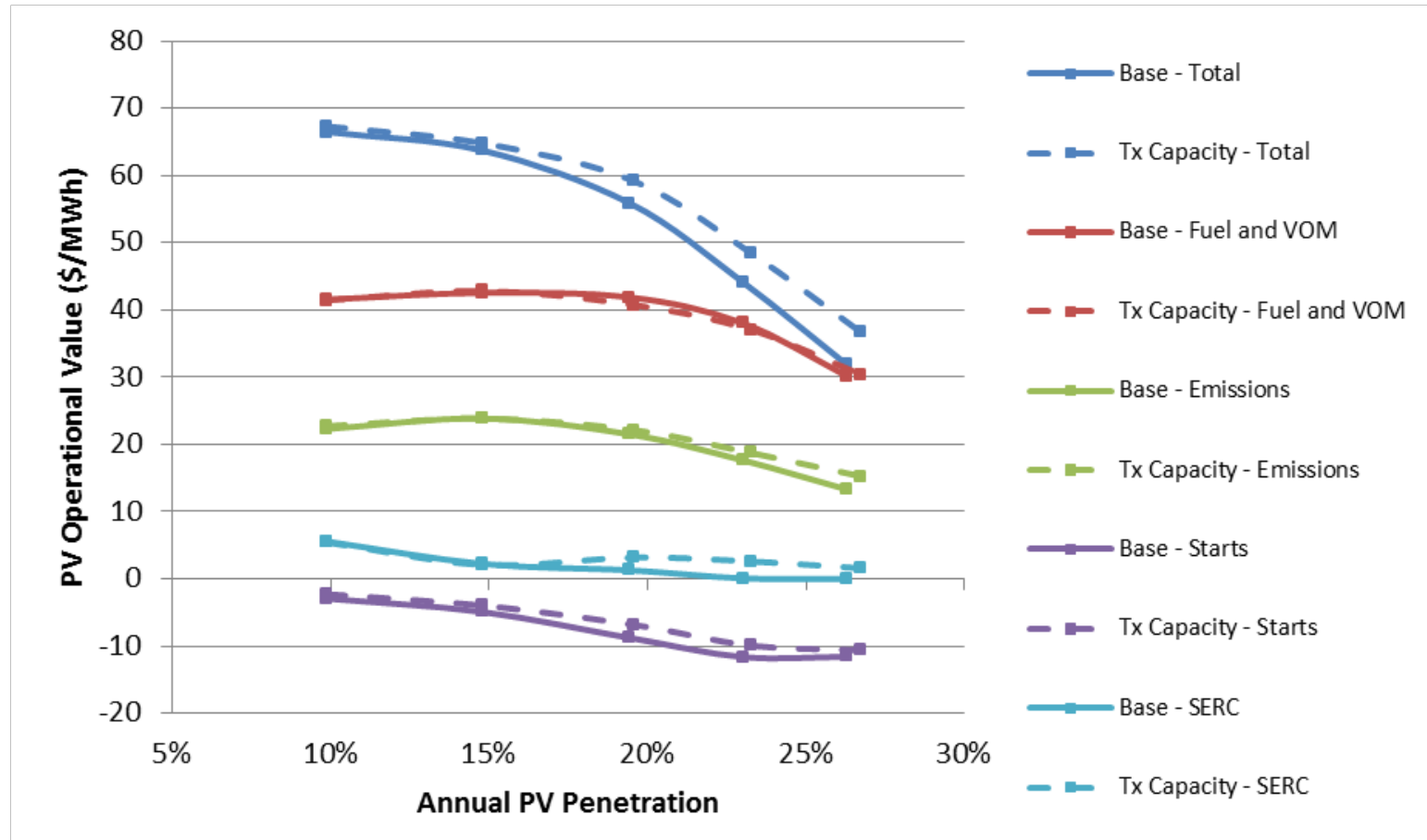

Figure 55. Change in PV operational value when increasing the capacity of the SERC-FRCC interface.

Figure 55 shows how the operational value changes with increased import/export capacity with SERC. Similar to the storage cases, the increased operational value of PV comes mostly from the reduced burden of start costs and net imports with SERC. Figure 56 shows how the online capacity of CCs and CTs changed, and it also shows the change in flow over the SERC-FRCC interface. 


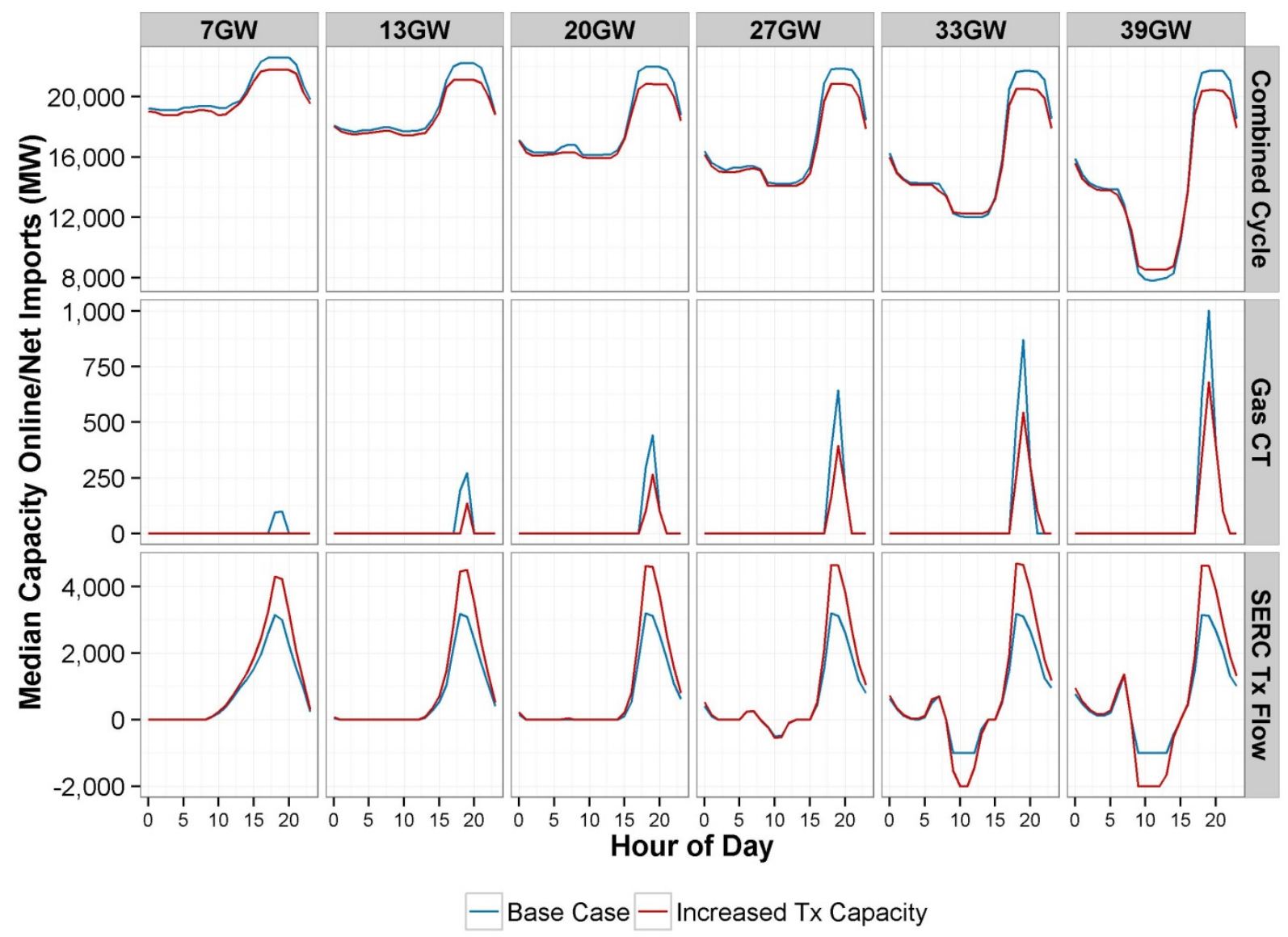

Figure 56. Change in CC and CT capacity online and flow on the SERC-FRCC interface when the capacity of the interface is increased, for each PV penetration.

Until the afternoon peak, CC and CT online capacity mostly remains the same between the base case and the increased transmission capacity. Across all penetrations, the online capacity at peak is reduced when the transmission capacity is increased. More of the peak power comes from SERC in those hours due to the alleviated congestion between the regions. This reduces the burden of start cost incurred by the system, but does increase the cost of net imports from SERC. However, as the PV penetration increases, FRCC begins to export to SERC in the middle of the day, sending some of the excess PV generation to SERC. At the two highest penetrations, more of the excess PV is exported when the capacity of the interfaces increases. This contributes to reducing the burden of net imports on the operational value of $\mathrm{PV}$.

The benefit of increasing the transmission capacity of the interface between FRCC and SERC correlates closely with the reduced curtailment in this flexibility scenario. As the PV penetration increases, so does the amount of reduced curtailment and annual operational savings (Figure 57). 


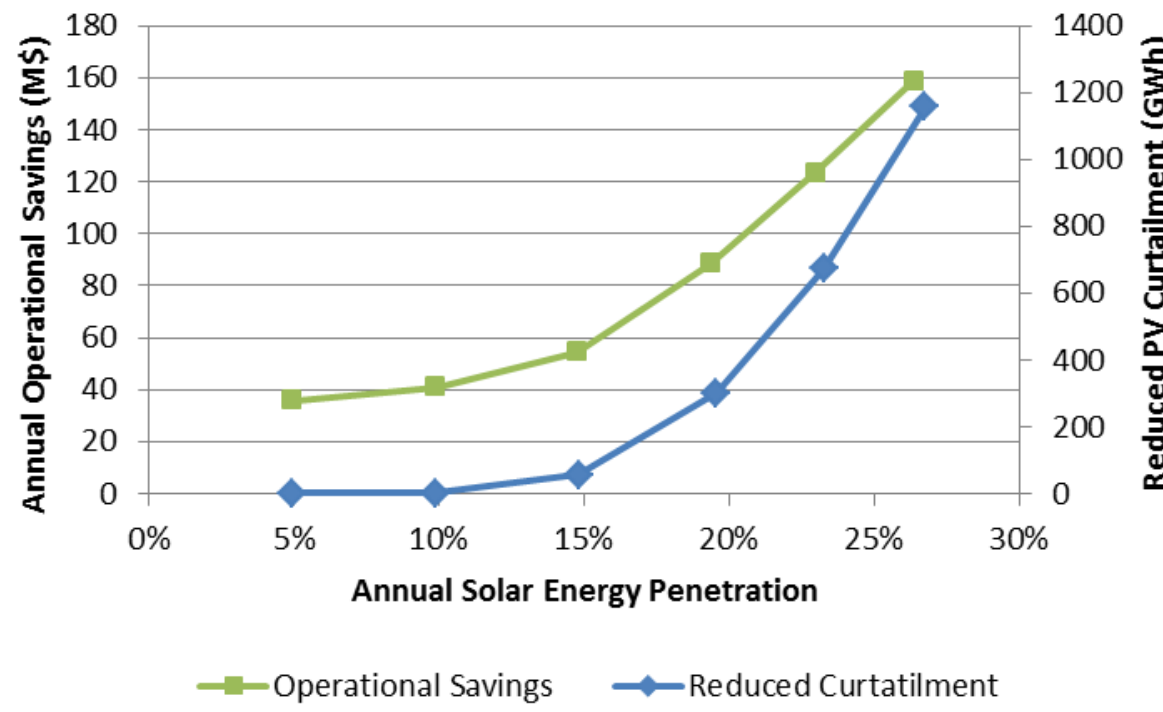

Figure 57. Annual operational savings and reduced curtailment with increased transmission capacity between FRCC and SERC.

There is a wide range of estimates for transmission capacity. Costs of new transmission can vary and depend on a variety of factors, such as length of the new lines, number of substations, and line-voltage class. Applying the transmission expansion used by the ReEDS model estimates 191 miles of new transmission capacity rated at $1.8 \mathrm{GW}$. Using a mid-range estimate of $\$ 1,347 / \mathrm{MW}$ mile (Pletka et al. 2014), this amount of new capacity would require a total cost of $\$ 463$ million. Annualized, this flexibility option (with an $8 \%$ discount rate and a 20 -year lifetime) would cost $\$ 47$ million dollars per year. Beginning with the $15 \% \mathrm{PV}$ penetration and for all higher penetrations, increasing the interface capacity between FRCC and SERC would be a net positive for the system.

It can be difficult to estimate accurately the exact distance of new transmission lines needed to increase the interface capacity. Multiple discrete lines would likely be needed, and it is unclear how long each individual line will need to be. To estimate the sensitivity of these results we use a range of between half and double the distance of 191 miles provided by ReEDS. Using this range of distances, the implementation cost for increasing the interface between FRCC and SERC will be between $\$ 231$ million and $\$ 925$ million. The range of annualized cost is between $\$ 24$ million and \$94 million. This range can affect when the project is a net positive for the system. At the low end, the project would be a net benefit for all PV penetrations. On the high end of the range, the project only becomes net positive around the point when PV meets around $20 \%$ of annual FRCC load.

Although not investigated in this study, the expansion of the interface capacity may also provide some capacity value, because SERC and FRCC may have different peaks and can help provide capacity to the other region during peak demand. This would increase the total value of the interface, potentially making this flexibility option a net positive even at the lowest of the PV penetrations studied. 


\subsubsection{Combined BA Cooperation and Increased Transmission Results}

Figure 58 shows how combining BA cooperation and increasing transmission capacity between SERC and FRCC changes the operational value of PV. The impacts are essentially the same results as the flexibility option that only increased transmission capacity. This is to be expected given the small impact in the enhanced BA cooperation case.

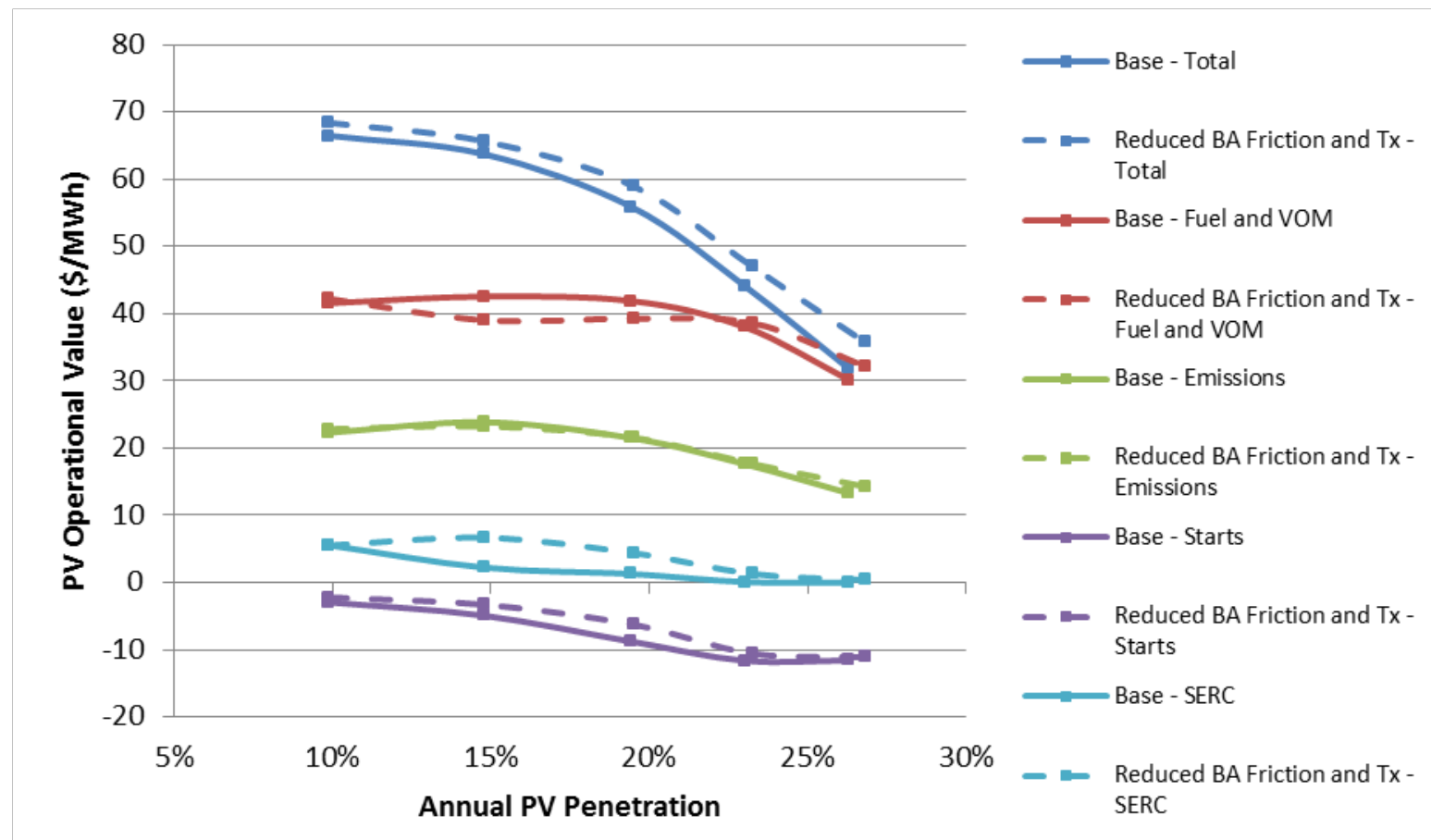

Figure 58. Change in PV operational value when increasing the capacity of the SERC-FRCC interface and removing BA friction.

Figure 59 shows how $\mathrm{CC}$ and $\mathrm{CT}$ online capacity changes, along with the flow on the interface between SERC and FRCC. This plot also shows little change from the results in Section 3.5.5. 


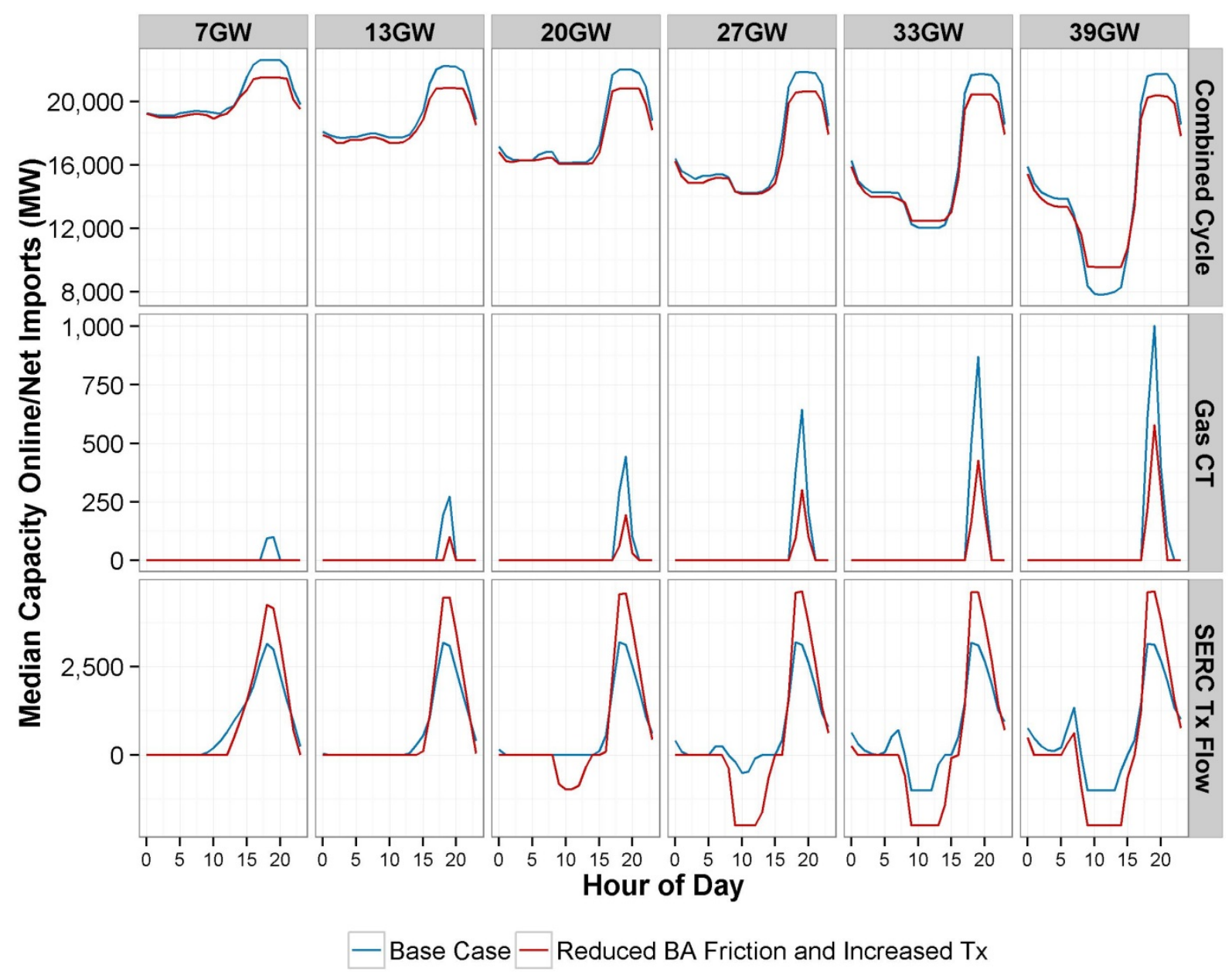

Figure 59. Change in CC and CT capacity online and flow on the SERC-FRCC interface when the capacity of the interface is increased and BA friction is removed, for each PV penetration.

Combining BA cooperation with increased transmission capacity of the FRCC/SERC interface shows a mix of the value observed for each flexibility option considered separately. Figure 60 shows that operational savings correlate with reduced curtailment, but not as strongly as when increased interface capacity is the only flexibility option included. The benefits are not necessarily additive, but the costs would be, with most costs associated with adding capacity to the interface. 


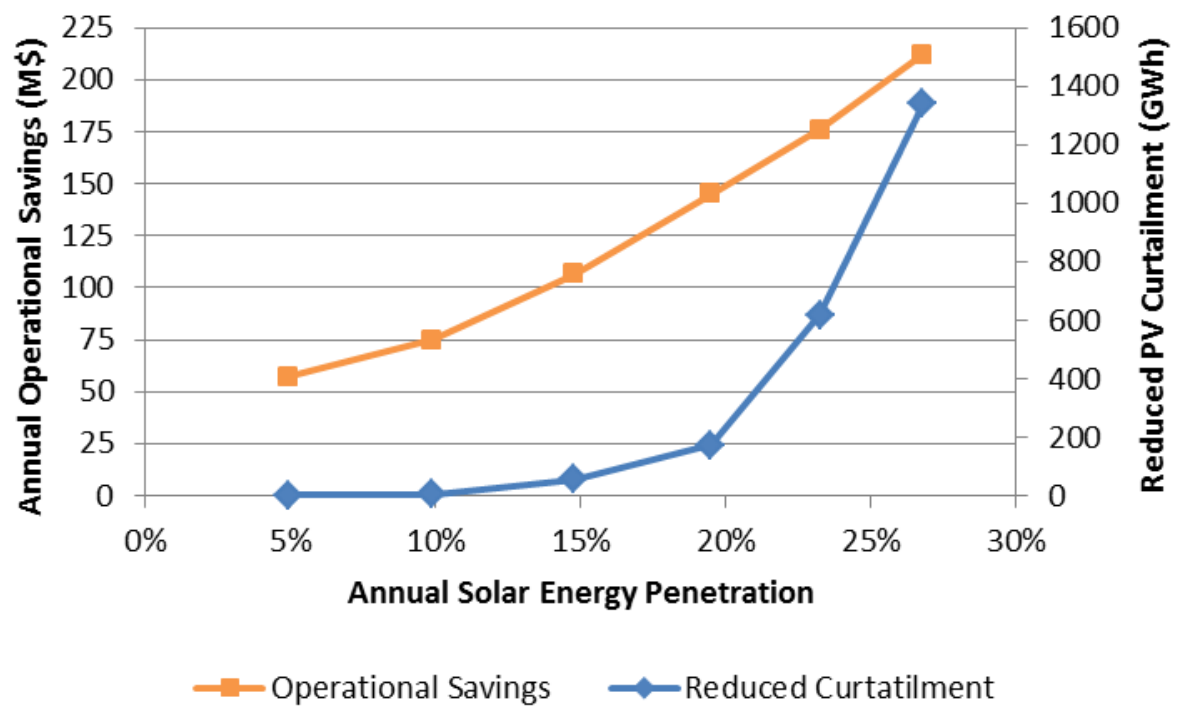

Figure 60. Annual operational savings and reduced curtailment with enhanced BA cooperation combined with increased transmission capacity between FRCC and SERC. 


\section{Case Study: Southwest Power Pool-Increasing Wind}

\subsection{Southwest Power Pool Model}

Similar to the FRCC model, we extracted the Southwest Power Pool (SPP) region from the 2026 Eastern Interconnection model developed at NREL for the Eastern Renewable Generation Integration Study. The SPP represents the windy, but less populated, middle section of the United States. Therefore, it represents an ideal test case for analyzing the effects of increasing wind generation. SPP comprises parts of fourteen states in the central U.S., and Figure 61 shows the geographical scope of its footprint.

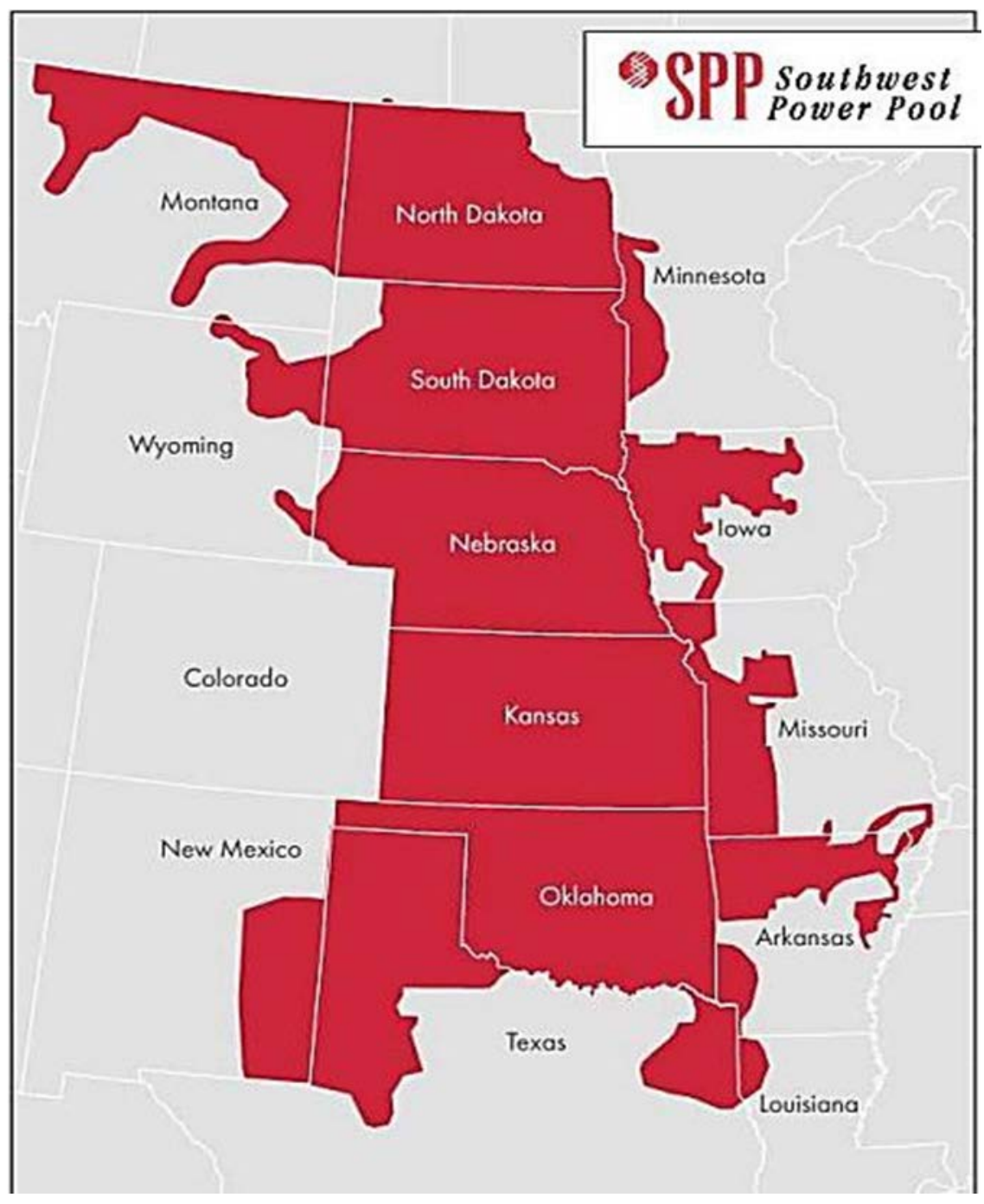

Figure 61. Map of SPP territory. ${ }^{26}$

\footnotetext{
${ }^{26} \mathrm{http}: / / \mathrm{www}$. ferc.gov/market-oversight/mkt-electric/spp/elec-spp-footprint.pdf
} 
Major changes made to create the SPP model from ERGIS included:

- Incorporating SPP's expanded territory to include the Integrated System, which is made up of Western Area Power Administration's Upper Great Plains Region, Basin Electric Power Cooperative, and Heartland Consumers Power District.

- Modest changes to the installed thermal capacity to better reflect the planning reserve margin required by SPP.

- Representing all regions within SPP and SPP's direct neighbors (Midcontinent Independent System Operator or MISO, and Canada) as zones, rather than using the ERGIS nodal model. This removes the possibility of intra-regional congestion (where regions are defined in Table 8). Current-day intra-regional transmission congestion can lead to wind curtailment. We assume these intra-regional congestion problems will be dealt with if the amount of wind studied here were built.

Further discussion of these changes and other components of the SPP are located in the appendix.

\subsection{Wind Penetration Scenarios}

We modeled fourteen penetrations of wind in SPP for this study, ranging from $12 \%-51 \%$ and increasing in about 3\% increments. The penetrations represent the percentage of annual SPP load that would be met by wind if all of the available generation were used, rather than curtailed. The total wind capacity starts at $10.1 \mathrm{GW}$ in the $12 \%$ case and increases to $41.8 \mathrm{GW}$ in the $30 \%$ case, as shown in Table 7.

Table 7. Wind Penetration Scenarios

\begin{tabular}{|c|c|c|}
\hline $\begin{array}{c}\text { Wind Pre- } \\
\text { Curtailment } \\
\text { Potential } \\
(\%)\end{array}$ & $\begin{array}{c}\text { Installed } \\
\text { Capacity } \\
(\text { GW) }\end{array}$ & $\begin{array}{c}\text { Annual Pre- } \\
\text { Curtailment } \\
\text { Energy } \\
\text { (TWh) }\end{array}$ \\
\hline 12 & 10.1 & 38.8 \\
\hline 15 & 12.6 & 47.3 \\
\hline 18 & 15.1 & 56.6 \\
\hline 21 & 17.6 & 66.4 \\
\hline 24 & 20.1 & 75.4 \\
\hline 27 & 22.6 & 84.9 \\
\hline 30 & 24.9 & 104 \\
\hline 33 & 27.3 & 113 \\
\hline 36 & 29.7 & 123 \\
\hline 39 & 32.1 & 132 \\
\hline 42 & 34.4 & 141 \\
\hline 45 & 36.7 & 151 \\
\hline 48 & 39.2 & 161 \\
\hline 51 & 41.8 & \\
\hline
\end{tabular}


We extracted wind sites and output profiles from the ERGIS National 30\% penetration scenario for each penetration. Larger penetrations are supersets of the smaller penetrations. The distribution of wind sites within SPP roughly approximates the geographical distribution in the ERGIS study. PV penetration remains constant at 3\% of SPP load for each wind penetration.

\subsection{Flexibility Options}

In addition to the fourteen wind sensitivities, we also considered several flexibility options. The options include: 1) allowing wind to provide reserves, 2) reduced minimum generation levels of gas combined-cycle and coal generators, 3) increased interface flow limits between zones, 4) energy storage, and 5) increased cooperation between SPP and its neighbors-MISO, Manitoba, and Saskatchewan.

The following sections detail the assumptions used to model these flexibility options.

\subsubsection{Allow Wind to Provide Reserves}

As stated in previous sections, reducing the required amount of thermal generation on the system can allow higher levels of VG utilization, thus reducing curtailment. Allowing wind to provide reserves, instead of requiring thermal generation to provide these services, can be one method to achieve this reduction. However, wind can provide up-reserves only during periods of curtailment (when it has sufficient capacity to increase generation), or down-reserves by curtailing when the reserves are called. We only considered up-reserves due to the computational burden, so wind can provide contingency and regulation only while being curtailed.

\subsubsection{Gas Combined-Cycle and Coal Minimum Generation Level}

In the base case, gas CCs in SPP have a minimum generation level of $50 \%$ of their installed capacity. Coal units under $600 \mathrm{MW}$ in capacity can reduce their output to $50 \%$ of their maximum, whereas units greater than $600 \mathrm{MW}$ can reduce their output to $30 \%$ of their maximum output. Both assumptions are consistent with ERGIS (Bloom et al. 2016). This flexibility scenario reduces the minimum generation level of all gas CCs and coal plants to $40 \%$ of their maximum capacity (coal plants above $600 \mathrm{MW}$ keep their $30 \%$ minimum generation level). Reducing the minimum generation level of these units adds an additional $4.1 \mathrm{GW}$ of operational range to SPP. However, the system only benefits from the increased operational range when these units are available and committed - meaning that the actual benefit to the system at any given time will likely be less than $4.1 \mathrm{GW}$.

\subsubsection{Increased Interface Flow Limits}

As mentioned previously, original ERGIS simulations determined the interface flow limits between all zones in this study. One large driver for wind curtailment is the inability to effectively transmit wind power from its source to load centers. This flexibility option expands the ability to transmit power between SPP and its neighbors (MISO).

Table 8 shows the interchange capacity between SPP regions and MISO regions. This flexibility option allows SPP and MISO to exchange double or quadruple the limits shown in the table. 
Table 8. Interchange Capacity between SPP and MISO Regions

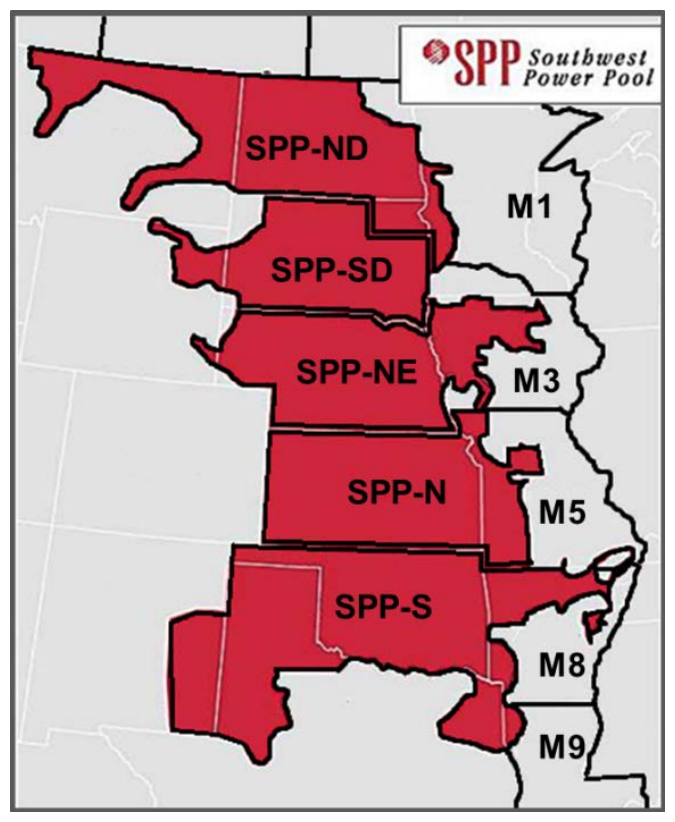

\begin{tabular}{|c|c|}
\hline \multicolumn{1}{|c|}{ Interface } & $\begin{array}{c}\text { Interchange Capacity } \\
\text { (MW) }\end{array}$ \\
\hline SPP-N to M3 & 250 \\
\hline SPP-N to M5 & 1,000 \\
\hline SPP-N to M8 & 250 \\
\hline SPP-NE to M3 & 2,000 \\
\hline SPP-S to M8 & 1,000 \\
\hline SPP-S to M9 & 1,000 \\
\hline SPP-ND to M1 & 1,000 \\
\hline SPP-SD to M3 & 1,500 \\
\hline
\end{tabular}

\subsubsection{Battery Storage}

Battery storage provides a mechanism to shift energy in time; therefore, it can add gridsignificant flexibility. We analyze two battery scenarios. The low-storage scenario adds 1,000 MW of battery capacity (roughly $1.5 \%$ of peak SPP load), whereas the high-storage scenario adds 4,000 MW of capacity (roughly $6 \%$ of peak SPP load). In both cases, the battery has 6 hours of storage capacity and $80 \%$ roundtrip efficiency. The battery capacity is distributed among the five SPP regions according to each region's proportion of total wind capacity.

\subsubsection{Increased Cooperation between SPP, MISO, and Canadian Regions}

SPP has various connections with the rest of the Eastern Interconnection via MISO. High-voltage direct-current (HVDC) ties also connect SPP to the Western Interconnection, but the capacities of the lines are small. Although market mechanisms exist to exchange energy between SPP and surrounding regions, this exchange is economically co-optimized across multiple time-scales. In our base case, we attempt to capture this market friction by imposing a $\$ 10 / \mathrm{MWh}$ hurdle rate to all transactions between SPP and MISO, and between MISO and the Canadian regions. In the enhanced flexibility case, we eliminate all hurdle rates, encouraging a more-efficient dispatch that could potentially assist in wind integration.

\subsection{Results}

\subsubsection{Base-Case Wind Capacity Value}

Unlike the sharply declining capacity value of PV in California and FRCC shown in the previous sections, the capacity value of wind does not decrease as dramatically at higher wind penetrations. Figure 64a shows the marginal capacity credit for wind in SPP, and Figure 64b shows the marginal capacity value (\$/MWh), assuming an annualized capacity cost of $\$ 190 / \mathrm{kW}$. Wind can generate at any hour, so it does not shift the net load peak as much as PV. Incremental wind power can also increase the marginal capacity credit of wind, as seen between the $30 \%$ and 
40\% wind penetrations on Figure 62. For the SPP model, discrete wind sites were added to reach the next penetration. An increase in the marginal capacity value demonstrates the diversity of wind profiles that exist in SPP. For example, going from $27 \%$ to $30 \%$ pre-curtailment wind penetration increases the marginal capacity value by about $\$ 4 / \mathrm{MWh}$. The wind sites that are added between these penetrations are able to contribute more to the net load peaks than prior sites because their generation profiles differ from the wind installed in the earlier penetrations. 


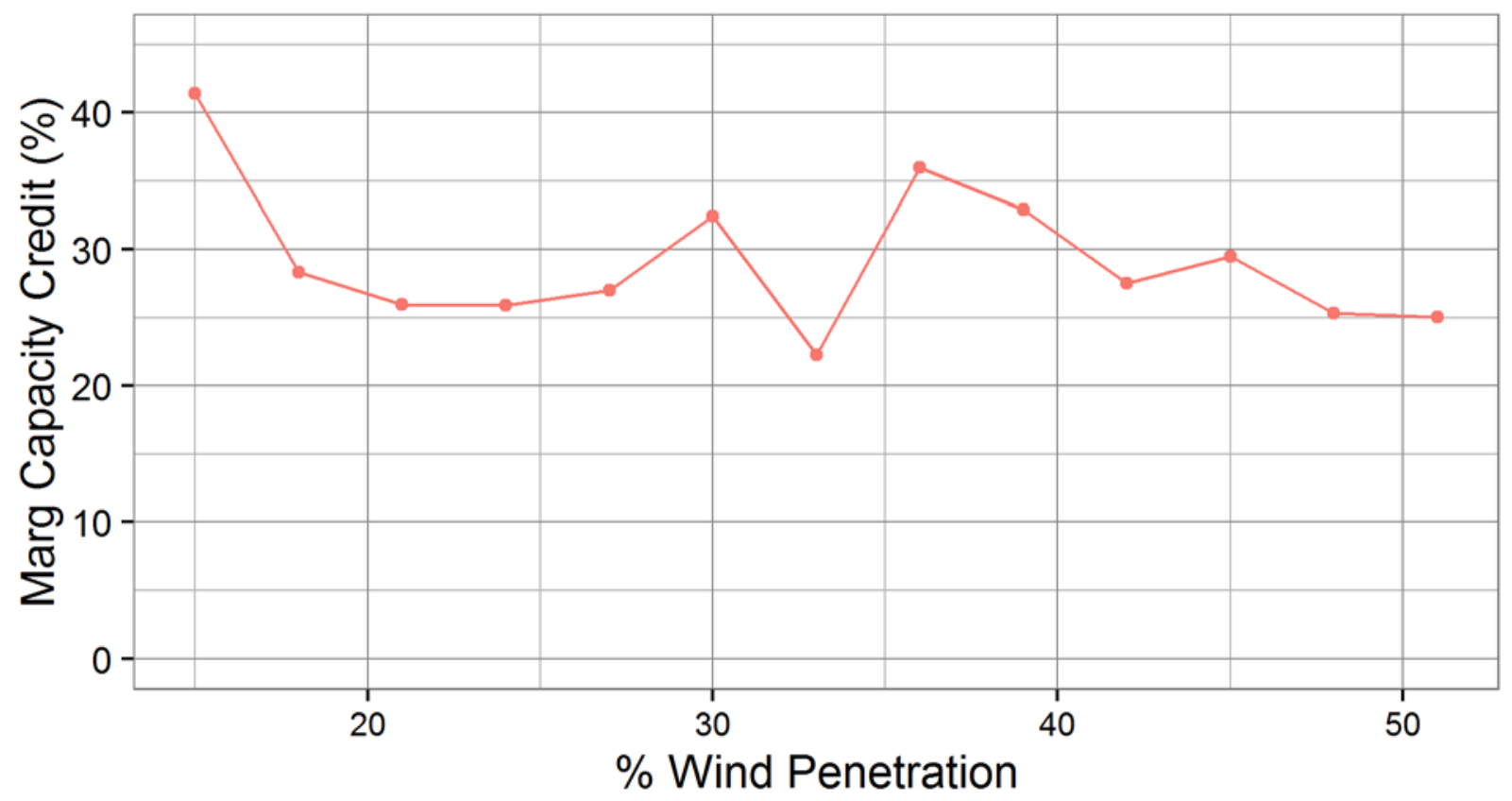

a) Capacity Credit

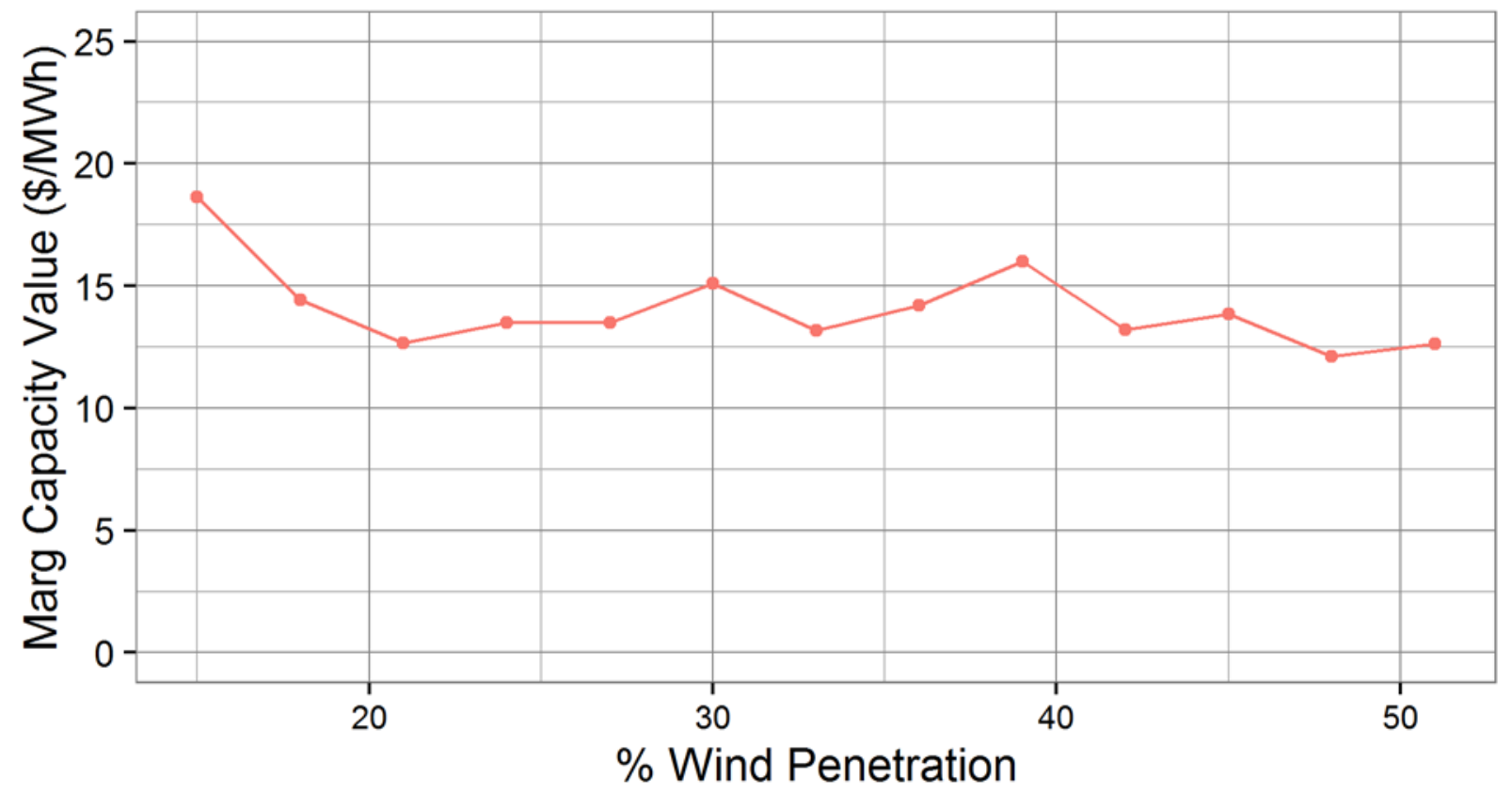

b) Capacity Value

Figure 62. Marginal capacity credt (\%) and value (\$/MWh) for wind.

\subsubsection{Wind Operational Value}

The components of the operational value of wind include: displaced generator fuel and variable O\&M costs, reduced $\mathrm{CO}_{2}$ emissions, and the change in generator start costs. In this section, we measure the system-wide impacts together, rather than disaggregating SPP impacts and 
neighboring region impacts. Figure 63 shows how the components of the marginal operational value of wind change as the penetration of wind increases with no flexibility options included. The marginal value of wind is mostly impacted by the reduced impact that new wind has on the cost of fuel and VOM. The largest component of the total value is the savings resulting from avoided $\mathrm{CO}_{2}$ emissions, which we assumed have a value of $\$ 50 /$ ton. The unit commitment and dispatch modeling does not incorporate this value stream, which represents the social cost of carbon. Therefore, the model has no monetary incentive to reduce emissions, and all emissions reductions simply result from using wind generation instead of burning fuel. The figure indicates that emissions savings stay constant across wind penetrations. Although curtailment increases as wind penetration increases, the relative amount of avoided coal also increases. Coal, which has nearly double the carbon emissions per unit of fuel burned, is less expensive than gas. Therefore, at lower penetrations, the higher-priced fuel (gas) is displaced in slightly higher proportion. As wind penetration increases and can replace less gas generation, the relative displacement of coal rises. So, curtailment reduces the emissions savings, but increased rates of coal displacement approximately cancel out the effect of curtailment.

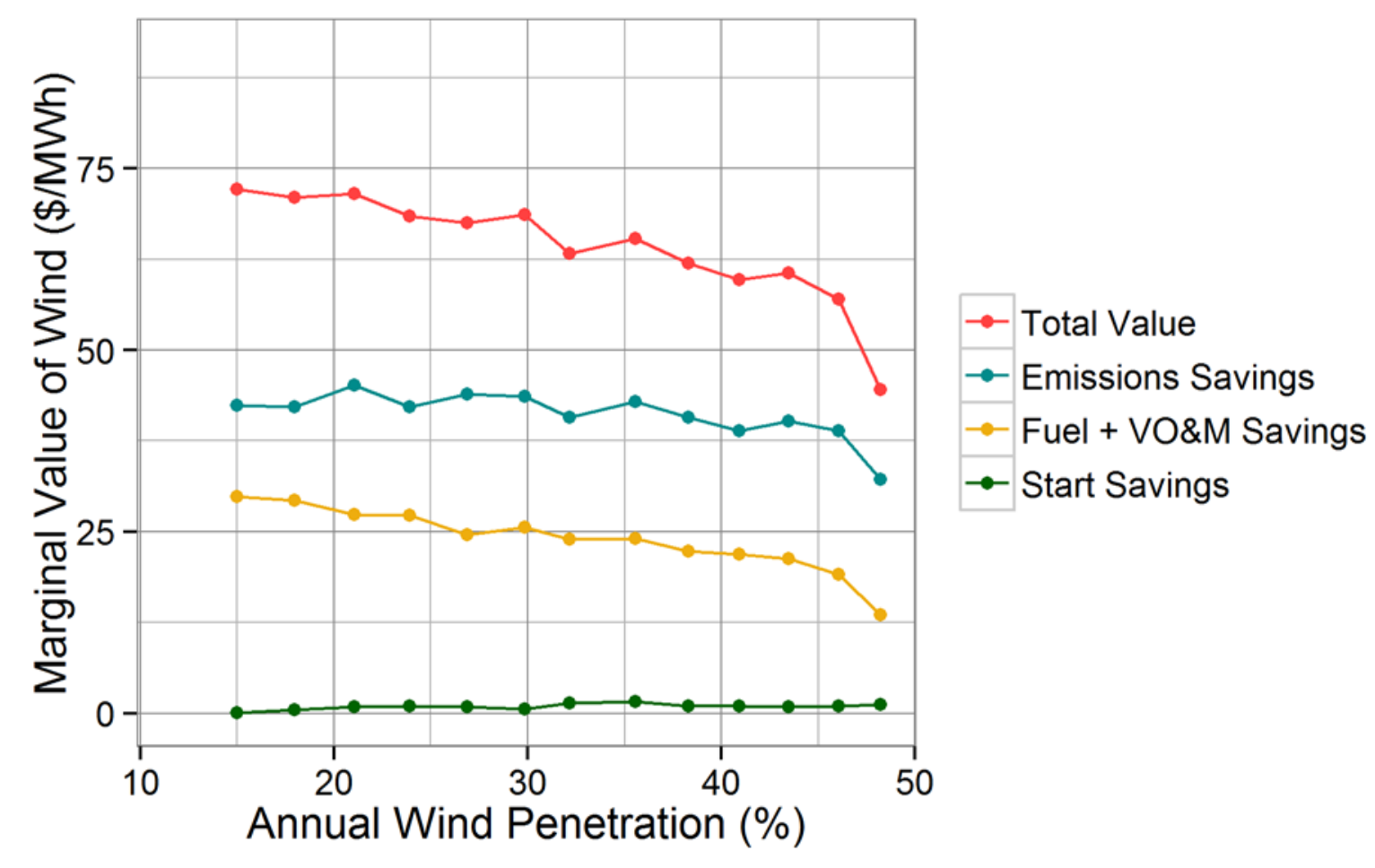

Figure 63. Base-case wind operational value.

Generally, increased flexibility leads to less marginal curtailment (see Figure 64). As shown in Figure 65, the effects of each flexibility option are not as clear as the trends shown with PV in previous sections, for several reasons. First, unlike PV, wind generation is not limited to a certain time of day; therefore, extreme low-demand periods are not as common for wind, leading to generally lower curtailment rates. Although flexibility options may still have economic benefits, their impact on curtailment is smaller because the overall curtailment for wind is lower than that of PV. Second, wind sites are generally larger in size than PV sites, so increasing wind penetration by $3 \%$ (one point horizontally on the graph in Figure 65) may only represent two or 
three new wind sites. In our zonal model, this means that even geographical dispersion throughout SPP is challenging, which leads to some incremental wind generation being more susceptible to curtailment due to transmission congestion and unique region constraints.

Furthermore, certain zones - namely, SPP-ND and SPP-SD — have a larger proportion of wind sites relative to their load. Subsequently, integrating new wind in those regions might prove more challenging than adding wind in other less-saturated zones.

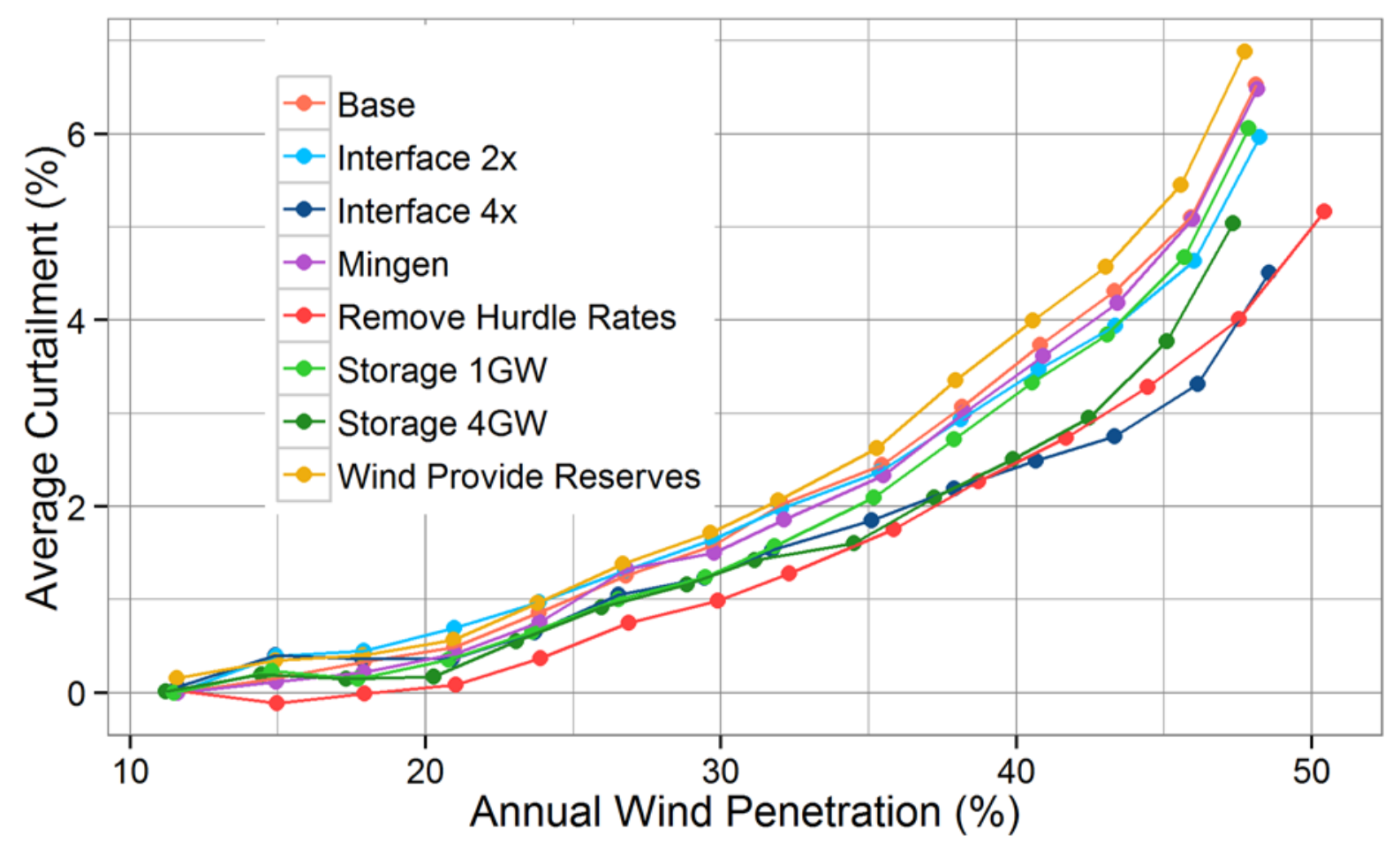

Figure 64. Average wind curtailment in SPP. 


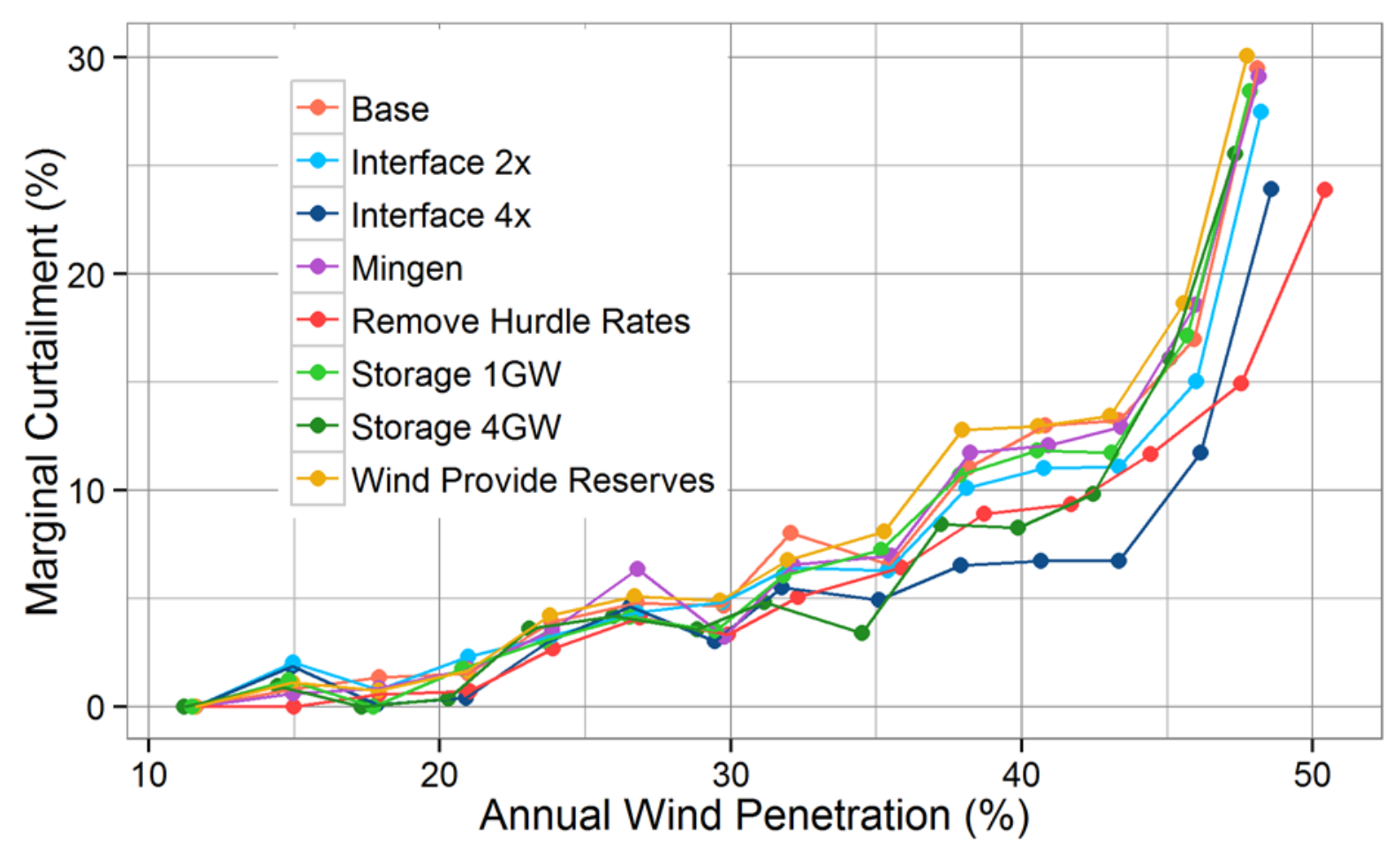

Figure 65. Impact of flexibility options on marginal curtailment in SPP.

Figure 66 shows the marginal operational value, showing the limited drop in value compared to the PV cases. The small amount of curtailment limits the ability of flexibility options to enhance the value of wind. 


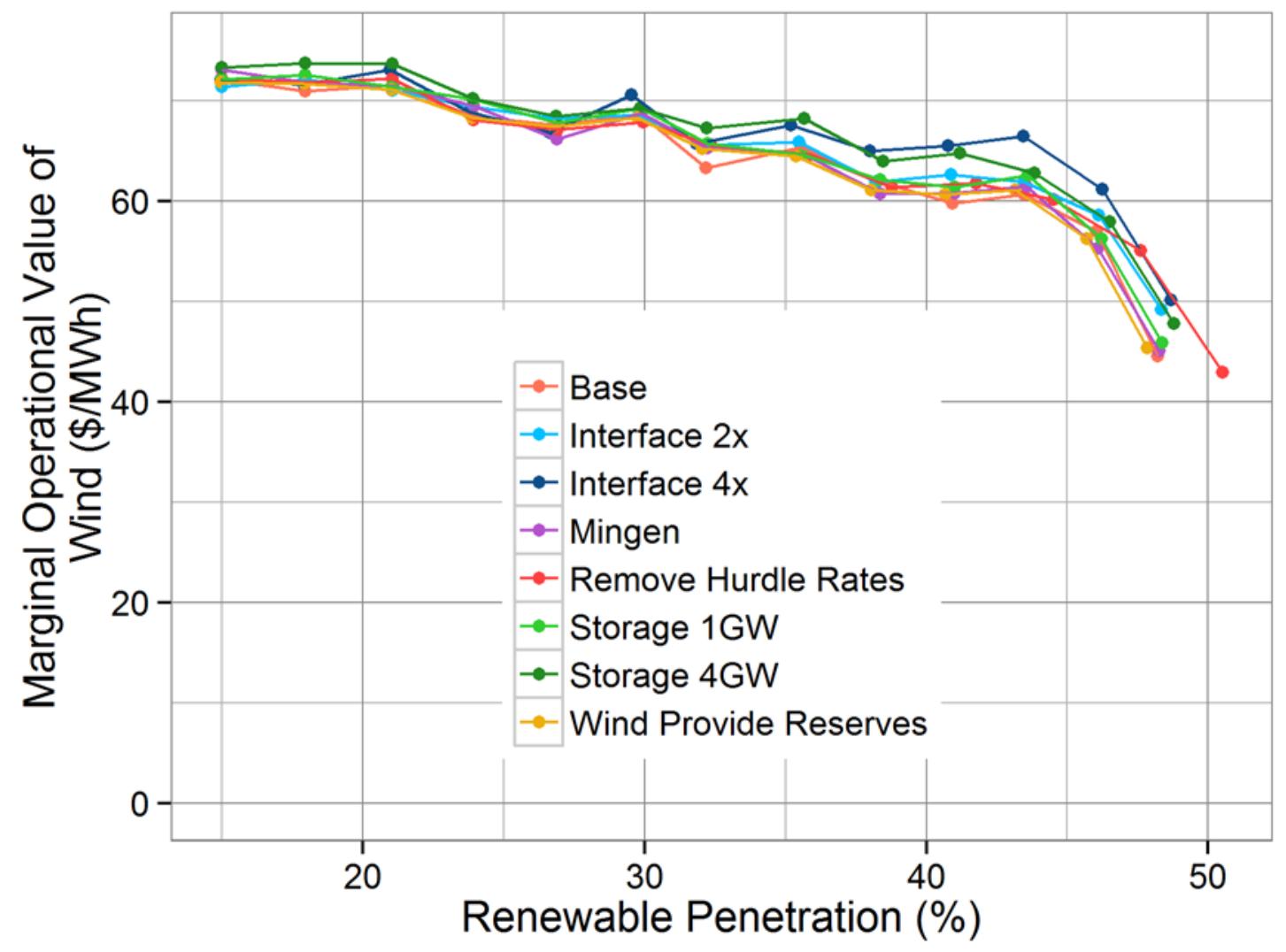

Figure 66. Marginal operational value of wind for all flexibility cases in SPP.

\subsubsection{Wind Total Value}

Figure 67 shows the total marginal value of wind for all cases. The similarity of all the curves is due to the limited changes in marginal curtailment that result from the flexibility options, as indicated in Figure 65. In addition, the total value in all cases does not decrease drastically from lower wind penetrations to higher wind penetrations - especially when compared to the dramatic reduction in value associated with increasing PV penetrations shown in preceding sections. Much of the comparatively small reduction in value of wind results from the much lower curtailment levels compared to PV. The highest wind penetration case (51\% before curtailment) has the highest level of curtailment, but it is still less than $6 \%$. By comparison, Figure 13 indicates that $6 \%$ curtailment of $\mathrm{PV}$ in California would occur somewhere around $18 \%$ penetration. 


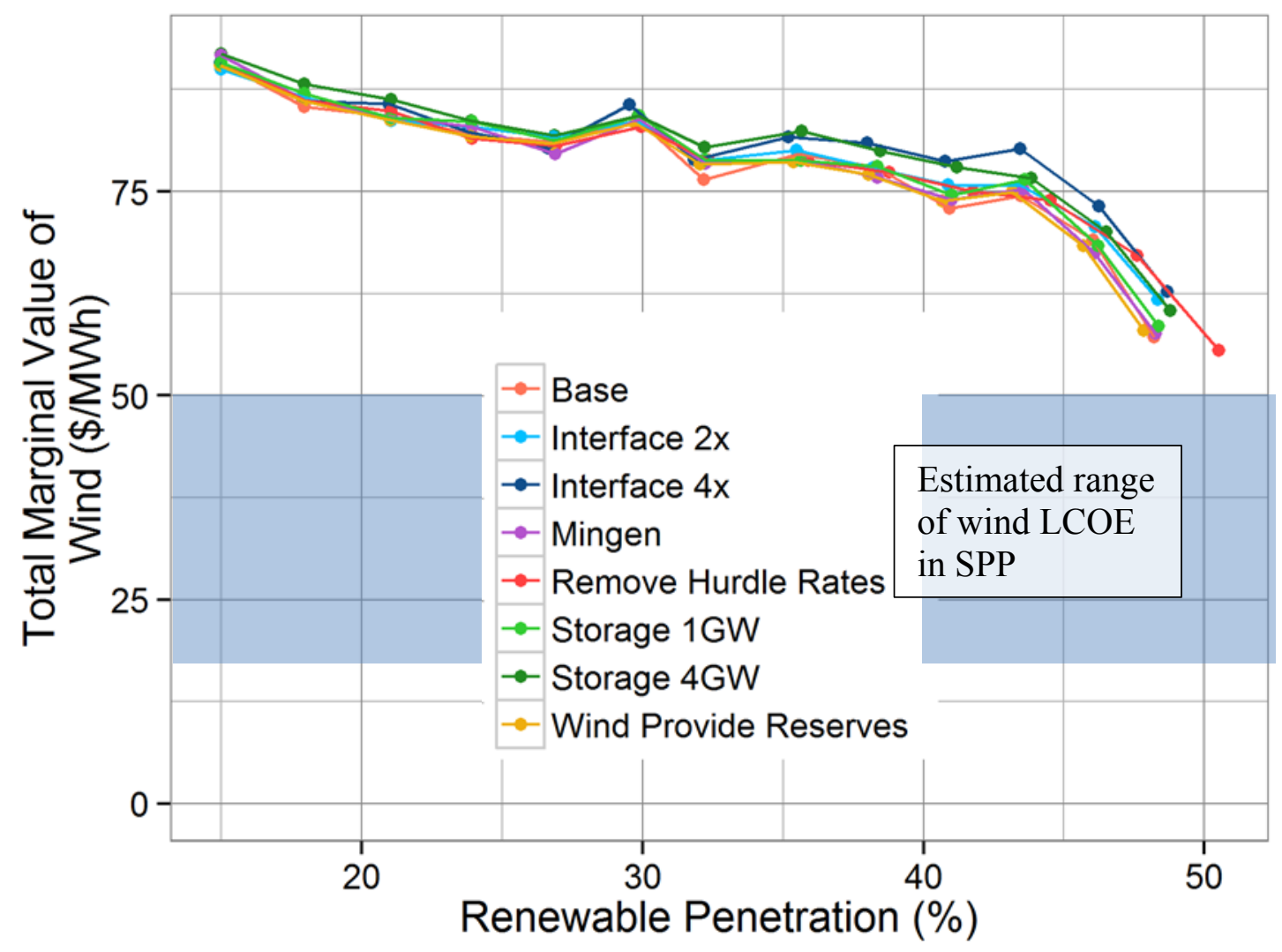

Figure 67. Marginal total value of wind for all flexibility cases in SPP.

Figure 67 includes a comparison of the estimated total value to the cost of wind. A range of values is shown, with the lower value of about $\$ 20 / \mathrm{MWh}$ representing the cost including the investment tax credit (ITC), and the upper range representing values without the ITC (Wiser and Bolinger 2016). This figure indicates that the value of wind (when including the social cost of carbon) remains above the cost even at about $50 \%$ penetration.

Even in the absence of renewable energy, flexibility options can still provide economic benefit to the system. However, as Figure 67 indicates, the value can also depend on the amount of wind. For this system, the greatest economic benefit comes from increasing intra-zonal transmission capacity. Even at the lowest penetrations of wind, the economic benefit from increased power exchange is large. Allowing the most economic power to get most effectively to where it is needed can benefit the system, even without large amounts of wind.

\subsubsection{Value of Flexibility Options}

Just as in the California and FRCC case studies, flexibility options in SPP add value to the system. Most options only add operational value, and Figure 68 shows how the operational value changes for each flexibility option as wind penetration increases. 


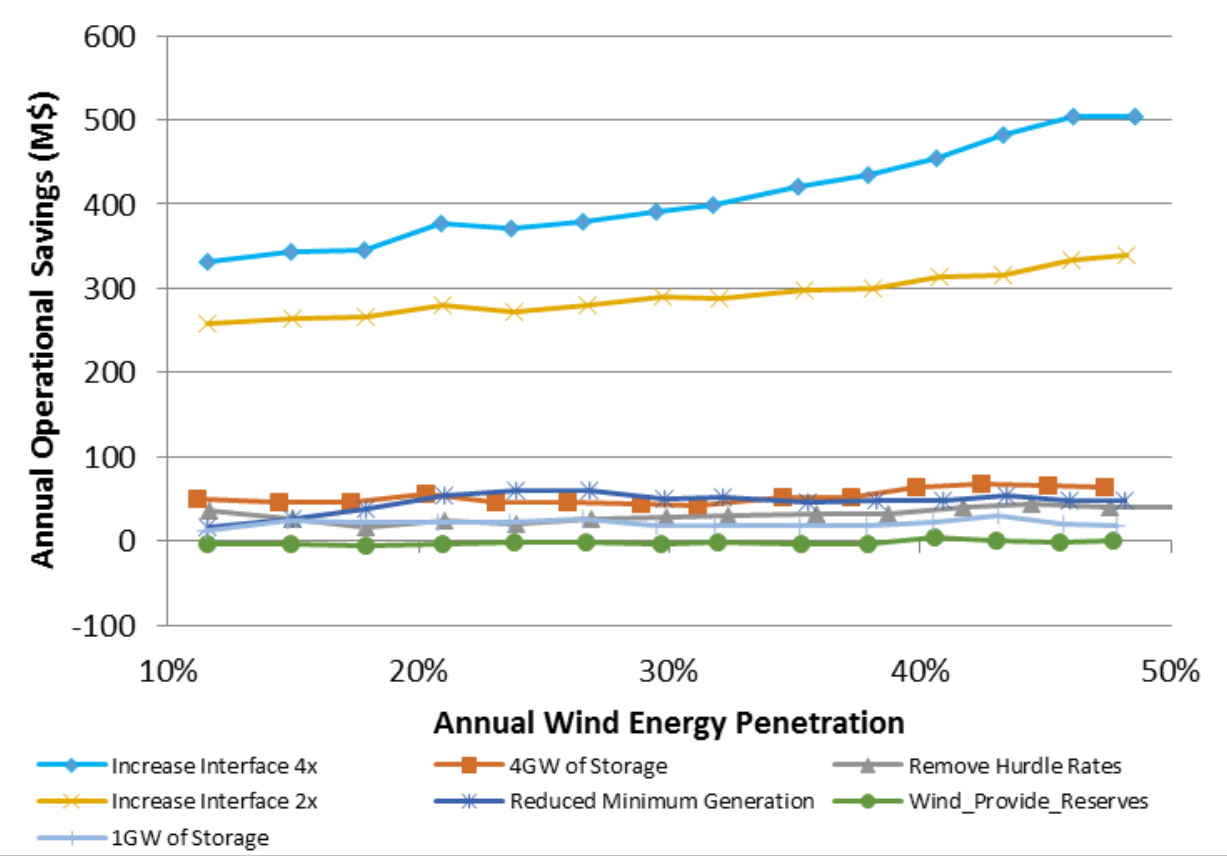

Figure 68. Operational benefits of flexibility options in SPP.

In the case of wind in SPP, by far the largest operational benefit comes from expanding the capacity of the interfaces connecting SPP to the rest of the Eastern Interconnection. The operational value of increasing the interface capacity clearly increases as the wind penetration increases. However, most other flexibility options show only small or no correlation with wind energy penetration.

\subsection{Discussion of Results for Individual Flexibility Options}

\subsubsection{Increased Interface Exchange Capacity}

As mentioned in the previous section, increasing the interchange capacity provides the greatest economic benefit among all flexibility options considered. This flexibility option allows regions to exchange either two times or four times the amount of power considered in the base case. Furthermore, the economic benefit of this flexibility option substantially increases with wind penetration. We expect this result because wind generation is not always well-correlated with nearby load.

Figure 69 shows the annual amount of net imports into SPP from MISO. For reference, the total annual load of SPP is about $320 \mathrm{TWh}$, meaning that in the base $12 \%$ wind case, MISO supplies roughly $3 \%$ of the load. In the two cases with increased interface capacity, exports decrease while still remaining positive overall. Even at just $12 \%$ wind, SPP has excess wind generation during certain times of the year, and the increased interface capacity allows more exports - and thus, lower net imports. In all cases, SPP is a net exporter at the highest wind penetrations, but the increased interface capacity allows even higher levels of exports. 


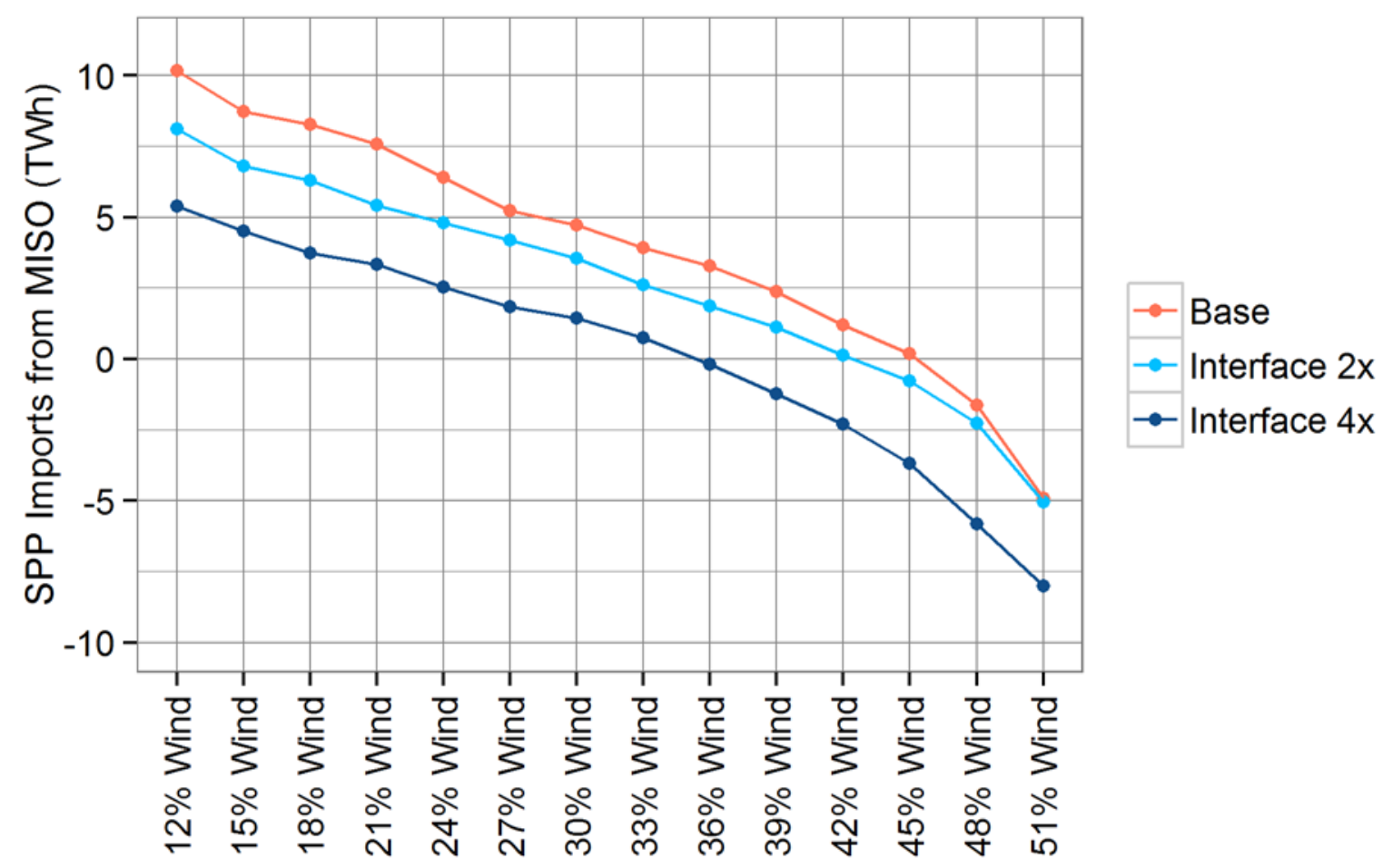

Figure 69. Annual SPP imports from MISO.

Figure 70 shows a clear correlation between avoided wind curtailment and increased annual operational savings when the interface capacity increases. However, there are also significant savings at low wind penetrations when little to no curtailment is avoided. At $11 \%$ wind, annual savings from doubling the interface limits reaches more than $\$ 250$ million. This suggests that large savings are possible by using thermal generation more efficiently. Annual savings from quadrupling the interface limits reaches $\$ 325$ million at $11 \%$ wind - an increase, but hardly a doubling of the savings over the smaller interface-limit increase. Therefore, much of the efficiency gains from using the most cost-effective thermal generators are already achieved when the interface limits are doubled. 


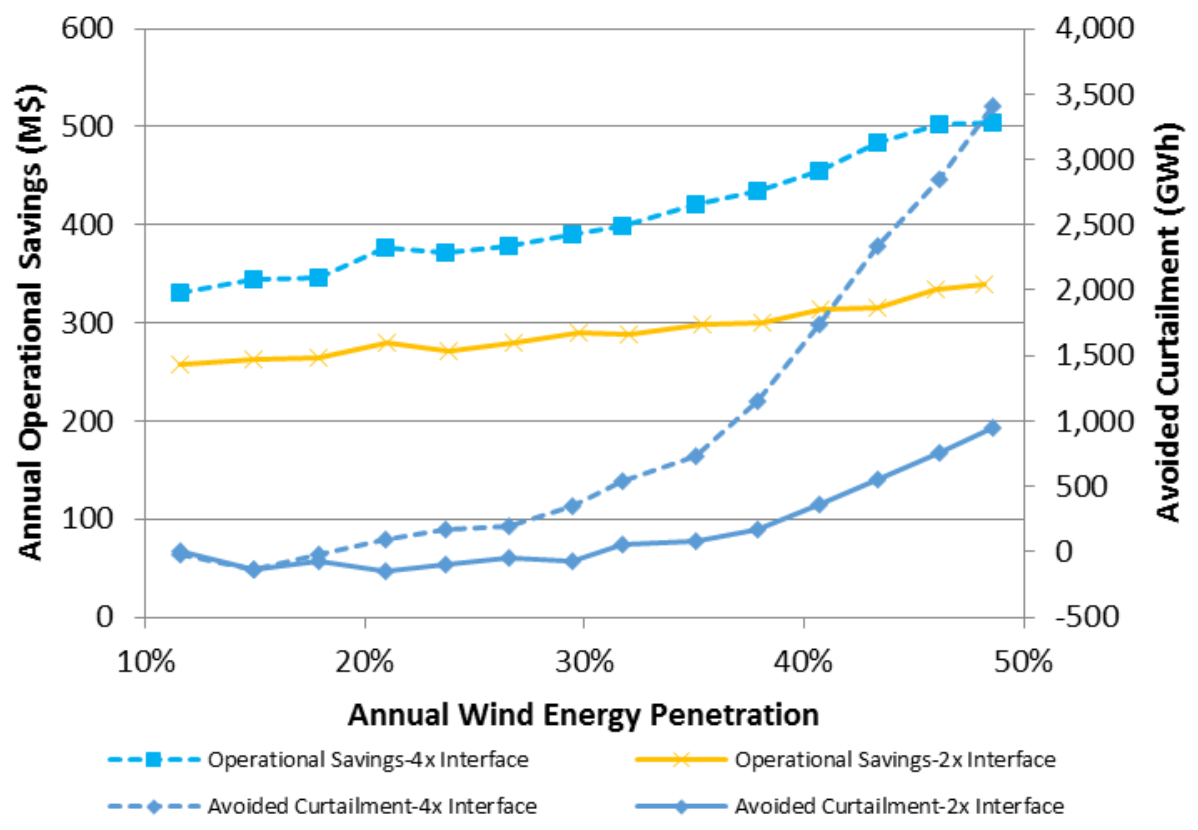

Figure 70. Annual operational savings and reduced curtailment with increased interface transmission capacity between zones in SPP.

The annual operational savings between the two increases in the interface capacity diverge as the wind penetration increases. The large interface expansion is able to avoid three times the curtailment at the highest wind penetration relative to the smaller interface expansion. This allows the large interface expansion to save more than $\$ 150$ million over the smaller option.

As mentioned previously, nodal runs of the Eastern Interconnection determined the original interface limits for the base case (Bloom et al. 2016). These nodal runs, representing the year 2026, already include some transmission that does not exist today. Increasing transmission capacity beyond those assumptions would involve new investments in transmission lines. Although increased transmission capacity has substantial monetary benefits, it also has substantial costs.

Total interface capacity increases by $8 \mathrm{GW}$ and $24 \mathrm{GW}$ for the smaller and larger interface expansion scenarios, respectively. Using the same ReEDS assumptions discussed in Section 3.5.5 for FRCC, the total project cost to double and quadruple the interface limits is $\$ 2.3$ billion and $\$ 7$ billion, respectively - which translates into $\$ 238$ million and \$716 million annually, respectively. For all wind penetrations, doubling the size of the interfaces is a net positive to the system, whereas even at the highest wind penetrations, quadrupling the interface size never breaks even when only operational cost savings are considered.

\subsubsection{Reduced Minimum Generation Levels}

Minimum generation levels of conventional generators can be a substantial constraint on the system. Generators cannot turn down past their minimum generation levels, which means that generating at lower levels requires turning off a generator. Some generators require several hours to start up after being turned off. Thus, lowering the minimum generation levels of plants, which increases their operating range, can add flexibility to the system. Conventional generators are 
also required to turn down to accommodate high penetrations of wind generation. For instance, in the base $12 \%$ wind case, the coal fleet in SPP is at its minimum generation level for $27 \%$ of its operating hours. In the base $51 \%$ wind case, that number increases to $38 \%$.

As mentioned previously, the base cases assume a minimum generation level of $50 \%$ of their maximum capacity for all gas CCs and most coal generators (large coal generators have a minimum generation level of $30 \%$ ). For this sensitivity, we reduce the minimum generation level to $40 \%$ for all generators that had previously been $50 \%$. Initially, we observe that the minimum generation levels are much less frequently binding constraints. In the $12 \%$ wind case, coal generators are operating at their minimum generation levels for only $1.4 \%$ of the time, and in the $51 \%$ wind case, for $6 \%$ of the time.

Figure 71 shows the coal fleet for the study area for four days in June. The upper panel shows the lowest wind penetration case, and fleet dispatch is nearly identical because the minimum generation level never constrains fleet output. However, in the $51 \%$ wind case in the bottom panel, the fleet turns down to its minimum level during the night in three of the selected days due to low load levels and high wind output. Reducing the minimum generation level allows a larger operational range, which means that the fleet can turn down generation from 9,700 MW to 8,300 $\mathrm{MW}$, thus accommodating more wind generation.

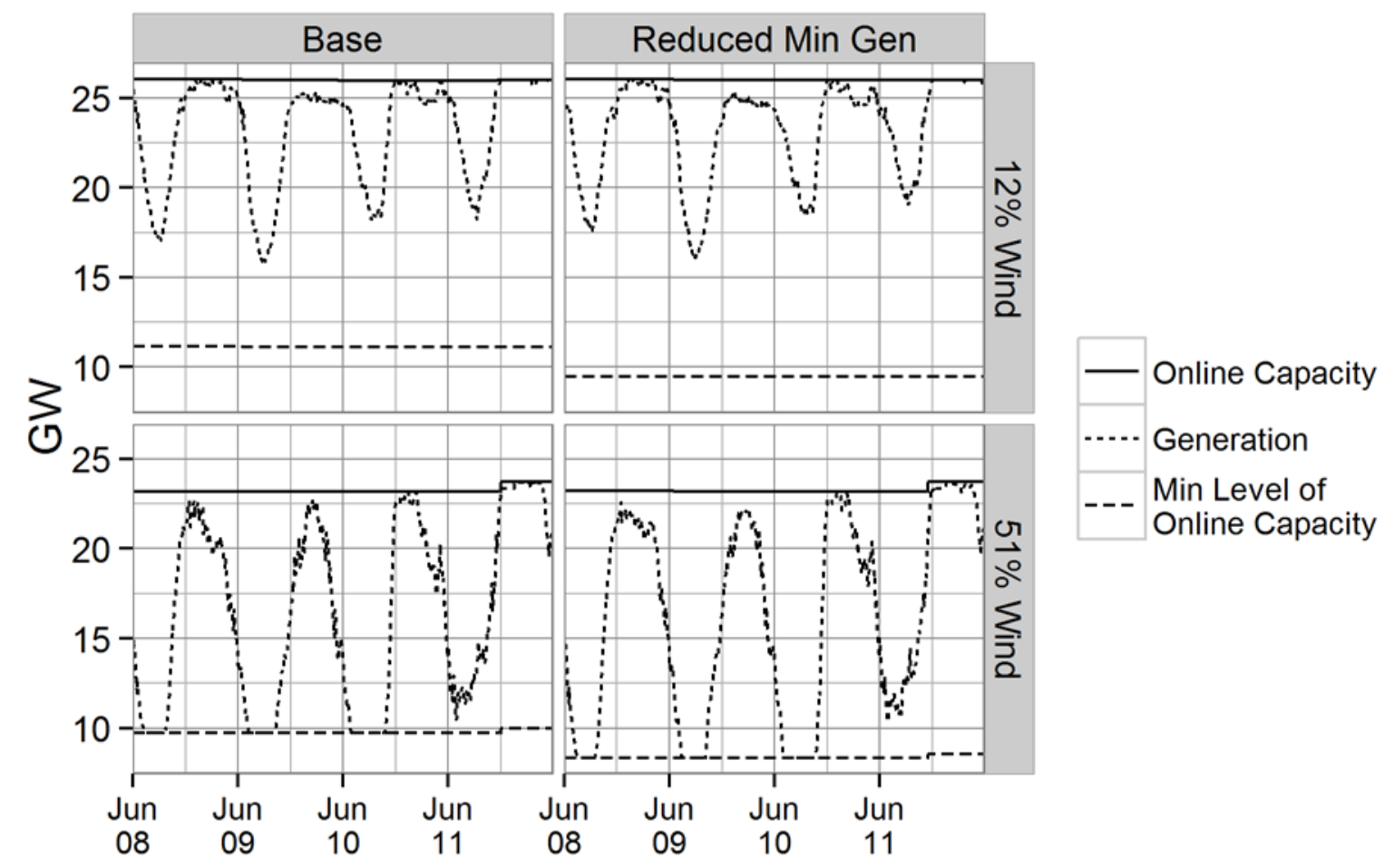

Figure 71. Coal fleet dispatch during four days in June.

Lower minimum generation costs do provide economic value in these cases, as well as higher value at increased wind penetrations. However, as Figure 65 shows, the impact on marginal curtailment is small. There is some economic benefit to being able to use wind energy instead of coal with reduced minimum generation level (as is shown in the 51\% case in Figure 71). 
However, most of the economic benefit coming from reduced minimum generation level is associated with avoiding fuel costs through better utilization of the thermal fleet.

Reducing the minimum generation level of CCs and select coal units in SPP provides increasing operational savings at the lower end of the wind penetrations studied, as shown in Figure 72. At $11 \%$ wind, savings top $\$ 15$ million and increase to $\$ 60$ million when wind generation exceeds $25 \%$ of total load. However, after reaching $25 \%$ wind, the annual operational savings level out around $\$ 50$ million. These savings show little correlation with avoided wind curtailment.

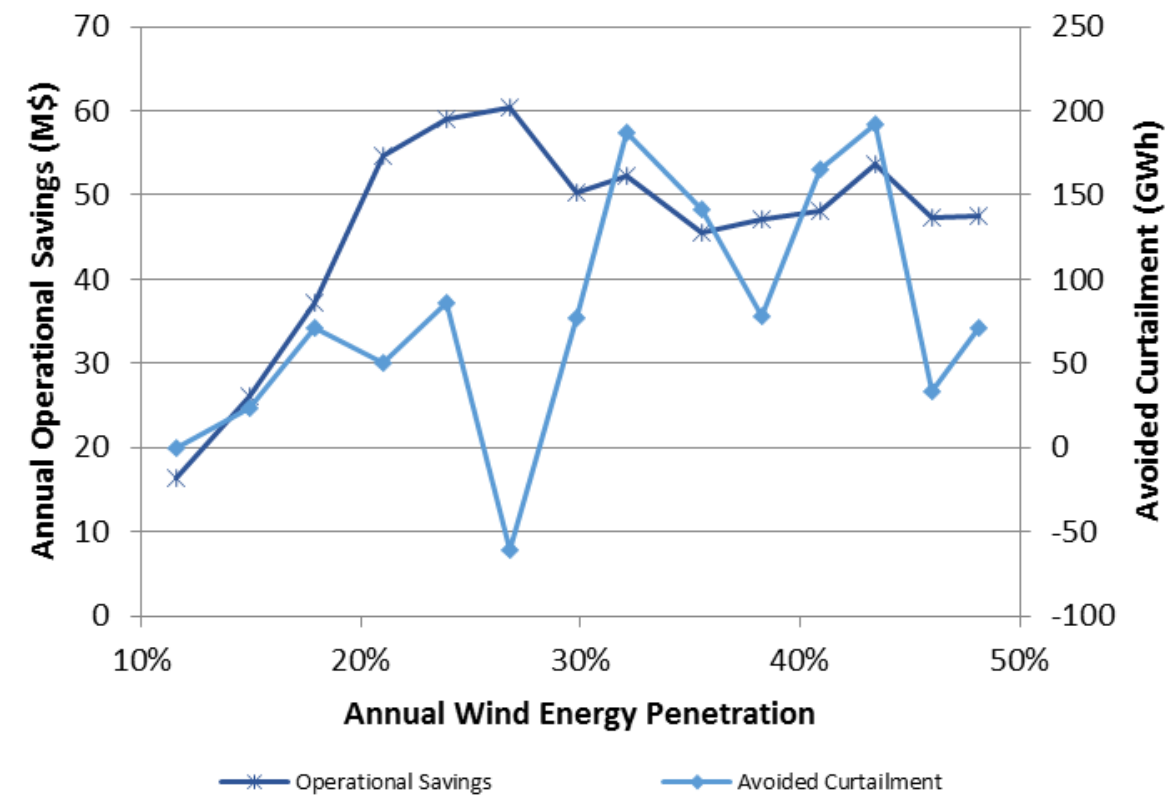

Figure 72. Annual operational savings and reduced curtailment with reduced minimum generation levels for CCs and coal in SPP.

\subsubsection{Elimination of Hurdle Rates}

Market forces that distort the true cost of electricity can cause inefficient dispatch. We use a $\$ 10 / \mathrm{MWh}$ hurdle rate for energy exchange between zones to represent market friction. In this sensitivity, we eliminate the hurdle rate, which means that energy can flow between two regions due to any price difference (but it is still subject to interface flow limits). As Figure 73 shows, even relatively small hurdle rates can have a large impact on imports. Without hurdle rates, SPP imports substantially more energy at lower wind penetrations, and it exports substantially more energy at higher penetrations. 


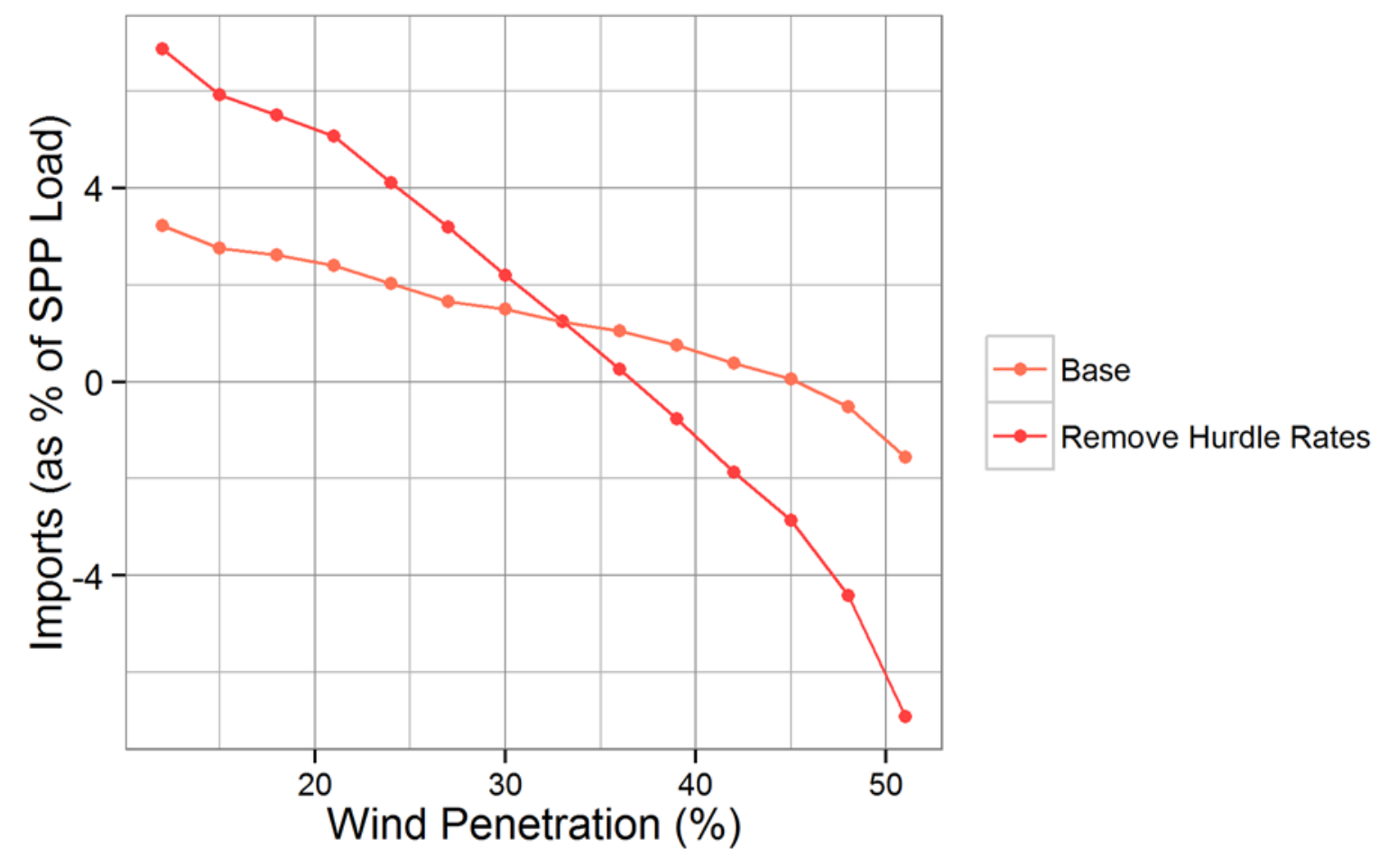

Figure 73. Annual imports as a percent of total SPP load.

Figure 74 shows a histogram of the average price difference between SPP and MISO for each of the 5-minute intervals in this study. A positive difference indicates that the price in MISO is higher, and a negative difference indicates that the price in SPP is higher. As the graph indicates, a great majority of intervals (at least $85 \%$ in each base scenario) fall between positive and negative $\$ 10 / \mathrm{MWh}$, which means that an exchange would not occur. In the Remove Hurdle Rates scenarios, we see many more price differentials at or near $\$ 0 / \mathrm{MWh}$, which indicates that the price is the same in both regions due to efficient trading. Also, as wind penetration increases in the Remove Hurdle Rate scenario, the price differential between SPP and MISO increases because the presence of $\$ 0 / \mathrm{MWh}$ wind in SPP reduces the average price in SPP but can only reduce the price in MISO to a certain extent due to interface limits. 


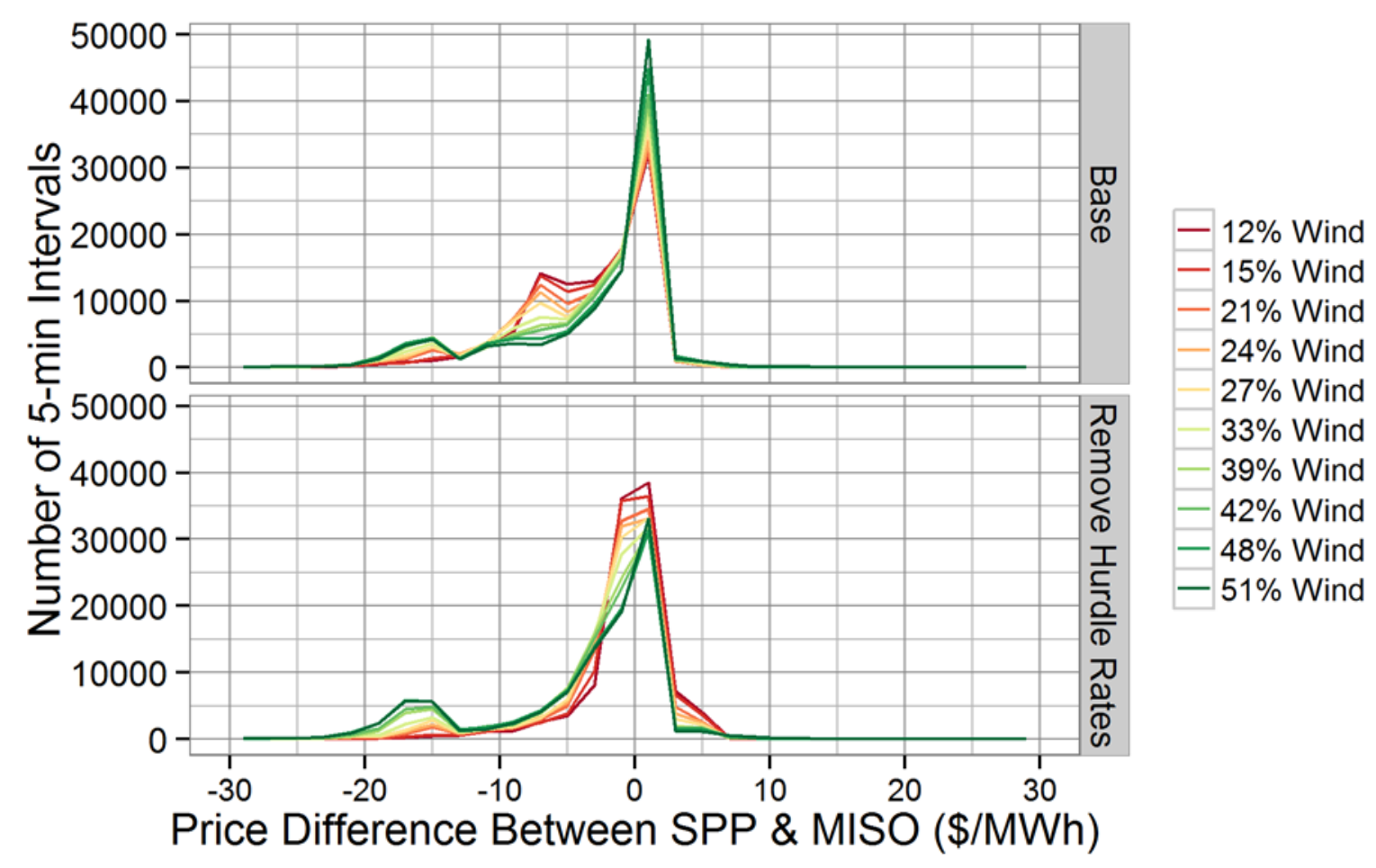

Figure 74. Histogram of price differences between SPP and MISO.

Eliminating hurdle rates between SPP and MISO captures increased cooperation between the two entities and assumes lower market friction. This allows both regions to more efficiently use generation, as demonstrated in Figure 75. Even at small wind penetrations, there are annual savings from eliminating hurdle rates. 


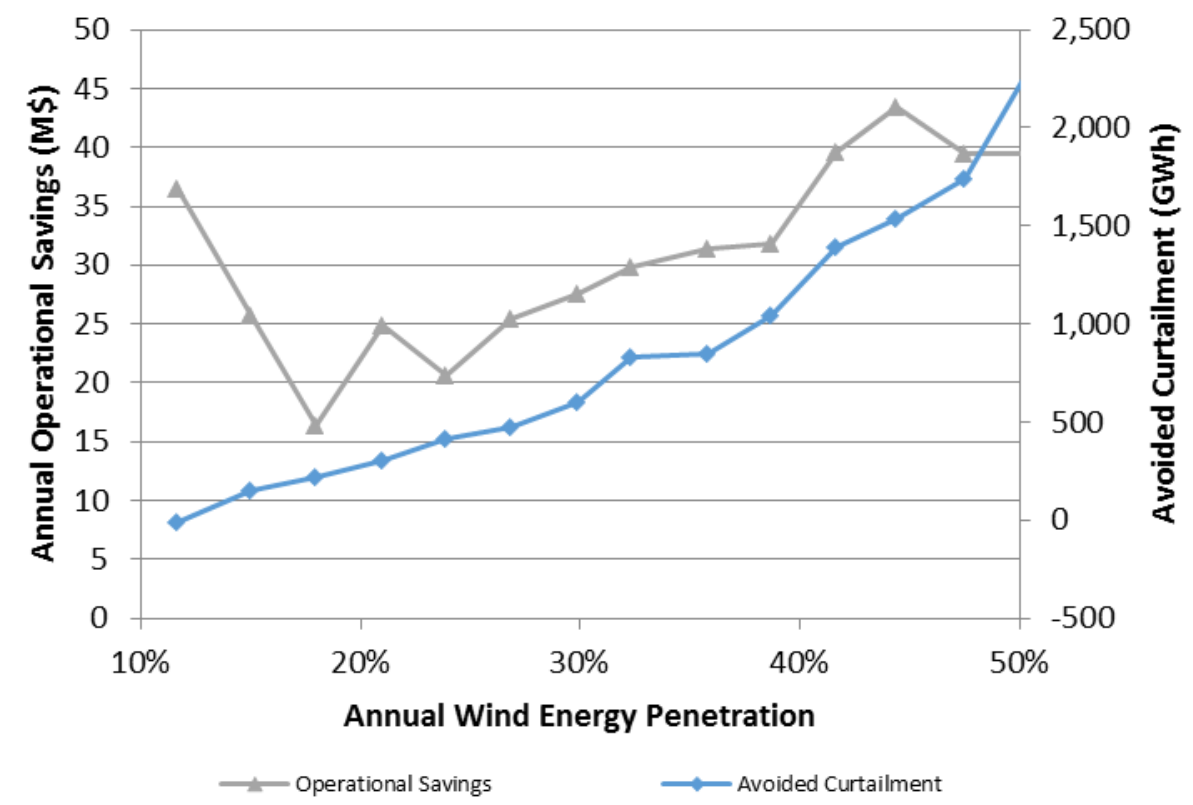

Figure 75. Annual operational savings and reduced curtailment with the elimination of hurdle rates between MISO and SPP.

The costs of eliminating hurdle rates are best estimated using the assumed cost of incorporating all of WECC into the Energy Imbalance Market. As discussed for the FRCC in Section 3.5.3, incorporating WECC into the EIM is expected to cost a total of \$19.6 million. The annual savings from removing hurdle rates between SPP and MISO exceeds this amount, except for the $18 \%$ wind penetration. The combined peak loads of SPP and MISO are comparable to that of WECC. This flexibility option is clearly a net positive to the system.

\subsubsection{Addition of Energy Storage}

Energy storage can help with integration of wind energy by shifting energy over time-from times of high supply to times of high demand. Here, we study two energy storage cases that add $1 \mathrm{GW}$ and $4 \mathrm{GW}$ of energy storage to the SPP system. In both cases, we see economic benefits to the addition of storage, as well as a modest reduction in marginal curtailment.

In general, storage functions to increase demand during times of low net load and to reduce load during times of high demand. Figure 76 shows the shape of average net load (load minus contributions from wind and solar) during different seasons. In general, the impact of additional wind on net-load shape is to reduce net load, especially during the overnight hours when wind generation is the highest. This daily effect of wind generation is most evident during the summer. Figure 76 indicates that storage in SPP will generally charge overnight and displace generation during the afternoon or evening peak. 

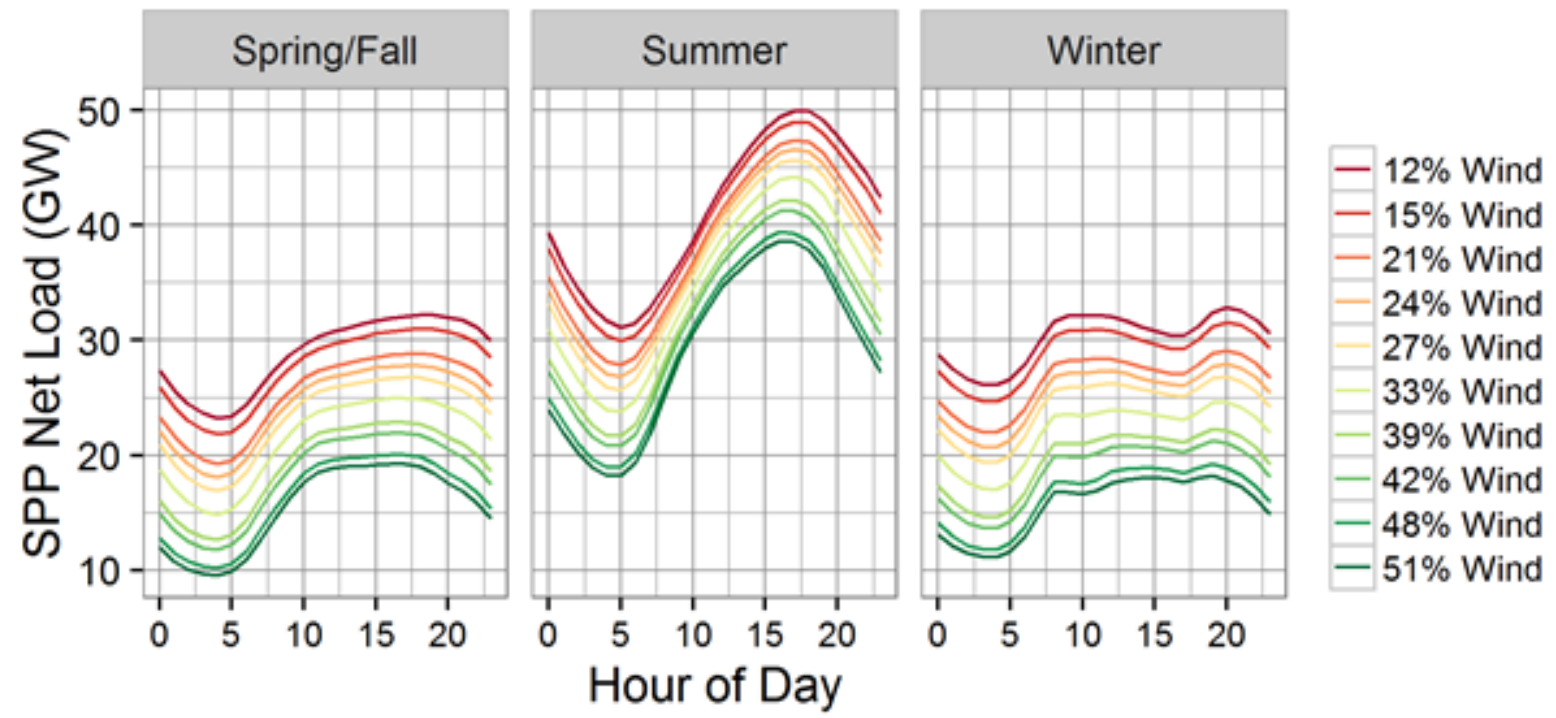

Figure 76. Average daily net-load shape in SPP.

Figure 77 shows the actual storage dispatch in this system for the two storage cases. Negative values indicate that storage is charging and is therefore consuming electricity. As predicted by the net-load shapes, storage is generating during the evening hours during every season and is charging in the night. During the winter, spring, and fall, storage will often also displace energy during the morning peaks. The plot also indicates how dispatch changes across wind penetration scenarios. Generally, the dispatch shape does not change much across wind penetrations, largely because the overall net-load shape is not changing dramatically (Figure 76). However, the storage utilization does decrease slightly due to higher wind penetrations. For instance, the capacity factors of the $1-\mathrm{GW}$ storage devices are $28 \%$ at $12 \%$ wind and $23 \%$ in the $51 \%$ case ( $21 \%$ and $19 \%$ in the $4-\mathrm{GW}$ cases, respectively). Capacity factor drops the most dramaticallyby $30 \%$ - during the winter months and only by $2 \%$ in the summer months. Figure 77 indicates that wind effectively flattens the morning and evening winter net-load peak; thus, the utilization of storage decreases. In the summer months, even though the wind dramatically reduces the net load, the overall load shape changes very little and the utilization of storage is similar across wind penetrations. 


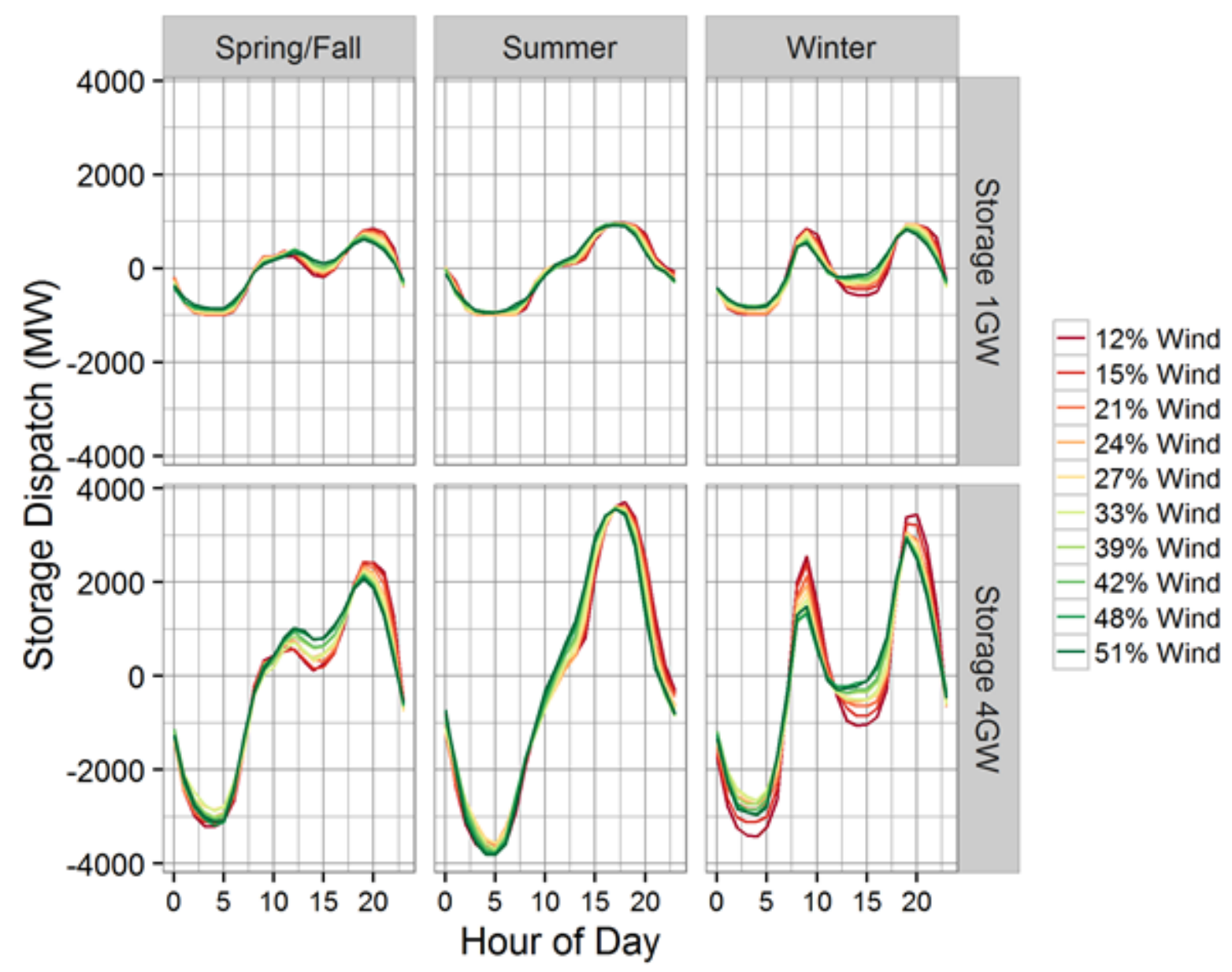

Figure 77. Average daily operation of storage in SPP for various wind penetrations.

Figure 78 compares the reduction in PV curtailment and annual operational savings of the two battery flexibility scenarios ( $1 \mathrm{GW}$ of batteries and $4 \mathrm{GW}$ of batteries). Unlike the California and FRCC case studies, the annual operational savings do not show a strong correlation with avoided curtailment. 


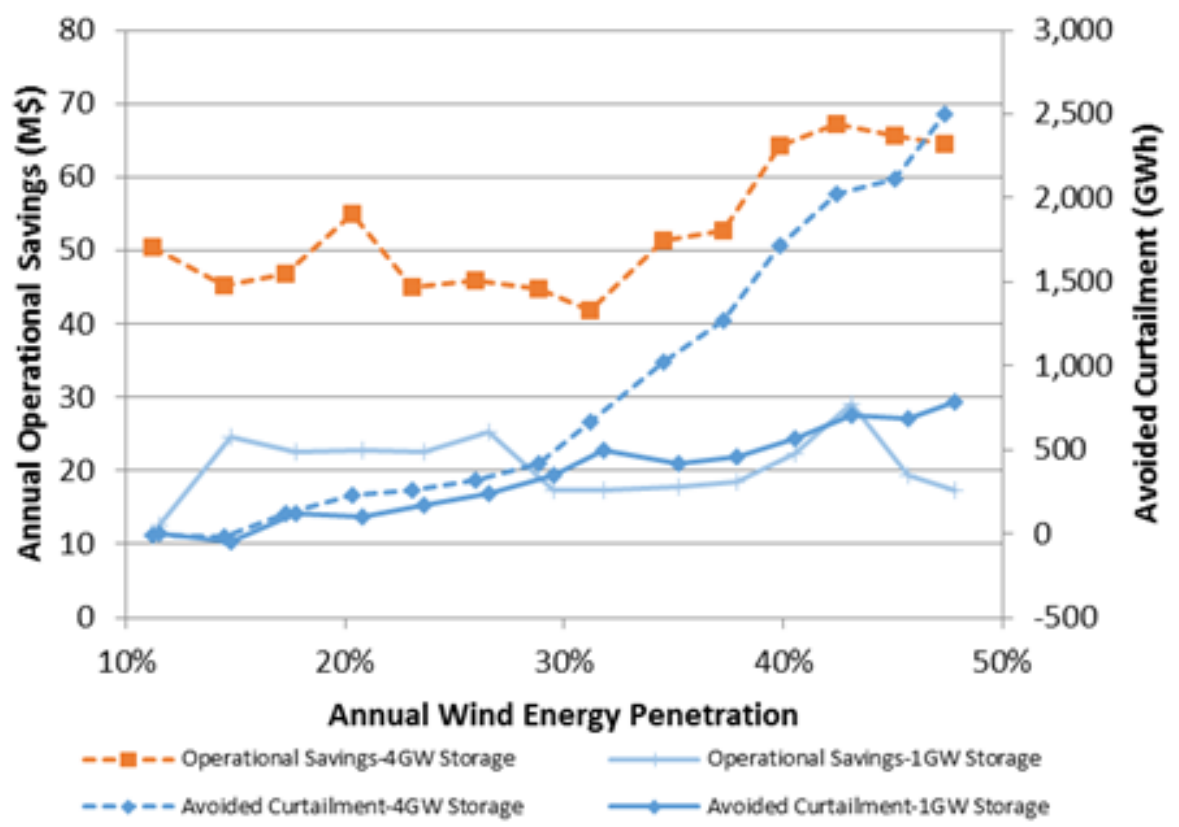

Figure 78. Annual operational savings and reduced curtailment with different capacities of energy storage in SPP.

As discussed in Section 2.5.3 of the California case study, much of the value of energy storage comes from its capacity value. Figure 79 shows how high and low assumptions change the total value of the battery storage options. No matter what the assumed capacity value of the battery, the total capacity value is an order of magnitude greater than the operational value. Therefore, the total value of battery storage remains essentially constant across all wind penetrations.

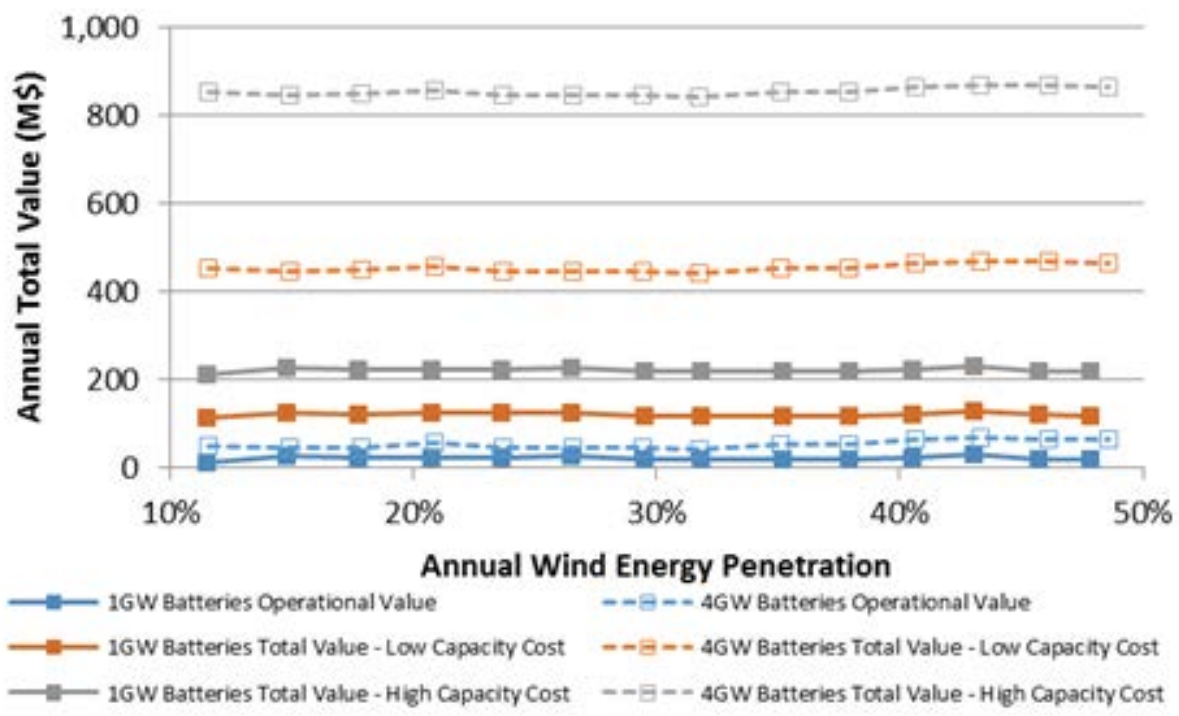

Figure 79. Total value of energy storage in SPP.

Assuming the same capital costs of energy storage as in the California case study $(\$ 200 / \mathrm{kWh}-$ $\$ 350 / \mathrm{kWh}$ ), the annualized costs of battery storage range from $\$ 122-\$ 214$ million for $1 \mathrm{GW}$ of battery deployment (solid lines in Figure 79) and \$489-\$856 million for $4 \mathrm{GW}$ (dashed lines in 
Figure 79). These ranges in costs fall almost exactly on the bounds of the total annual value with different assumptions for the capacity value. This finding indicates considerable uncertainty in whether energy storage will provide enough total value to be a net benefit to the system.

\subsubsection{Allowing Wind to Provide Reserves}

As mentioned previously, allowing renewable generators to provide operating reserves can improve grid flexibility. Allowing conventional generator capacity to provide reserves will ensure, at times, that too much conventional generator capacity is online-sometimes at the expense of curtailing renewable energy. Because we only model up-reserves here, wind generation must have spare upward capacity in order to provide reserves. Practically, this means that wind generation must actually be curtailed to have spare capacity. In theory, if wind generation is already being curtailed, then allowing that capacity to provide reserves will free up thermal generation to operate more efficiently.

We see a negligible impact of this flexibility option, although wind generators are contributing to reserve provision as indicated in Figure 80. Especially at the lower wind penetration cases, curtailment is so low that wind generators do not have much spare upward capacity. At higher penetrations, the conventional generator fleet is turned down to accommodate more wind, and it has considerable upward capacity without the spare upward capacity from curtailed wind. For instance, at the $12 \%$ wind scenario, the online coal generators are operating at $84 \%$ of their maximum capacity and gas generators are operating at $76 \%$. At $51 \%$ penetration, these generators are operating at $76 \%$ and $73 \%$, respectively.

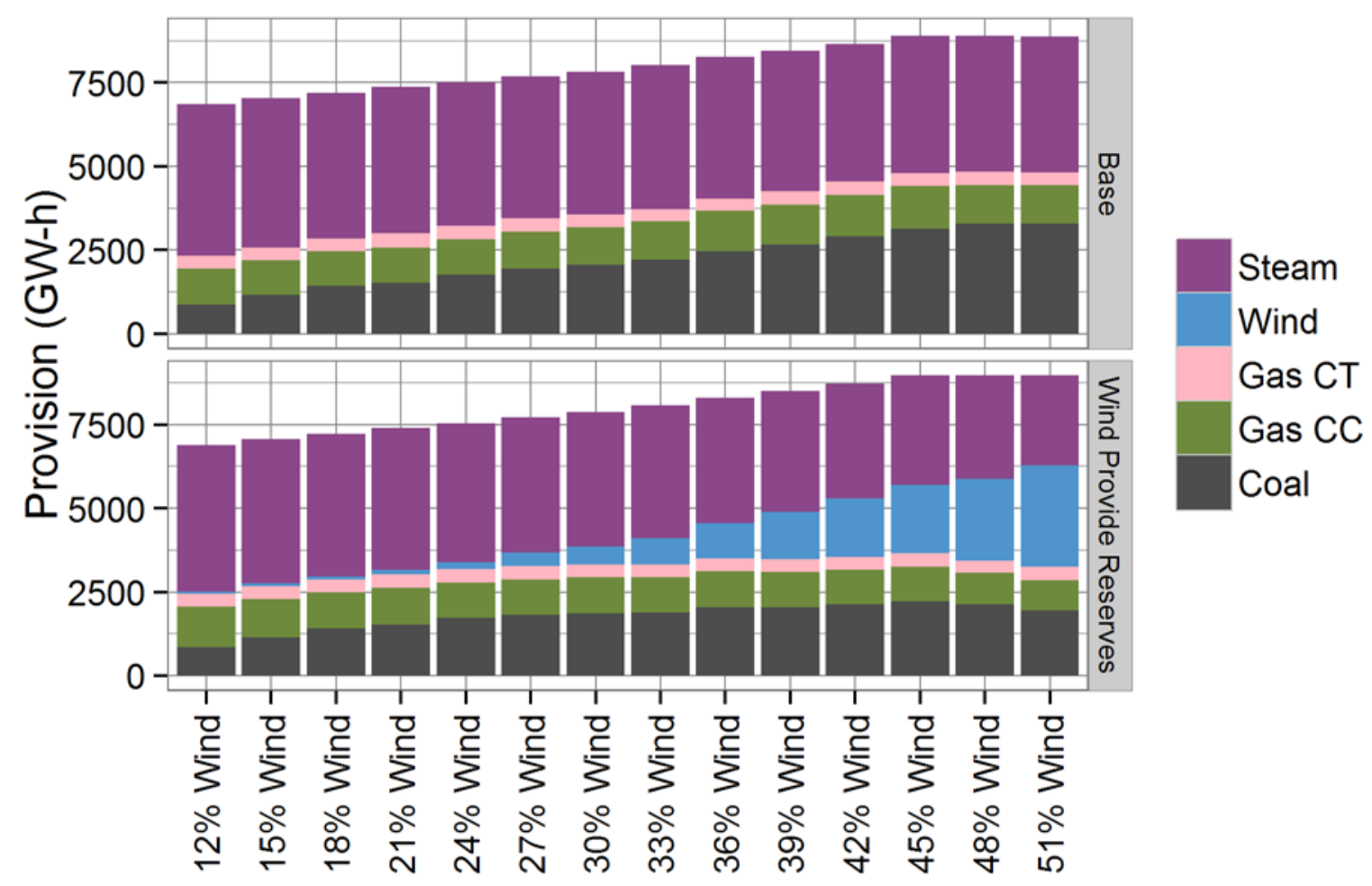

Figure 80. Breakdown of reserve provision by generator type. 
The flexibility option of wind providing reserves does not lead to any operational value to the system. It also increases curtailment in general because wind, at times, is determined to be more valuable as reserves than as energy. However, the results of the analysis show a very limited value of wind providing reserves. As in the FRCC case, this result reflects some of the limitations in how reserves are modeled. This includes the lack of estimating the additional cost of varying the output of plants to respond to a regulation signal (Hummon et al. 2013b). As a result, this analysis cannot provide the true value of wind in providing operating reserves. Furthermore, a significant benefit of wind providing reserves may be derived from provision of stability services including inertia and primary frequency response (Miller et al. 2014). Further analysis is needed to quantify the benefits of these services. 


\section{Conclusions}

In this study, we have attempted to quantify the benefits of various options of grid flexibility by measuring the impact of the options on two measures: economic carrying capacity and system costs.

The first measure, economic carrying capacity (ECC), determines the level of penetration of variable-generation (VG) renewable energy (RE) at which the costs outweigh the benefits and where additional VG is no longer economically desirable. The second measure, system costs, includes determining the reduced operating costs resulting from increased efficiency of operation, as well as reduced capital costs if the flexibility measure reduces the need for conventional capacity.

We conducted modeling for case studies in three regions of the country-California, Florida, and the central U.S. - which allowed us to study different aspects of variable-generation integration, including generation mix and wind/solar mix. We compared the benefits of increased ECC in each region to costs, which helped to further understand the flexibility supply curve. We draw three overall conclusions below based on these results.

- The concept of economic carrying capacity, particularly when applied to VG resources, has evolved over time. Historically, physical or technical issues have been perceived to fundamentally limit the penetration of VG. However, a more nuanced understanding has been gained through grid integration studies and operational experience. Specifically, there is growing recognition that although technical challenges to VG integration are real, they can generally be addressed by a variety of solutions - each one having an associated implementation cost. As a result, the limit of RE penetration is primarily economic, driven by factors that include transmission availability and operational flexibility.

- Flexibility can increase economic carrying capacity and reduce overall system costs. In some cases, options that provide a limited increase in ECC can provide significant operational savings, thus demonstrating the need to evaluate flexibility options using multiple metrics. The value of flexibility options varies regionally due to different generation mixes and types of renewables. The more rapid decline in photovoltaic value compared to wind makes photovoltaics more dependent on adding flexibility options, including transmission and energy storage.

- New analysis methods and data sources will be needed to evaluate some flexibility options, including the ability of VG to provide reserves and the role of demand response in integrating variable generation.

Comparison between the case studies is difficult because the ECC of a power system is highly specific to region and can change over time - as when inflexible generators retire, or demand and renewable supply forecasting improves, or market designs evolve, or enabling technologies such as storage become more affordable. But we highlight some key takeaways from our three analyses.

- California case study. This study examined the value of PV. Near-term flexibility options now being deployed will substantially increase ECC and reduce operating costs in California. These options relate to allowing a greater fraction of load to be served by 
VG and to increasing the sharing of resources across the state. Exports and energy storage can also substantially increase ECC. Demand response can provide significant value, but the DR assumptions used in the study produce only a modest increase in ECC. This outcome is due to the limited availability of shiftable load in the spring and fall, which are periods of greatest PV curtailment. This result points to the need for additional understanding of the potential to shift load during the spring - the period characterized by the so-called "duck curve."

- Florida case study. This study also evaluated PV, and demonstrates significant operational value and increased ECC from both increased transmission and energy storage. Fewer benefits were demonstrated from providing reserves from PV. This result is due, in part, to the limited ability to evaluate the very short-term benefits of PV providing frequency response and frequency regulation. Limited benefits were also found from reducing combined-cycle flexibility. This counter-intuitive result is largely due to the inherent flexibility of the combined-cycle fleet to frequently cycle on/off, even on a daily basis. Paired with accurate day-ahead forecast of the PV resource, the on/off cycling limits the value of reducing the minimum generation level. Reducing that level would add more value if on/off cycling is actually more restrictive than assumed in this study. This result points to the need for more detailed analysis of plant cycling costs compared to the benefits of reduced curtailment and increased ECC.

- Southwest Power Pool case study. The results of this study, which evaluated wind, are substantially different from the other regions. The value of wind as a function of deployment is fairly flat relative to PV, with an ECC of at least $50 \%$ due to the low cost of wind, and when including the assumed cost of carbon. As a result, wind did not need flexibility options to increase the ECC under the scenarios evaluated. Although the impact on ECC is limited, this case shows significant value of new transmission. Net cost savings, rather than increasing ECC, is the more important value of flexibility in this region. 


\section{References}

Aho, J., A. Buckspan, J. Laks, P. Fleming, J. Yunho, F. Dunne, M. Churchfield, L. Pao, K. Johnson (2012). A Tutorial of Wind Turbine Control for Supporting Grid Frequency Through Active Power Control, American Control Conference (ACC), 27-29 June 2012, vol., pp. 31203131. DOI: $10.1109 /$ ACC.2012.6315180

Bertsch, J., C. Growitsch, S. Lorenczik, S. Nagl (2016). Flexibility in Europe's Power SectorAn Additional Requirement or an Automatic Complement?, Energy Economics, vol. 53, January 2016, pp. 118-131, ISSN 0140-9883, http://dx.doi.org/10.1016/j.eneco.2014.10.022

Bloom, A, A. Townsend, D. Palchak, J. Novacheck, J. King, M. O'Connell, E. Ibanez, G. Jordan, C. Barrows, M. Hummon, C. Draxl (2016). Eastern Renewable Generation Integration Study.

Bouillon, B. (2014). Prepared Statement of Brad Bouillon on behalf of the California Independent System Operator Corporation UNITED STATES OF AMERICA BEFORE THE FEDERAL ENERGY REGULATORY COMMISSION Reliability Technical Conference Docket No. AD14-9-000. http://www.ferc.gov/CalendarFiles/20140610083142Bouillon,\%20CAISO.pdf

Brinkman, G., J. Jorgenson, A. Ehlen, J. Caldwell (2015). The California 2030 Low Carbon Grid Study, TP- 6A20-64884.

CAISO (2010). Integration of Renewable Resources: Operational Requirements and Generation Fleet Capability at 20\% RPS. Folsom, CA. Accessed May 2, 2014: http://www.caiso.com/Documents/Integration-RenewableResourcesOperationalRequirementsandGenerationFleetCapabilityAt20PercRPS.pdf

CAISO (2011). Summary of Preliminary Results of 33\% Renewable Integration Study-2010 CPUC LTPP Docket No. R.10-05-006. Folsom, CA. Accessed May 2, 2014: http://www.cpuc.ca.gov/NR/rdonlyres/E2FBD08E-727B-4E84-BD987561A5D45743/0/LTPP_33pct_initial_results_042911_final.pdf

CAISO (2011a). Track I Direct Testimony of Mark Rothleder on Behalf of the California Independent System Operator Corporation (Corrected)," Before the Public Utilities Commission of the State of California, Order Instituting Rulemaking to Integrate and Refine Procurement Policies and Consider Long-Term Procurement Plans, Rulemaking 10-05-006. (2011). Accessed March 27, 2013: http://www.caiso.com/Documents/2011-08-10_ErrataLTPPTestimony_R10-05006.pdf

CAISO (2012). Annual Report on Market Issues and Performance. Folsom, CA. Accessed May 2, 2014: http://www.caiso.com/Documents/2012AnnualReport-MarketIssue-Performance.pdf

CAISO (2015). California Independent System Operator Corporation Filing of ISO Rate Schedule No. 79 Docket No. ER15- 
1802. https://www.caiso.com/Documents/May28_2015_EIM_ImplementationAgreementbetwee nArizonaPublicService_CaliforniaISO_ER15-1802.pdf

CAISO (2016). https://www.caiso.com/Documents/SB350Study AggregatedReport.pdf

CAISO

(2013). https://www.caiso.com/Documents/FlexibleResourcesHelpRenewables_FastFacts.pdf

California Energy Commission (2011). Renewable Power in California: Status and Issues CEC150-2011-002-LCF-REV1. Sacramento, CA. Accessed May 2,

2014: http://www.energy.ca.gov/2011publications/CEC-150-2011-002/CEC-150-2011-002-

LCF-REV1.pdf

California Energy Commission (2014). California Electricity Statistics and Data. Sacramento, CA. Accessed: January 30,

2014: http://energyalmanac.ca.gov/electricity/electricity_generation.html

(2015). "Historical California Electricity Demand." Sacramento, CA. Accessed

December 30, 2014: http://energyalmanac.ca.gov/electricity/historic_peak_demand.html

CPUC (California Public Utilities Commission) (2013). California Public Utilities Commission Rulemaking 13-12-010, Order Instituting Rulemaking to Integrate and Refine Procurement Policies and Consider Long-Term Procurement Plans, December 19, 2013, http://docs.cpuc.ca.gov/PublishedDocs/Published/G000/M084/K241/84241040.PDF

CPUC (2015a). Beyond 33\% Renewables: Grid Integration Policy for a Low-Carbon Future: A CPUC Staff White Paper.

CPUC (2015b). "Demand Response Monthly Reports.” Accessed December

2015. http://www.cpuc.ca.gov/PUC/energy/Demand+Response/Monthly+Reports/2015 DR.htm.

Cochran, J., P. Denholm, B. Speer, and M. Miller (2015). Grid Integration and the Carrying Capacity of the U.S. Grid to Incorporate Variable Renewable Energy. Golden, CO: National Renewable Energy Laboratory. NREL/TP-6A20-

62607. http://www.nrel.gov/docs/fy15osti/62607.pdf.

Cochran, J., M. Miller, O. Zinaman, M. Milligan, D. Arent, B. Palmintier, M. O'Malley, S. Mueller, E. Lannoye. A. Tuohy, B. Kujala, M. Sommer, H. Holttinen, J. Kiviluoma, S. K. Soonee (2014). Flexibility in 21st Century Power Systems. Golden, CO: National Renewable Energy Laboratory. NREL/TP-6A20-61721. http:/www.nrel.gov/docs/fy14osti/61721.pdf.

Denholm, P., K. Clark, and M. O’Connell (2016). On the Path to SunShot: Emerging Issues and Challenges in Integrating High Levels of Solar into the Electrical Generation and Transmission System. Golden, CO: National Renewable Energy Laboratory. NREL/TP-6A20-65800. http://www.nrel.gov/docs/fy16osti/65800.pdf.

Denholm, P.; Y.-H. Wan, M. Hummon, M. Mehos (2013). An Analysis of Concentrating Solar Power with Thermal Energy Storage in a California 33\% Renewable Scenario. NREL/TP-6A20- 
58186. Golden, CO: National Renewable Energy Laboratory. Access May 2, 2014: http://www.nrel.gov/docs/fy13osti/58186.pdf

Denholm, P., R. Margolis, B. Palmintier, C. Barrows, E. Ibanez, L. Bird (2014). Methods for Analyzing the Benefits and Costs of Distributed Photovoltaic Generation to the U.S. Electric Utility System. NREL Report No. TP-6A20-62447.

Eichman, J., P. Denholm, J. Jorgenson, and U. Helman (2015). Operational Benefits of Meeting California's Energy Storage Targets. NREL/TP- 5400-65061. Golden, CO: National Renewable Energy Laboratory. http://www.nrel.gov/docs/fy16osti/65061.pdf

Ela, E., M. Milligan, A. Bloom, A. Botterud, A. Townsend, T. Levin (2014). 2014 Evolution of Wholesale Electricity Market Design with Increasing Levels of Renewable Generation. NREL/TP-5D00-61765.

Energy and Environmental Economics, Inc. (2013). Investigating a Higher Renewables Portfolio Standard in California. San Francisco, CA: January. Accessed May 2, 2014: https://ethree.com/documents/E3 Final RPS Report 20140106 with appendices.pdf

ERCOT (2014). Demand Response in ERCOT. 2014 Operators Training Seminar, http://www.ercot.com/services/training/archives

GE Energy, Western Wind and Solar Integration Study (2010). NREL/SR-550-47434. Golden, CO: NREL. Accessed January 2013: http://www.nrel.gov/docs/fy10osti/47434.pdf

Gevorgian, V., and B. O'Neill (2016). Advanced Grid-Friendly Controls Demonstration Project for Utility-Scale PV Power Plants. Golden, CO: National Renewable Energy Laboratory. NREL/TP-5D00-65368. http://www.nrel.gov/docs/fy16osti/65368.pdf.

Hogan, M and B. Paulos (2014). "Dealing With the Duck." Public Utilities Fortnightly. January 2014, pp. 22-25.

Holttinen, H. et al. (2013). The Flexibility Workout: Managing Variable Resources and Assessing the Need for Power System Modification, IEEE Power \& Energy, vol. 11, no. 6, pp. $53-62$.

Hummon, M., D. Palchak, P. Denholm, J. Jorgenson, D. J. Olsen, S. Kiliccote, N. Matson, M. Sohn, C. Rose, J. Dudley, S. Goli, and O. Ma (2013). Grid Integration of Aggregated Demand Response, Part 2: Modeling Demand Response in a Production Cost Model. Golden, CO: National Renewable Energy Laboratory. NREL/TP-6A2058492. http://www.nrel.gov/docs/fy14osti/58492.pdf.

M. R. Hummon; P. Denholm; J. Jorgenson; D. Palchak; B. Kirby; O. Ma (2013b). Fundamental Drivers of the Cost and Price of Operating Reserves NREL/TP-6A20-58491

Ibanez, E., G. Brinkman, M. Hummon, D. Lew (2013). Solar Reserve Methodology for Renewable Energy Integration Studies Based on Sub-Hourly Variability Analysis. Prepared for the $2^{\text {nd }}$ Annual International Workshop on Integration of Solar Power into Power Systems on 
November 12-13 in Lisbon, Portugal. NREL/CP-5500-

56169. www.nrel.gov/docs/fy12osti/56169.pdf

IEA (2014). The Power of Transformation - Wind, Sun and the Economics of Flexible Power Systems https://www.iea.org/publications/freepublications/publication/the-power-oftransformation---wind-sun-and-the-economics-of-flexible-power-systems.html;

Jorgenson, J., P. Denholm, M. Mehos (2014). Estimating the Value of Utility-Scale Solar Technologies in California under a 40\% Renewable Portfolio Standard, NREL Report No. TP6A20-61685.

Kundur, P., J. Paserba, V. Ajjarapu, G. Andersson, A. Bose, C. Canizares, N. Hatziargyriou, D. Hill, A. Stankovic, C. Taylor, T. Van Cutsem, and V. Vittal (2004). "Definition and Classification of Power System Stability." IEEE Transactions on Power Systems 19(2): 1387-1401.

Lannoye, E., D. Flynn, M. O'Malley (2012). Evaluation of Power System Flexibility, IEEE. Trans. Power Syst., vol. 27, no. 2, pp. 922-931.

Lannoye, E., D. Flynn, M. O'Malley (2015). Transmission, Variable Generation, and Power System Flexibility, IEEE Transactions on Power Systems, vol. 30, no. 1, pp. 57-66. DOI: 10.1109/TPWRS.2014.2321793

Lazar, J. (2014). Teaching the Duck to Fly. Regulatory Assistance Project.

Lew, D., G. Brinkman, E. Ibanez, A. Florita, M. Heaney, B.-M. Hodge, M. Hummon, G. Stark, J. King, S.A. Lefton, N. Kumar, D. Agan, G. Jordan, S. Venkataraman (2013). The Western Wind and Solar Integration Study: Phase 2. NREL/TP-5500-55588. Golden, CO: National Renewable Energy Laboratory. Accessed May 2, 2014: http://www.nrel.gov/docs/fy13osti/55588.pdf

Lew, D., M. Schroder, N. Miller, M. Lecar (2015). Integrating Higher Levels of Variable Energy Resources in California. Schenectady, NY: GE Energy Consulting. Online at http://www.largescalesolar.org/files/Final-CA-VER-Integration-6-15-15.pdf

Liu, S. (2014a). Phase 1.A. Direct Testimony of Dr. Shucheng Liu on Behalf of the California Independent System Operator Corporation. Proceeding R.13-12-010, August 13. San Francisco, CA: California Public Utilities Commission. Online at http://www.caiso.com/Documents/Aug13 2014_InitialTestimony_ShuchengLiu_Phase1A_LT PP_R13-12-010.pdf

Liu, S. (2014b). Phase 1.A. Reply Testimony of Dr. Shucheng Liu on Behalf of the California Independent System Operator Corporation. Proceeding R.13-12-010, October 22. San Francisco, CA: California Public Utilities Commission. Online at http://www.caiso.com/Documents/Oct22 2014 ReplyTestimony ShuchengLiu Phase1ALon g-TermProcurementPlans R13-12-010.pdf 
Ma, O., K. Cheung, N. Alkadi, D. Bhatnagar, P. Cappers, A. B. Currier, P. Denholm, J. Dudley, S. Goli, M. Hummon, J. Jorgenson, S. Kiliccote, J. MacDonald, N. Matson, D. Olsen, D. Palchak, C. Rose, M. D. Sohn, M. Starke, B. Kirby, and M. O'Malley (2016). "Demand Response and Energy Storage Integration Study," DOE EE-1282.

Madaeni, S. H., R. Sioshansi, and P. Denholm (2013). “Comparing Capacity Value Estimation Techniques for Photovoltaic Solar Power,” IEEE Journal of Photovoltaics 3(1) 407-415.

Miller, N.W., M. Shao, S. Pajic, R. D'Aquila (2014). Western Wind and Solar Integration Study Phase 3-Frequency Response and Transient Stability. NREL/SR-5D00-62906 External Note: Work performed by GE Energy Management, Schenectady, New York.

Mills, A., R. Wiser (June 2012a). Changes in the Economic Value of Variable Generation at High Penetration Levels: A Pilot Case Study of California. LBNL-5445E. Berkeley, CA: Ernest Orlando Lawrence Berkeley National Laboratory. Accessed May 2, 2014: http://emp.lbl.gov/sites/all/files/lbnl-5445e.pdf

Mills, A., R. Wiser (2012b). An Evaluation of Solar Valuation Methods Used in Utility Planning and Procurement Processes. LBNL-5933E. Berkeley, CA: Ernest Orlando Lawrence Berkeley National Laboratory. Accessed May 2, 2014: http://emp.lbl.gov/sites/all/files/lbnl-5933e_0.pdf

Mills, A.D., R.H. Wiser (2015). Strategies to Mitigate Declines in the Economic Value of Wind and Solar at High Penetration in California, Applied Energy, vol. 147, pp. 269-278.

Nelson, J. (2014). Prepared Opening Testimony of Dr. Jimmy Nelson on Behalf of the Union of Concerned Scientists and Sierra Club, including Errata. Proceeding R.13-12-010, September 24. San Francisco, CA: California Public Utilities Commission. Online at https://content.sierraclub.org/coal/sites/content.sierraclub.org.coal/files/docs/2014-0930\%20Testimony $\% 20$ Dr. $\% 20$ Jimmy $\% 20$ Nelson $\% 20$ on $\% 20$ behalf $\% 20$ of $\% 20$ the $\% 20$ UCS $\% 20$ an d\%20SC.pdf

Nosair, H., F. Bouffard (2015). Flexibility Envelopes for Power System Operational Planning, IEEE Transactions on Sustainable Energy 6.3, pp. 800-809.

NREL (National Renewable Energy Laboratory) (2012). Renewable Electricity Futures Study. NREL/TP-6A20-52409.

Olsen, D. J., N. Matson, M. D. Sohn, C. Rose, J. Dudley, S. Goli, S. Kilicote, M. Hummon, D. Palchak, P. Denholm, J. Jorgenson, and O. Ma (2013). Grid Integration of Aggregated Demand Response, Part 1: Load Availability Profiles and Constraints for the Western Interconnection. Berkeley, CA: Lawrence Berkeley National Laboratory. LBNL6417E. http://eetd.lbl.gov/sites/all/files/lbnl-6417e.pdf.

Palmintier, B., R. Broderick, B. Mather, M. Coddington, K. Baker, F. Ding, M. Reno, M. Lave, A. Bharatkumar (2016). On the Path to SunShot: Emerging Issues and Challenges in Integrating Solar with the Distribution System. SAND2016-2524 R 
Perez, R., M. Taylor, T. Hoff, and J.P. Ross (2008). "Reaching Consensus in the Definition of Photovoltaics Capacity Credit in the USA: A Practical Application of Satellite-Derived Solar Resource Data." IEEE Journal of Selected Topics in Applied Earth Observations and Remote Sensing 1(1):28-33. http://dx.doi.org/10.1109/JSTARS.2008.2004362.

Pletka, R., J. Khangura, A. Rawlins, E. Waldren, D. Wilson (2014). Capital Costs for Transmission and

Substations. https://www.wecc.biz/Reliability/2014 TEPPC Transmission_CapCost_Report B+ $\underline{\text { V.pdf }}$

Sioshansi, R., S.H. Madaeni, and P. Denholm (2014). "A Dynamic Programming Approach to Estimate the Capacity Value of Energy Storage" IEEE Transactions on Power Systems 29(1) 395-403.

Venkataraman, S., G. Jordan, M. O'Connor, N. Kumar, S. Lefton, D. Lew, G. Brinkman, D. Palchak, J. Cochran (2013). Cost-Benefit Analysis of Flexibility Retrofits for Coal and GasFueled Power Plants: August 2012 - December 2013 NREL/SR-6A20-60862.

WECC (Western Electricity Coordinating Council) (2014). 2014 TEPPC Study Program by Transmission Expansion Planning and Policy Committee. Salt Lake City, UT: Western Electricity Coordinating Council.

Wiser, R. H., and M. Bolinger (2015). Wind Technologies Market Report., 2016.

Woodhouse, M., R. Jones-Albertus, D. Feldman, R. Fu, K. Horowitz, D. Chung, D. Jordan, S. Kurtz (2016). On the Path to SunShot: The Role of Advancements in Solar Photovoltaic Efficiency, Reliability, and Costs NREL/TP-6A20-65872

Zhao, J., T. Zheng, E. Litvinov (2016). A Unified Framework for Defining and Measuring Flexibility in Power System, IEEE Transactions on Power Systems vol. 31, no. 1 pp. 339-347. 


\section{Appendix A}

The analysis in all three case study regions uses the PLEXOS production-cost model, which simulates the operation of all power plants throughout the analyzed region. The California study uses a database largely derived from publically available data sets. However, the FRCC and SPP models use a database largely developed by NREL. To provide greater transparency, the following sections describe the specific modeling assumptions for these regions in greater detail.

\section{FRCC Model}

\section{FRCC Balancing Areas}

To better capture internal operations within FRCC, six balancing areas (BAs) were set up within FRCC to represent the major investor-owned, municipal, and rural cooperative utilities. In some cases, smaller utilities are aggregated into larger BAs to simplify the model. The six BAs are named for the largest utilities they represent. The BAs chosen include: Florida Power \& Light (FPL), Duke Energy (Duke), Tampa Electric Company (TECO), Florida Municipal Power Pool (FMPP), Jacksonville Electric Authority (JEA), and Seminole Electric Cooperative (SEC).

The load assumptions for FRCC were unchanged from ERGIS. We developed the load for FRCC using 2006 hourly load data, scaling it according to load forecasts to represent load in 2026, and adding 5-minute variability based on analysis completed for ERGIS (Bloom et al. 2016). Table A-1 shows total and peak load in each of the BAs modeled in this study.

Table A-1. Total and Peak Load for FRCC BAs

\begin{tabular}{|l|c|c|c|c|c|c|}
\hline & FPL & Duke & TECO & FMPP & JEA & SEC \\
\hline $\begin{array}{l}\text { Peak Load } \\
\text { (GW) }\end{array}$ & 25.6 & 11.8 & 4.7 & 2.8 & 1.7 & 3.9 \\
\hline $\begin{array}{l}\text { Annual Load } \\
\text { (GWh) }\end{array}$ & 129,700 & 59,700 & 24,000 & 14,300 & 8,600 & 19,800 \\
\hline
\end{tabular}

\section{Transmission Representation}

Similar to ERGIS, we ran the FRCC model maintaining full nodal representation. Throughout FRCC there are about 3,000 nodes. This study enforces the thermal limits for all lines with voltages of $230 \mathrm{kV}$ or $500 \mathrm{kV}$, which are the two highest line-voltage classes in FRCC. We determined power flow along all lines using a decoupled approximation of $\mathrm{AC}$ power flow.

Market friction between FRCC BAs is captured by adding a "hurdle rate." In order for neighboring regions to exchange energy, the price difference must exceed $\$ 10 / \mathrm{MWh}$. This hurdle rate does not actually increase the cost of energy; rather, it only acts to decrease the efficiency of system operation in regions without organized markets. 


\section{Thermal Fleet Assumptions}

We made several modifications to the FRCC conventional fleet assumed in ERGIS based on recommendations from FPL. First, all oil generators are retired for this study. Second, the planning reserve margin (only considering conventional capacity) was reduced to about $20 \%$ for each BA. The planning reserve margin is defined as the spare capacity above the peak load. To reduce the planning reserve margin, we removed some of the combustion turbines and combined cycles added to the model as new generating capacity in ERGIS. The final assumed capacity by each type of generator for each BA is shown in Table A-2. 
Table A-2. Installed Capacity (MW) by BA

\begin{tabular}{|l|c|c|c|c|c|c|c|}
\hline & FPL & Duke & TECO & FMPP & JEA & SEC & Total \\
\hline NG CC & 22,000 & 8,700 & 4,000 & 1,800 & 600 & 1,800 & 39,000 \\
\hline Nuclear & 3,300 & - & - & - & - & - & $\mathbf{3 , 3 0 0}$ \\
\hline Coal & 1,600 & 1,700 & 1,700 & 1,200 & 1,100 & 1,300 & $\mathbf{8 , 6 0 0}$ \\
\hline NG & 3,700 & 4,200 & 230 & 400 & 760 & 500 & $\mathbf{9 , 7 0 0}$ \\
\hline CT/Boiler & - & 14 & - & 40 & - & - & $\mathbf{5 4}$ \\
\hline Biomass & - & 47 & - & - & - & - & 47 \\
\hline Hydro & $\mathbf{3 0 , 6 0 0}$ & $\mathbf{1 4 , 4 0 0}$ & $\mathbf{5 , 9 0 0}$ & $\mathbf{3 , 4 0 0}$ & $\mathbf{2 , 5 0 0}$ & $\mathbf{3 , 6 0 0}$ & $\mathbf{6 0 , 7 0 0}$ \\
\hline Total & & & & & & & \\
\hline
\end{tabular}

Generator data - including minimum generation level, part-load heat rates, minimum up and down times, ramp rates, startup costs, and variable O\&M costs - are derived from the ERGIS study database (Bloom et al. 2016). The $3.3 \mathrm{GW}$ of nuclear is inflexible, running at $100 \%$ of capacity when operational. Coal less than $600 \mathrm{MW}$ and all combined-cycle generators can reduce their output to $50 \%$ of their maximum capacity. At minimum generation, coal's average heat rate is $106 \%$ of its average heat rate at full load, whereas CC average heat rate is $113 \%$ of its full-load average heat rate.

\section{Connection with SERC}

Even though FRCC is the focus of this study, we also modeled SERC because connections exist between the regions and trade can and does occur between the regions. This modeling helps to understand how interaction between SERC and FRCC may change as the penetration of PV increases.

SERC itself is modeled as a single generator with prices that vary depending on power output. This generator represents the approximate energy supply curve if SERC were to be modeled with the same detail as FRCC. SERC's entire load is also aggregated to exist at the same node as the single generator. Finally, a simplified set of lines connect the single SERC node to FRCC. This configuration approximately captures how the flow between the two regions would be broken 
out among the lines connecting them. The total flow on these lines is limited to 3,200 MW of import to FRCC and 1,000 MW of export to SERC. ${ }^{27}$

\section{Reserve Requirements}

FRCC currently requires about $700 \mathrm{MW}$ of spinning reserves that are used primarily for contingency reserves, but can also be used for regulation. Each BA is required to hold a portion of the $700 \mathrm{MW}$. We assumed that coal, as well as natural gas CC gas turbines, CTs, and steam plants are allowed to provide contingency reserves.

For this study, we included a separate regulation product to account for the increased reserves needed to handle variability in the PV output. The regulation product is also required to cover $1 \%$ of load, even though this in not formally held in FRCC today. The total amount of regulation required to be held changes throughout the day and depends on the penetration of $\mathrm{PV}$. The algorithm used to determine the regulation requirement is described in Ibanez et al. (2013). The basis of the algorithm is to ensure that the regulation reserve provision can cover $95 \%$ of 10 minute PV forecast errors. All generators that can provide contingency reserves are also allowed to provide regulation reserves, with the exception of combustion turbines.

\section{SPP Model}

\section{SPP Geography}

In ERGIS, SPP contained three sub-regions: SPP-S, SPP-N, and SPP-NE. During the course of the ERGIS project, SPP expanded its territory to include the Integrated System, which is made up of Western Area Power Administration's Upper Great Plains Region, Basin Electric Power Cooperative, and Heartland Consumers Power District. The expanded territory adds most of North and South Dakota, and portions of Iowa, Minnesota, Montana, and Wyoming to SPP. For this study, we moved the nodes belonging to non-MISO utilities in the states listed above into SPP. We created two new SPP regions in the model to include these new nodes: SPP-SD and SPP-ND.

\section{Transmission Representation}

This study employs a zonal transmission representation of five sub-regions in SPP (i.e., SPP-S, SPP-N, SPP-NE, SPP-SD, and SPP-ND) and the bordering five MISO and two Canadian zones. This methodology assumes sufficient intra-zonal transmission to deliver wind to load, and it ignores local congestion.

We restrict flow between zones in two ways. First, we enforce flow limits on the interfaces connecting zones, including interfaces connecting SPP to outside regions and intra-SPP interfaces. The flow limits on the interfaces were based on the limits set by the ERGIS study simulations, which captured nodal transmission congestion. Second, and similar to the FRCC modeling, we apply a "hurdle rate" to capture market friction between SPP and its neighbors. For SPP to exchange energy with MISO, for example, the price difference in each region must exceed $\$ 10 / \mathrm{MWh}$. The hurdle rates do not apply to zones within SPP.

\footnotetext{
${ }^{27}$ According to FPL, the export limit to SERC is lower than the import limit due to voltage stability constraints in
} SERC. The import limit is due to thermal limits on lines in the interface. 


\section{Reserve Requirements}

Reserve requirement assumptions follow the assumptions in FRCC, which means that we modeled both a contingency reserve product and a regulation requirement. The contingency requirement remains the same for all scenarios and is equivalent to $3 \%$ of load in each time step. The regulation requirement covers the geographic sum of $1 \%$ of load and $95 \%$ of the 10 -minute wind and PV forecast errors. Because the regulation requirement depends on magnitude of wind forecast errors, the requirement is proportional to the installed capacity. We allow coal, combined cycles, natural gas boilers, and natural gas combustion turbines to provide contingency reserves. The methodology for reserve requirements is discussed in more detail in Ibanez et al. (2013). 